


\section{POLITICS AND SOCIETY BETWEEN ELECTIONS}

This book studies patterns in public opinion on politics and society between elections in India. By using survey data covering 24 Indian states, including the National Capital Region of Delhi (NCR), it will serve as state barometers of public opinion.

The surveys seek to understand how politics and governance processes are nested in the social and political relationships between citizens inter se and with government functionaries. The book explores citizens' perceptions about the social and political universes they inhabit in the periods between elections. It examines the social attitudes of citizens, friendship ties across social groups, gender roles, and relationships; opinions on governance, ease of public service access, the citizen-state interface, and trust in political institutions; and, political attitudes and identity, nationalism, freedom of expression, and populism. This book explores public perceptions of everyday development and governance outcomes that are shaped by how the government functions between elections: how it relates to citizens on a regular basis; how it provides routine public services to them; and how public order is maintained.

An incisive study on public opinion of politics, society, and governance in India, this book will be of great interest to scholars and researchers of political science, governance, public policy, and South Asian studies. It will also be of immense interest to bureaucrats, policymakers, think tanks, and organisations working in the areas of development studies, politics, society, and governance.

Siddharth Swaminathan is Professor at Azim Premji University (Bengaluru, India). He has published in Journal of Conflict Resolution, Social Science and Medicine, International Interactions, Economic and Political Weekly, Studies in Indian Politics among other journals, and in edited volumes. His research interests focus on public opinion, citizenship, state capacity, and political demography.

Suhas Palshikar, based at Pune, has been a Professor of Political Science. He is co-director of programme on comparative democracy, Lokniti, located at CSDS, Delhi, India and chief editor of the journal, Studies in Indian Politics. He has co- edited Party Competition in Indian States: Electoral Politics in Post-Congress Polity, 2014, (with K.C. Suri and Yogendra Yadav) and Electoral Politics in India: Resurgence of Bharatiya Janata Party, 2017, Routledge (with Sanjay Kumar and Sanjay Lodha). His recent publications include, Indian Democracy (2017). 
$\Longrightarrow$ Taylor \& Francis Taylor \& Francis Group

http://taylorandfrancis.com 


\section{POLITICS AND SOCIETY BETWEEN ELECTIONS}

Public Opinion in India's States

\section{Edited by}

Siddharth Swaminathan

and

Subas Palshikar

Routledge 
First published 2021

by Routledge

2 Park Square, Milton Park, Abingdon, Oxon OX14 4RN

and by Routledge

52 Vanderbilt Avenue, New York, NY 10017

Routledge is an imprint of the Taylor \& Francis Group, an informa business

(C) 2021 selection and editorial matter, Siddharth Swaminathan and Suhas Palshikar; individual chapters, the contributors

The right of Siddharth Swaminathan and Suhas Palshikar to be identified as the authors of the editorial material, and of the authors for their individual chapters, has been asserted in accordance with sections 77 and 78 of the Copyright, Designs and Patents Act 1988.

With the exception of Section 3.3, no part of this book may be reprinted or reproduced or utilised in any form or by any electronic, mechanical, or other means, now known or hereafter invented, including photocopying and recording, or in any information storage or retrieval system, without permission in writing from the publishers. Section 3.3 of this book is available for free in PDF format as Open Access from the individual product page at www.routledge.com. It has been made available under a Creative Commons Attribution-Non Commercial-No Derivatives 4.0 license.

The views and opinions expressed in this book are those of the respondents, the authors and the editors, and do not necessarily reflect the views and opinions of the Publishers.

Trademark notice: Product or corporate names may be trademarks or registered trademarks, and are used only for identification and explanation without intent to infringe.

British Library Cataloguing-in-Publication Data

A catalogue record for this book is available from the British Library

Library of Congress Cataloging-in-Publication Data

A catalog record has been requested for this book

ISBN: 978-0-367-63666-1 (hbk)

ISBN: 978-1-003-12048-3 (ebk)

Typeset in Sabon

by Deanta Global Publishing Services, Chennai, India 


\section{CONTENTS}

List of figures vii

List of tables xiv

List of State Lokniti Coordinators $\quad \mathrm{xV}$

Politics and Society between Elections (2016-2019) Committee xvi

Acknowledgements xvii

1 Introduction 1

Notes 6

2 Social Universe

2.1 Friendship Ties 8

2.2 Preferences over Leader Identity 19

2.3 Perceptions of Social Community 23

2.4 Gender Roles and Rights 43

2.5 Conclusion 53

Note 55

3 Political Universe

3.1 Freedom of Expression 57

3.2 National and Regional Identity 71

3.3 Nationalism 80

3.4 Populism 94

3.5 Conclusion 104

Notes 106

4 Political Institutions

4.1 The Citizen-State Interface 108

4.2 Governing Land 128

4.3 Trust in Institutions 136

4.4 Conclusion 158 
CONTENTS

5 Conclusion $\quad 161$

6 Appendix 165

6.1 Sampling and Data Collection 165

6.2 State Schemes 169

6.3 Index Construction Method 171

6.4 Questionnaire 174

Bibliography

196 


\section{FIGURES}

2.1.1 Have a Dalit Close Friend (by State) 9

2.1.2 Have a Dalit Close Friend (by Caste and Education) 9

2.1.3 Have an Adivasi Close Friend (by State) 10

2.1.4 Have an Adivasi Close Friend (by Caste and Education) 10

2.1.5 Have an OBC Close Friend (by State) 11

2.1.6 Have an OBC Close Friend (by Caste and Education) 12

2.1.7 Have an Upper Caste Close Friend (by State) 12

2.1.8 Have an Upper Caste Close Friend (by Caste and Education) 13

2.1.9 Have a Muslim Close Friend (by State) 14

2.1.10 Have a Muslim Close Friend (by Religion and
Education)

2.1.11 Have a Muslim Close Friend (by Religion and
Rural-Urban)

2.1.12 Have a Christian Close Friend (by State) 15

2.1.13 Have a Christian Close Friend (by Religion and 16

2.1.14 Have a Hindu Close Friend (by State) 17

2.1.15 Have a Hindu Close Friend (by Religion and
Education)

2.1.16 Have a Close Friend of Opposite Gender (by State) 18

2.1.17 Have a Close Friend of Opposite Gender (by Gender and Education) 18

2.2.1 Preference on Caste of Leader to Get Work Done (by State) 19

2.2.2 Preference on Caste of Leader to Get Work Done
(by Caste and Rural-Urban)

2.2.3 Preference on Caste of Leader to Get Work Done
(by Caste and Economic Class) 
2.2.4 Preference on Religion of Leader to Get Work Done (by State)

2.2.5 Preference on Religion of Leader to Get Work Done (by Religion and Rural-Urban)

2.2.6 Preference on Religion of Leader to Get Work Done (by Religion and Economic Class)

2.3.1 Ten-Point Scale for "Hardworking or Lazy"

2.3.2 Ten-Point Scale for "Patriotic or Unpatriotic"

2.3.3 Ten-Point Scale for "Peaceful or Violent"

2.3.4 Perceptions About Dalits as Being "Hardworking or Lazy" (by State)

2.3.5 Perceptions About Dalits as Being "Hardworking or Lazy" (by Caste)

2.3.6 Perceptions About Dalits as Being "Hardworking or Lazy" (by Education)

2.3.7 Perceptions About Adivasis as Being "Hardworking or Lazy" (by State)

2.3.8 Perceptions About Adivasis as Being "Hardworking or Lazy" (by Caste)

2.3.9 Perceptions about Adivasis as being "Hardworking or Lazy" (by Education)

2.3.10 Perceptions About Upper Caste as Being "Hardworking or Lazy" (by State)

2.3.11 Perceptions About Upper Caste as Being "Hardworking or Lazy" (by Caste)

2.3.12 Perceptions About Upper Caste as Being "Hardworking or Lazy" (by Education)

2.3.13 Perceptions About Muslims as Being "Patriotic or Unpatriotic" (by State)

2.3.14 Perceptions About Christians as Being "Patriotic or Unpatriotic" (by State)

2.3.15 Perceptions About Hindus as Being "Patriotic or Unpatriotic" (by State)

2.3.16 Perceptions About Sikhs as Being "Patriotic or Unpatriotic" (by State)

2.3.17 Perceptions About Muslims as Being "Peaceful or Violent" (by State)

2.3.18 Perceptions About Christians as Being "Peaceful or Violent" (by State)

2.3.19 Perceptions About Hindus as Being "Peaceful or Violent" (by State) 
2.3.20 Perceptions About Sikhs as Being "Peaceful or Violent" (by State)

2.4.1 Statements on Role of Women 44

2.4.2 Support for Statements on Role of Women 44

2.4.3 Women Should Prioritize Home over Work (by Gender) 45

2.4.4 Women Should Prioritize Home over Work (by State) 45

2.4.5 Women and Men Should Have Equal Responsibility for Child Rearing (by Gender) 46

2.4.6 Women and Men Should Have Equal Responsibility for Child Rearing (by State) 46

2.4.7 Women Should Have the Right to Decide to Get Married or Not (by State) $\quad 47$

2.4.8 Women Should Have the Right to Decide to Get Married or Not (by Gender)

2.4.9 It is up to Women to Decide Whom to Get Married to (by Gender)

2.4.10 It is up to Women to Decide Whom to Get Married to (by State)

2.4.11 Educating Boys is More Important Than Educating Girls (by Gender)

2.4.12 Educating Boys is More Important Than Educating Girls (by State)

2.4.13 Men Should be Paid More Than Women Even if it is the Same Job (by Gender)

2.4.14 Men Should be Paid More Than Women Even if it is the Same Job (by State)

2.4.15 Women Should Have a 50 Percent Reservation of all Jobs (by Gender)

2.4.16 Women Should Have a 50 Percent Reservation of all Jobs (by State)

3.1.1 Dictatorship over Democracy (by State) 59

3.1.2 Dictatorship over Democracy (by Education) 60

3.1.3 Criticizing Elected Leaders (by State) 61

3.1.4 Criticizing Elected Leaders (by Religion) 61

3.1.5 Criticizing Elected Leaders (by Education) 62

3.1.6 Making Fun of Other Religious Communities (by State)

3.1.7 Making Fun of Other Religious Communities (by Religion)

3.1.8 Making Fun of Religious Communities (by Education) 65 
3.1.9 Promoting Violence Against Other Communities (by State)

3.1.10 Promoting Violence Against Other Communities (by Religion)

3.1.11 Promoting Violence Against Other Communities (by Education)

3.1.12 Promoting Violence Against the Indian State (by State) 68

3.1.13 Promoting Violence Against the Indian State (by Education)

3.1.14 Independence for Certain Parts of India (by State)

3.1.15 Independence for Certain Parts of India (by Education) 69

$\begin{array}{lll}\text { 3.2.1 Regional and National Identity (by State) } & 72\end{array}$

3.2.2 Regional and National Identity (by Rural-Urban) 73

3.2.3 "More Regional" and "More National" (by State and Rural-Urban)

3.2.4 "More Regional" and "More National" (by State and Religion)

3.2.5 Regional and National Identity (by Education) 76

3.2.6 "More Regional" and "More National” (by State and Media Exposure)

3.2.7 Preference for Local Language Versus Any Language in Public Spaces (by State)

3.2.8 Preference for Any Language (by State and RuralUrban)

3.2.9 Preference for Any Language (by State and Education) 79

3.3.1 Opinion on Punishment to Those Who Don't Stand for National Anthem at Public Places (by State)

3.3.2 Opinion on Punishment to Those Who Don't Stand for National Anthem at Public Places (by Caste/ Community)

3.3.3 Opinion on Punishment to Those Who Do Not Say "Bharat Mata ki Jai" at Public Functions (by State)

3.3.4 Opinion on Punishment for Those Who Do Not Say "Bharat Mata ki Jai" at Public Functions (by Caste/Community)

3.3.5 Opinion on Punishment to Those who Eat Beef/ Cow Meat (by State)

3.3.6 Opinion on Punishment to Those Who Eat Beef/ Cow Meat (by Caste/Community)

3.3.7 Opinion on Punishment to Those who Engaged in Religious Conversions (by State) 
3.3.8 Opinion on Punishment to Those who engaged in Religious Conversion (by Caste/Community)

3.3.9 Index of Nationalism (by State) 90

3.3.10 Index of Nationalism (by Caste/Community) 91

3.3.11 Index of Nationalism (by Rural-Urban) 92

3.3.12 Index of Nationalism (by Media Exposure) 92

3.3.13 Index of Nationalism (by Education) 93

3.4.1 Anti-Elite Sentiment (by State) 96

3.4.2 Anti-Elite Sentiment (by Age Group) 96

3.4.3 Anti-Elite Sentiment (by Religion) 97

3.4.4 Anti-Elite Sentiment (by Caste) 97

3.4.5 Anti-Elite Sentiment (by Education) 98

3.4.6 Battle or Compromise (by State) 99

3.4.7 Battle or Compromise (by Age Group) 99

3.4.8 Battle or Compromise (by Education) 100

3.4.9 Elected Leaders can Override Courts (by State) 100

3.4.10 Elected Leaders can Override Courts (by Age Group) 101

3.4.11 Elected Leaders can Override Courts (by Education) 101

3.4.12 Populism (by State) 102

3.4.13 Populism (by Education) 103

3.4.14 Populism (by Religion) 103

3.4.15 Populism (by Caste) 103

4.1.1 Awareness of Central and State Schemes (by State) 111

4.1.2 Index of Awareness of Central and State Schemes (by State)

4.1.3 Index of Awareness of Central and State Schemes (by Caste-Communities)

4.1.4 Index of Awareness of Central and State Schemes (by Education)

4.1.5 Beneficiaries of Schemes (by State) 115

4.1.6 Beneficiaries of Central and States' Agricultural Schemes (by Type of Farmer)

4.1.7 Beneficiaries of Central and States' Housing Schemes (by Caste/Communities)

4.1.8 Beneficiaries of Central and States' Employment Schemes (by Caste/Communities)

4.1.9 Beneficiaries of Central and States' Health Schemes (by Caste/Communities)

4.1.10 Experience Availing of Public Services (by State) 119 
4.1.11 Experience Availing of Public Services (by Caste/ Communities)

4.1.12 Institutions to Approach to Get an Important Work Done (by State)

4.1.13 Institutions to Approach to Get Important Work Done (by Rural-Urban)

4.1.14 Institutions to Approach to Get Important Work Done (by Education)

4.1.15 Preferred Forums to Resolve Property Disputes (by State)

4.1.16 Preferred Forums to Resolve Marital Disputes (by State)

4.1.17 Preferred Forums to Resolve Neighbourhood Dispute (by State)

4.1.18 Preferred Forums to Resolve Dispute Related to Domestic Violence (by State)

4.2.1 Modes of Land Acquisition (by State) 130

4.2.2 Modes of Land Acquisition (by Farmer-Non-Farmer) 130

4.2.3 Modes of Land Acquisition (by Type of Farmer) 131

4.2.4 Response to Land Acquisition (by State) 132

4.2.5 Response to Land Acquisition (by Farmer-NonFarmer)

4.2.6 Response to Land Acquisition (by Type of Farmer) 133

4.2.7 Modes of Dispute Resolution (by State) 134

4.2.8 Modes of Dispute Resolution (by Farmer-Non-Farmer)135

4.2.9 Modes of Dispute Resolution (by Type of Farmer) 135

4.3.1 Trust in Institutions 137

4.3.2 Effective Trust in Institutions 138

4.3.3 Effective Trust in Institutions (by State) 139

4.3.4 Effective Trust in Institutions (by Education) 140

4.3.5 Effective Trust in Institutions (by Religion) 141

4.3.6 Statements on Effectiveness and Procedural Fairness 142

4.3.7 Effectiveness and Procedural Fairness of Police (by State)

4.3.8 Effectiveness and Procedural Fairness of Government Officials (by State)

4.3.9 Effectiveness and Procedural Fairness of Courts (by State)

4.3.10 Effectiveness and Procedural Fairness of Police (by Religion) 
4.3.11 Effectiveness and Procedural Fairness of

Government Officials (by Religion)

4.3.12 Effectiveness and Procedural Fairness of Courts (by Religion)

4.3.13 Effectiveness and Procedural Fairness of Police (by Caste)

4.3.14 Effectiveness and Procedural Fairness of

Government Officials (by Caste)

4.3.15 Effectiveness and Procedural Fairness of Courts (by Caste)

4.3.16 Rich or Poor - Who Will the Police Favour? (by State) 148

4.3.17 Rich or Poor - Who Will the Government Officials Favour? (by State)

4.3.18 Rich or Poor - Who Will the Courts Favour? (by State) 149

4.3.19 Upper Caste or Dalit - Who Will the Police Favour? (by State)

4.3.20 Upper Caste or Dalit - Who Will the Government Officials Favour? (by State)

4.3.21 Upper Caste or Dalit - Who Will the Courts Favour? (by State)

4.3.22 Hindu or Non-Hindu - Who Will the Police Favour? (by State)

4.3.23 Hindu or Non-Hindu - Who Will the Government Officials Favour? (by State)

4.3.24 Hindu or Non-Hindu - Who Will the Courts Favour? (by State)

4.3.25 Men or Women - Who Will the Police Favour? (by State)

4.3.26 Men or Women - Who Will the Government Officials Favour? (by State)

4.3.27 Men or Women - Who Will the Courts Favour? (by State)

4.3.28 Men or Women - Who Will the Police Favour? (by Gender)

4.3.29 Men or Women - Who Will the Government Officials Favour? (by Gender)

4.3.30 Men or Women - Who Will the Courts Favour? (by Gender) 


\section{TABLES}

A1 Politics and Society between Elections (Rounds and Coverage)

A2 Distribution of the Achieved Sample

A3 Representativeness of Sample

A4 Languages Used for Translation

A5 List of State Schemes 


\section{LIST OF STATE LOKNITI COORDINATORS}

\begin{tabular}{ll}
\hline States & State Coordinators \\
\hline Andhra Pradesh \& Telangana & E. Venkatesu \\
Assam & Dhurba Pratim Sharma \\
Bihar & Rakesh Ranjan \\
Chhattisgarh & Anupama Saxena \\
Delhi & Biswajeet Mohanty \\
Gujarat & Bhanu Parmar and Mahashweta Jani \\
Haryana & Anita Agarwal and Kushal Pal \\
Jammu and Kashmir & Aijaz Ashraf Wani and Ellora Puri \\
Jharkhand & Harishwar Dayal \\
Karnataka & Veena Devi and Reetika Syal \\
Kerala & Sajad Ibrahim \\
Madhya Pradesh & Yatindra Singh Sisodia \\
Maharashtra & Nitin Birmal \\
Mizoram & Lallian Chunga \\
Nagaland & Amongla N. Jamir \\
Odisha & Prabhat Mohanty and Gyana Ranjan Swain \\
Punjab & Jagroop Kaur \\
Rajasthan & Sanjay Lodha \\
Tamil Nadu & P. Ramajayam \\
Tripura & Anindya Sarkar \\
Uttar Pradesh & Shashi Kant Pandey and Sudhir Khare \\
Uttarakhand & Rakesh Negi \\
West Bengal & Suprio Basu and Jyotiprasad Chatterjee \\
\hline
\end{tabular}




\section{POLITICS AND SOCIETY BETWEEN ELECTIONS (2016-2019) COMMITTEE}

\section{Core Committee}

Azim Premji University

Siddharth Swaminathan

Arjun Jayadev

\section{Lokniti}

Sanjay Kumar, (CSDS)

Suhas Palshikar (Savitri Bhai Phule University (Retd) and Chief Editor, Studies in Indian Politics)

Sandeep Shastri (Jain University)

External Advisory Committee

Sudhir Krishnaswamy (National Law School University of India)

Ashutosh Varshney (Brown University) 


\section{ACKNOWLEDGEMENTS}

We are foremostly thankful to Azim Premji University and Lokniti for enabling Politics and Society between Elections (2016-2019) and recognizing its value. We also thank Azim Premji University for a research grant without which this project would not have been possible.

Colleagues from Azim Premji University and Lokniti contributed to the various reports of Politics and Society between Election (2016-2019) through writing and data analysis. We are extremely grateful to Varsha Aithala, Vibha Attri, Srikrishna Ayyangar, Malini Bhattacharjee, Rishikesh, B., Geetisha Dasgupta, Sunayana Ganguly, Pranav Gupta, Sakshi Khemani, Jyoti Mishra, Amrit Negi, Sushmita Pati, Prateeti Prasad, Ajit Phadnis, and Asha Venugopalan for their contribution to the project.

Jyoti Mishra and Asha Venugopalan (at Lokniti and Azim Premji University, respectively) managed the project across all rounds to the very last details. Ajay Swaero Palle worked tirelessly to produce all the figures. We cannot thank them enough for their efforts.

Our thanks also to the State Coordinators of the Lokniti Network for conducting the fieldwork and data collection. We have listed all the State Coordinators involved.

We are also thankful to Himanshu Bhattacharya, Arushi Gupta, Dhananjay Kumar Singh, Sana Salim, Vijay Prakash, and Anurag Jain at Lokniti for all the research support during the course of this project. At Azim Premji University, Ajay Swaero, Narsana Mesa, and Rohan Raj provided excellent research assistance. We also thank Kshiraja Krishnan, Krithika K., and Tejas Pande, the design team at Azim Premji University, for producing superb graphics for this project.

We also greatly appreciate the intellectual insights and support from Sudhir Krishnaswamy, Sanjay Kumar, Arjun Jayadev, Sandeep Shastri, and Ashutosh Varshney. 


\section{ACKNOWLEDGEMENTS}

Finally, we thank the panelists who commented on the results from the various rounds at events organized in Bengaluru and Delhi at different times during the project. They include: Hilal Ahmed, Zoya Hassan, R. Indira, Niraja Gopal Jayal, Sandeep Shastri, Siddharth Varadarajan, Ashutosh Varshney, and Yogendra Yadav. 


\section{1 \\ INTRODUCTION}

The puzzles of India's development and governance are routinely linked to the logic of India's electoral democracy. As a result, a great deal is known about elections, but paradoxically our knowledge of politics and society between elections is relatively underdeveloped. As much as anything else, development and governance outcomes are shaped by how the government and other State institutions function between elections; including how they relate to citizens on a regular basis, how the government provides routine public services to them, and how public order is maintained. Governance processes are ultimately nested in the social and political relationships between citizens inter se and with government functionaries and state institutions. But what happens to State-citizen interaction once elections are over? How do interactions between the State and the citizen unfold in periods between elections? What characterizes interactions between citizens across class, caste, and community? And what sorts of perceptions, attitudes, and opinions do everyday forms of governance engender? These questions are of immense importance in a democracy undergoing significant political, economic, and social transformation.

This report presents an analysis of a public opinion study based on a survey titled "Politics and Society between Elections (2016-2019)" - the product of a research collaboration between Azim Premji University and Lokniti (CSDS). We surveyed a large number of respondents in times between elections across 23 states and the National Capital Region of Delhi focusing on public opinion about the social and the political universes Indian citizens inhabit. ${ }^{1}$ The survey questions cover a range of topics of interest to social scientists studying India, such as: friendship ties across social groups, perceptions of social community, citizens' trust in political institutions, political networks, awareness of public services and ease of access, citizen-State interfaces and land governance, gender roles and relationships, nationalism and political identity, freedom of expression, and populism. ${ }^{2}$

The report is organized into five parts with sections. Following the introduction (Part 1), Part 2 focuses on the social universe and explores how 
inter-caste and inter-community networks shape perceptions of social and political relations. Part 2 is divided into four sections that look at friendship ties across caste and community identity, citizen preferences over the caste-community identity of the leaders they approach, citizen perceptions of social communities, and opinion about gender roles. Part 3 considers the political universe and is divided into four sections that explore opinions on freedom of expression, national and regional identities, nationalist, and populist attitudes. Part 4 explores political institutions and is divided into three sections that consider opinions on citizen-State interfaces and welfare schemes, land governance and public trust in elected and non-elected institutions. Part 5 concludes the study.

We rely on a distinction between electoral and non-electoral politics. Elections are episodic; governance is routine. Electoral politics is focused on getting the vote, and intensifies during a defined election period. These are periods of heightened popular mobilization. Political parties intensify their engagement with voters, thread together themes of governance, security, and development, as part of their campaign message, and employ a variety of campaign strategies during elections. While it may be argued that contemporary democracies like India are engaged in a permanent electoral campaign, this is a rhetorical rather than an empirical claim. If one looks at the states separately, they do ordinarily follow a five-year electoral cycle though national elections to Lok Sabha intervene in this cycle in case of majority of states.

Between elections, governments consolidate their political mandate, outline new directions in policy, mould institutions, and routinize governance. New ideas emerge or older ideologies resurface in public discourse. Spaces for engagement between State and citizens either expand or contract, and extant forms of vertical and horizontal citizenship strengthen or fray in times between elections. And equally important are the perceptions, attitudes, and opinions citizens hold about others across caste, community and geography, as well as those relating to their relationship with State institutions and officials that both shape and in turn are shaped by politics and society between elections.

Our point is not that electoral politics ceases to exert influence beyond the ballot box nor is it that politics in times of elections and between elections is unconnected. Nor is it that one does not influence the other. We realize that political leaders are driven by an electoral (or re-election) calculus and the actions of the political elite reflect an unwavering focus on (potential) electoral gains. In addition, many of the campaign promises made by leaders during elections find place in policy during governance between elections - and a lot happens between elections that often feeds into the context of the next election. Our point is that choices individuals make during elections are electoral choices circumscribed by the menu both in terms of issues and personnel. Periods between elections are periods 
during which patterns of public opinion take root and consolidate to become enduring ones, potentially shaping or affecting the political culture of the society. While this distinction does not entirely eliminate the blurred line between the electoral and the non-electoral, it is a useful one, allowing us to focus on individuals as citizens and not only as voters.

Since the mid-1990s, Lokniti's National Election Studies (NES) have systematically researched electoral behaviour in India, covering parliamentary elections since 1996 as well as well as state assembly elections (Shastri, Suri, and Yadav, 2009; Palshikar, Suri, and Yadav, 2014; Palshikar, Kumar, and Lodha, 2017; Jaffrelot and Kumar, 2009; Chhibber and Verma, 2014; Chhibber and Verma, 2018, among others; special issues of Asian Survey, 2012 [volume 52, issue 2], Economic and Political Weekly, 2004 [51], 2009 [39] and 2014 [39], and Studies in Indian Politics, 2015 [volume 3, issue 1], and 2019 [volume 7, issue 2]). Commentaries have also regularly appeared in leading newspapers such as The Hindu and The Indian Express among others. These and other studies show that even marginal citizens of India are wooed at the time of elections (Banerjee, 2014; Ahuja and Chhibber, 2012). We now know that since the late 1980s and early 1990s, the economically poorer, the lower castes, and the less-educated citizens of India have voted as much as, or more than, the economically richer, the upper castes and the more educated (Yadav, 2000). Democratic theory, developed and tested in the West, has always said the opposite: the more educated and the richer citizens vote more than the less educated and the poorer (Verba and Nie, 1972). This Indian defiance of a basic canon of democratic theory is grounded in robust empirical evidence. The NES data conclusively demonstrate that in voting, if nothing else, India's democracy has developed an unmistakable plebeian bent. These and other insights from an analysis of NES data have contributed tremendously to our understanding of Indian elections, electoral behaviour, and party system.

However, not many systematic nationwide studies have been undertaken about politics and society between elections. Large-scale surveys, for example the National Sample Surveys and National Family Health Surveys, deal with economic matters and demographic information such as consumption, employment, maternal and child health, and reproductive behaviour. Since the mid-1990s, when both the framework of competitive politics and the paradigm of politics began changing, Lokniti conducted investigations into citizens' attitudes and opinions about a range of issues from economic reform to State-citizen relations starting with National Election Study of 1996 (and the findings based on this survey analyzed in Mitra and Singh (1999) as well as in a special issue of India Today), but that study coincided with the general election of 1996. Subsequently, Lokniti has conducted national surveys that have not coincided with the electoral cycle, for example, the State of Democracy in South Asia (round one in 2006 and round two in 2013) and the State of the Nation Surveys. In addition, other 
surveys have also examined similar topics (Chhibber, Shastri, and Sisson 2004). However, these are nationally representative surveys and do not allow cross-state comparisons. Besides, we still do not know enough about which social groups (castes, tribes, religious communities, classes, gender) get better public services (water, sanitation, roads, electricity, irrigation, education, medical care); which groups do the police protect and which ones it do they not in times of need; in which states do marginal groups face less discrimination from government agencies and fellow citizens; and which states do a better job of providing public services. Many have indeed studied the successes and failures of policies across a swath of domains, the regional differences in identity, the changing political discourse(s), citizenstate interactions, the role(s) of political actors, and so on. It has also been hypothesized that "a distinctive culture of democracy has given a regional flavour to political practice... as emancipatory ideas confront majoritarianism and the populist tendency faces pragmatism" (Yadav and Palshikar, 2008, Seminar, November, 591). However, our basic point remains: our knowledge of such matters - for India as a whole, and especially at the statelevel - is meagre. To generate such knowledge we need data that allows a subnational (and nationwide) understanding of everyday development and governance.

In this report we undertake three kinds of mapping: a mapping of the ideas that have characterized social and political universes in India, a geographic mapping that examines variation in attitudes, perceptions, and opinions across states, and a socio-demographic mapping that considers the same across identities, and other factors typically considered the drivers of modernization such as urbanization and education. While we examine public opinion across categories of interest to social scientists such as castecommunity (religious) identity, gender, location (whether rural or urban), economic class, and levels of education, our primary focus is on the findings on subnational variations. Our approach follows in the tradition of studies that have advocated a greater focus on a subnational comparative politics of India (Yadav and Palshikar, 2003; Tillin, 2013; Jacob, 2015; Sinha, 2015).

We set out a list of enquiries that guide our data analysis of public opinion directly addressing the social and political universes Indian citizens inhabit and the institutions with which they interact:

(a) Identity and consciousness: What are the primary identities - national, sub-national, religious, caste, urban-rural - in different parts of the country? Are urban identities different from rural identities? Is the South different from the North in the way caste and religious identities are experienced and expressed? How do religious, caste, and linguistic identities interact? Which one becomes dominant in which part of the country and how? Which communities are seen as lazy and which ones 
as hardworking? Similarly, who is seen as unpatriotic and who is seen as violent?

(b) Discrimination and violence: Which communities face discrimination from the state and/or fellow citizens? Which ones face violence from the state and/or fellow citizens? Is there a state-level difference? Is there an urban-rural difference? For instance, Ambedkar had famously argued that the village is a cesspool for Dalits in particular (and for lower castes in general) and the city would offer them a better life. Is that true? Which states provide evidence for Ambedkar's claim, and which ones do not? Similarly, in which states do minorities face acute deprivation? Is there a relationship between discrimination by state authorities and discrimination by fellow citizens?

(c) Majoritarian nationalism and populism: What are public perceptions toward key tenets of the right to the freedom of expression as written in the Constitution of India. To what extent are citizens open to ideas of regime change or allowing a public criticism of elected leaders? Do current public ideas about what the "freedom to express" entails align with constitutional values? Has India become populist? How do Indian citizens perceive symbols of nationalism? And to what extent is a majoritarian nationalism prevalent in India today? How do populist ideas fare in India? In what states? And what other sorts of variation can we observe?

(d) Delivery of public services and public order: What communities receive what sorts of public services (for example, education, health and sanitation, power, water)? What are the mechanisms that promote or hinder service delivery? How aware are citizens of central and state schemes for agriculture, health, housing, and employment guarantee? Who benefits from welfare schemes? And how easily are citizens able to access services? In what ways are services distributed across states? What roles do political agents and/or community engagement play in service delivery? What strategies do citizens deploy to engage with the State? What are the subnational differences?

(e) Economic process and governance: How is economic governance specifically with respect to land experienced by citizens? How do citizens perceive the validity of land acquisition undertaken by the state for development? Are there significant differences between urban and rural populations? And among rural populations do big farmers view things differently compared to small farmers or agricultural labour? What do they think are legitimate forms of popular resistance toward State action that involves land appropriation? And what are acceptable State responses to such opposition?

(f) Citizen perception of State institutions: How do citizens perceive State institutions and their capacity to govern? Does this vary by social group? To what extent do citizens trust the (a) legislature, (b) executive, 
(c) judiciary, (d) bureaucracy, (e) police, and (f) army? Do citizens relate to parts of the State machinery - different departments and across hierarchies - differently? Is there a state-level or urban-rural variation in perceptions? Do citizens see institutions as procedurally and distributively fair? These questions are centrally related to the legitimacy of the state and the citizens' sense of belonging.

This report undertakes a modest task. The patterns in public opinion that we present are primarily descriptive in nature. We describe the broad similarities and differences that emerge across states and other categories of interest using cross-tabulations. ${ }^{3}$ We do not specify hypotheses, nor do we undertake statistical hypothesis testing. However, the sample being large and representative at the state-level allows for cross-state (as well as within-state) comparisons using statistical techniques. Studies that statistically test specific relationships across the many variables of interest using the "Politics and Society between Elections" dataset appear in issue of the journal Studies in Indian Politics (December, 2020). We also hope that colleagues will further delve into more nuanced analyses spurred by the preliminary findings reported here. At the same time, this report will serve a critical purpose of bringing forward for public discussion an outline of how Indians approach many of the issues listed above, and what implications this has for both competitive politics and governance in the times to come. We also expect that everyone interested in India's social and political processes will keenly watch the durability and intensity of the opinions and views that are reported here.

\section{NOTES}

1 The states covered include 23 states (at the time of data collection) and the National Capital Region of Delhi. They are Andhra Pradesh, Assam, Bihar, Chhattisgarh, Gujarat, Haryana, Jammu and Kashmir, Jharkhand, Karnataka, Kerala, Madhya Pradesh, Maharashtra, Mizoram, Nagaland, Odisha, Punjab, Rajasthan, Tamil Nadu, Telangana, Tripura, Uttarakhand, Uttar Pradesh, and West Bengal. Note that Jammu and Kashmir was a state at the time of survey and for the sake of convenience we continue to refer to it as so in this report. Our sample size consists of 48542 respondents. Note that we refer to a subnational unit using small letters (state) except in the figures and section headings.

2 Details regarding the survey rounds, sampling, and questionnaire are provided in the Appendix. For additional details visit: The Centre for Regional Political Economy (crpe.azimpremjiuniversity.edu.in) or Lokniti (lokniti.org).

3 The results we present are weighted to account for differences in state populations. 


\section{SOCIAL UNIVERSE}

Part 2 examines public opinion within a citizen's social universe. While persons of different castes, religions, and genders co-exist within a larger spatial universe, the actual social universe of these persons can be quite narrow. Social lives tend to remain homogenous and exclusive. Such exclusion reinforces stereotypes about the so-called "others" and the stereotypes, in turn, discourage people from forging closer ties with those others. Thus, there is co-existence with an emotional distance; just as there is a formal approval of gender equality starkly marked by predominance of gendered roles. These characteristics of India's social universe pose a challenge for any discourse of unity with fraternity. 


\subsection{FRIENDSHIP TIES}

The idea of a multi-cultural India has changed since it was first imagined in early years of independence. Since the 1990s, India has witnessed a stronger consolidation of caste and religious identities for both progressive and conservative politics (Hansen, 1999; 2018). The relationship between caste, religion, and politics between elections is therefore of great significance since the various communities have "lived together separately" (Roy and Hasan, 2005). How is India's "social universe" influenced by friendship ties? Are social cleavages stronger and social lives inclusive? We look at friendship as an indicator in order to understand the "social universe" that Indians inhabit. In this section, we examine caste and community friendship ties across states, social identity, and levels of education. ${ }^{1}$

We asked respondents the following question:

"Is any of your close friends a __?" for eight social identities: Dalit, Adivasi, OBC, Upper Caste, Muslim, Christian, Hindu, and opposite gender. The response categories were: "Yes", "No", and "Don't Know".

In most states, over 50 percent of the respondents say they have a Dalit close friend (Figure 2.1.1). The proportion is over 70 percent in Madhya Pradesh, Maharashtra (73 percent), Jharkhand (74 percent), Andhra Pradesh (78 percent), and Telangana (83 percent). However, this number falls below 40 percent in Assam, Jammu and Kashmir, and West Bengal. In Mizoram, only around five percent says they have a Dalit friend.

As expected, Dalit respondents are the most likely to have a Dalit friend (75 percent) followed by Adivasi ( 63 percent) and OBC ( 62 percent) respondents (Figure 2.1.2). Upper caste respondents (57 percent) are the least likely to have a Dalit close friend. As levels of education increase, the likelihood of having a Dalit friend also increases. This is seen across all caste groups.

A majority of respondents in several states (Bihar, Gujarat, Haryana, Jammu and Kashmir, Karnataka, Kerala, Rajasthan, Tamil Nadu, Uttar Pradesh, and Uttarakhand) report not having an Adivasi close friend likely the result of small shares of an Adivasi population (Figure 2.1.3). Over 50 percent of the respondents report having an Adivasi close friend in Andhra Pradesh (51 percent), Assam (51 percent), Madhya Pradesh (53 percent), Odisha (55 percent), and Maharashtra (57 percent). Over 70 percent report having an Adivasi friend in Jharkhand (73 percent), Nagaland (74 percent), Tripura (76 percent), and Chhattisgarh (78 percent). In Mizoram only five percent of the respondents report having an Adivasi friend. The lowest proportions of respondents having an Adivasi friend are seen in Bihar (12 percent), Punjab (seven percent), and Haryana (four percent). 


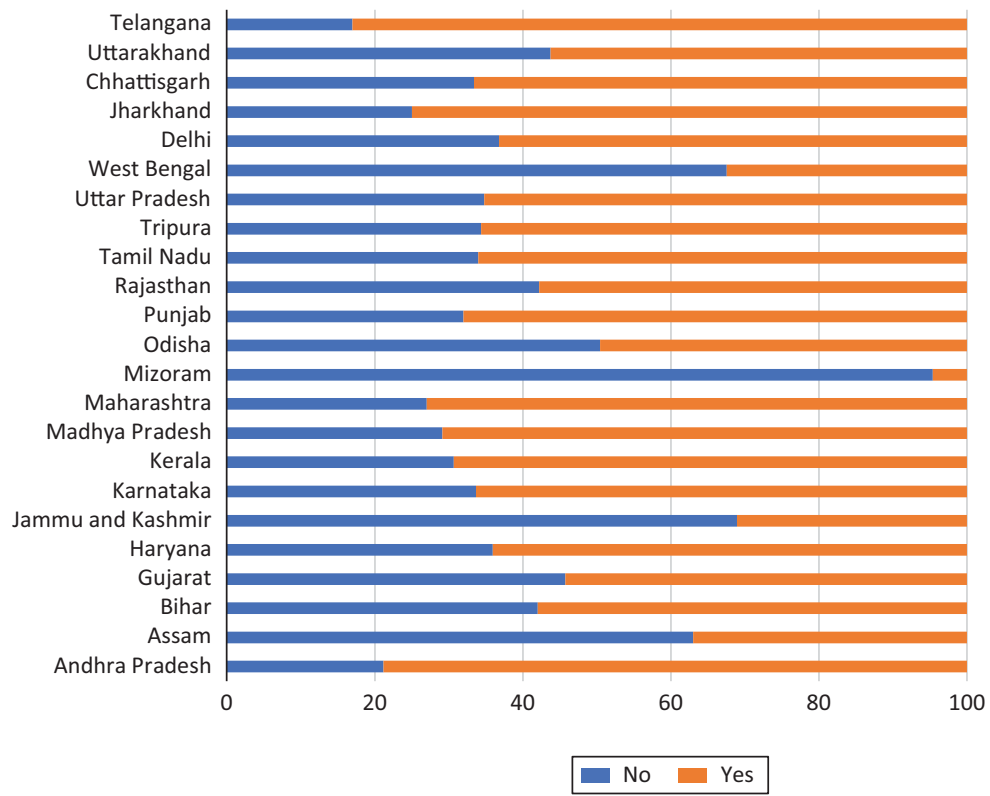

Figure 2.1.1 Have a Dalit Close Friend (by State)

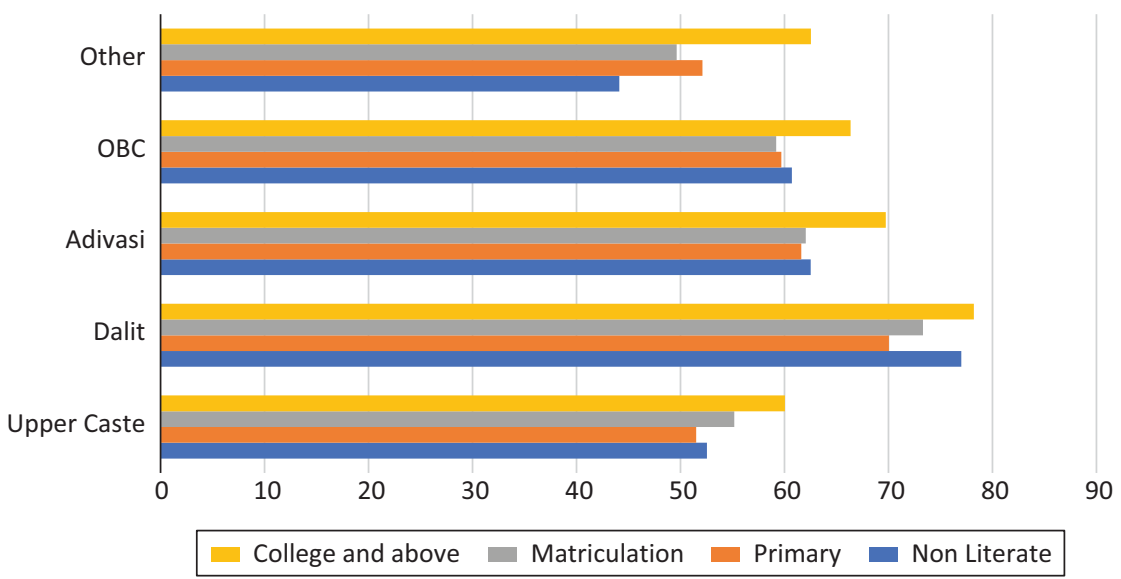

Figure 2.1.2 Have a Dalit Close Friend (by Caste and Education) 


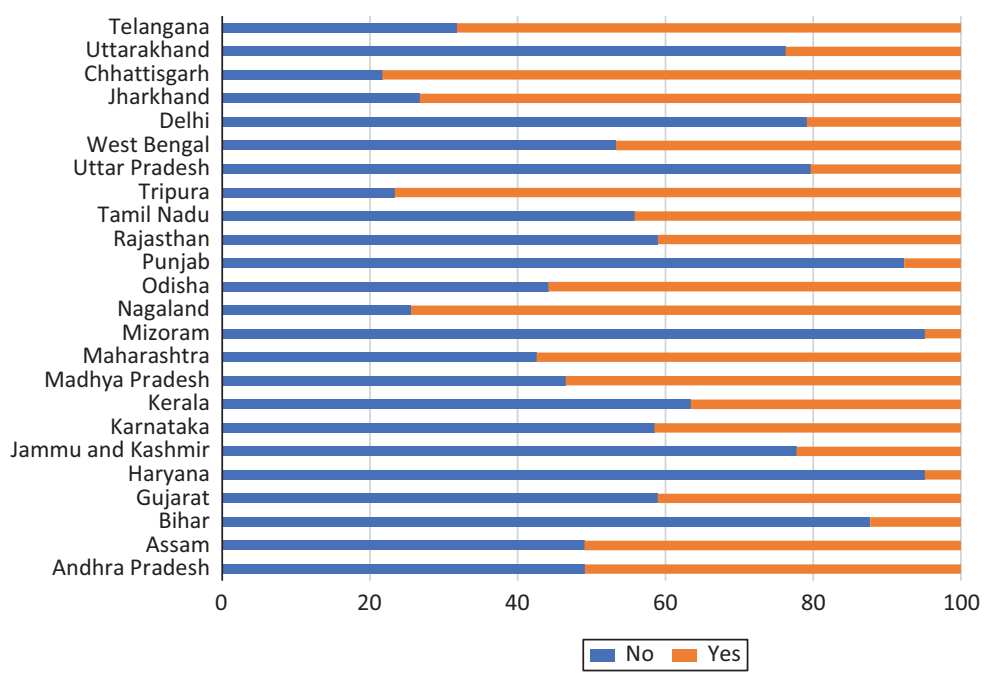

Figure 2.1.3 Have an Adivasi Close Friend (by State)

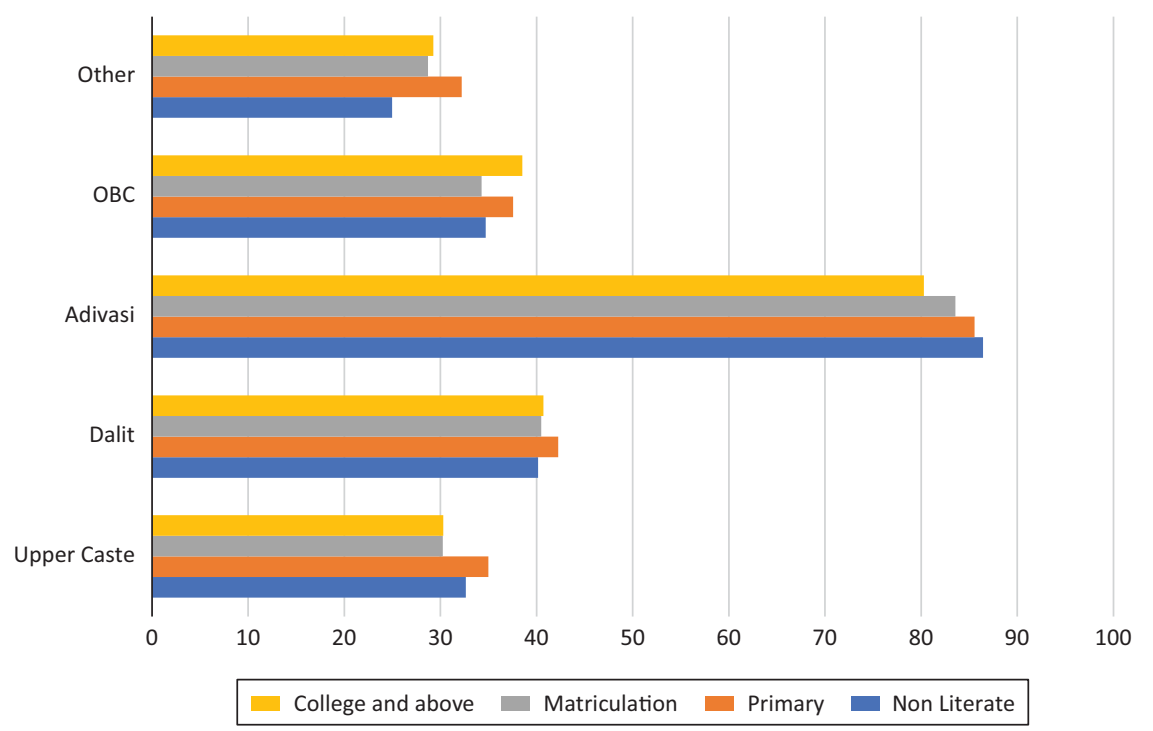

Figure 2.1.4 Have an Adivasi Close Friend (by Caste and Education)

Adivasi respondents are the most likely to have an Adivasi close friend (85 percent) followed by Dalits (41 percent), OBC (36 percent), and upper caste (32 percent) respondents (Figure 2.1.4). Education produces mixed effects on having an Adivasi friend among the caste groups. There are no differences in the likelihood of having an Adivasi friend across education levels 


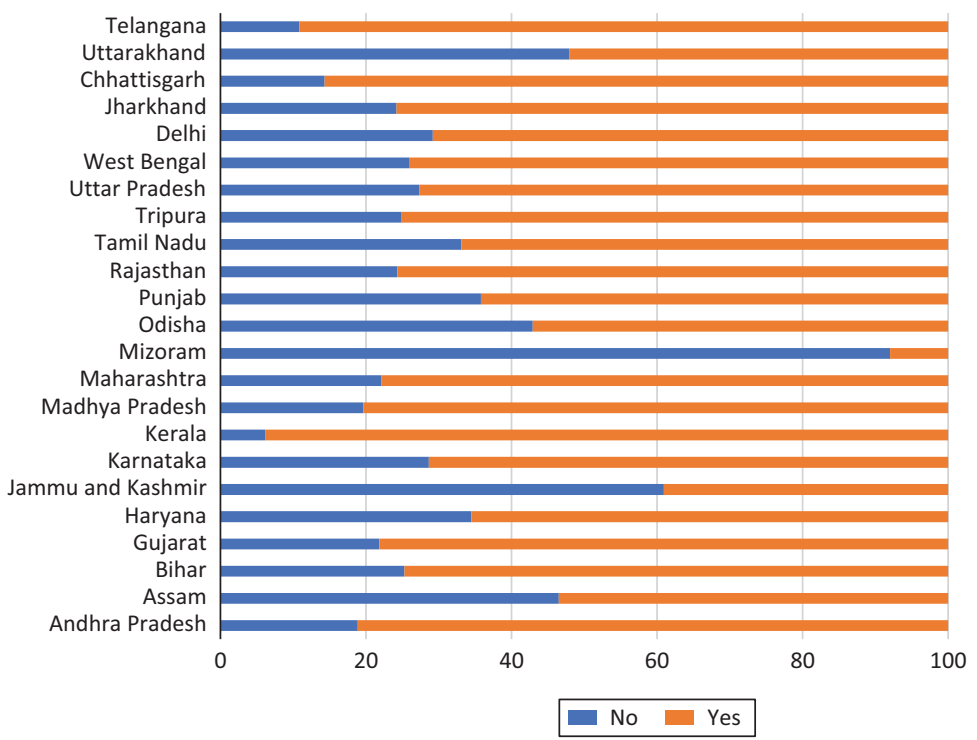

120

Figure 2.1.5 Have an OBC Close Friend (by State)

for Dalits. The proportion of OBC respondents who have an Adivasi friend increases across levels of education, while the same proportion decreases marginally for upper caste respondents. The share of Adivasi respondents with Adivasi close friends falls from 86 percent among non-literate respondents to 80 percent among college educated.

Most states see a significant share of respondents who have an OBC friend (Figure 2.1.5), for example Kerala (93 percent), Telangana ( 89 percent), Chhattisgarh (85 percent), Andhra Pradesh (81 percent), and Madhya Pradesh (80 percent) record the highest proportions of respondents with a friend who is OBC. The only states with low proportions of respondents with friend who is OBC are Jammu and Kashmir (39 percent) and Mizoram (eight percent).

At between 70-73 percent Adivasi, Dalit, and upper caste respondents have OBC close friends (Figure 2.1.6). This is expectedly greater for OBC respondents (78 percent). There is an increase in the share of respondents with an $\mathrm{OBC}$ close friend as levels of education increase. The increase between non-literate and college educated respondents is three percentage points for upper caste, nine percentage points for Dalit, nine percentage points for Adivasi, and five percentage points for OBC respondents.

Respondents in Delhi (82 percent) and Kerala (89 percent) report the highest proportions with an upper caste friend (Figure 2.1.7). Over 60 percent of 


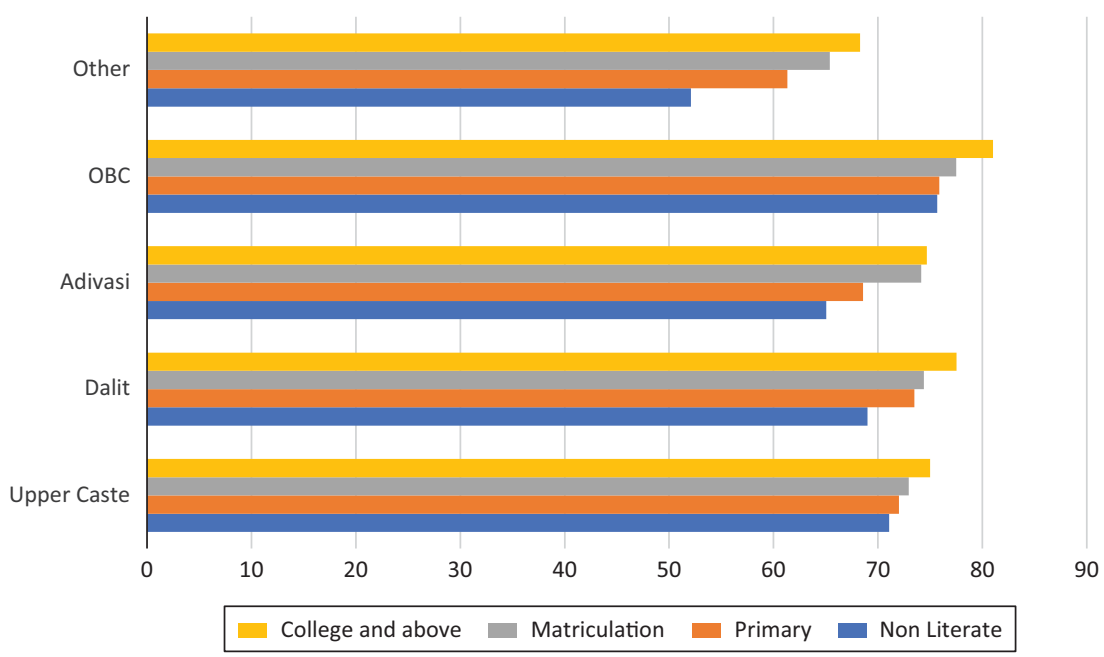

Figure 2.1.6 Have an OBC Close Friend (by Caste and Education)

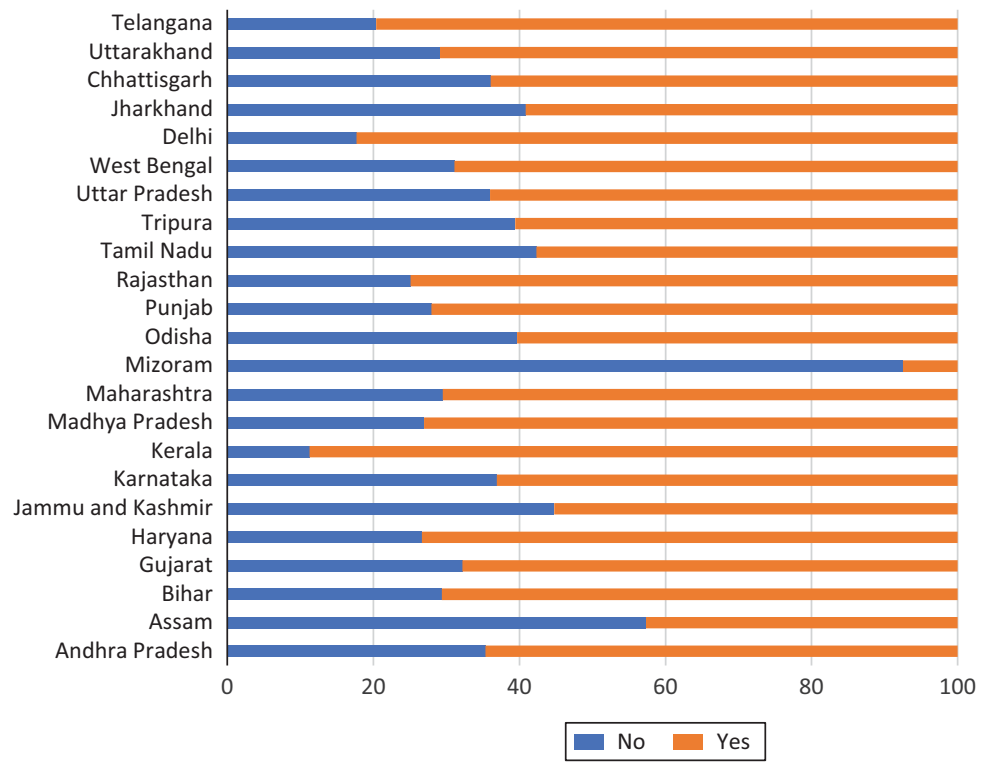

Figure 2.1.7 Have an Upper Caste Close Friend (by State) 


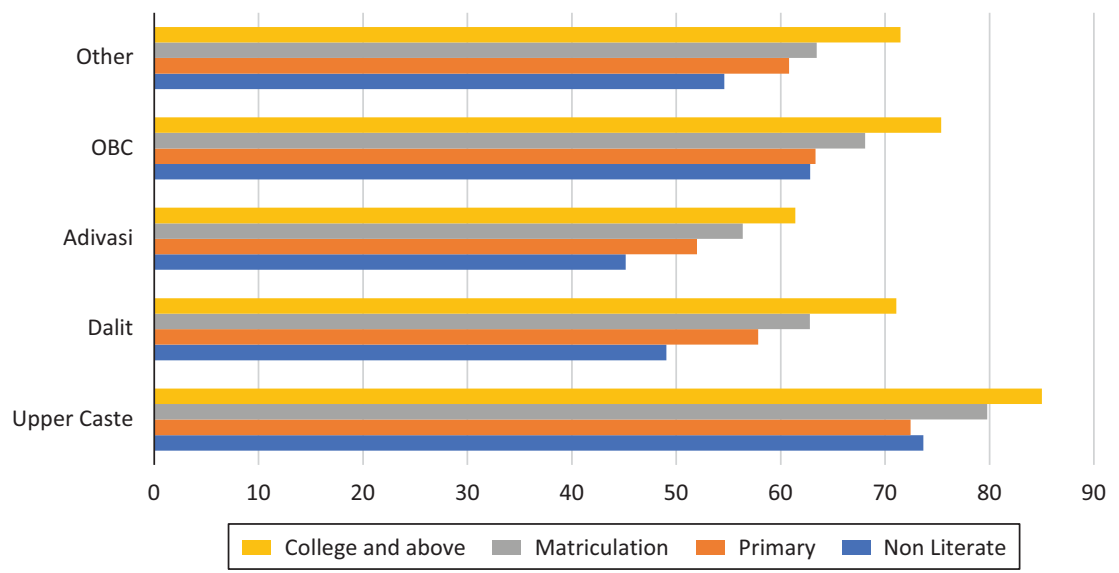

Figure 2.1.8 Have an Upper Caste Close Friend (by Caste and Education)

the respondents in most other states also report having a close upper caste friend. However, only about 40 percent of the respondents in Assam and less than ten percent of the respondents in Mizoram say they have an upper caste friend.

While 80 percent upper caste respondents report having a close upper caste friend, this proportion drops to 68 percent for OBC, 60 percent for Dalit, and 52 percent for Adivasi respondents (Figure 2.1.8). With higher levels of education, a larger share of people among all caste groups have an upper caste friend. The increase is about 22 percentage points for Dalit, 16 percentage points for Adivasi and 12 percentage points for OBC respondents. The increase for upper caste respondents is about 11 percentage points.

Over half the respondents do not have a Muslims friend in Bihar, Gujarat, Haryana, Madhya Pradesh, Mizoram, Nagaland, Odisha, Punjab, Rajasthan, Tamil Nadu, Tripura, Uttar Pradesh, Jharkhand, Chhattisgarh, and Uttarakhand (Figure 2.1.9). Mizoram (14 percent) and Chhattisgarh (25 percent) report the lowest proportions of respondents with a Muslim friend. Over 60 percent of respondents in Andhra Pradesh, Maharashtra, Delhi, and Telangana say they have a Muslim friend. Respondents from Kerala ( 84 percent) and Jammu and Kashmir ( 82 percent) are most likely to have a Muslim friend.

Muslim respondents (as seen with the other groups) are most likely to have a close Muslim friend (Figure 2.1.10). About 89 percent Muslim respondents say they have a close Muslim friend. Of Christian respondents, 59 percent report having a Muslim close friend - while 42 percent of Hindus and 35 percent of Sikhs do. As levels of education increase the proportion of respondents with 


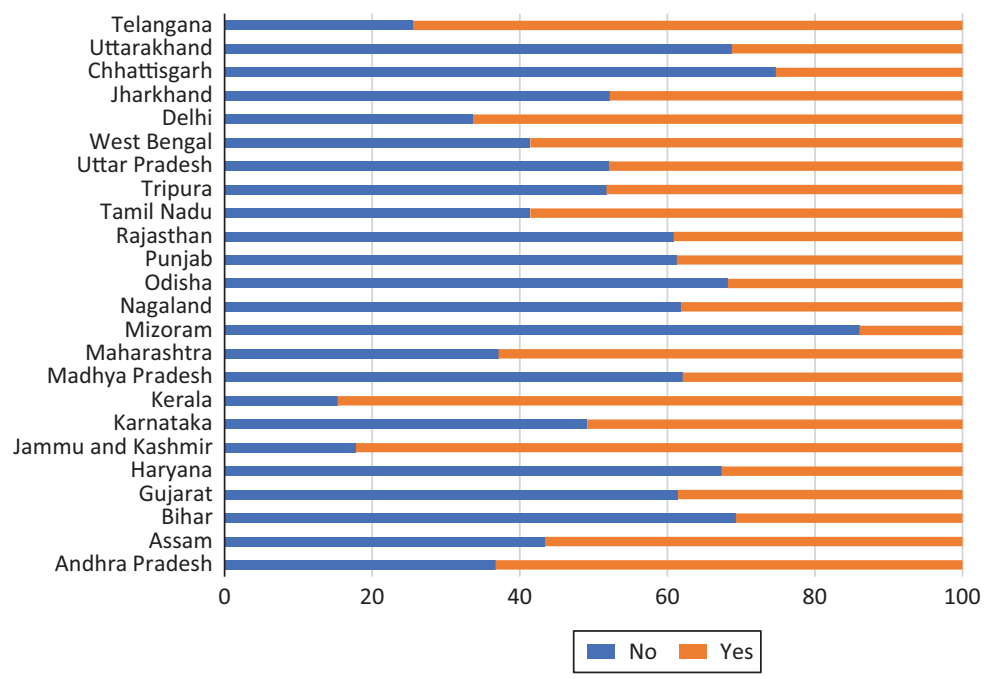

Figure 2.1.9 Have a Muslim Close Friend (by State)

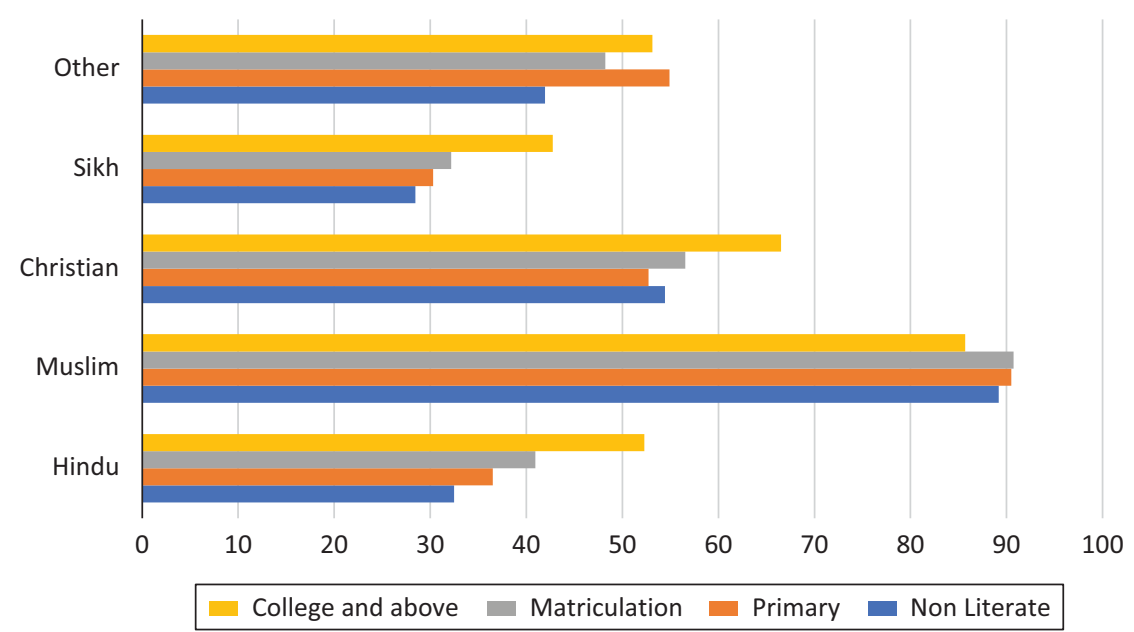

Figure 2.1.10 Have a Muslim Close Friend (by Religion and Education)

a close Muslim friend also increases for Hindus (20 points), Christians (23 points), and Sikhs (18 points) but remains constant for Muslims.

Urban respondents are more likely to have a close Muslim friend compared to rural respondents (Figure 2.1.11). This pattern is seen across all groups. The difference in urban and rural proportions is about 13 points 


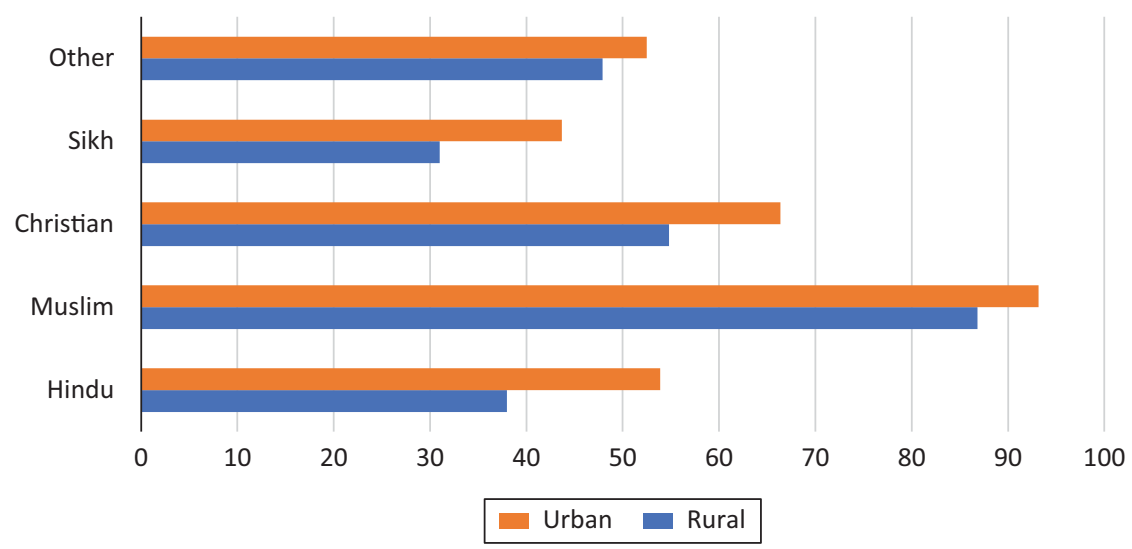

Figure 2.1.11 Have a Muslim Close Friend (by Religion and Rural-Urban)

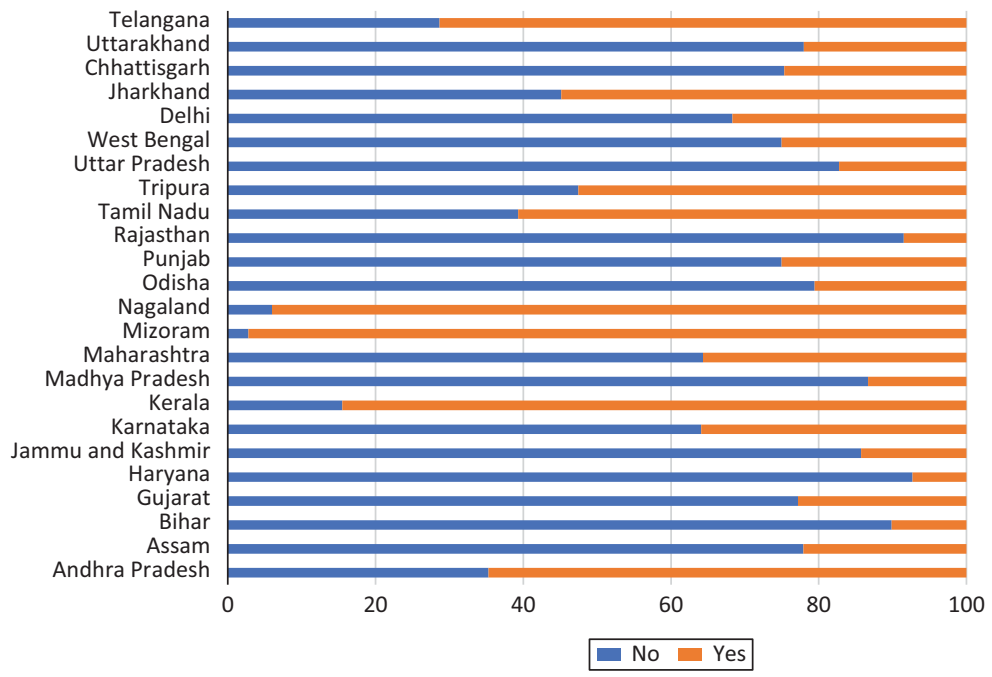

Figure 2.1.12 Have a Christian Close Friend (by State)

for Hindus, 22 points for Christians, 13 points for Sikhs, and about five percentage points for Muslims.

Over 60 percent of the respondents in most states say they do not have a Christian close friend (Figure 2.1.12). A majority of respondents in Tripura, Jharkhand, Tamil Nadu, Andhra Pradesh, Telangana, Kerala, 


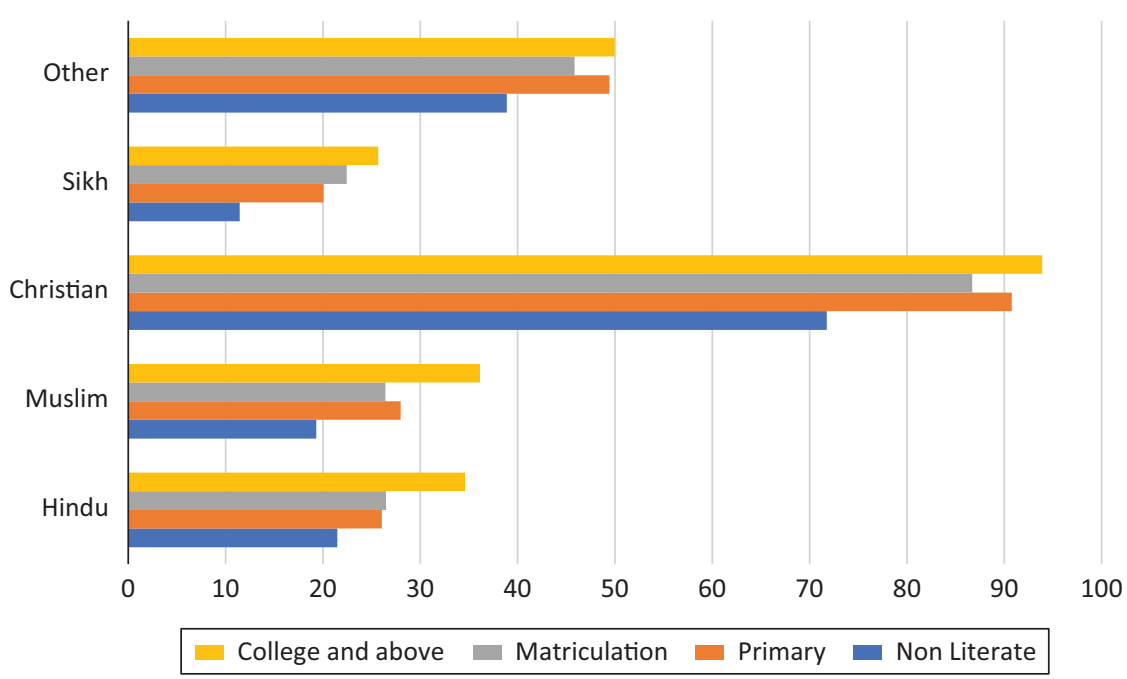

Figure 2.1.13 Have a Christian Close Friend (by Religion and Education)

Nagaland, and Mizoram say they have a Christian friend. Respondents in Mizoram (97 percent), Nagaland (94 percent) and Kerala (84 percent) are most likely to have a Christian friend. Less than ten percent of the respondents in Haryana (seven percent), Rajasthan (eight percent), and Bihar (ten percent) have a Christian friend while 13 percent of respondents in Madhya Pradesh and 14 percent in Jammu and Kashmir have a Christian friend.

As expected, Christian respondents are more likely to have a Christian close friend ( 89 percent) compared to Hindu (28 percent), Muslim (28 percent), and Sikh (21 percent) respondents (Figure 2.1.13). As education level increases, a large share of respondents across all groups report having a close Christian friend. This proportion increases by about 16 points between non-literate and college-educated and non-literate Muslim respondents. For Hindu and Sikh respondents, the increase is approximately 13 and 14 points respectively.

A majority of the respondents in most states, expectedly, have a Hindu close friend (Figure 2.1.14). In Mizoram about 19 percent say they have a Hindu friend. This proportion increases to 45 percent in Jammu and Kashmir and 52 percent in Nagaland.

While 90 percent of Hindu respondents say they have a close Hindu friend, 85 percent of Christians and 75 percent of Muslims also say the same (Figure 2.1.15). Increased level of education has only a small effect on the likelihood of having a Hindu friend. The only exception are Sikh 


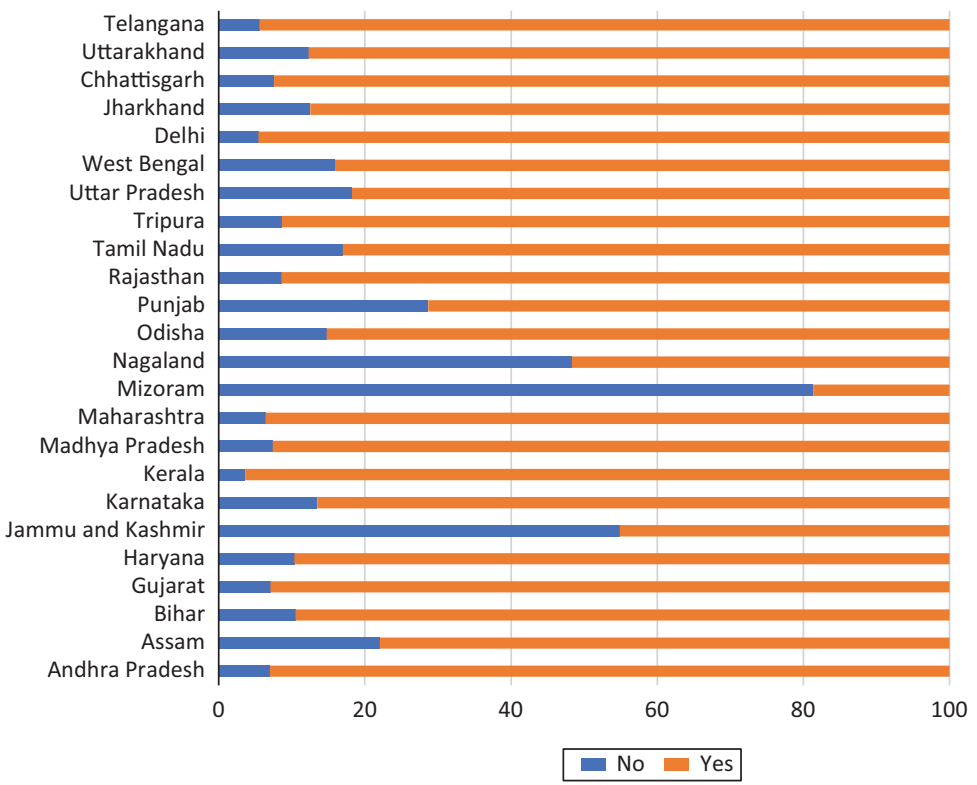

Figure 2.1.14 Have a Hindu Close Friend (by State)

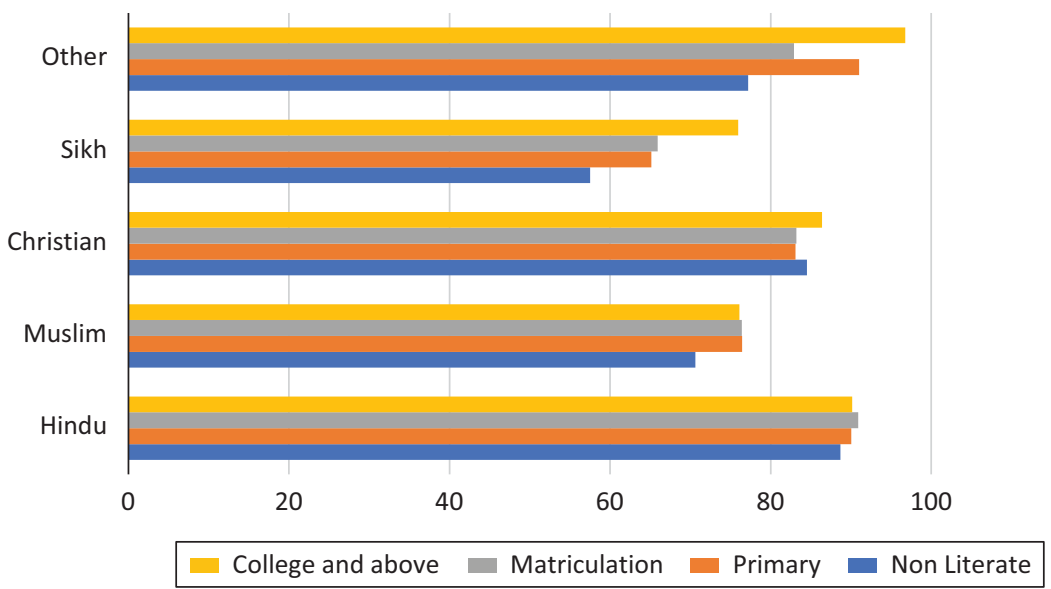

Figure 2.1.15 Have a Hindu Close Friend (by Religion and Education)

respondents for whom the likelihood increases by about 18 points across higher levels of education.

A majority of the respondents in most states say they do not have a friend of the opposite gender (Figure 2.1.16). The only exceptions are Kerala (33 percent), Mizoram (49 percent), and Nagaland (25 percent). 


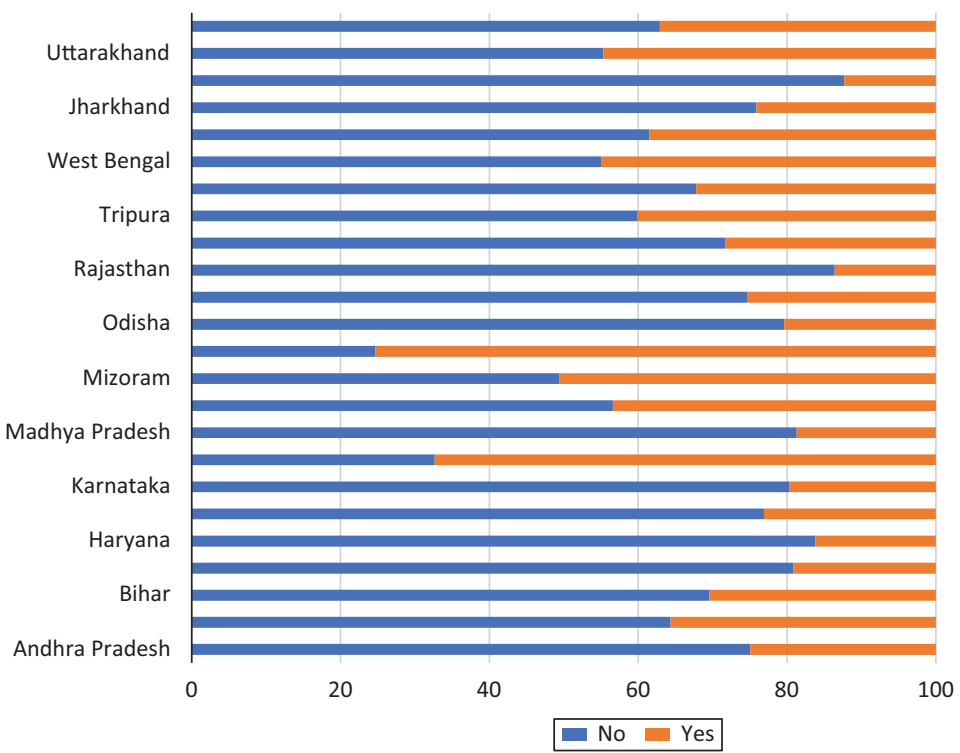

Figure 2.1.16 Have a Close Friend of Opposite Gender (by State)

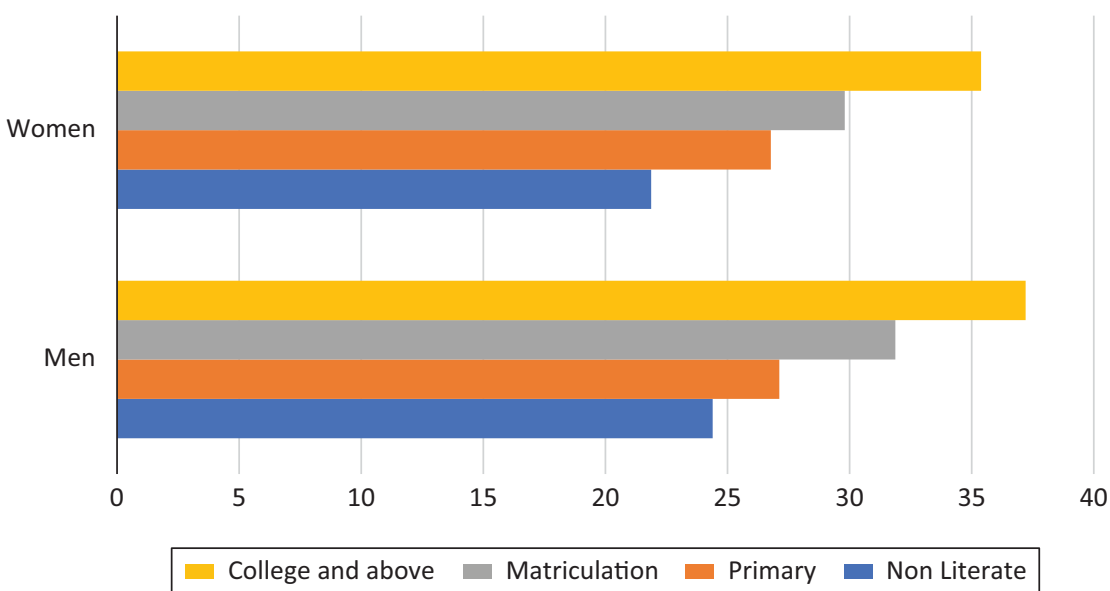

Figure 2.1.17 Have a Close Friend of Opposite Gender (by Gender and Education)

Men are more likely to report having a close friend of the opposite gender compared to women (Figure 2.1.17). The difference, however, is small - about four percentage points. The likelihood of reporting having a friend of the opposite gender also grows with increasing levels of education. The change across levels of education for both men and women lies at about 13 percentage points. 


\subsection{PREFERENCES OVER LEADER IDENTITY}

Do citizens prefer approaching a leader from their own caste group or religious community in order to get their (official) work done? And to whom do these differences matter? In this section, we examine the responses on the preference for the caste-community identity of the leader by state, identity (caste/religion), location, and economic class.

We measure this using a set of questions that are as follows:

"Suppose there are two leaders from the same political party and equally competent to get your work done. If one is from your caste/ religion while the other from a different caste/religion, whom would you be willing to contact first?”

The answer categories are "1. Leader from same caste/religion", "2. Leader from different caste/religion", and " 3 . Will not make any difference". The respondents were further provided with an option of "No opinion".

Over 50 percent of the respondents in 15 states (Bihar, Gujarat, Haryana, Karnataka, Madhya Pradesh, Mizoram, Nagaland, Odisha, Rajasthan, Tripura, Uttar Pradesh, West Bengal, Jharkhand, and Chhattisgarh) prefer approaching a leader from their own caste (Figure 2.2.1). This preference is highest in Mizoram (75 percent) and Nagaland (72 percent) where at least seven out of every ten respondents prefer a leader from their caste. Most respondents in Kerala (74 percent), Punjab (56 percent), Jammu and Kashmir (55 percent), Assam (52 percent), and Uttarakhand (50 percent) do not hold a caste preference for the leader they would approach to get work done. The difference in the share of respondents who do not have a caste
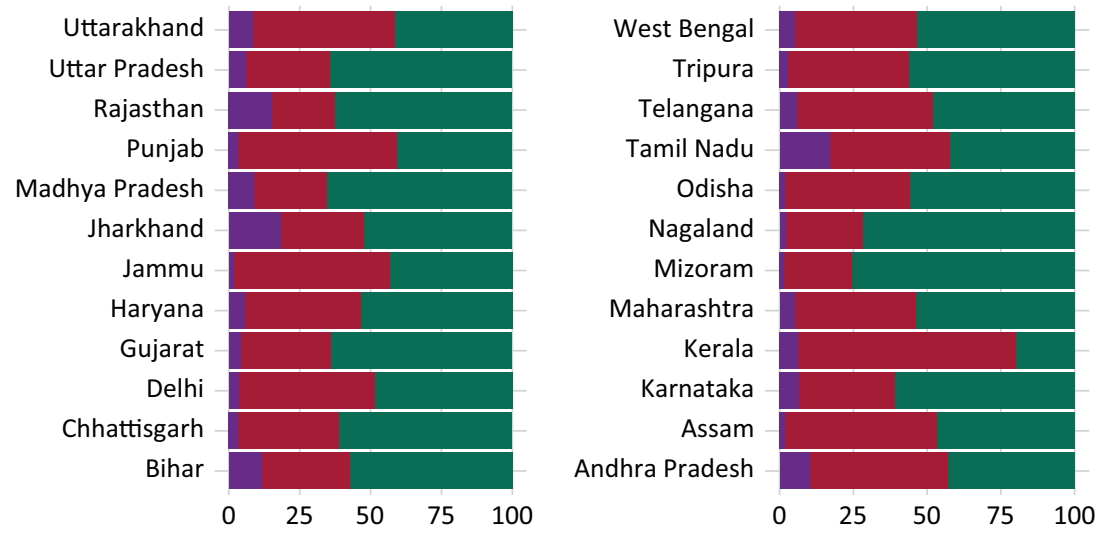

Leader from same caste Caste does not matter

Leader from different caste

Figure 2.2.1 Preference on Caste of Leader to Get Work Done (by State) 
preference and those who prefer a leader from the same caste is less than ten percentage points in Assam (five), Andhra Pradesh (four), and Delhi (one). In contrast, this difference is 54 percentage points in Kerala, 16 in Punjab, 12 in Jammu and Kashmir, and nine in Uttarakhand. The same difference is negative in other States (i.e. more respondents prefer approaching a leader from their caste). While the share of respondents who prefer a leader from a different caste is relatively small, over 15 percent of the respondents in Jharkhand (19 percent) and Tamil Nadu (17 percent) prefer a leader from a different caste to their own.

A majority of the rural respondents across the caste groups prefer a leader from their own caste (Figure 2.2.2). A larger share of urban Dalit (51 percent) and Adivasi respondents (66 percent) prefer a leader from the same caste. Among urban upper caste and $\mathrm{OBC}$ respondents approximately 48 percent and 45 percent, respectively, say that caste will not matter.

There is a decline in preference for a leader from the same caste among wealthier respondents, compared to poorer respondents across all caste groups (Figure 2.2.3). The decline for upper caste respondents is 11 points, five points for Dalit respondents, 16 points for Adivasi, and nine points for OBC respondents.

A majority of the respondents in Bihar, Karnataka, Gujarat, Haryana, Jammu and Kashmir, Madhya Pradesh, Maharashtra, Mizoram, Nagaland, Odisha, Rajasthan, Tripura, Uttar Pradesh, West Bengal, Jharkhand, and Chhattisgarh prefer to approach a leader from the same religious community (Figure 2.2.4). In Mizoram and Nagaland about 77 percent and 67 percent of the respondents respectively preferred a leader from their own religion. At least half of the respondents in Delhi (50 percent), Assam (51 percent),

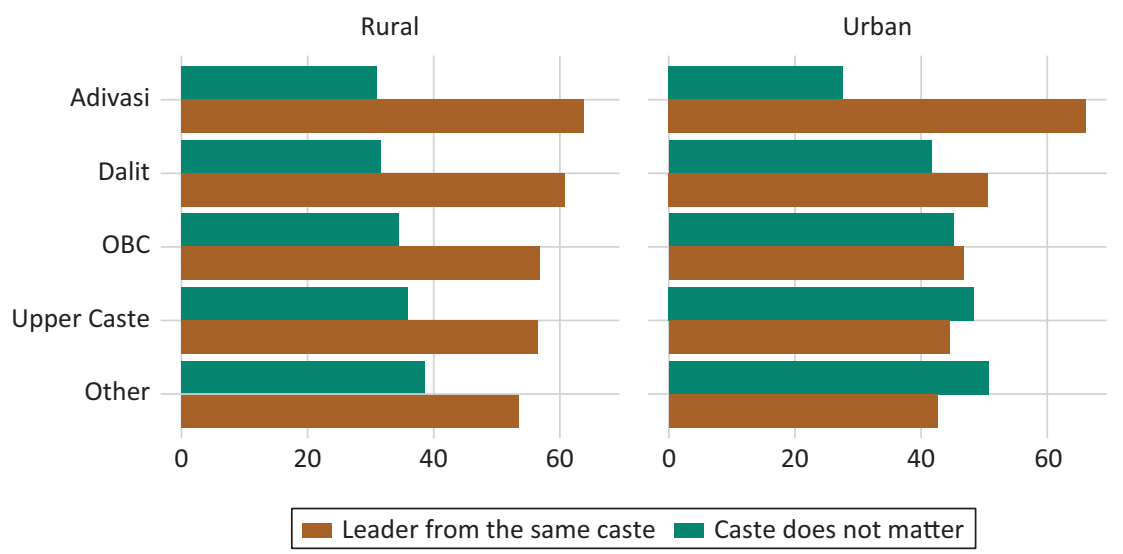

Figure 2.2.2 Preference on Caste of Leader to Get Work Done (by Caste and Rural-Urban) 


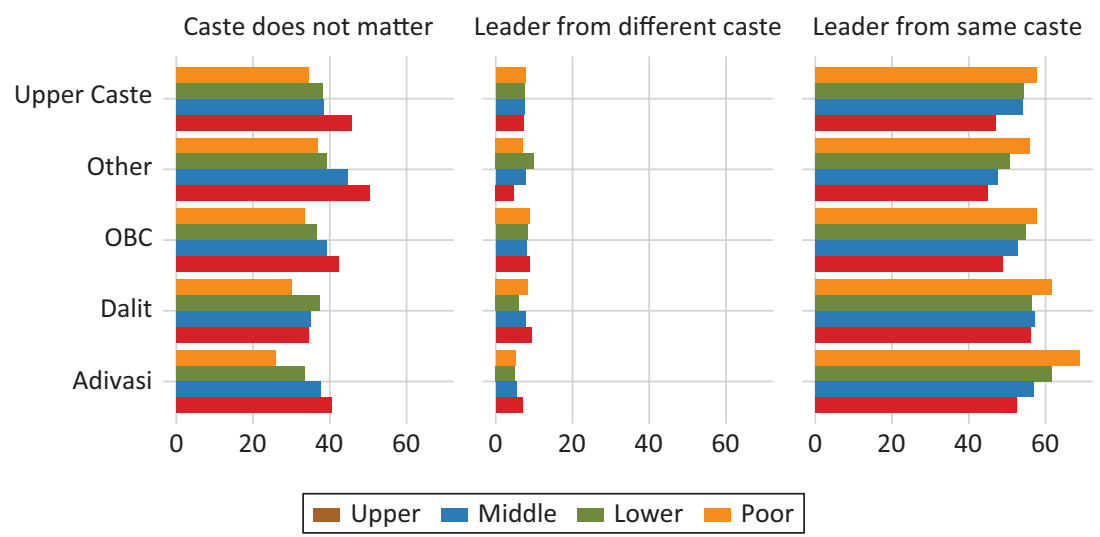

Figure 2.2.3 Preference on Caste of Leader to Get Work Done (by Caste and Economic Class)
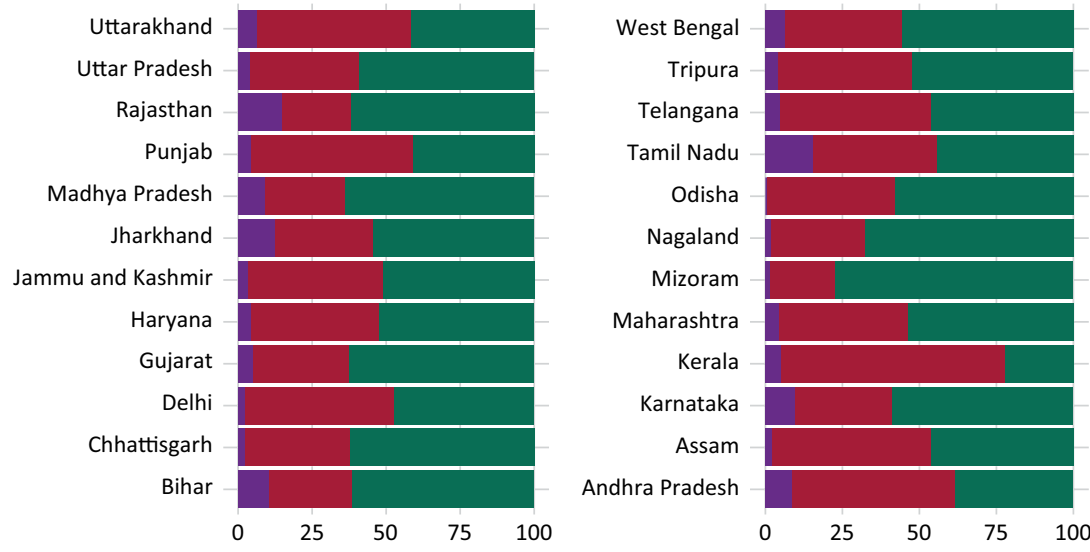

Leader from the same religion Religion does not matter Leader from different religion

Figure 2.2.4 Preference on Religion of Leader to Get Work Done (by State)

Uttarakhand (52 percent), Andhra Pradesh (53 percent), Punjab (54 percent), and Kerala (72 percent) say that the religion of the leader did not matter. Although only small share of respondents across all states preferred to approach a leader who is from a different religious community, in Rajasthan and Tamil Nadu around 15 percent of the respondents hold this view.

Hindu and Muslim respondents prefer to approach a leader from the same religion (Figure 2.2.5). The exception are Christian and Sikh respondents, for whom religious identity of the leader they approach does not matter. Rural respondents prefer to approach a leader from their own community 


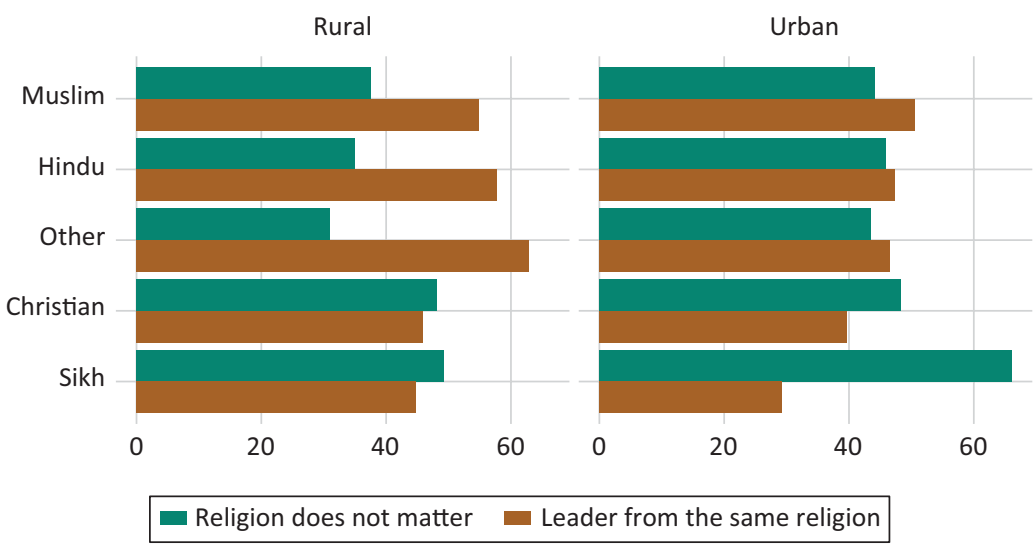

Figure 2.2.5 Preference on Religion of Leader to Get Work Done (by Religion and Rural-Urban)

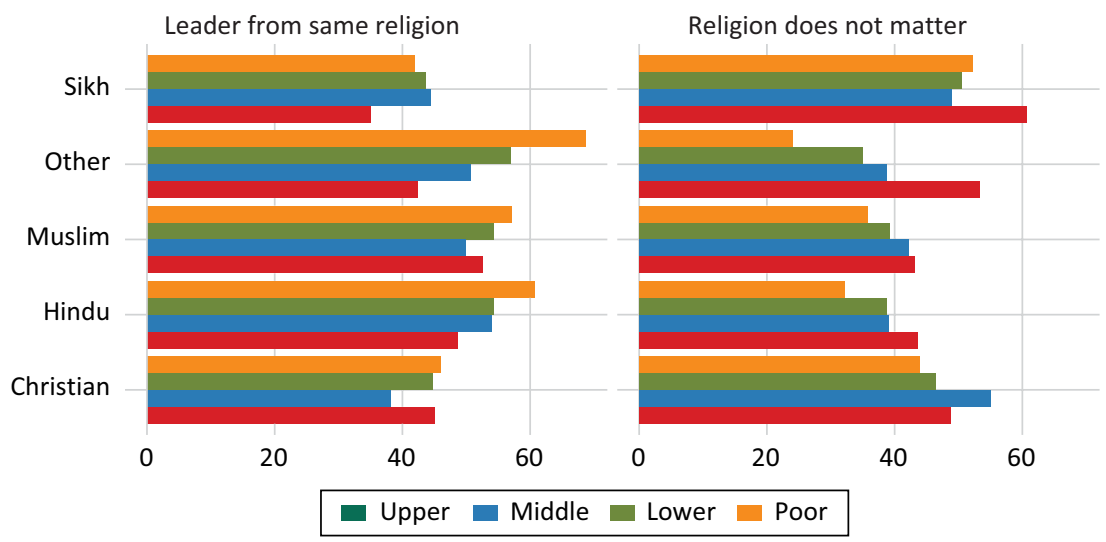

Figure 2.2.6 Preference on Religion of Leader to Get Work Done (by Religion and Economic Class)

more so than do urban respondents. The difference between proportions of rural and urban respondents is large in the case of Sikhs (15 points) and Hindus (11 points) but smaller for Muslim (four points) and Christian (six points) respondents.

Respondents from wealthier backgrounds are less likely to prefer approaching a leader from the same religion compared to poorer respondents (Figure 2.2.6). This pattern holds for Hindu, Muslim and Sikh respondents. This difference is about 12 percent for Hindu, four percent for Muslim, and seven percent for Sikh respondents. However, the change is only marginal across class for Christian respondents. 


\subsection{PERCEPTIONS OF SOCIAL COMMUNITY}

Here we explore the perceptions that citizens hold about religious and caste communities other than their own along three dimensions: habits (specifically, work ethic), patriotism, and perception of "violent or peaceful". In this section, we begin with perceptions about whether certain caste groups are hardworking or lazy, followed by perceptions about patriotism and the proclivity of religious communities to violence or peace. Our examination focuses on the variation in perceptions by state, caste identity, and levels of education.

\subsubsection{Hardworking or Lazy}

We ask a question about the work habit of caste identities as follows:

"On a ladder of 10 steps where the 1st step at the bottom stands for extremely lazy and the 10th step at the top stands for extremely hardworking, on which step from 1 to 10 would you place the following communities?”

The communities we ask about are Dalits, Adivasis, and upper castes. The respondents are shown a scale from one to ten and asked to select a level on the scale (Figure 2.3.1). If the respondent declines to answer, "No Opinion" is recorded. We interpret the responses equal to or above the value six on the scale as generally meaning hard-working and those equal to or below as "lazy". We report responses for only those states with significant populations of the caste groups of interest. Perceptions towards Dalits does not include Mizoram and Nagaland, and perceptions towards upper castes does not include Mizoram.

For perceptions on the patriotism of religious communities we ask the following question:

"On a ladder of 10 steps where the 1st step at bottom stands for extremely unpatriotic and the 10th step at the top stands for extremely patriotic, on which step from 1 to 10 would you place the following communities?"

The communities we ask about are Hindus, Muslims, Christians, and Sikhs. The respondents are shown a scale from one to ten and asked to select a level on the scale (Figure 2.3.2). If the respondent declines to answer, "No

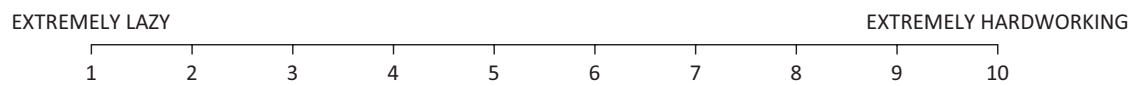

Figure 2.3.1 Ten-Point Scale for "Hardworking or Lazy" 


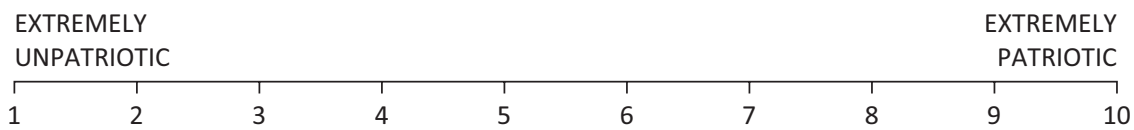

Figure 2.3.2 Ten-Point Scale for "Patriotic or Unpatriotic"

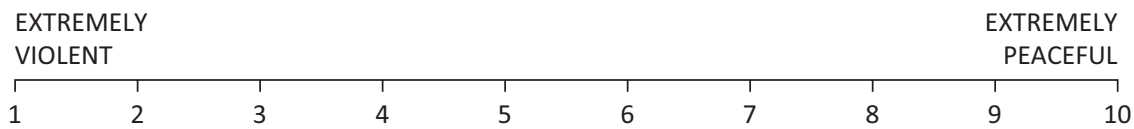

Figure 2.3.3 Ten-Point Scale for "Peaceful or Violent"

Opinion" is recorded. We interpret the responses equal to or above the value six on the scale as generally patriotic and those equal to or below four as generally meaning "unpatriotic".

To explore the perceptions on the nature of communities - whether peaceful or violent - we ask: "On a ladder of 10 steps, where the 1 st step at the bottom stands for extremely violent and the 10th step at the top stands for extremely peaceful, on which step from 1 to 10 would you place the following communities?"

Once again, the communities of interest are Hindus, Muslims, Christians, and Sikhs. Respondents are shown a scale from one to ten and asked to select a level on the scale (Figure 2.3.3). If the respondent declined to answer the question, "No Opinion" is recorded. We interpret the responses equal to or above the value six on the scale as generally "peaceful" and those equal to or below four as generally "violent".

While in most of the states less than 20 percent of the responses tend toward perceiving Dalits as "lazy", a higher share of respondents in Uttar Pradesh (34 percent), Uttarakhand (29 percent), Bihar (35 percent), and Tamil Nadu (20 percent) hold this view (Figure 2.3.4). Around eight percent of respondents in Uttar Pradesh and Uttarakhand and seven percent in Tamil Nadu perceive Dalits to be extremely lazy whereas less than five percent in other states hold the same opinion. In Odisha 34 percent of respondents perceive Dalits as extremely hardworking - this belief is at 32 percent in Chhattisgarh followed by Andhra Pradesh (29 percent), Assam (29 percent), and Punjab (27 percent). In the remaining states, between 16 and 35 percent respondents see Dalits as hardworking. In Kerala, 41 percent of survey respondents do not answer this question, followed by around 25 percent in Assam and 23 percent in Gujarat and Tamil Nadu. In other states, this number is significantly lower and in the five percent to 20 percent range. Only Bihar, Karnataka, and Jharkhand record very low non-responses (one percent or less). 
SOCIAL UNIVERSE
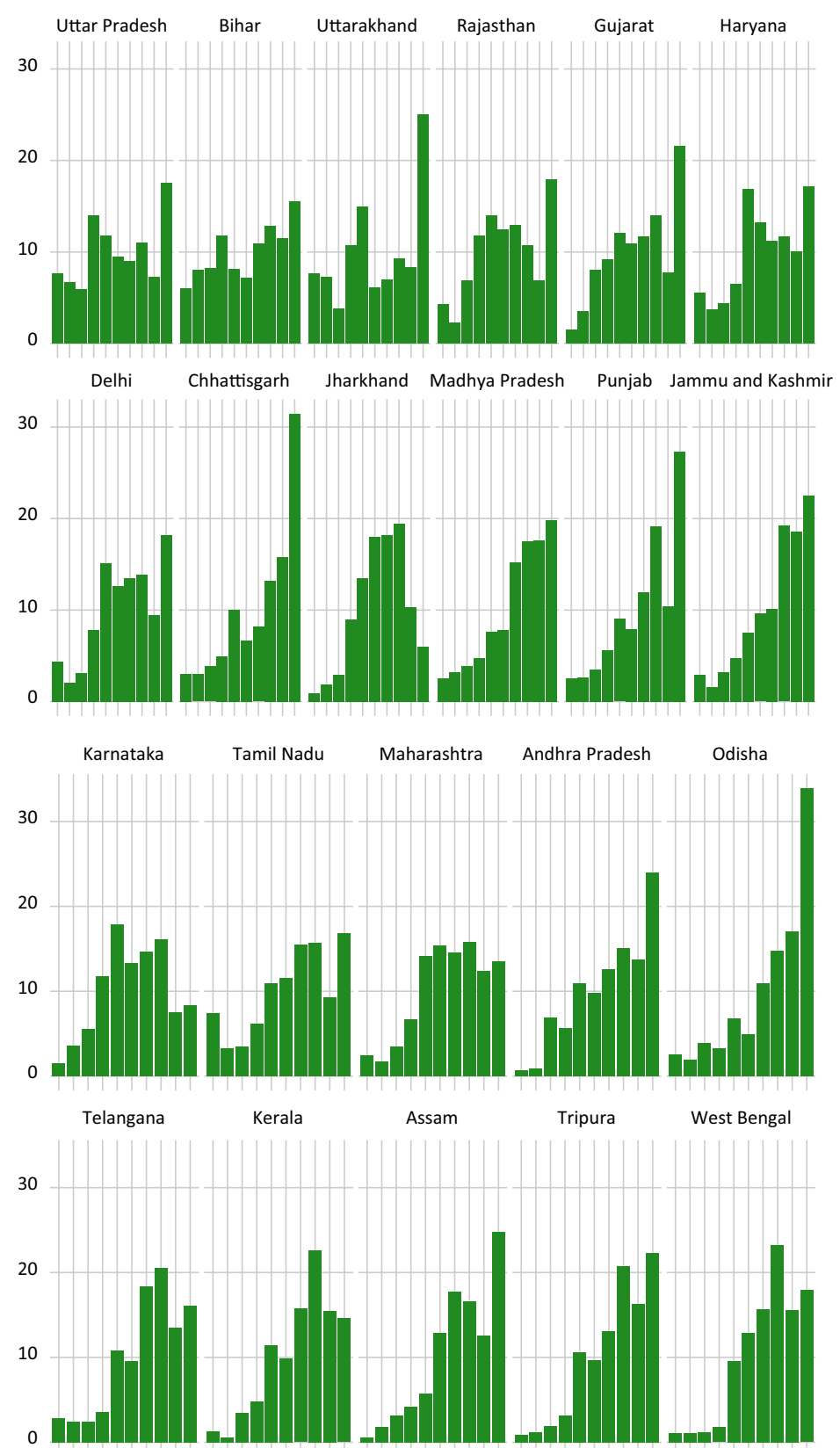

Figure 2.3.4 Perceptions About Dalits as Being "Hardworking or Lazy" (by State) 


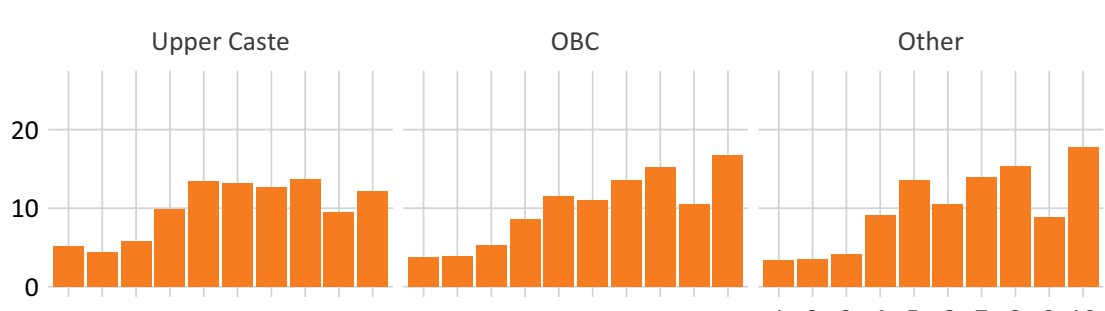

$\begin{array}{llllllllll}1 & 2 & 3 & 4 & 5 & 6 & 7 & 8 & 9 & 10\end{array}$

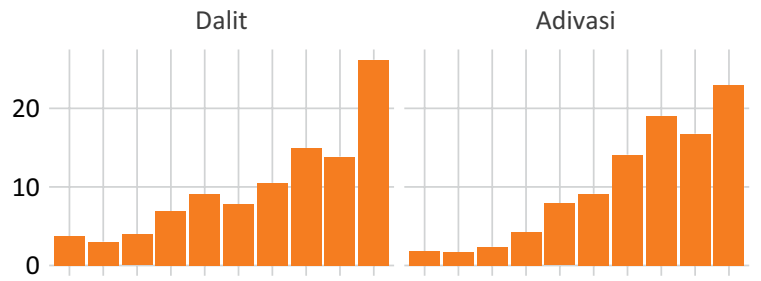

$\begin{array}{llllllllllllllllllll}1 & 2 & 3 & 4 & 5 & 6 & 7 & 8 & 9 & 10 & 1 & 2 & 3 & 4 & 5 & 6 & 7 & 8 & 9 & 10\end{array}$

Figure 2.3.5 Perceptions About Dalits as Being “Hardworking or Lazy” (by Caste)

About 75 percent of Dalit respondents see themselves as hardworking. Upper castes are the least likely to see Dalits as hardworking compared to Adivasis, OBCs, or Dalits themselves (Figure 2.3.5). Of upper caste respondents, 12 percent see Dalits as extremely hardworking and this number increases to 23 percent among Adivasis, 17 percent among OBCs, and 26 percent among Dalits. Additionally, 25 percent of upper caste and 22 percent of OBC respondents see Dalits as generally lazy. However, all caste groups see Dalits as more hardworking than lazy. About 28 percent of Adivasis and nearly 13 percent of OBC respondents do not answer this question. About nine percent of Dalis do not express an opinion about themselves while less than nine percent of upper caste respondents decline to respond to this question.

We observe an inverse relationship between levels of education and perceptions of Dalits as hardworking (Figure 2.3.6). While 24 percent of non-literate respondents think of Dalits as extremely hardworking, the number falls to 15 percent among the college educated. The proportion of respondents who see that Dalits are generally hardworking decreases from 74 percent among non-literates to 67 percent among the college educated.

In most states, more than 60 percent of the respondents show support for the idea that Adivasis are hardworking (Figure 2.3.7). In Mizoram (56 percent), Nagaland (37 percent), Karnataka (37 percent), and Uttar Pradesh (33 percent), opinions are concentrated in the centre. In Haryana, nearly 30 percent feel that Adivasis are lazy and 23 percent in Uttar Pradesh. In other states' perceptions of Adivasis tends toward the higher end of the scale. In Assam, Kerala, Mizoram, Jharkhand, Tripura, and West Bengal 


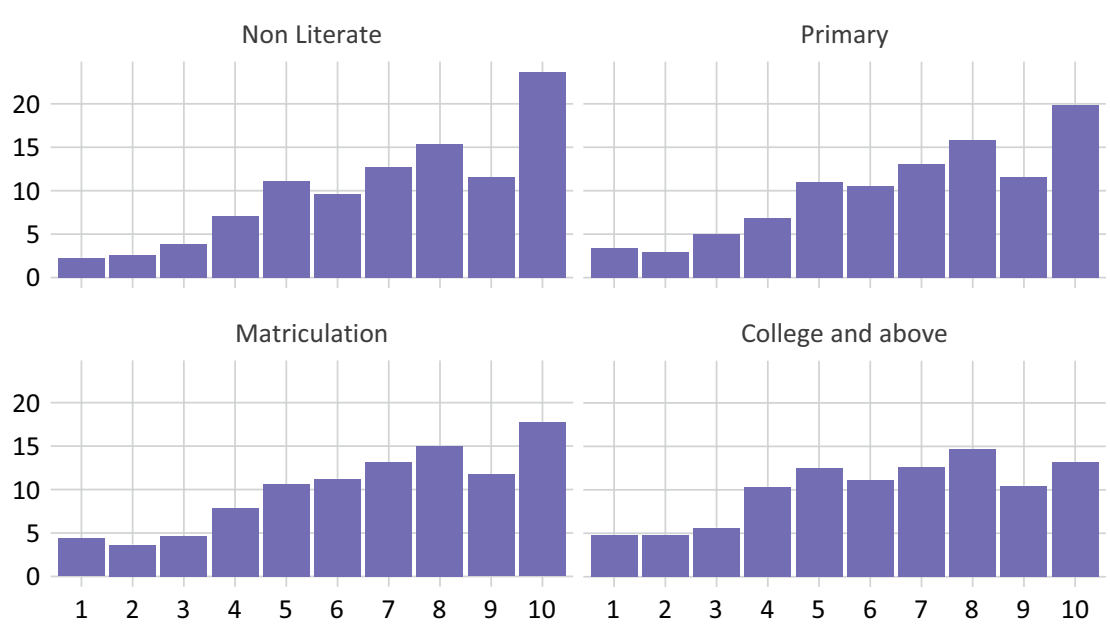

Figure 2.3.6 Perceptions About Dalits as Being "Hardworking or Lazy" (by Education)

the proportion of responses at the lower end of the scale is less than ten percent. The share of respondents who decline to give an opinion is 63 percent in Mizoram and 41 percent in Kerala. In Assam, Jammu and Kashmir, Nagaland, Punjab, Gujarat, and Tamil Nadu, more than 20 percent of the respondents refuse to answer.

Adivasis are considered generally hardworking across all caste groups (Figure 2.3.8). About 70 percent of upper caste, 73 percent OBCs and 74 percent Dalit respondents find Adivasis hardworking. About 90 recent Adivasi respondents think of themselves as hardworking. Upper castes are the least likely to find Adivasis extremely hardworking - 12 percent of upper-class respondents believe this while 22 percent of Dalits, 18 percent of OBCs, and 35 percent Adivasi see Adivasis as extremely hardworking. Additionally, 18 percent of upper caste and 27 percent OBC respondents see Adivasis as lazy. Note that about 26 percent of Adivasi respondents choose not to answer; this is roughly 13 percentage points higher than other caste communities.

Higher levels of education reduce a perception of Adivasis as extremely hardworking (Figure 2.3.9). The proportion of respondents who see Adivasis as extremely hardworking drops by five percentage points as levels of education increase; 75 percent of non-literate respondents perceive Adivasis as hardworking while that number is at 70 percent for the college educated. It is notable that almost five percent fewer college-educated respondents decline to answer compared to non-literate respondents.

We observe that in Assam, Bihar, Haryana, Maharashtra, Nagaland, Gujarat, Kerala, Rajasthan, Tripura, Delhi, Chhattisgarh, Telangana, and 
SOCIAL UNIVERSE
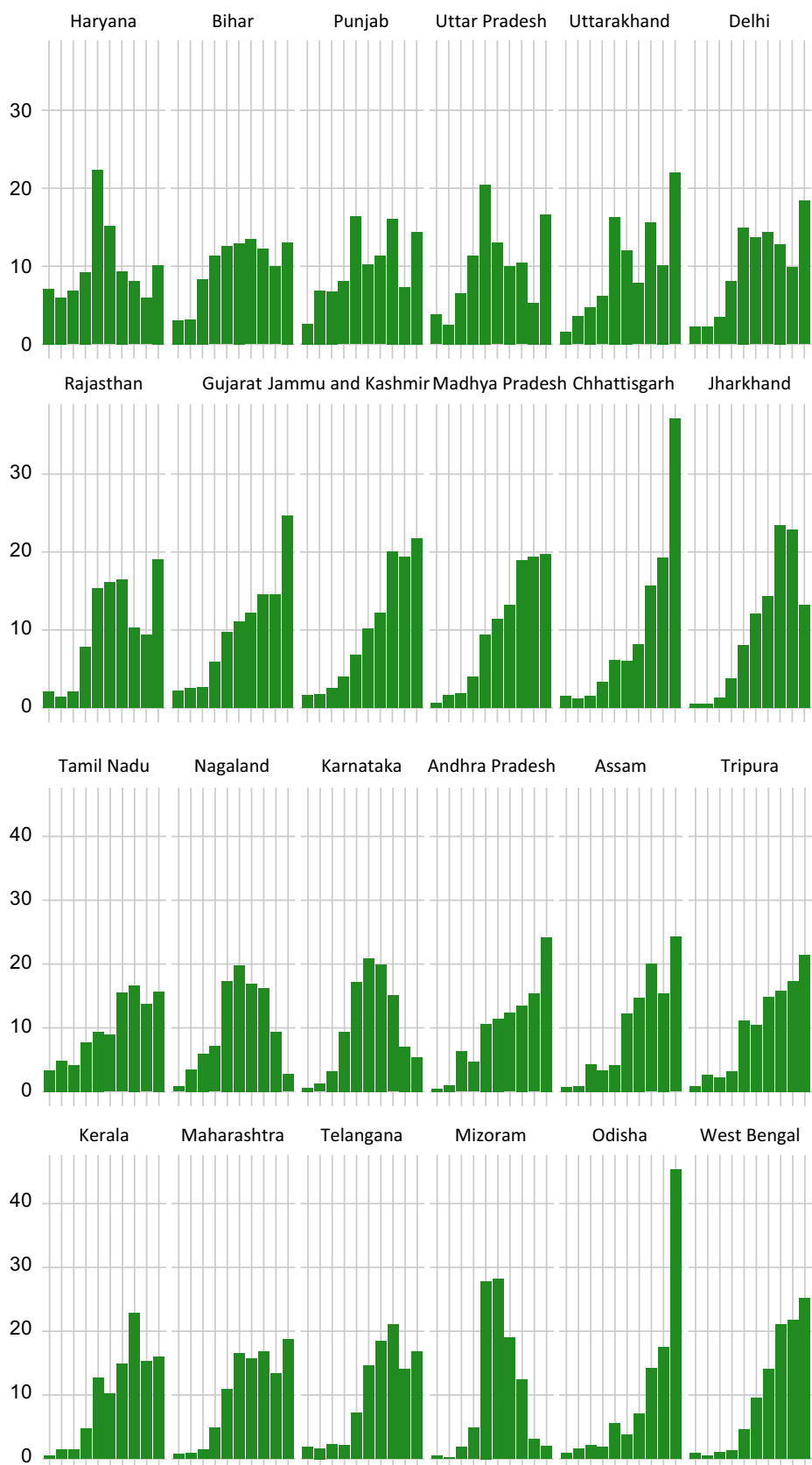

Figure 2.3.7 Perceptions About Adivasis as Being "Hardworking or Lazy" (by State) 


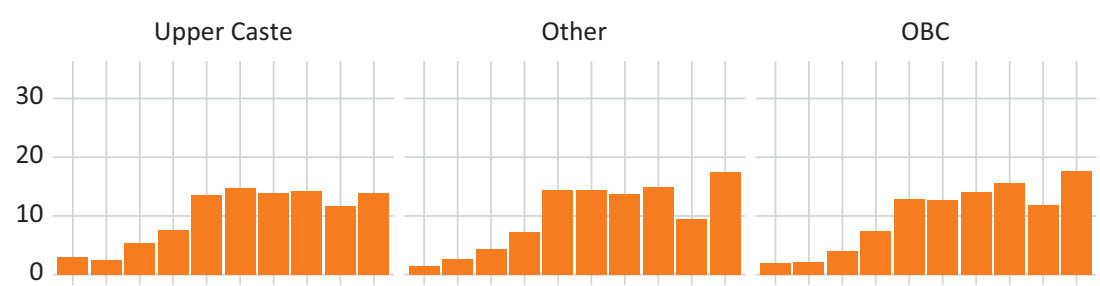

$\begin{array}{llllllllll}1 & 2 & 3 & 4 & 5 & 6 & 7 & 8 & 9 & 10\end{array}$

Dalit

Adivasi

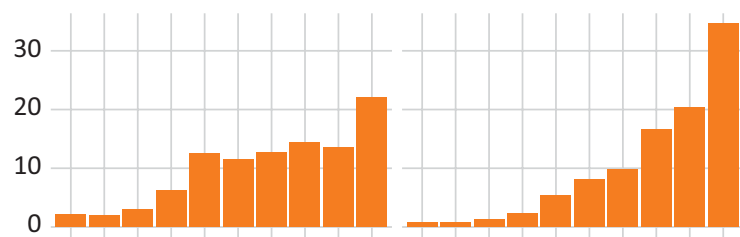

$\begin{array}{llllllllllllllllllll}1 & 2 & 3 & 4 & 5 & 6 & 7 & 8 & 9 & 10 & 1 & 2 & 3 & 4 & 5 & 6 & 7 & 8 & 9 & 10\end{array}$

Figure 2.3.8 Perceptions About Adivasis as Being "Hardworking or Lazy" (by Caste)

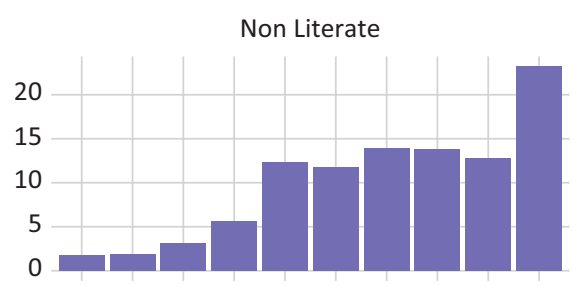

Matriculation

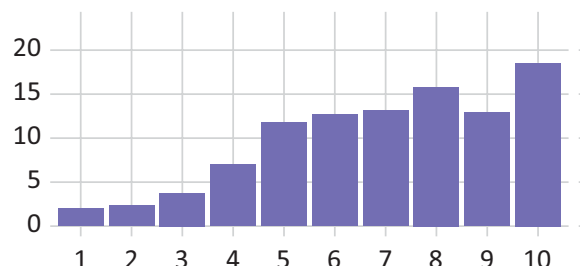

Primary

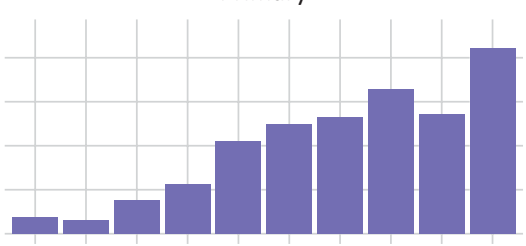

College and above

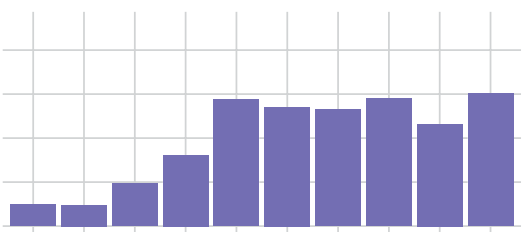

$\begin{array}{llllllllllllllllllll}1 & 2 & 3 & 4 & 5 & 6 & 7 & 8 & 9 & 10 & 1 & 2 & 3 & 4 & 5 & 6 & 7 & 8 & 9 & 10\end{array}$

Figure 2.3.9 Perceptions about Adivasis as being "Hardworking or Lazy" (by Education)

Uttarakhand 60 percent or more respondents view upper castes as hardworking (Figure 2.3.10). This result is particularly pronounced in Kerala, Tripura, Chhattisgarh, Uttarakhand, and Gujarat where 60 percent of the respondents hold this view. Nearly 24 percent in Uttarakhand and 23 percent in Chhattisgarh perceive upper castes to be extremely hardworking. In 

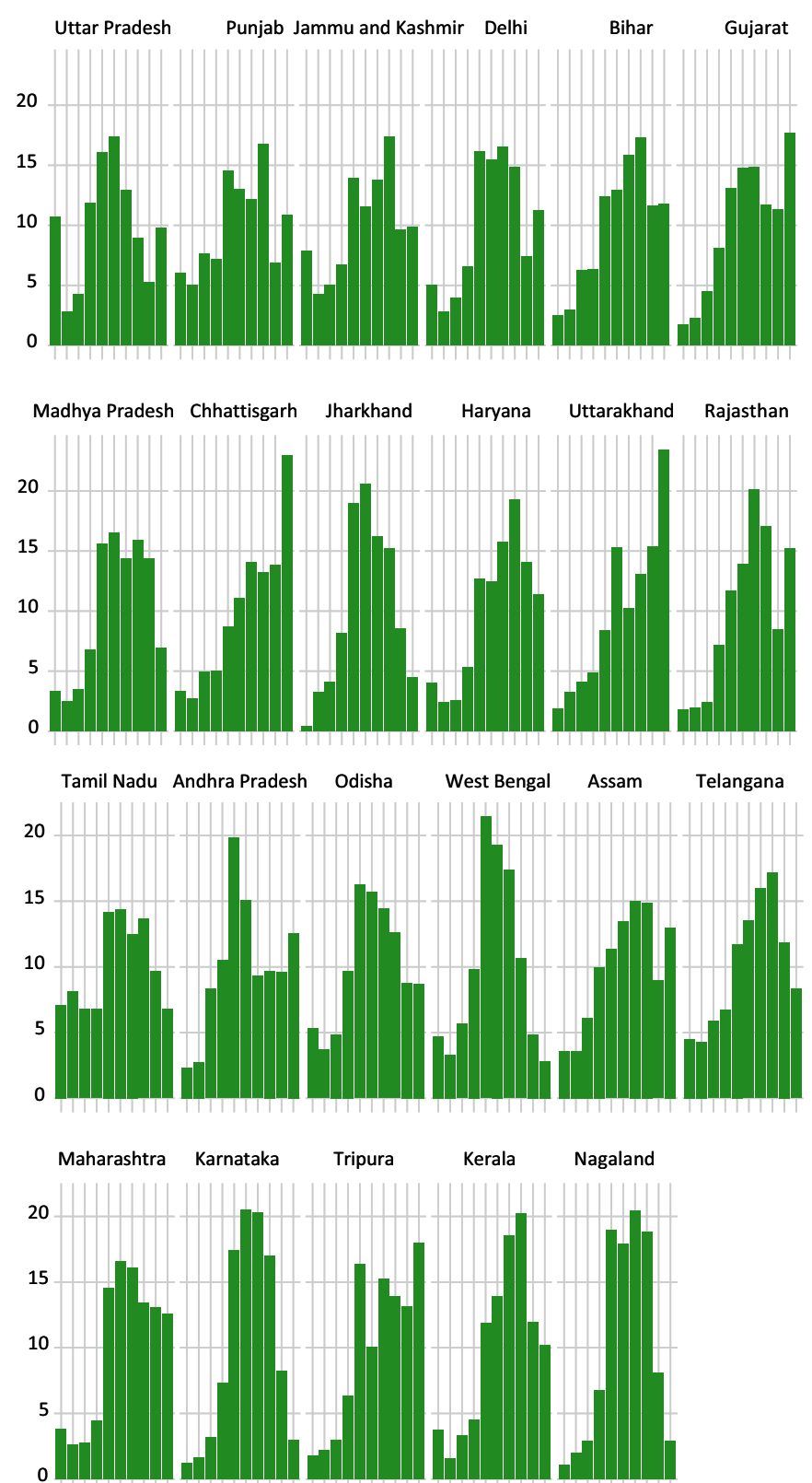

Figure 2.3.10 Perceptions About Upper Caste as Being "Hardworking or Lazy" (by State) 
Dalit

Other

$\mathrm{OBC}$

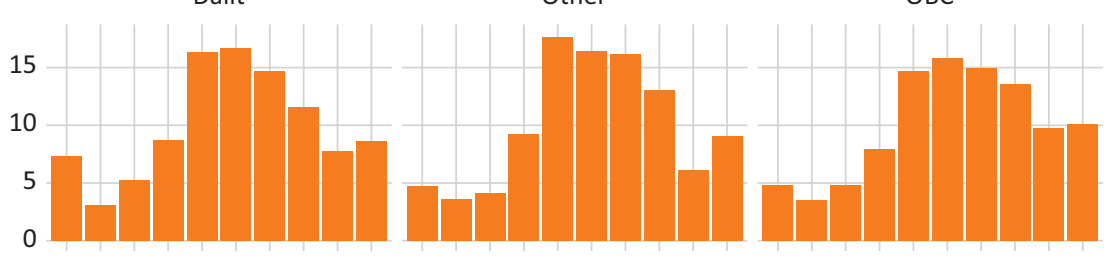

Adivasi

Upper Caste

$\begin{array}{llllllllll}1 & 2 & 3 & 4 & 5 & 6 & 7 & 8 & 9 & 10\end{array}$

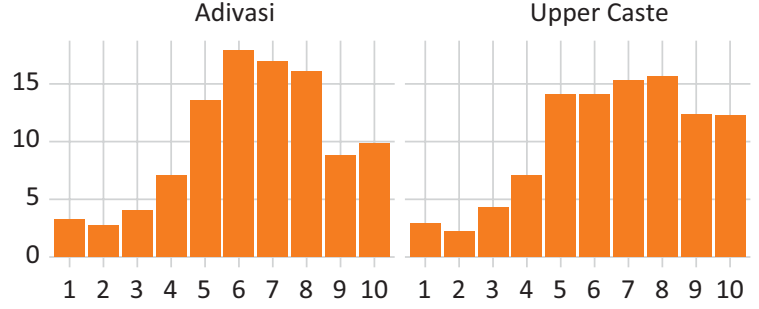

Figure 2.3.11 Perceptions About Upper Caste as Being "Hardworking or Lazy" (by Caste)

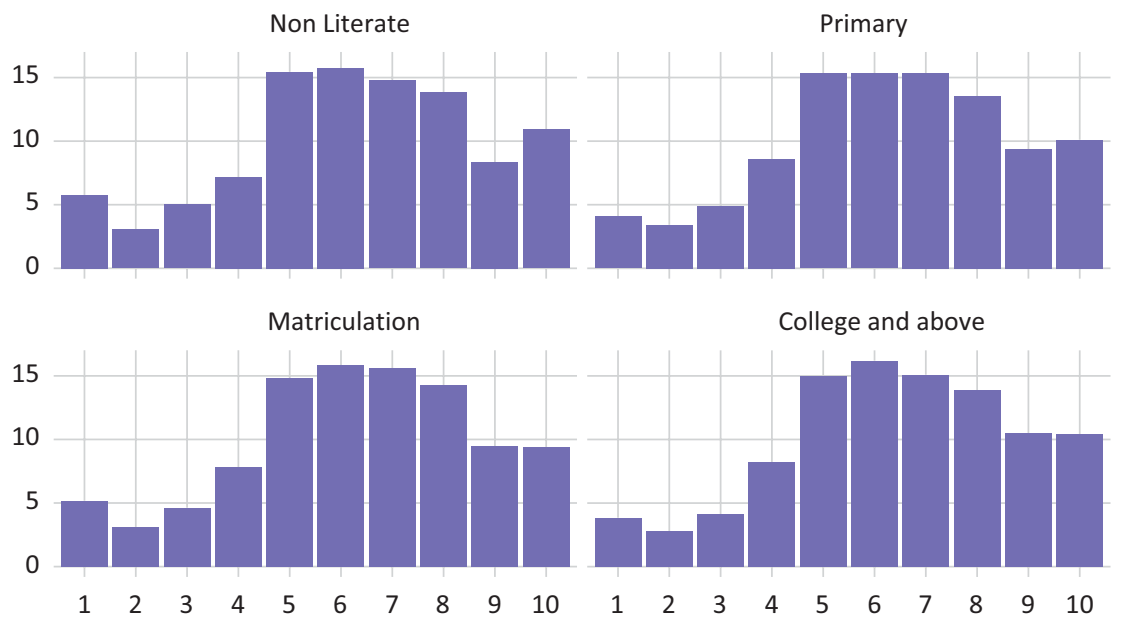

Figure 2.3.12 Perceptions About Upper Caste as Being "Hardworking or Lazy" (by Education)

Kerala we find an extremely large number (41 percent) of "No Opinion" responses, followed by Nagaland at 27 percent, and Assam, Gujarat, and Tamil Nadu at around 24 percent.

Almost 69 percent of upper caste respondents see themselves as hardworking and 12 percent perceive themselves to be extremely hardworking 
(Figure 2.3.11). Nine percent of Dalit respondents, ten percent of OBC, and ten percent of Adivasi view upper castes as extremely hardworking. The perceptions of other caste groups tend to cluster at the middle of the scale. Nearly seven percent of Dalits and five percent OBCs perceive the upper castes as extremely lazy. Between 22 and 23 percent of Dalit and OBC respondents view upper castes as being generally lazy. Adivasis record the largest share of non-responses at 29 percent. Less than ten percent of upper caste and Dalit respondents do not express an opinion.

Unlike the perceptions of Adivasis and Dalits, the perception of upper caste as hardworking increases marginally with higher levels of education (Figure 2.3.12). The difference is about two percentage points. The share of non-responses decreases across increases across levels of education, with 16 percent of non-literate respondents not providing a response and only about 11 percent of college level respondents failing to respond.

\subsubsection{Patriotic or Unpatriotic}

While a majority of respondents in Bihar (65 percent), Uttar Pradesh (58 percent), Odisha (54 percent), and Haryana (51 percent) think of Muslims as unpatriotic, the opposite is true in Assam, Andhra Pradesh, Jammu and Kashmir, Maharashtra, Telangana, and Kerala (Figure 2.3.13). Among respondents in Rajasthan, 44 percent perceive Muslims as generally unpatriotic, and a similar 43 percent believe this in Uttarakhand. In Bihar (31 percent), Odisha ( 22 percent), and Haryana ( 21 percent) there are significant proportions who perceive Muslims as extremely unpatriotic, followed by Uttar Pradesh (19 percent), Madhya Pradesh (14 percent), Chhattisgarh and Uttarakhand (13 percent). In contrast, more than 66 percent in Jammu and Kashmir and Kerala, 57 percent in Assam, and 56 percent in Andhra Pradesh view Muslims positively; over 20 percent in these states perceive Muslims to be extremely patriotic. In the remaining states, the responses cluster around the middle - approximately 35 percent in in West Bengal, Mizoram, and Nagaland, and 25 percent in Delhi, Karnataka, Punjab, Tamil Nadu, and Tripura. Note that half of the respondents in Mizoram and over a third of the respondents in Kerala did not record any opinion.

More than 70 percent of respondents in Kerala see Christians as patriotic (Figure 2.3.14). In Jammu and Kashmir, Mizoram, and Tripura more than 60 percent of the respondents see Christians as patriotic. In Assam and Tripura more than 20 percent of respondents view Christians as extremely patriotic, followed by Chhattisgarh and Andhra Pradesh at 17 percent. Except for Uttar Pradesh and Bihar, where around 38 percent of the population perceives Christians as unpatriotic, less than 30 percent of the respondents in most states perceive Christians as being unpatriotic. As noted in 


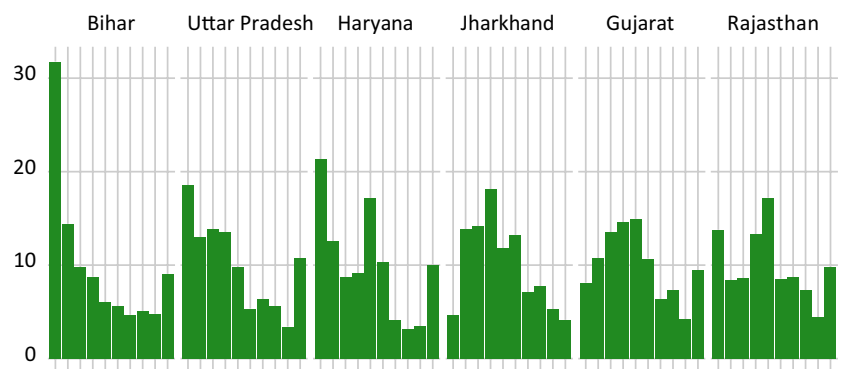

Madhya Pradesh Uttarakhand Chhattisgarh Delhi Punjab Jammu and Kashmir
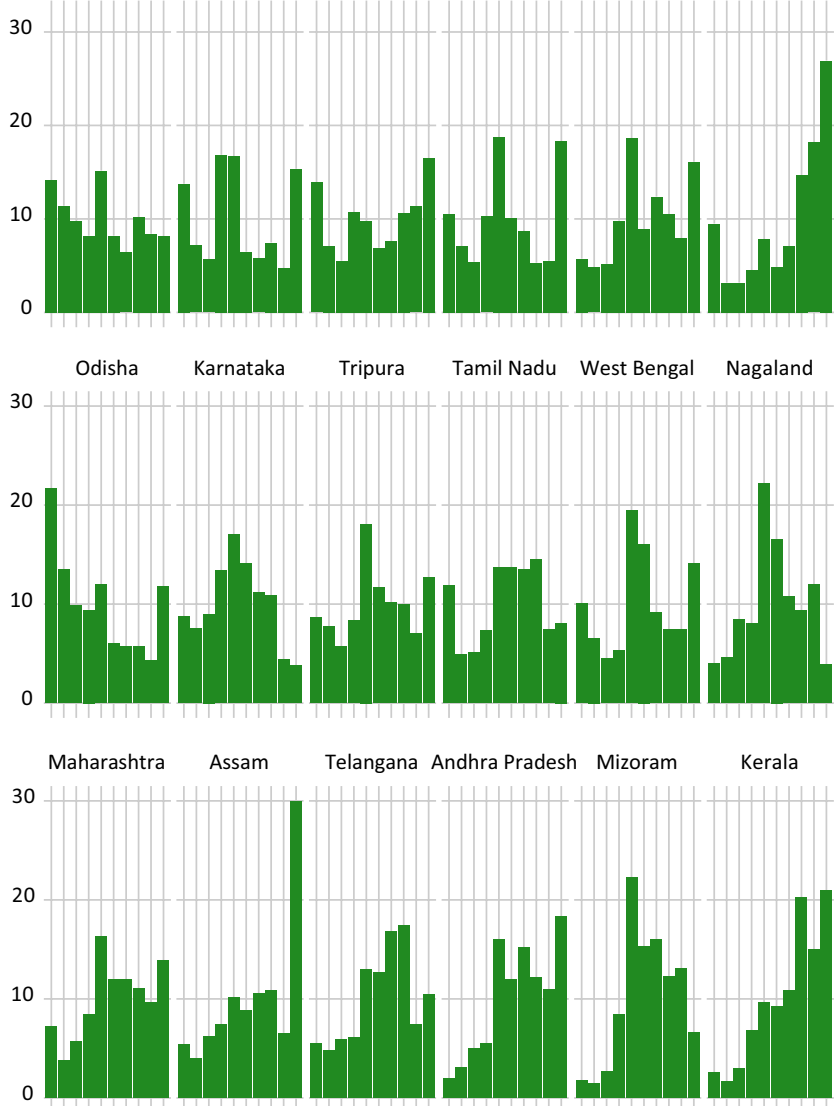

Figure 2.3.13 Perceptions About Muslims as Being "Patriotic or Unpatriotic" (by State) 

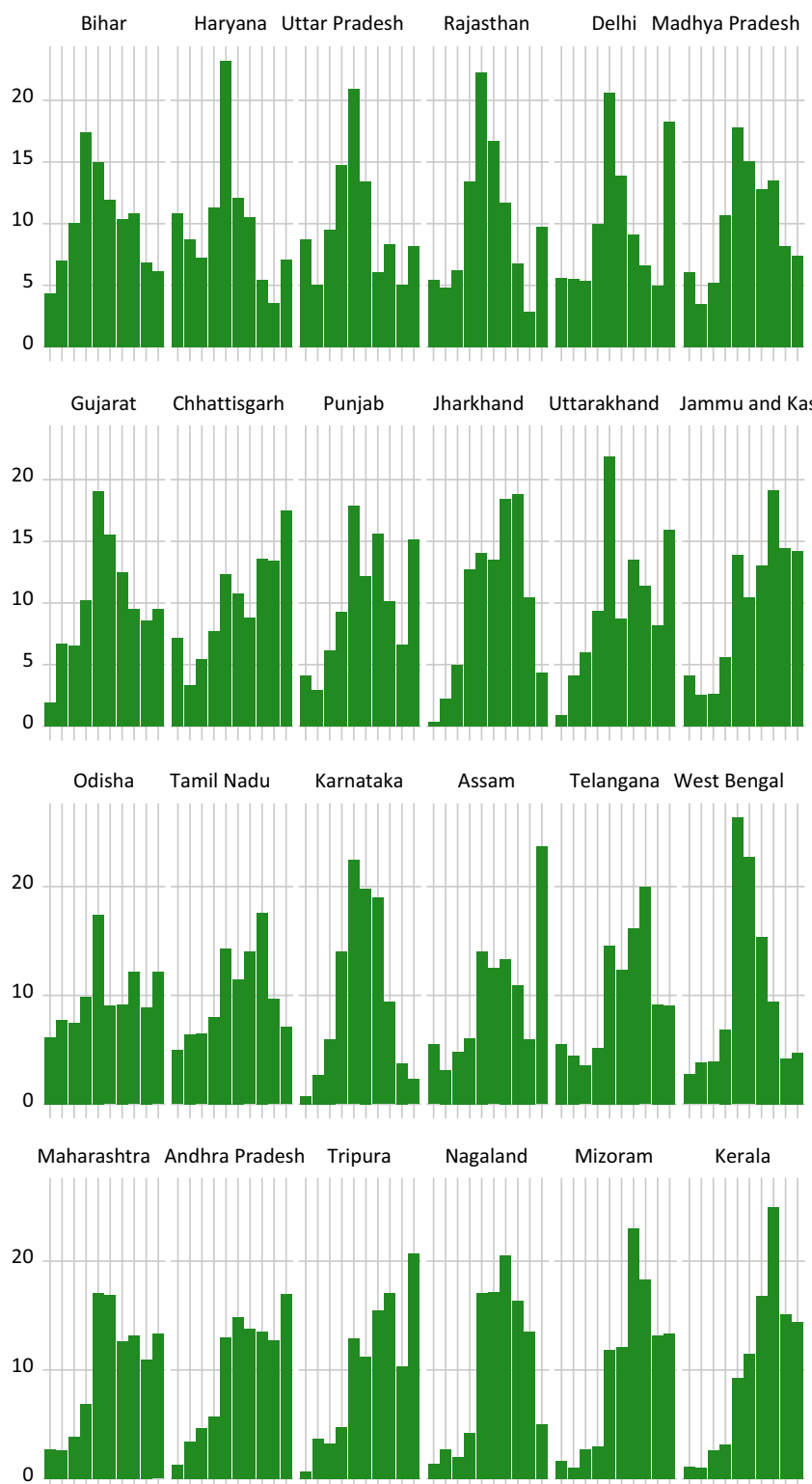

Figure 2.3.14 Perceptions About Christians as Being "Patriotic or Unpatriotic" (by State) 
earlier results, Kerala (38 percent) again records the largest share of nonresponses followed by West Bengal (31 percent).

The share of respondents who see Hindus as patriotic is around 70 percent or more in all states, except for Mizoram (52 percent) and Nagaland (58 percent) (Figure 2.3.15). In Uttarakhand, Chhattisgarh, Delhi, Odisha and Bihar, 40 percent or more respondents view Hindus as extremely patriotic, followed by Assam, Haryana, Maharashtra, Rajasthan, Tripura, and Uttar Pradesh, where more than one in three respondents share this view. Mizoram records the highest share of non-responses at 48 percent followed by the lack of respondents from Kerala at 37 percent.

More than a third of respondents perceive Sikhs as extremely patriotic in Punjab, Haryana, Delhi, Uttarakhand (states with a large Punjabi speaking community), as well as in Assam, Chhattisgarh, and Uttar Pradesh (Figure 2.3.16). Predictably, states with significantly large the Punjabi speaking populations in particular hold a very positive view about Sikhs. Interestingly, they also hold a similar view of Sikhs. However, the share of respondents who perceive Sikhs as extremely patriotic is much lower in the states with negligible Sikh populations, such as Tamil Nadu, Karnataka, Kerala, Jharkhand, and West Bengal. In West Bengal and Karnataka, particularly, most responses gather around the middle of the scale. Kerala records the largest share of non-responses (40 percent) followed by West Bengal at 36 percent, Tamil Nadu at 29 percent, and Andhra Pradesh at 24 percent. This figure does not include respondents from Mizoram, Nagaland, and Tripura.

\subsubsection{Peaceful or Violent}

In Chhattisgarh (16 percent), Uttarakhand (12 percent), Uttar Pradesh (12 percent), Delhi (13 percent), West Bengal (10 percent), Tripura (10 percent), Odisha (18 percent), Gujarat (13 percent), Madhya Pradesh (12 percent), Bihar (25 percent) and Haryana (21 percent), more than ten percent of respondents think of Muslims as extremely violent (Figure 2.3.17). In Karnataka, Maharashtra, Punjab, Rajasthan, West Bengal, Telangana, Delhi, Tamil Nadu, Tripura, Mizoram, and Nagaland the responses tend to cluster around the middle. In Assam, Jammu and Kashmir, Andhra Pradesh, and Kerala, most respondents perceive Muslims to be peaceful. In Mizoram 42 percent of respondents refuse to answer, with a similar number of 38 percent from Kerala also refusing to answer.

Christians are generally perceived as being peaceful (Figure 2.3.18). This perception is most prevalent in the responses from Mizoram, Nagaland, and Tripura where 87 percent, 71 percent, and 66 percent of the respondents perceive Christians to be largely peaceful. Twenty six percent of respondents from Mizoram, 22 percent from Chhattisgarh, 19 percent from Tripura, 17 percent from Uttarakhand, and 16 percent from Assam, 

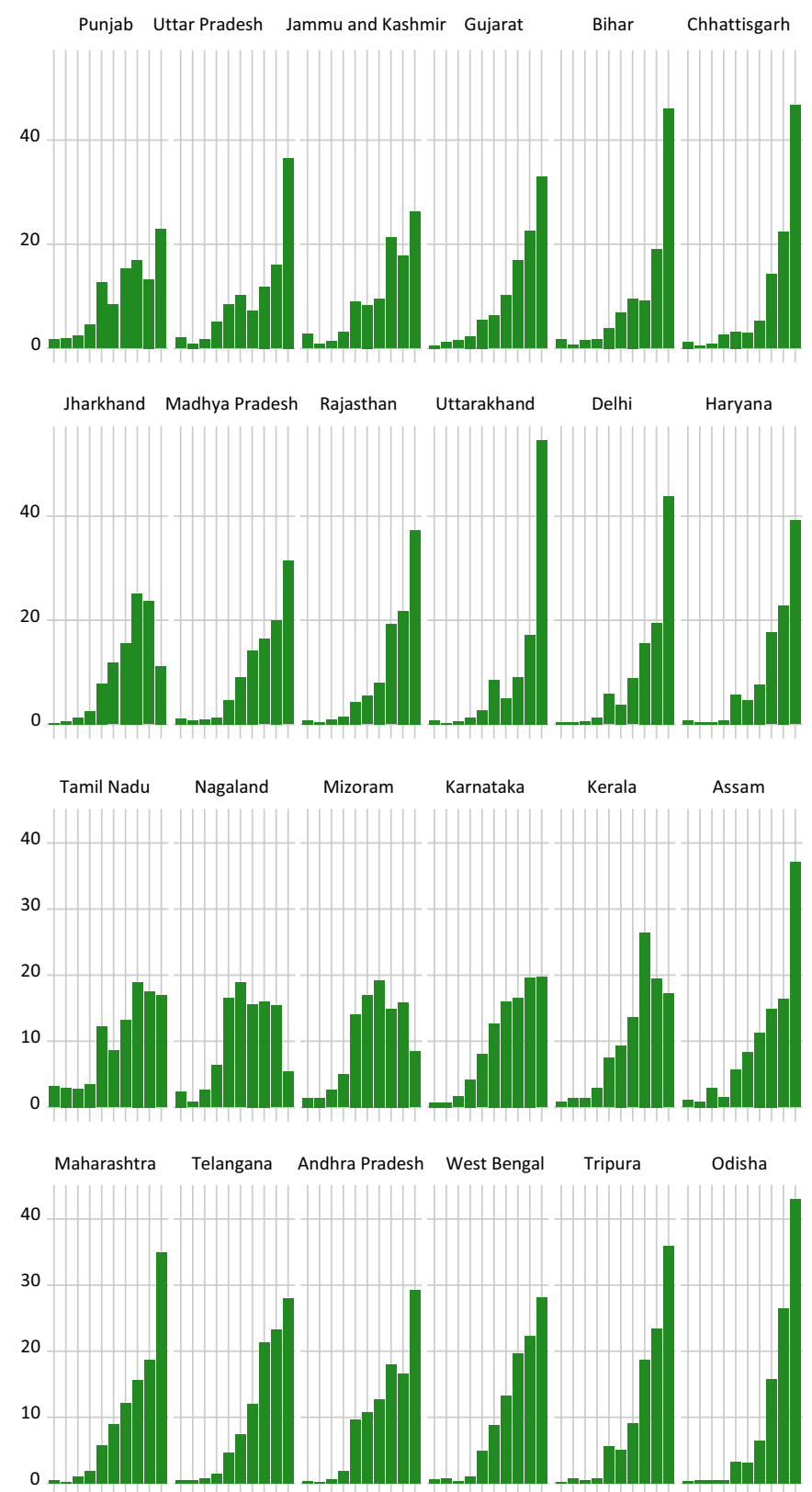

Figure 2.3.15 Perceptions About Hindus as Being "Patriotic or Unpatriotic" (by State) 


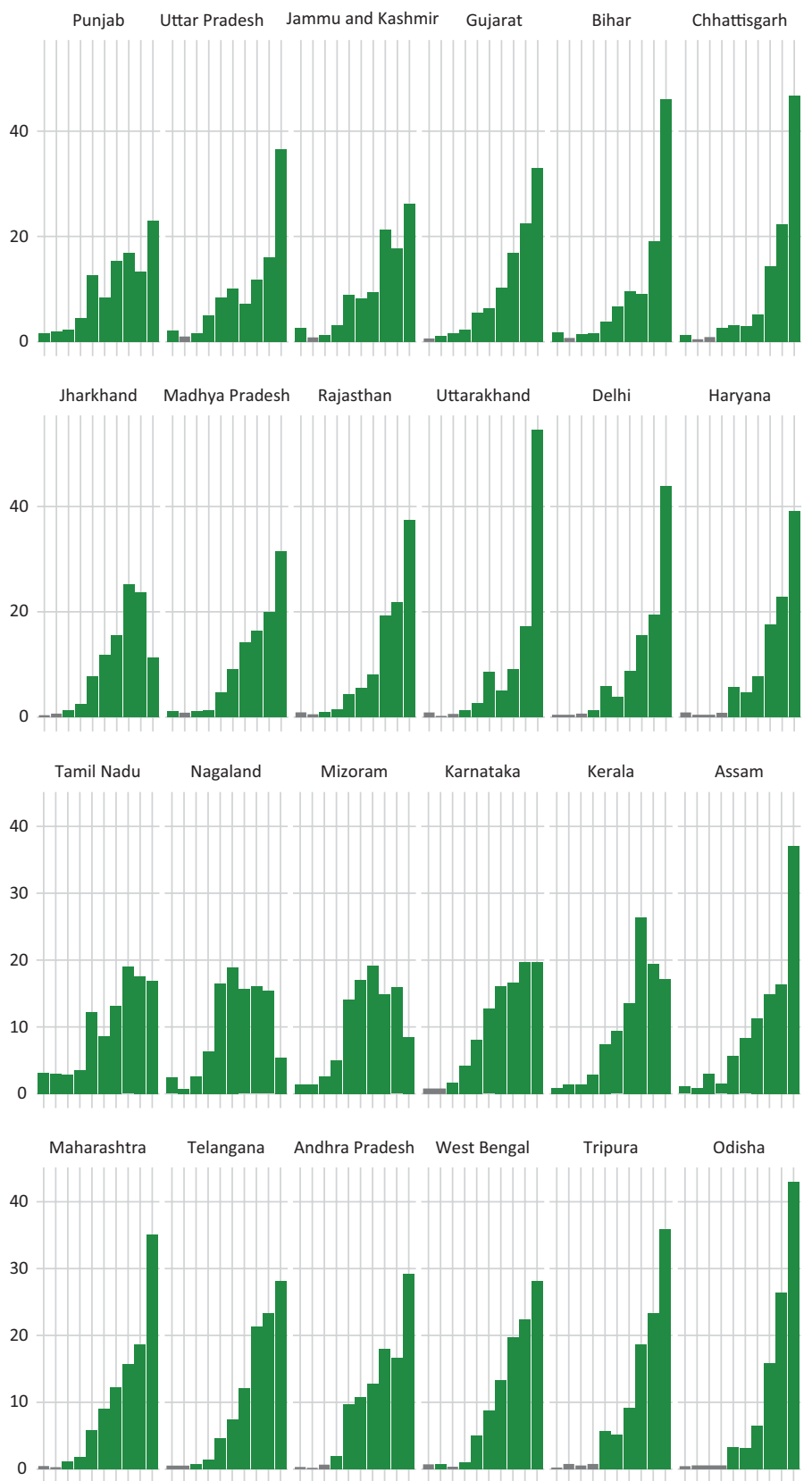

Figure 2.3.16 Perceptions About Sikhs as Being "Patriotic or Unpatriotic" (by State) 

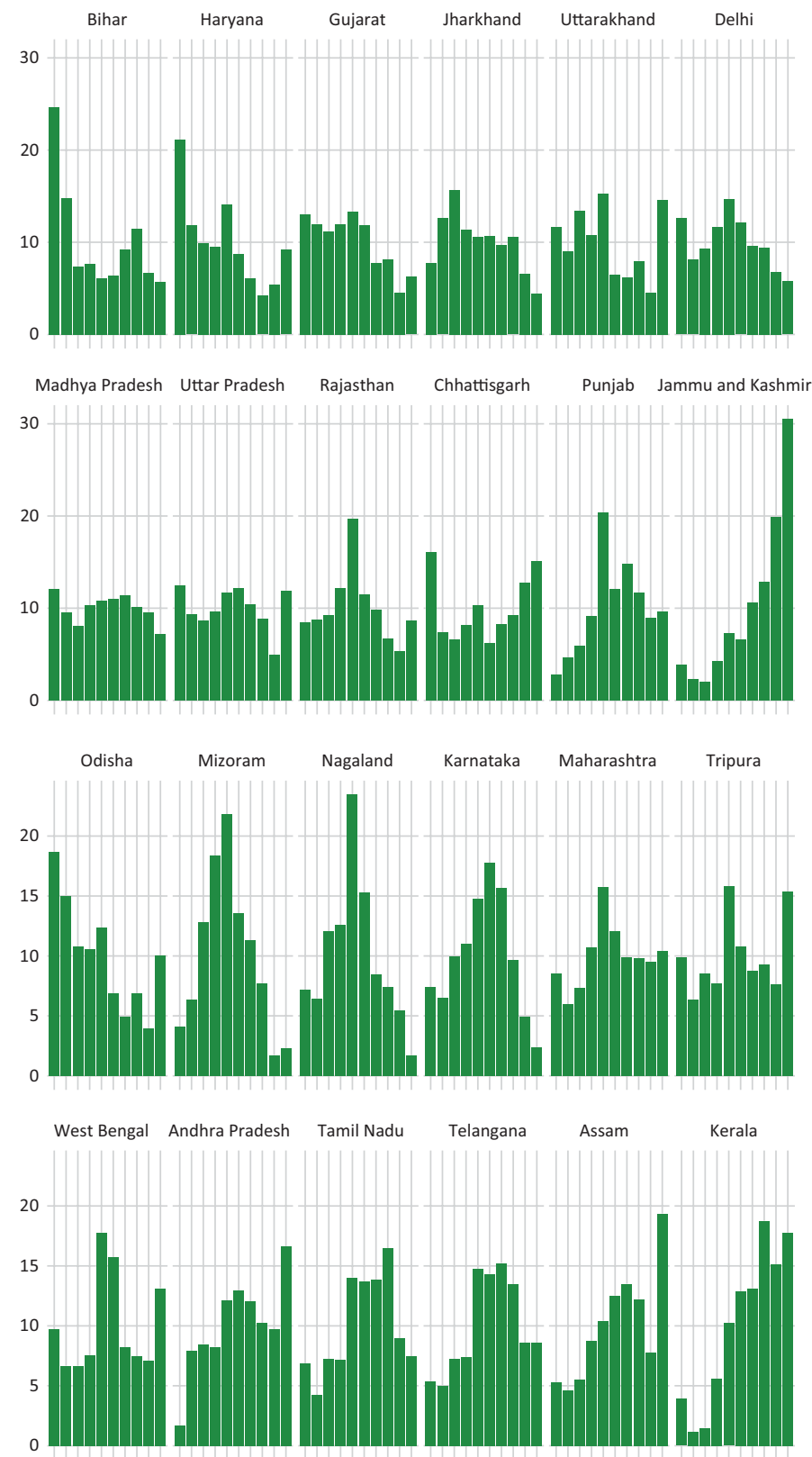

Figure 2.3.17 Perceptions About Muslims as Being "Peaceful or Violent" (by State) 

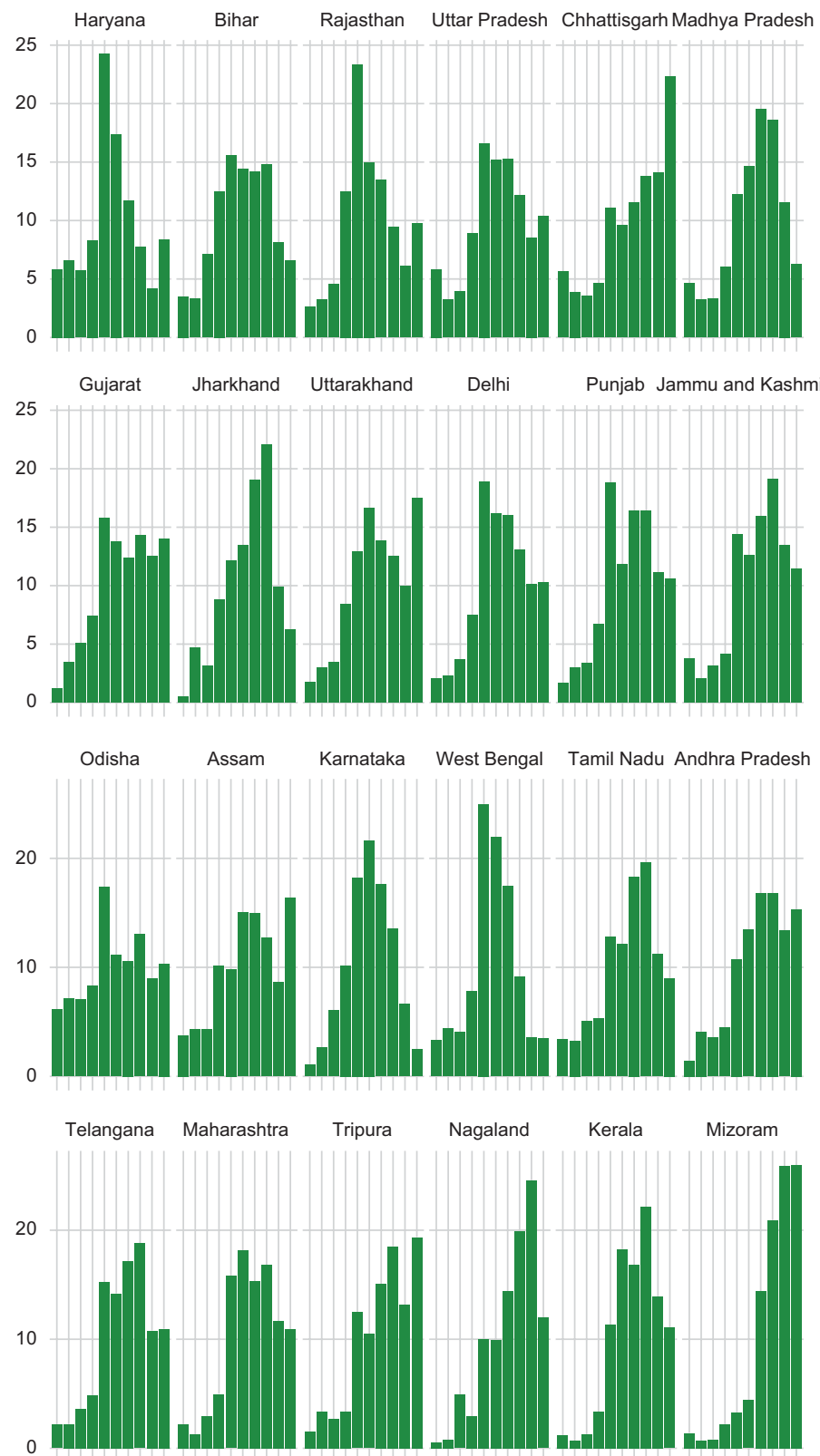

Figure 2.3.18 Perceptions About Christians as Being "Peaceful or Violent" (by State) 


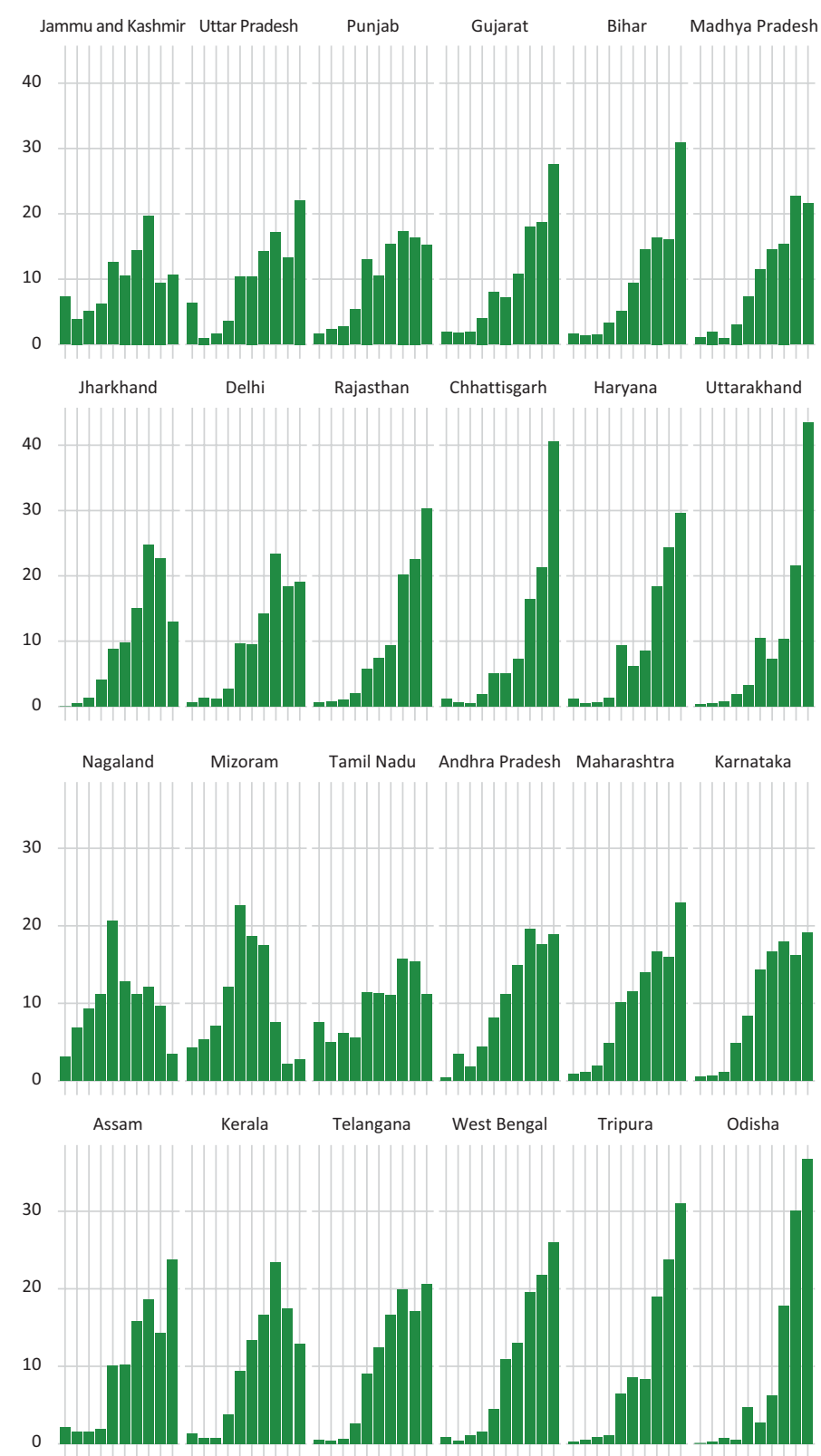

Figure 2.3.19 Perceptions About Hindus as Being "Peaceful or Violent" (by State) 

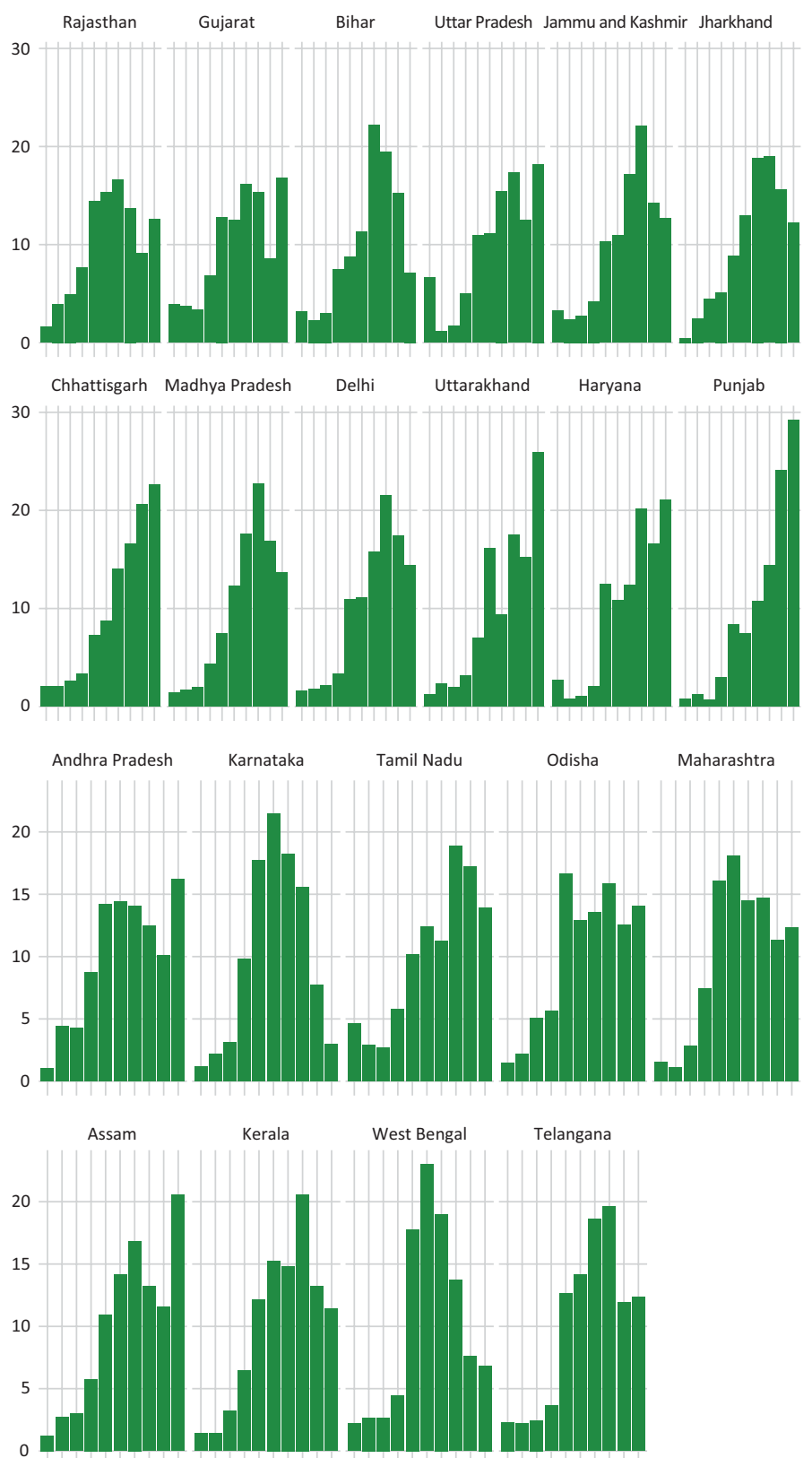

Figure 2.3.20 Perceptions About Sikhs as Being "Peaceful or Violent" (by State) 
consider Christians to be extremely peaceful. The other states - particularly Andhra Pradesh, Gujarat, Jammu and Kashmir, Kerala, Punjab, and Tamil Nadu - share a similar sentiment about Christians, where most of the responses tend to cluster on the higher end of the scale.

Over 85 percent of the respondents in Bihar, Gujarat, Haryana, Odisha, Rajasthan, Tripura, West Bengal, Delhi, Jharkhand, Chhattisgarh, and Uttarakhand consider Hindus to be peaceful (Figure 2.3.19). This perception marginally reduces to above 80 percent in Andhra Pradesh, Assam, Kerala, Madhya Pradesh, and Telangana. About 43 percent of respondents in Uttarakhand and 40 percent in Chhattisgarh, 37 percent in Odisha, 31 percent in Tripura, 30 percent in Rajasthan, and 26 percent in West Bengal believe that Hindus are extremely peaceful. In Nagaland, Mizoram, Jammu and Kashmir, and Tamil Nadu, perceptions accumulate around the middle. Over 22 percent of the respondents in Jammu and Kashmir and Tamil Nadu and almost 30 percent of the respondents in Mizoram and Nagaland perceive Hindus to be violent. Forty one percent of respondents from Mizoram and 40 percent from Kerala did not respond.

States with higher Sikh populations show a greater share of respondents who think of Sikhs as generally peaceful when compared to states with smaller Sikh populations (Figure 2.3.20). While more than 75 percent of the respondents in Jammu and Kashmir and Uttarakhand see Sikhs as generally peaceful, the proportion increases to about 80 percent in Delhi and Haryana and 88 percent in Punjab. In Chhattisgarh, 74 percent of respondents hold this opinion about Sikhs. In Assam, Bihar, Madhya Pradesh, Tamil Nadu, and Kerala, where Sikhs account only a fraction of the population, Sikhs are still seen as peaceful by a smaller share (relative to the northern states). Karnataka and West Bengal record the lowest share of respondents who perceive Sikhs to be extremely peaceful and a bulk of the responses concentrate around the middle of the scale. Over 40 percent of survey respondents from Kerala and West Bengal and nearly 31 percent from Tamil Nadu do not respond. 


\subsection{GENDER ROLES AND RIGHTS}

This section explores the attitudes held towards women's roles at home and work, their responsibilities, and their rights in marriage. Specifically, we examine attitudes regarding the role of women in the family, toward women's education and workplace equality, and on agency in choice of partner or marriage. We classify questions on gender roles, responsibilities, and relations into three main ideas - family: gender relations at home; marriage: agency in decision making processes in marriage, and work and education: support for equal treatment in work and education. There is a preference for women's confinement, even seclusion, to the domestic sphere in much of India and South Asia (Sharma, 1990). When an economic rationality that drives a woman to work is present, it is largely to work on the family farm or in a family enterprise. This outcome is a result of the micro-level ideology of gender discrimination within the family and macro-level inequality in the wage and opportunity structure (Desai \& Jain, 1994). Attitudes that emphasize the domestic role of women engender a loss of power for a woman by reducing opportunities to earn income independent of her husband or other kin (Acharya \& Bennet, 1983; Omvedt, 1980). Persistent ideas (with cultural and regional roots) on specific roles and structures of gender relations have also limited women's choices and agency in decision-making around choice of marriage or partner. Despite universal primary education, and campaigns toward inclusive education for the girl child, such as "beti bachao beti padhao", parental decisions regarding "investing" in schooling for girls and boys are determined by perceived differences in "returns". Social considerations such as perceptions of gender roles (implicit in gendered division of labour) and preferences for sons (biased intra-household allocation of resources) tend to undervalue female education and widen the difference in perceived returns from education for boys and girls have also led to educational discrimination against the female child. We examine responses through the lens of gender, rural-urban location, and across states.

We ask a series of questions of the form:

"I am now going to read out some statements about men and women and their place in the family. Please tell me how much you agree or disagree with the following statements", followed by the seven statements (Figure 2.4.1). The response options are: "Strongly Agree", "Somewhat Agree", "Somewhat Disagree", "Strongly Disagree", and "No Opinion".

Of respondents, 74 percent agree (either strongly or somewhat) that women should prioritize the home over work (Figure 2.4.2), and 86 percent agree that men and women should be equally responsible for child rearing. Additionally, 66 percent agree that women have the right to decide 


\begin{abstract}
Family A woman should prioritise managing home over outside work. Women and men should have equal responsibility for child rearing.

Marriage It is up to women to decide whom to get married to. Women should have the right to decide to get married or not.

Education Educating boys is more important than educating girls and Work Men should be paid more than women even if it,s the same job. Women should have $50 \%$ reservations in all jobs.
\end{abstract}

Figure 2.4.1 Statements on Role of Women

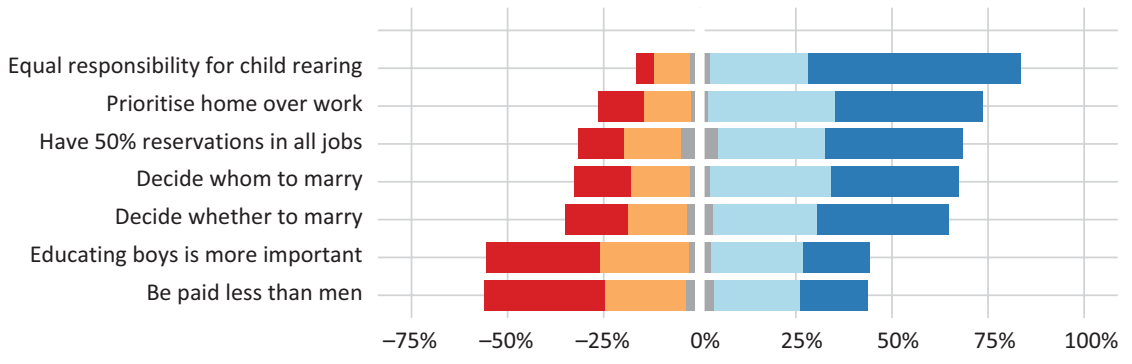

Strongly disagree - Somewhat disagree No opinion Somewhat agree Strongly agree

Figure 2.4.2 Support for Statements on Role of Women

whether to marry and 68 percent agree that that women should have a right to decide who to marry. Two out of every five respondents ( 44 percent) feel that educating boys is more important than educating girls, 43 percent agree that men should be paid more even if it is the same job, and 71 percent agree that half of all jobs must be reserved for women.

\title{
2.4.1 Family
}

Across gender, we find that 39 percent of men and 38 percent of women respondents strongly agree that women should prioritize home over paid work (Figure 2.4.3). About 11 percent of men strongly disagree and 13 percent women do the same. There are no major differences between men and women. Overall, we also find that a greater proportion of respondents either strongly or somewhat agree.

The strongest agreement with the proposition that women should prioritize work over home is seen in Odisha, at 56 percent, followed closely by Mizoram at 53 percent, and Haryana at 50 percent (Figure 2.4.4). Bihar followed by Karnataka and Tamil Nadu show strong support from 47 percent, 


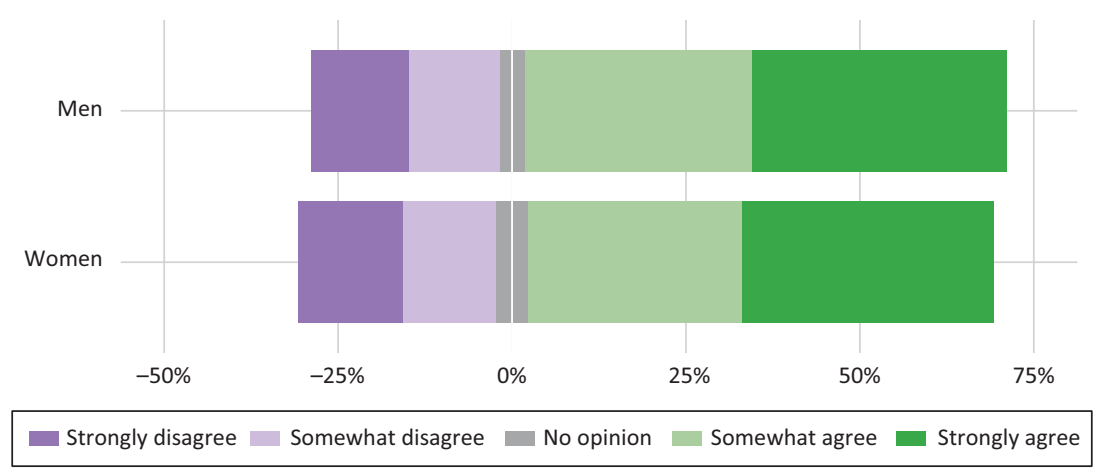

Figure 2.4.3 Women Should Prioritize Home over Work (by Gender)

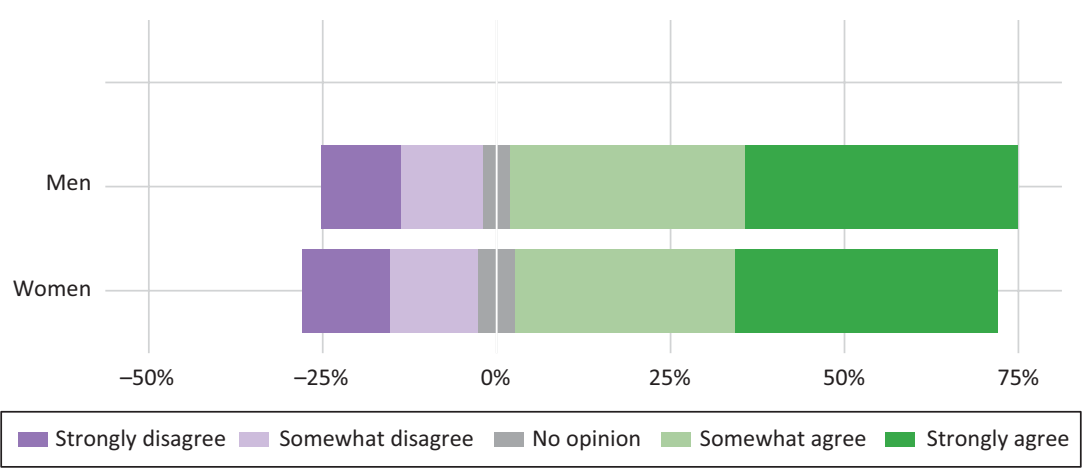

Figure 2.4.4 Women Should Prioritize Home over Work (by State)

46 percent, and 45 percent respectively. The other states where at least two in every five respondents showed strong support with the statement are Gujarat, Jammu and Kashmir, Punjab, Rajasthan, and Uttar Pradesh. It is only in Delhi that we see strong disagreement on this question, at 39 percent - almost 13 percent more respondents strongly disagree with the statement than strongly agree with it. The states where the gap between those who fully agreed and fully disagreed with this statement was the lowest in Kerala (at just one percentage point), followed by Andhra Pradesh (two percentage points), and Nagaland (three percentage points). The highest gap is noted in Mizoram (50 percentage points), followed by Odisha (48 percentage points), Bihar (44 percentage points), and Karnataka (42 percentage points).

Fifty four percent of men and 57 percent women strongly agree that men and women should have equal responsibility for child rearing (Figure 2.4.5). Fifty nine percent men and 61 percent women either strongly or somewhat 


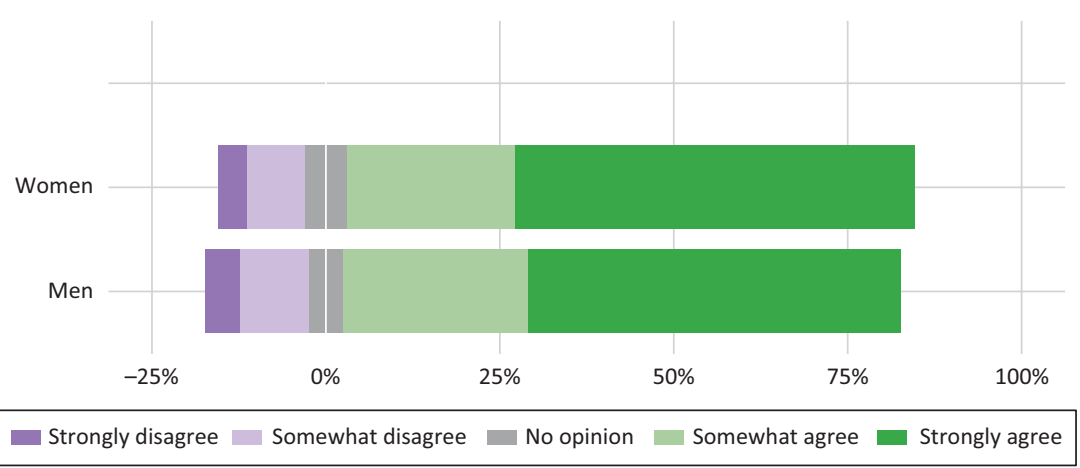

Figure 2.4.5 Women and Men Should Have Equal Responsibility for Child Rearing (by Gender)

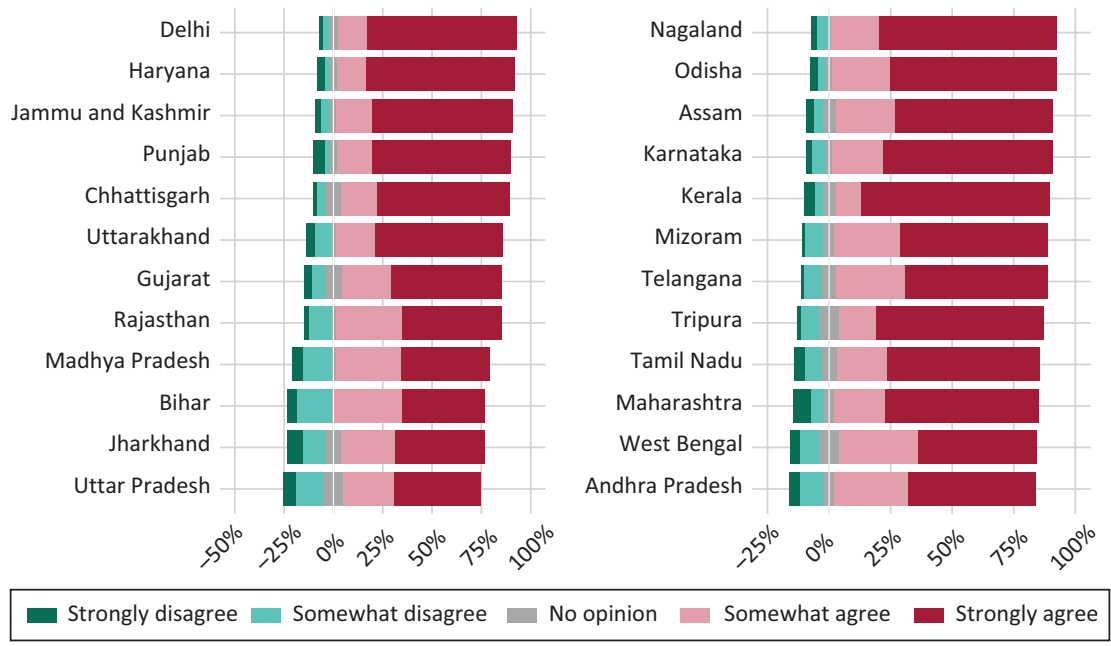

Figure 2.4.6 Women and Men Should Have Equal Responsibility for Child Rearing (by State)

disagree. Similarly, five percent men strongly disagree and about four percent women do so. About 80 percent of all respondents agree, either strongly or somewhat.

The highest proportion in the "strongly agree" category can be seen in Kerala and Delhi (76 percent in both), followed by Haryana (75 percent), Nagaland (72 percent), Jammu and Kashmir (71 percent), and Punjab (70 percent) (Figure 2.4.6). While the share in Karnataka, Odisha, 
Tripura, Chhattisgarh, and Tripura is more than 65 percent, it drops to about 60 percent in Assam, Maharashtra, Mizoram, Tamil Nadu, and Uttarakhand. In Telangana, Rajasthan and Gujarat the share falls lower to about 50 percent and is lowest (in the 40 percent range) in Bihar, Madhya Pradesh, Uttar Pradesh, Jharkhand, and West Bengal. In addition, the gap between those who agree and disagree (strongly and somewhat agree, minus strongly and somewhat disagree) is highest in Delhi (86 percent) followed by Nagaland ( 85 percent), Odisha ( 85 percent), and Haryana ( 83 percent). In contrast, the gap is smallest in Uttar Pradesh (49 percent), followed by Jharkhand (52 percent), and Bihar (53 percent).

\subsubsection{Marriage}

The pattern that we see in the data is a broad support for choice in the decision to get married (Figure 2.4.7). The proportion of respondents either strongly or somewhat agreeing ranges between 50 percent and 78 percent. In Kerala, three out of every five respondents strongly agreed with the statement that women should have the right to decide to get married or not. Other states with majority strong support include Nagaland, Mizoram, and Tamil Nadu. On the other hand, the proportions who strongly disagreed with this idea were highest in Punjab (34 percent), Madhya Pradesh and Haryana (both 27 percent each), and Bihar (25 percent).

Both men and women largely support the idea of a women's right to decide (Figure 2.4.8). However, a much higher proportion of women (37 percent) strongly supported woman's right to decide whether to get married or not compared to men (32 percent). Similarly, 29 percent of women either

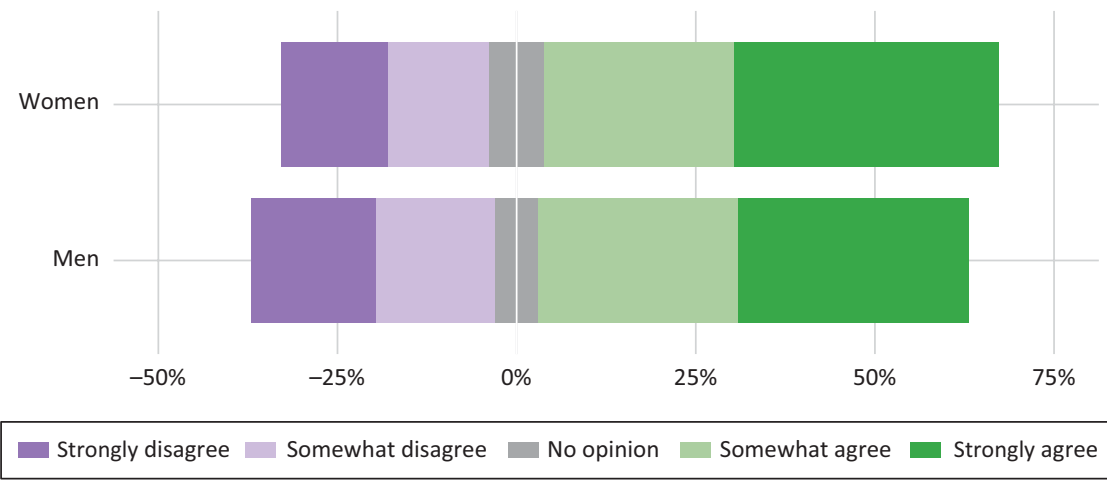

Figure 2.4.7 Women Should Have the Right to Decide to Get Married or Not (by State) 


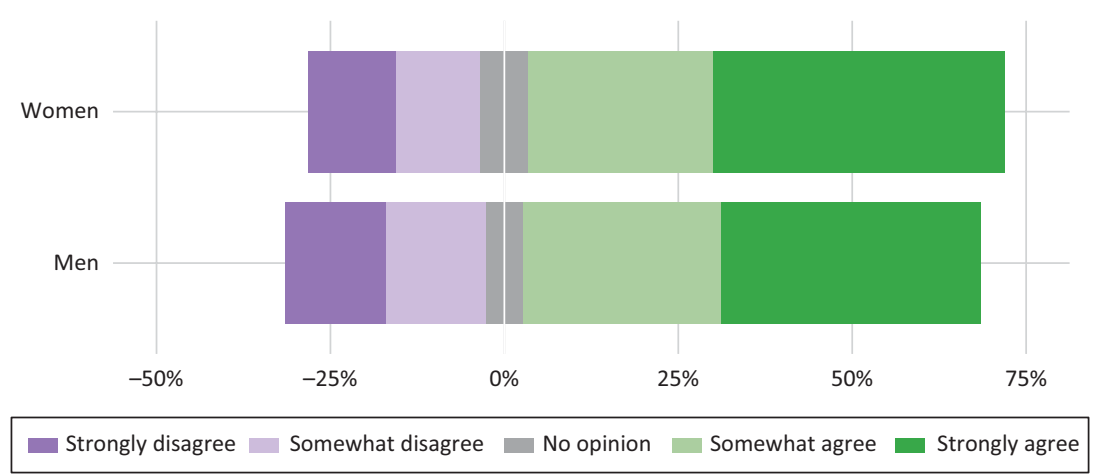

Figure 2.4.8 Women Should Have the Right to Decide to Get Married or Not (by Gender)

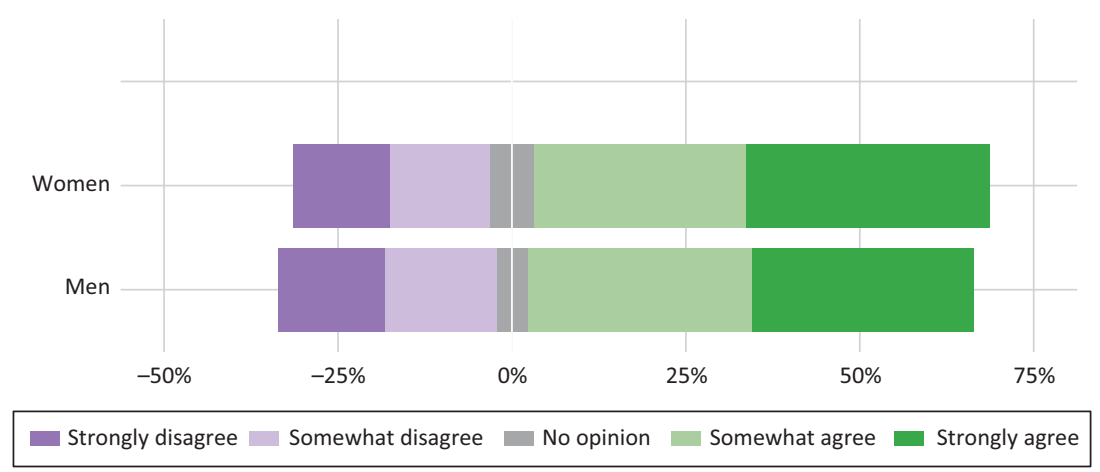

Figure 2.4.9 It is up to Women to Decide Whom to Get Married to (by Gender)

strongly or somewhat disagree, and 34 percent men do the same. The difference between men and women is small.

Women show a marginally higher level of support for a woman's right to choose her partner (Figure 2.4.9). The difference in strong agreement between women and men is about three percentage points. Similarly, 31 percent men either strongly or somewhat disagree and 28 percent women do.

Once again, we find that across states support for a woman's right to choice of partner ranges between 48 percent and 88 percent (Figure 2.4.10). Strongest support comes from Mizoram (60 percent), Uttarakhand (53 percent), Nagaland (52 percent), and Kerala (51 percent). Highest levels of disagreement are found in Punjab (49 percent), Maharashtra (41 percent), Madhya Pradesh (40 percent), Haryana (34 percent), Bihar (33 percent), and Jharkhand (32 percent). 

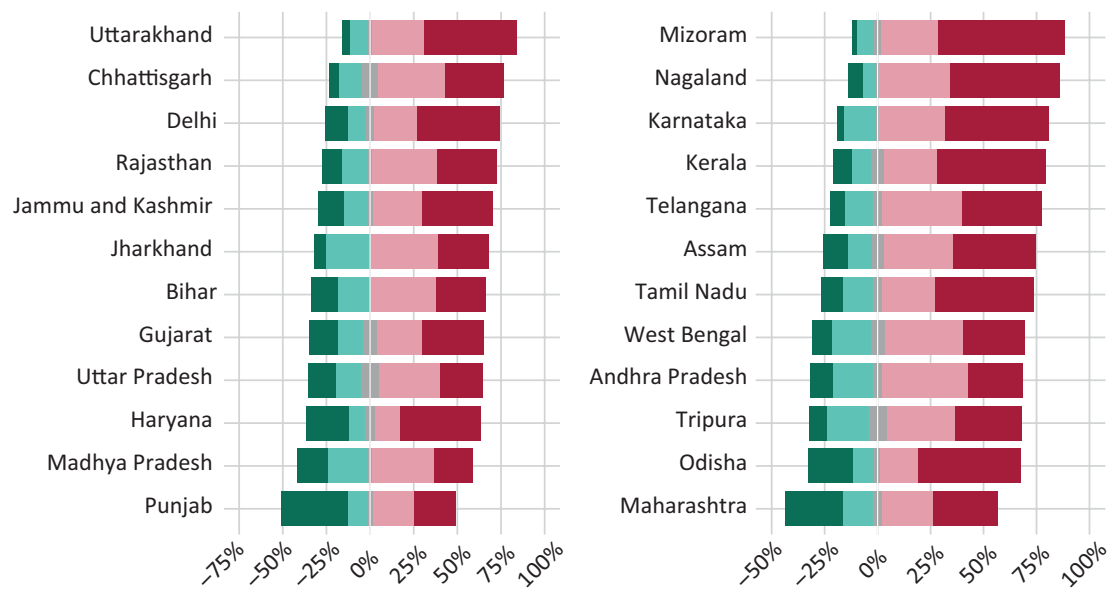

Strongly disagree $\square$ Somewhat disagree $\square$ No opinion $\quad$ Somewhat agree

Strongly agree

Figure 2.4.10 It is up to Women to Decide Whom to Get Married to (by State)

\subsubsection{Education and Work}

We find that more or less equal proportions of men and women are distributed across the response categories (Figure 2.4.11). Twenty nine percent of men and 30 percent of women strongly disagree that educating boys is more important than educating girls. Twenty four percent of men and 22 percent of women somewhat disagree, while 25 percent of men and 23 percent of women somewhat agree. Equal proportions strongly agree (17 percent).

Across the states, the proportion of respondents that strongly agree is unevenly distributed (Figure 2.4.12). In Kerala, Delhi, and Nagaland, almost

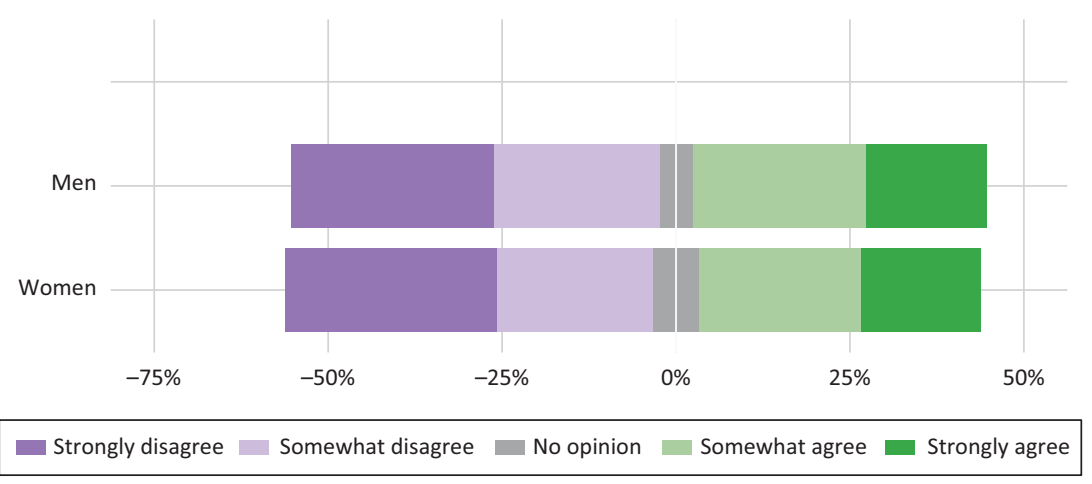

Figure 2.4.11 Educating Boys is More Important Than Educating Girls (by Gender) 

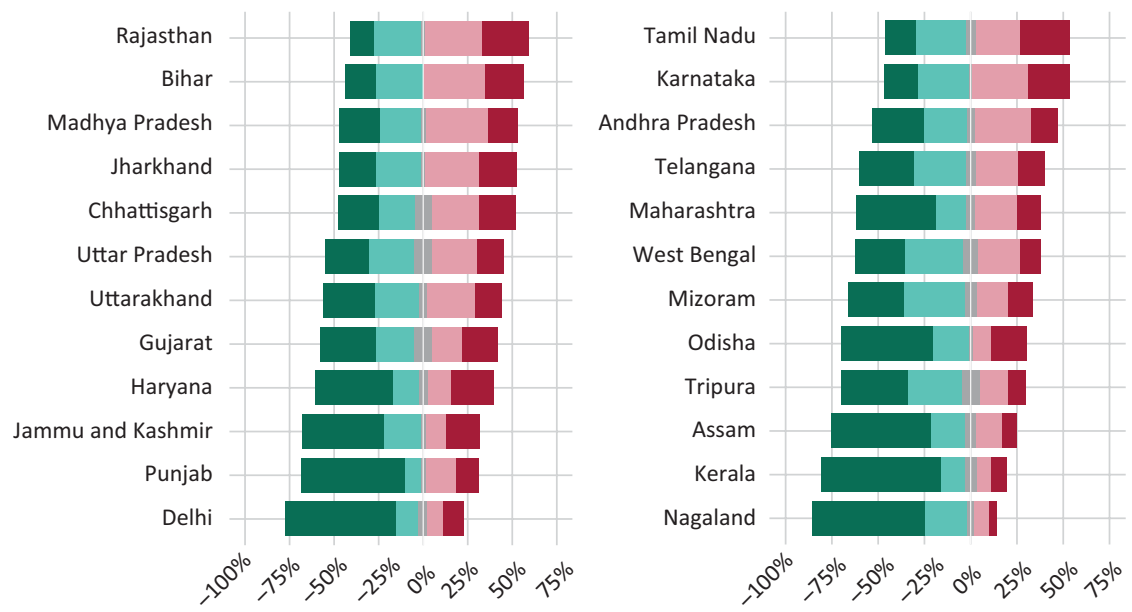

Strongly disagree Somewhat disagree No No opinion Somewhat agree

Strongly agree

Figure 2.4.12 Educating Boys is More Important Than Educating Girls (by State)

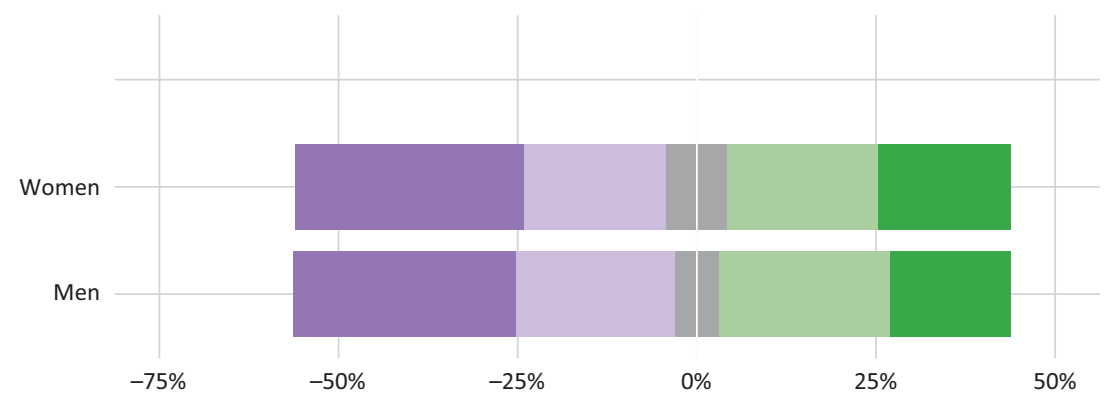

Strongly disagree $\square$ Somewhat disagree No opinion Somewhat agree Strongly agree

Figure 2.4.13 Men Should be Paid More Than Women Even if it is the Same Job (by Gender)

two out of three respondents strongly disagree with the statement that educating boys is more important than educating girls. This proportion drops and is lowest in Rajasthan (13 percent), Tamil Nadu (16 percent), and Bihar (17 percent). A majority in Rajasthan, Bihar, Karnataka, Madhya Pradesh, Jharkhand, and Tamil Nadu agree that educating boys in more important than educating girls.

We find similar proportions of men and women both agree and disagree that men should be paid more than women even if it is the same job 


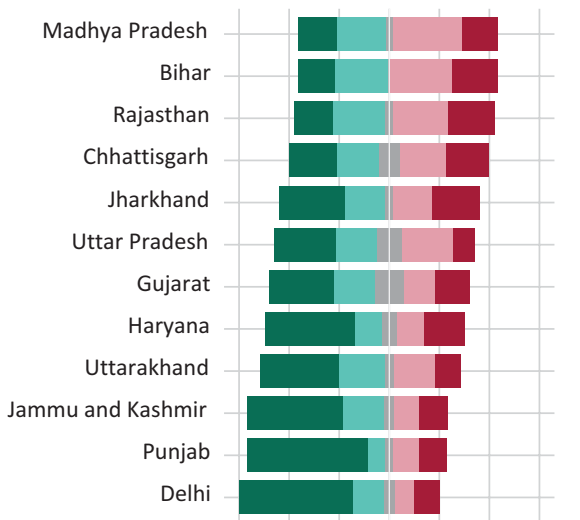

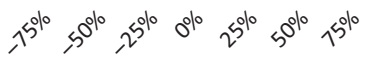

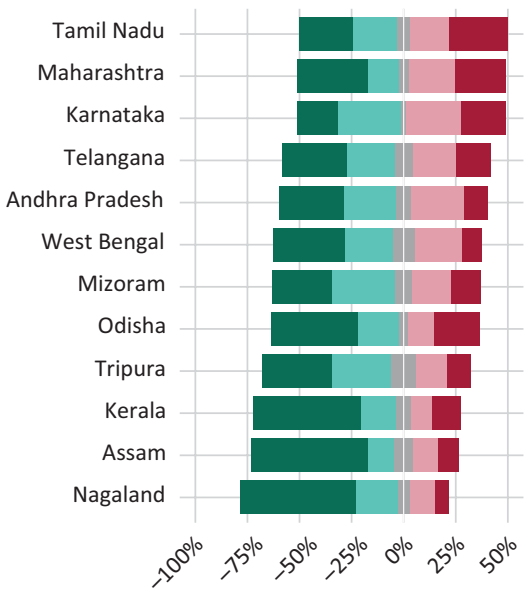

- Strongly disagree - Somewhat disagree $\quad$ No opinion Somewhat agree Strongly agree

Figure 2.4.14 Men Should be Paid More Than Women Even if it is the Same Job (by State)

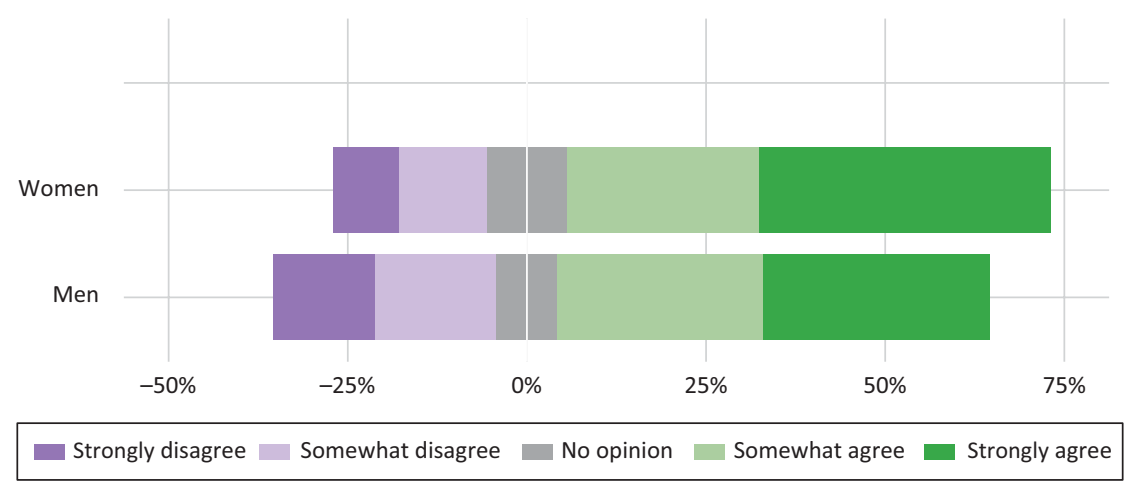

Figure 2.4.15 Women Should Have a 50 Percent Reservation of all Jobs (by Gender)

(Figure 2.4.13). While 52 percent men and women disagree, about 40 percent women and 41 percent men agree.

In Punjab, Delhi, Assam, Nagaland, and Kerala more than 50 percent respondents strongly disagree (Figure 2.4.14). In Mizoram, Tamil Nadu, Chhattisgarh, Karnataka, Rajasthan, Bihar, and Madhya Pradesh, less than 30 percent of respondents strongly disagree. About one in four respondents in Bihar, Rajasthan, Jharkhand, Maharashtra, and Tamil Nadu agree that men should be paid more than women for the same job. 

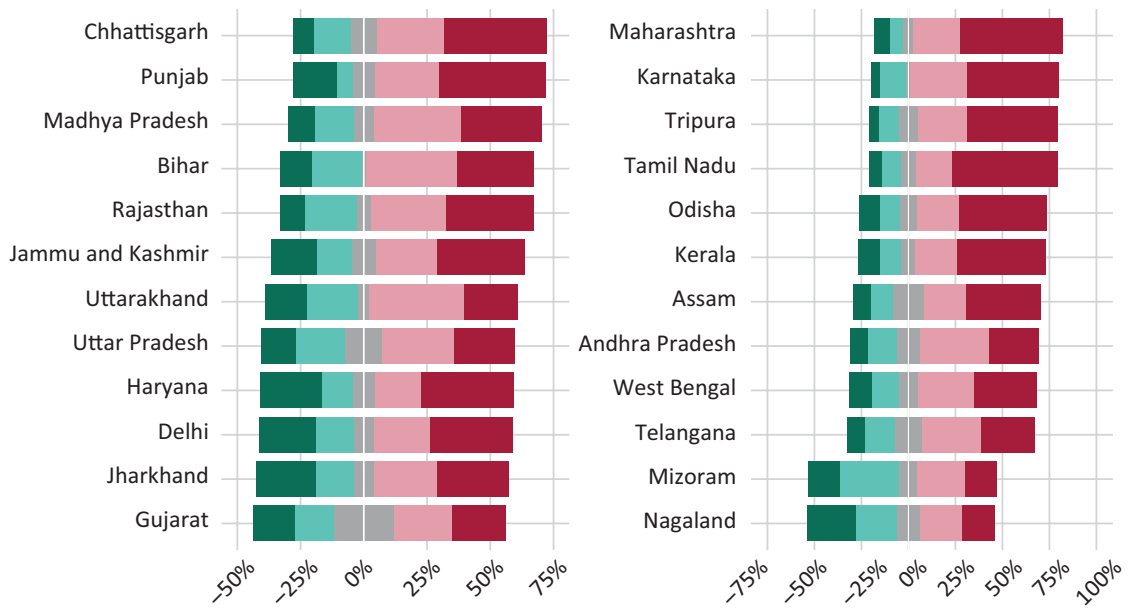

Strongly disagree $\square$ Somewhat disagree $\square$ No opinion $\square$ Somewhat agree

Strongly agree

Figure 2.4.16 Women Should Have a 50 Percent Reservation of all Jobs (by State)

Sixty-eight percent of women agree that women should have 50 percent reservation of jobs and 61 percent of men do so (Figure 2.4.15). Similarly, while 14 percent men strongly disagree, nine percent of women also do.

Nagaland shows the highest percentage of those who strongly disagree (26 percent), while Karnataka shows the least (four percent) (Figure 2.4.16). Tamil Nadu (56 percent) and Maharashtra (54 percent) show the highest levels of strong agreement. The difference in proportions of those who agree and disagree is large and positive for most states (for instance 64 percent in Maharashtra and 61 percent in Karnataka) except for Mizoram and Nagaland, where the difference is less than six and less than three respectively. 


\subsection{CONCLUSION}

Social and political networks driven by the institutions of caste and religion are critical to an understanding of Indian politics and society between elections. This section gives us a broad sense of what social networks exist and which political ones citizens choose to exercise during periods of routine politics and governance. By identifying an overarching sense of how intercaste and inter-religious networks function and shape social relations across India between elections, we develop what may be a useful baseline to contrast with these relations in other periods.

Social lives remain homogenous and exclusive. Spatially, large proportions of respondents have Dalit, OBC, and upper caste close friends. The proportion of respondents who have close Adivasi friends drops significantly in a number of states, and the states that exhibit higher proportions of respondents with Adivasi friends tend to be the ones with a relatively higher Adivasi population. This pattern is also seen for Muslims and Christians. Friendship ties with Muslims and Christians are greater in states with a relatively larger share of minority population but decreases significantly in states with smaller shares of minorities. Friendship ties are stronger within communities and are relatively much weaker across communities. All social groups report high proportions of close friends from within their communities. The proportion of respondents who report friends from other communities varies across different communities. Considering cross-caste identity friendships, upper caste respondents are the least likely to have close friends from other caste identity groups -especially Dalit and Adivasi friends. Dalit, OBC, and upper caste respondents are all less likely to have close Adivasi friends. Across communities, as expected, the ties are stronger within. Respondents from across religious communities are more likely to have a close friend from their own community. Ties across communities are weaker. Fewer Hindu and Sikh respondents have Muslim and Christian close friends. The variation in friendship ties across states and caste-community identity suggests that inter-caste-community friendships are stronger in spatial pockets. Education has a positive relationship with friendship ties, and across increasing levels of education respondents have a greater share of close friends from other communities.

While preference for a leader of the same caste or religion is prominent in most states, a handful of states remain indifferent to the caste and religion of the leader. This preference extends across caste and community. Similarly, rural respondents have a preference for a leader from their own caste or religion compared to urban respondents. Economic class tends to lower the preference for a leader form the same cate or religion across all caste and religious identities. This also reinforces the earlier finding of strong intracaste bonding and relative weaker inter-caste links. 
Perceptions of social groups in addition to social relationships (such as friendship) between people of different identities, is another key element of what constitutes a social universe. Theorists have consistently argued that to construct the "self", one needs to differentiate oneself from an "other". Social identities based on nationality, religion, caste, or race are constructed by differentiating themselves from others. Apart from the cultural basis for these identities, the social, economic, and political contexts also shape the attitudes, beliefs, and structure of these varied identities. How we perceive other communities also tells us about the likelihood and the nature of interaction with citizens from these other communities.

A large body of work in sociology and social anthropology shows that Dalits and Adivasis continue to remain among the most marginal social and economic groups and experience unfair treatment through overt discrimination and violence, and covert forms of exclusion and stereotyping (Newman and Thorat 2010, Deshpande 2011). Many have also noted that Dalits and Adivasis are often stereotyped as lazy and ridiculed as "sarkari damaad" ("government's son-in-law"), suggesting that they are underserving recipients of government benefits. Competition for limited government jobs and admission in universities has reinforced existing prejudices and has polarized views on government policy on affirmative action (Coffey et al. 2018). Contemporary political developments and discourses on nationalism have brought questions of patriotism and the nature of communities, whether peaceful or violent, to the forefront.

Spatial differences are also seen in how castes and communities are perceived. Most caste identities are perceived as generally hardworking, though there are exceptions where a relatively larger proportion of respondents within a state hold an extreme view (either positive or negative) of a particular community. Responses regarding the patriotism of a particular community produces greater polarization. Relatively large proportions of respondents view Muslims as unpatriotic in some states. Fewer respondents see Christians as unpatriotic. Expectedly, a substantial proportion of respondents see Hindus as extremely patriotic. However, responses tend to cluster in the middle for several states. Similar to responses on workethic, most communities are seen as generally peaceful across most states. As before extreme views appear in some states. All caste groups tend to perceive themselves as more hardworking compared to how other groups view them. For instance, similar proportions of Dalits and upper castes think of the other as lazy (and hardworking). The sharp contrast between a community's self-image and the perception by other communities suggests that these stereotypes may be remarkably resilient. Education has mixed effects on mitigating stereotypes about industry associated with castes and in some cases appears to have an inverse effect. However, it is also important to note that non-literates have a relatively high rate of non-response. Similarly, 
different communities see themselves as patriotic and peaceful, but some communities are seen as relatively more unpatriotic and violent.

We find support for ideas that empower women, but we also see a strong patriarchal strain often in seeming contradiction to statements supporting women's independence. For instance, while there is overwhelming support for the idea that both the man and woman are equally responsible for child rearing, there is similarly large support for the statement that women should prioritize home over work. Extant research suggests that greater women's political representation ensures an increased voice for women. Women elected to political office, in part under the reservation policy, invest more in the public services most closely linked to women's concerns (Chattopadhyay and Dufflo 2001). But more generally, how do we understand the contradictory positions that emerge from public opinion about gender roles? These questions deserve further examination.

\section{NOTE}

1 We are aware that terms such as "Dalit" and "Adivasi" contain a diversity of identities (a subject with a large body of scholarship). We use the terms here to represent respondent self-identified legal administrative categories Scheduled Castes (as Dalit) and Scheduled Tribes (as Adivasi). 


\section{POLITICAL UNIVERSE}

Part 3 reports findings about the foundations of the political universe in India. Looking at four aspects of the political universe - freedom of expression, regional and national identity, nationalism, and populism - we show that on each of these, there are regional variations just as there are variations across demographic characteristics. But more broadly, the political universe of Indians is made up of conditional support for freedom of expression, an urge to balance between regional and national identity, a nationalism that is slightly tilted to the conservative variety rather than the centrist one, and a mostly non-populist attitude to politics. 


\subsection{FREEDOM OF EXPRESSION}

Public opinion regarding what constitutes "freedom of expression", "who" is entitled to such freedoms and to "what extent" is essential to understanding a citizen's political universe.

The Constitution of India in Article 19(1) provides that all citizens have the right to the freedom of speech and expression. As the Supreme Court notes in Romesh Thapar v. State of Madras, (1950), "Freedom of speech and of the press lay at the foundation of all democratic organizations, for without free political discussion no public education, so essential for the proper functioning of the process of popular government, is possible." Democratic theorists have long argued that democracy is meaningless without freedom of speech and expression, the right to express one's views and opinions freely through words, in writing or through other visual forms, and all forms of communicable media without restrictions or fear of repression by the State. Rights guaranteeing the freedom of expression also contribute to enhancing human capacities, a key indicator of development.

Yet, freedom of expression is not unconditional. The First Amendment imposes a set of "reasonable restrictions" on the freedom of expression that curtail public speech against the "interests of the sovereignty and integrity of India, the security of the state, friendly relations with Foreign States, public order, decency or morality or in relation to contempt of court, defamation or incitement to an offence."

Many have argued that the breadth of these reasonable restrictions allow for constitutional interpretation upholding several legal restrictions. The provisions of the Indian Penal Code relating to sedition, criminal defamation, and hate speech are frequently misused to muzzle dissenting opinions. These claims are not entirely unjustified as recent events suggest. The arrests of students and civil society activists among others for allegedly "seditious", "anti-national" activities, and for "unpatriotic" comments on social media have further animated this debate. It is evident that there are multiple ways in which ideas of freedom of expression, and what constitutes "reasonable restrictions" on the freedom to express opinions, are being framed in India today.

In this section, we examine public perceptions toward key tenets of the right to the freedom of expression as written in the Constitution of India. We interrogate freedom of expression through three themes central to India's politics and society: democracy and democratic practice, secularism, and sovereign nationalism. In subsequent paragraphs, we provide a brief explanation of how freedom of expression is connected to these three themes.

Using a set of six questions, clustered in three sets of two questions, we examine each across several categories in order to understand factors that are associated with public opinion on freedom of expression. These questions ask whether people who hold or advocate a certain opinion should be 
allowed to express their opinion freely in public. These opinions include: (a) a preference for dictatorship over democracy, (b) criticism of elected leaders, (c) making fun of a religious community other than one's own, (d) promoting violence against another community in the form of hate speech, (e) advocating violence against the Indian State, and (f) advocating independence for any part of India. Questions are framed in ways that allow us to understand how people imagine freedom of expression, especially in those circumstances when an opinion pushes the limits to freedom of expression as articulated in the Indian Constitution.

The responses to these questions are "fully agree", "somewhat agree", "somewhat disagree", and "fully disagree".

Our analysis proceeds as follows. First, we examine cross-state variations in responses for each cluster of questions. We then focus on other important social sources of variations such as religious identity and education levels of the respondents.

\subsubsection{Freedom of Expression in Democratic Practice}

The Right to Freedom of Speech and Expression that is provided by Article 19 (1) of the Constitution of India, in many ways forms the backbone of several ideals such as democracy, secularism, and sovereign nationalism. It is intuitively and logically evident that if democracy is a form of government that is based on the consensus of the people, then freedom of speech and expression is vital. One cannot possibly imagine a situation where a democratic form of government is antithetical to this basic freedom. As Justice Bhagwati argued in Maneka Gandhi versus the Union of India (1978):

If democracy means "government of the people by the people", it is obvious that every citizen must be entitled to participate in the democratic process and in order to enable him to intelligently exercise his right of making a choice, free and general discussion of public matters is absolutely essential.

The Indian experience of democracy has shown how mobilization of hitherto underprivileged groups such as women, Dalits, religious minorities, and backward castes at particular points of time deepened and strengthened the foundations of our democracy. None of this would have been possible if the underprivileged did not have the right to resist dominant forces and to freely express their views and opinions on day-to-day politics.

Freedom of expression in democratic practice implies that citizens be allowed to freely articulate views, whether critical or not, of both democratic institutions as well as elected political leaders. Two questions that capture public opinion on freedom of expression in democratic practice are: (a) people should be allowed to express their opinion freely even if they 
promote dictatorship over democracy, and (b) people should be allowed to express their opinion freely even if they are criticizing elected leaders. The first question indicates that an individual should be allowed to freely express a view that advances a set of political institutions that likely curtail a multitude of political and civil rights. Does freedom of expression in democratic practice generate the space for individuals to freely promote a view that ironically calls for limiting or eliminating that very space? This is an important question, especially because several political parties in contemporary times reiterate the sacrosanct nature of Indian democracy and hence express deep reservations about opinions that are seen as challenging the sanctity of this institution.

The second question focuses on an opinion involving a relatively more familiar practice among citizens in a democracy, one that allows for individuals to freely criticize elected representatives. While citizen dissatisfaction (or satisfaction) with their elected representatives finds expression during elections, does freedom of expression in democratic practice allow individuals to freely criticize elected leaders regardless of how these leaders are generally perceived?

We find significant differences in attitudes toward freely expressing a preference for dictatorship over democracy across states (Figure 3.1.1). In Karnataka, Madhya Pradesh, Maharashtra, Rajasthan, Chhattisgarh, Bihar, Jharkhand, Kerala, Tamil Nadu, and Uttar Pradesh, between 40 to 60 percent of respondents either fully or somewhat agree. This proportion declines to between 30 and 36 percent in Assam, Jammu-Kashmir, Mizoram,

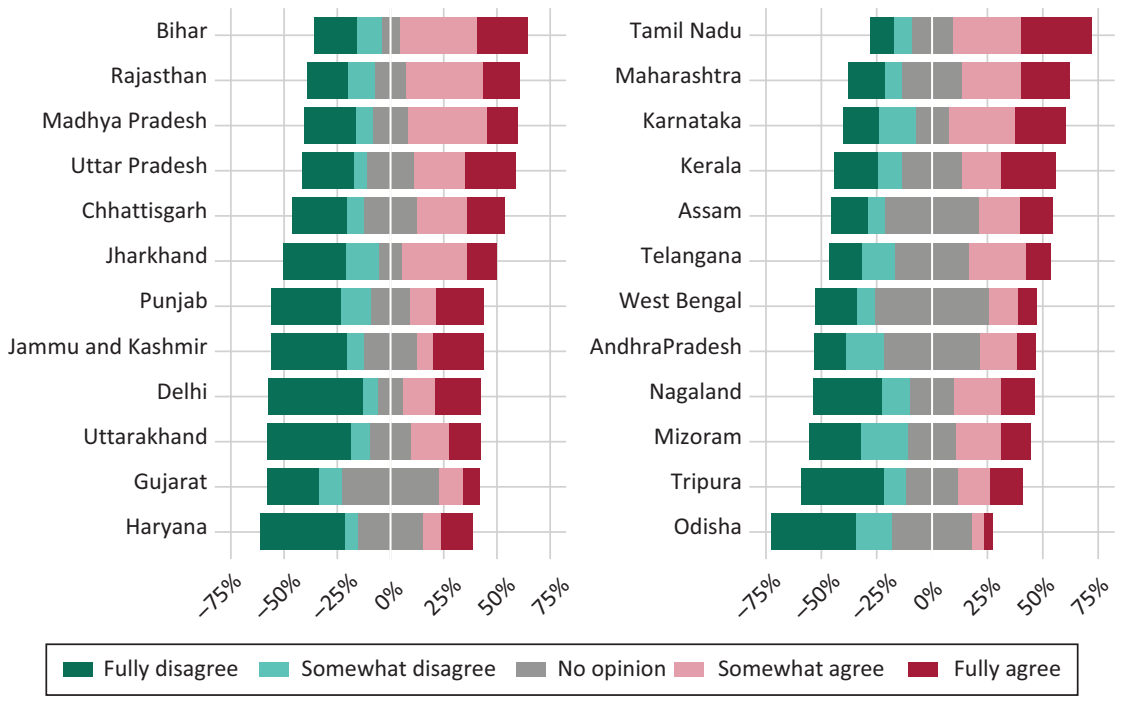

Figure 3.1.1 Dictatorship over Democracy (by State) 
Nagaland, Punjab, Tripura, Telangana, Delhi, and Uttarakhand. Less than one quarter of the respondents either strongly or somewhat agree in Gujarat, Haryana, Andhra Pradesh, Odisha, and West Bengal. It is also worth noting that Andhra Pradesh, Gujarat, Assam, and West Bengal exhibit the highest proportions of respondents who do not have an opinion at between 42 and 52 percent.

We do not find large differences across levels of education (Figure 3.1.2). Non-literate respondents are less likely to fully or somewhat agree (approximately 34 percent) that individuals should be allowed to express a view that favours dictatorship over democracy. About 48 percent of respondents with college or above level of education do the same. However, we find that a larger proportion of respondents with college level of education or higher, about 38 percent, fully or somewhat disagree while only 24 percent of nonliterates do the same. Forty-one percent of non-literates also do not have an opinion. Non-response decreases across levels of education.

About 50 percent or more of respondents across almost all the states either fully or somewhat agree with the opinion that people should be allowed to freely criticize elected leaders (Figure 3.1.3). The states that have lowest proportions of those agreeing are Gujarat (25 percent), Haryana (24 percent) and Odisha (30 percent). The proportion of those either fully or somewhat agreeing is relatively large in Jammu and Kashmir (73 percent), Kerala (72 percent), Punjab (73 percent), and Delhi (70 percent). The proportion of respondents who do not have an opinion is highest in Gujarat and Assam - about 41 and 37 percent respectively.

Religious identity produces differences on how criticism of elected leaders is viewed (Figure 3.1.4). Sikhs, Christians, and Muslims are more likely than Hindus to either somewhat or fully agree. About 67 percent of Sikhs,

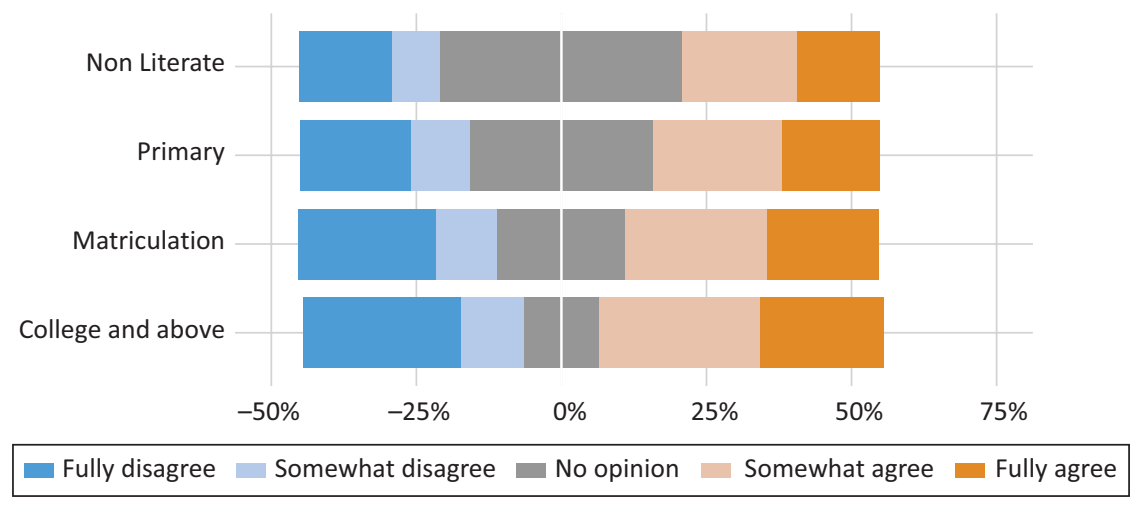

Figure 3.1.2 Dictatorship over Democracy (by Education) 

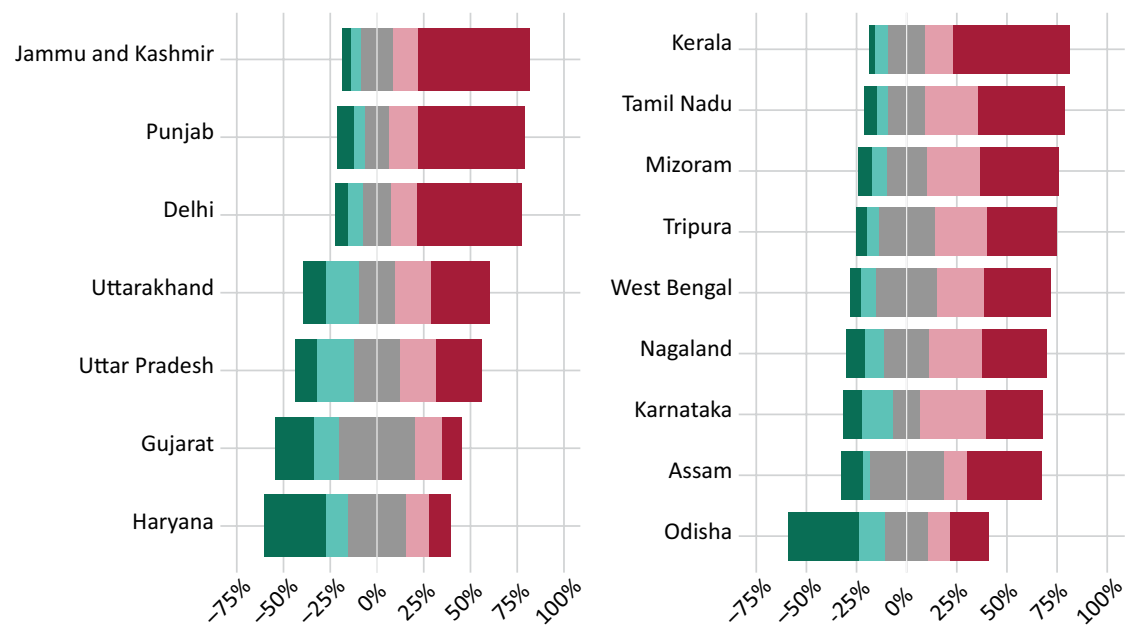

- Fully disagree Somewhat disagree No opinion

Somewhat agree

Fully agree

Figure 3.1.3 Criticizing Elected Leaders (by State)

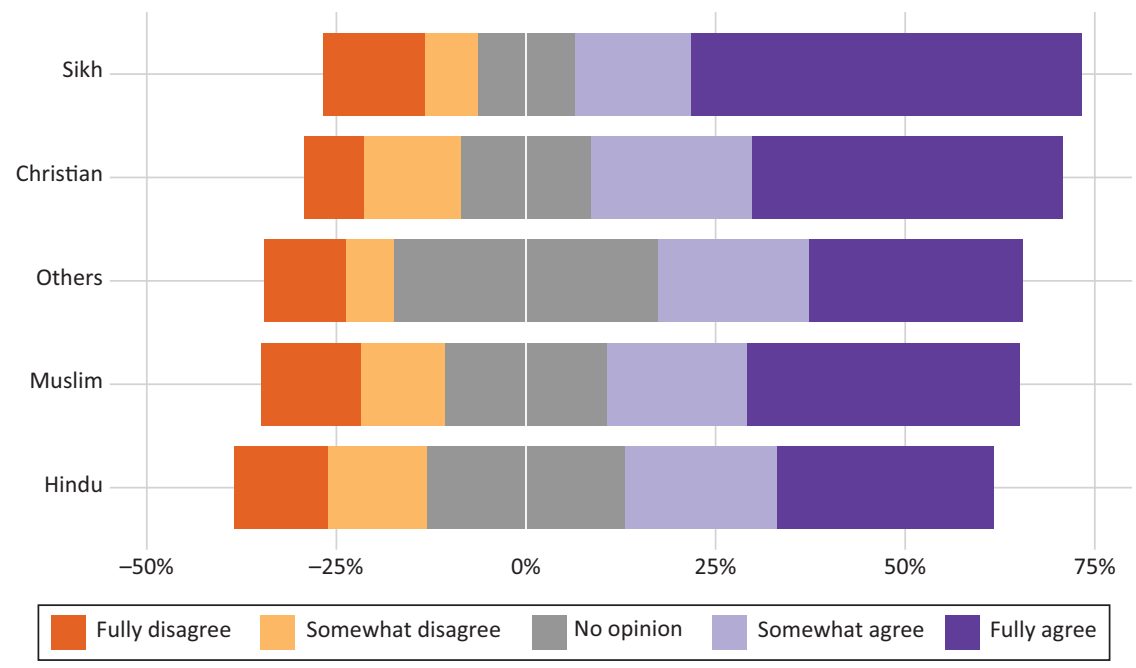

Figure 3.1.4 Criticizing Elected Leaders (by Religion)

followed by 64 percent of Christians and 59 percent of Muslims, hold this view while the comparable proportion for Hindus is about 50 percent.

We find very small differences in this opinion across levels of education (Figure 3.1.5). While 41 percent of non-literates are of the view (fully or somewhat) that people should be allowed to criticize elected leaders, 


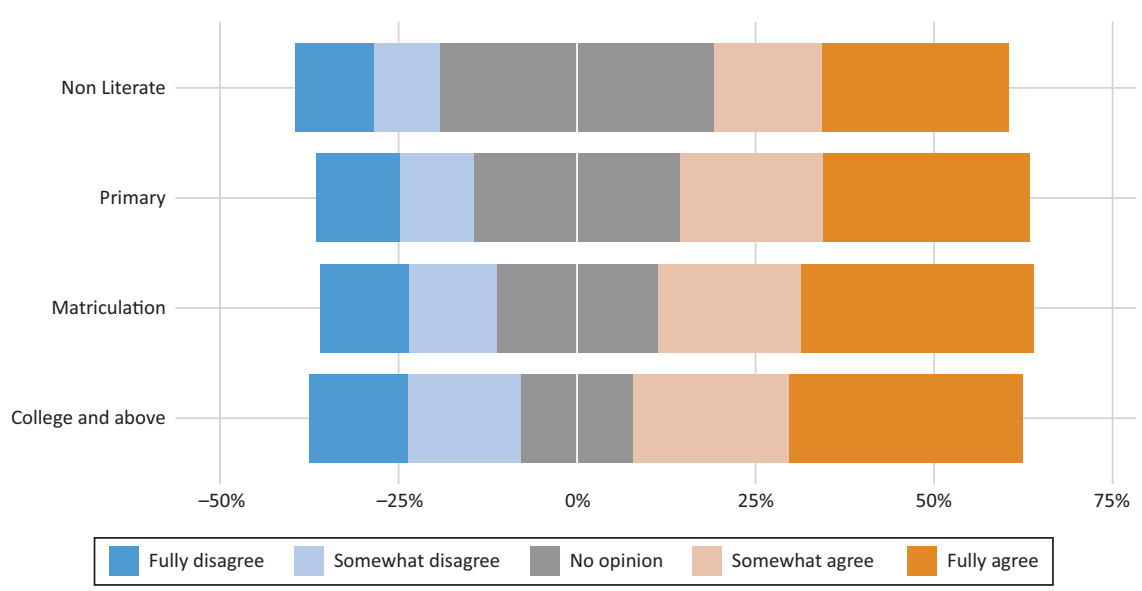

Figure 3.1.5 Criticizing Elected Leaders (by Education)

about 55 percent of individuals with a college education hold this position. However, it is notable that about 39 percent of non-literate respondents do not express an opinion. This number, however, drops to 15 percent for respondents with a college or above level of education.

\subsubsection{Freedom of Expression in Secularism}

The freedom of speech and expression is also embedded in the notion of secularism. Even as a conceptual idea that may not resonate entirely with the Indian experience, secularism is opposed to the idea of a theocratic State which makes freedom of expression an essential ingredient for its successful practice. The Indian variant of secularism which calls for equal treatment of all religions makes it even more imperative that the freedom of speech and expression be upheld. The Indian Constitution provides for the Right to Freedom of Religion under Articles 25-28 which guarantees all citizens the freedom of conscience and free profession, practice and propagation of religion, freedom to manage religious affairs, freedom from paying taxes for promotion of any religion, and the freedom to attend a religious instruction or religious worship in certain education institutions. Enjoyment of these rights thus entails the provision of free speech and expression.

How does one practice and propagate one's faith without the freedom of expression? Or, how would minority religious groups exercise dissent to any efforts by majoritarian groups at encroaching upon their cultural rights? We tap into freedom of expression embedded in the idea of secularism using two questions: (a) people should be allowed to express their opinion freely 
even if they make fun of religious communities other than their own, and (b) people should be allowed to express their opinion freely even if they are promoting violence against other communities. Both questions speak to what constitutes freedom of expression in ethnically heterogeneous societies where equal rights for all religions lies at the heart of nation-building.

Does freedom of expression include freely making fun of persons from other religious communities and their practices, and promoting violence in the form of hate speech against other communities? More broadly, are these notions of freedom of expression consistent with the practice of secularism in India? We examine the factors that appear to drive differences in public opinion on freedom of expression and how it relates to an underlying idea of secularism.

When it comes to allowing people to freely make fun of religious communities other than one's own, we find that large numbers of respondents either fully or somewhat disagree (Figure 3.1.6). Kerala (48 percent) is followed by Bihar (29 percent) in the share of respondents strongly agreeing. Between ten and 20 percent strongly agree in Madhya Pradesh (15 percent), Maharashtra (17 percent), Punjab (13 percent), Rajasthan (19 percent), Tamil Nadu 18 percent), Uttar Pradesh (11 percent), Jharkhand (15 percent), Chhattisgarh (17 percent), and Uttarakhand (12 percent). Less than ten percent fully agree in the remaining states. We also find that Gujarat, Andhra Pradesh, and Assam have larger proportions of respondents with no opinion ranging between 30 and 40 percent.
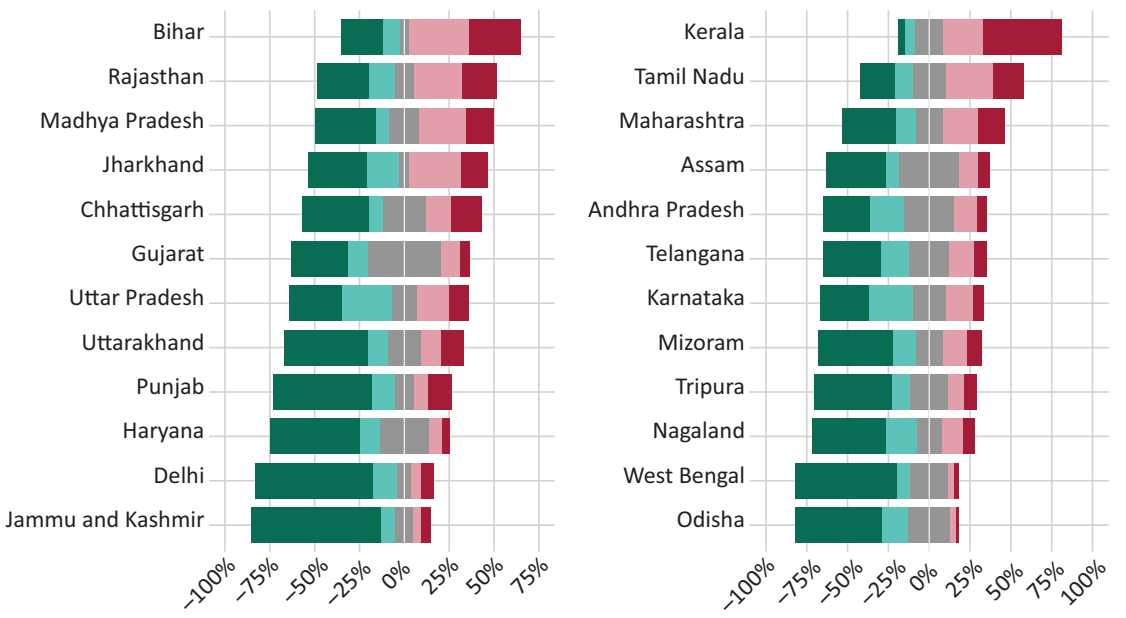

- Fully disagree Somewhat disagree No opinion

nomewhat agree

Fully agree

Figure 3.1.6 Making Fun of Other Religious Communities (by State) 
Hindus and Christians are more likely to either fully or somewhat agree with this view compared to Muslims and Sikhs (Figure 3.1.7). Approximately 32 percent of Hindu and 39 percent of Christian respondents either fully or somewhat agree that people should be allowed to freely express an opinion that makes fun of other communities. The proportions of Muslim and Sikh respondents who fully disagree are about 44 and 53 percent, respectively. A greater share of respondents either fully or somewhat disagree (50 percent) compared to fully or somewhat agreeing (31 percent).

We do not find differences among respondents based on levels of education (Figure 3.1.8). For instance, about 27 percent of non-literate respondents tend to either fully or somewhat disagree that people should be allowed to express an opinion even if it makes fun of other communities. This proportion increases to about 34 percent for respondents who have a college or higher level of education. However, about 32 percent of non-literate respondents do not have a response while this is only ten percent for those with a college or above level of education.

For most states, the proportion of respondents who either fully or somewhat agree that people should be allowed to freely express an opinion that promotes violence against other communities is relatively low (Figure 3.1.9). Less than ten percent of respondents in Andhra Pradesh, Assam, Gujarat, Haryana, Jammu and Kashmir, Mizoram, Nagaland, Odisha, Tripura, West Bengal, Delhi, and Telangana strongly agree. Between ten and 20 percent strongly agree in Kerala (19 percent), Madhya Pradesh (14 percent), Maharashtra (17 percent), Punjab (11 percent), Rajasthan (19 percent), Tamil Nadu (22 percent), Uttar Pradesh (15 percent), Jharkhand

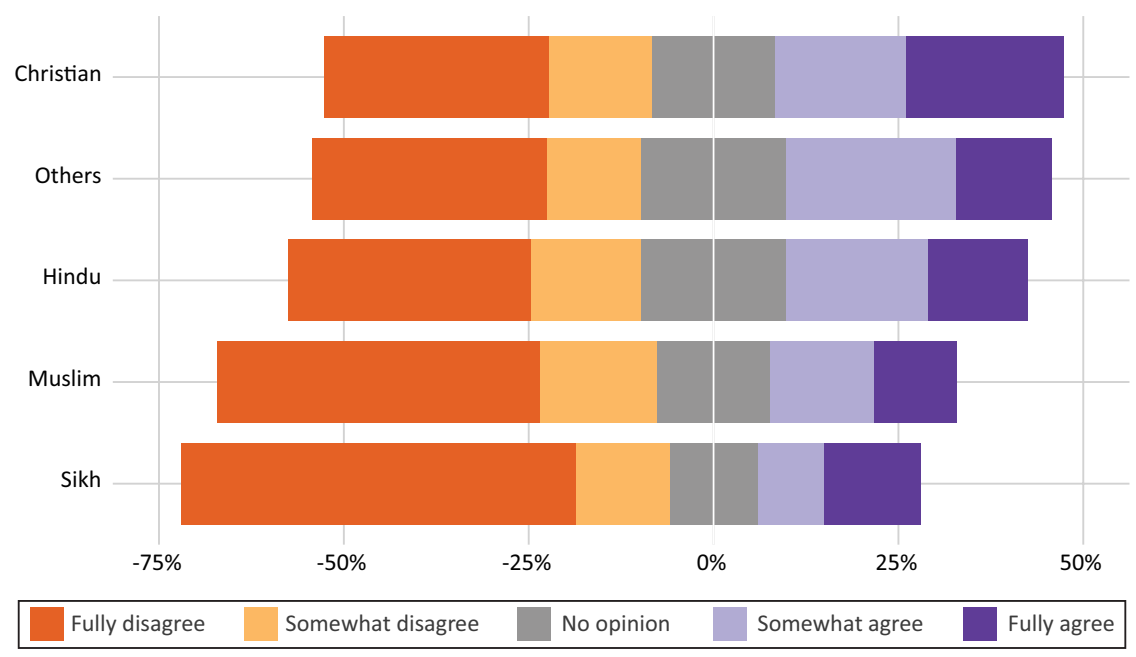

Figure 3.1.7 Making Fun of Other Religious Communities (by Religion) 


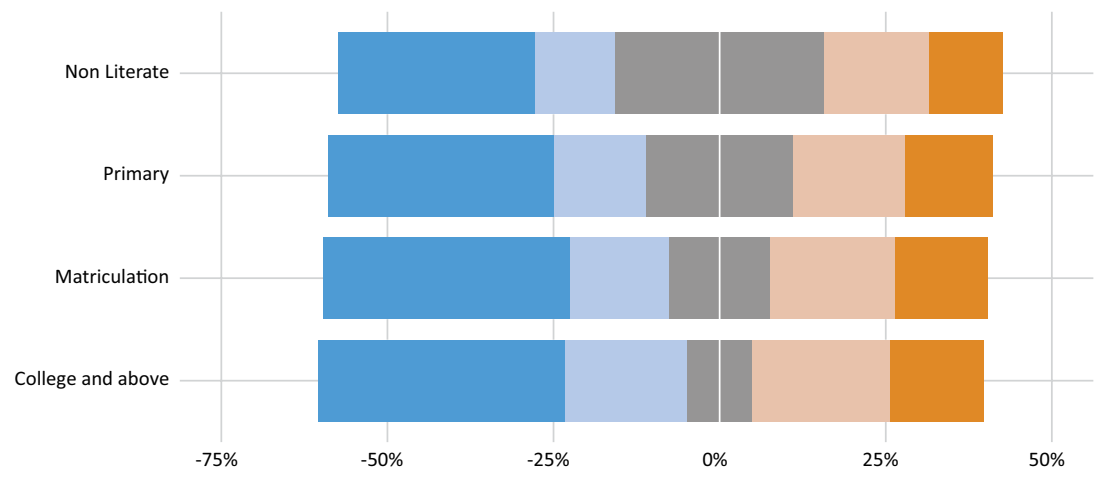

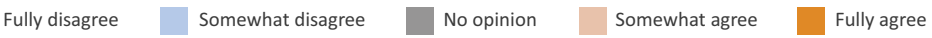

Figure 3.1.8 Making Fun of Religious Communities (by Education)

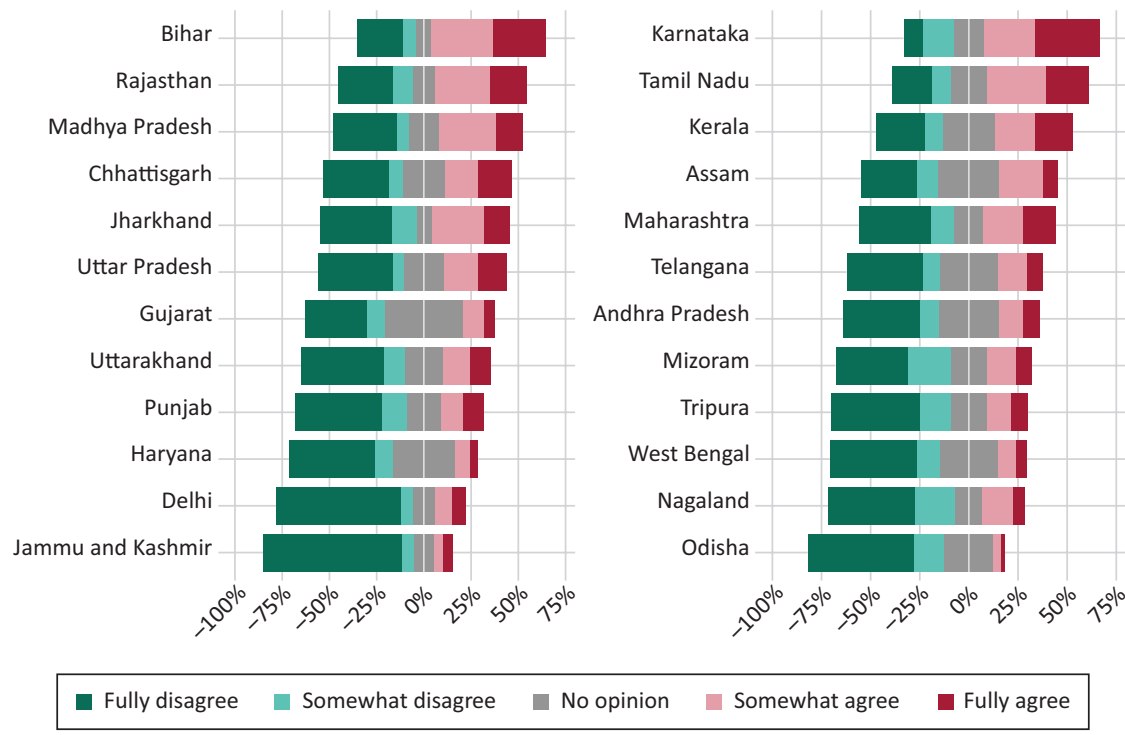

Figure 3.1.9 Promoting Violence Against Other Communities (by State)

(13 percent), Chhattisgarh (18 percent), and Uttarakhand (11 percent). However, the proportion of those who either fully or somewhat agree is about 50 percent or more in Bihar, Karnataka, Rajasthan, and Tamil Nadu. Once again, Gujarat, Andhra Pradesh, and Assam have the highest proportion of non-responses. 


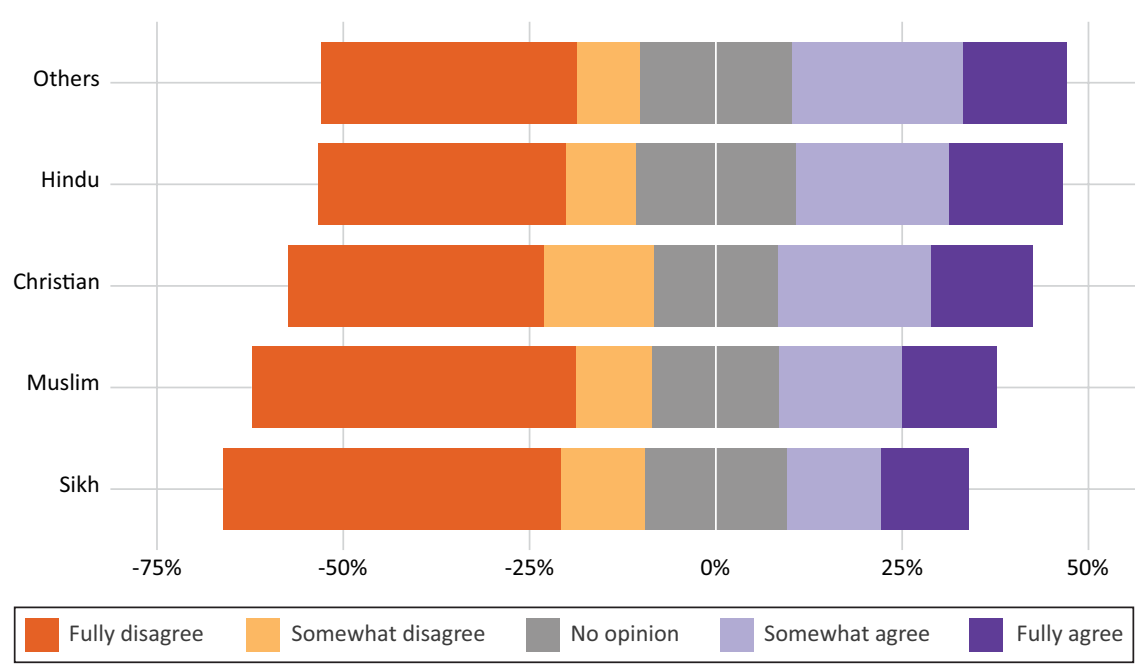

Figure 3.1.10 Promoting Violence Against Other Communities (by Religion)

We observe differences across religious identities (Figure 3.1.10). Hindus are most likely to either fully or somewhat agree with this opinion - approximately 36 percent. About 34 percent of Christians are also likely to strongly or somewhat agree with the view that an individual promoting violence against other communities should be allowed to express that opinion freely. This number falls to about 28 percent for Muslims and about 25 percent for Sikhs. About 43 percent of Muslim and 45 percent of Sikh respondents fully disagree.

We only find small differences across respondents based on levels of education and the expression of ideas that promote violence against other communities (Figure 3.1.11). Approximately 29 percent of non-literates agree with this view, the proportion increases to about 37 percent among respondents with a college level of education. Once again, we find that about 34 percent of non-literates do not offer an opinion. This proportion decreases to about 11 percent for college or above level of education.

\subsubsection{Freedom of Expression in Nationalism}

The third theme that freedom of expression locates itself in is sovereign nationalism. Though not clearly articulated in the Indian Constitution, it firmly supports the Indian freedom movement and the politics of post-independence India. Contrary to other kinds of nationalisms that were based on either language or religion, as evident in Europe and certain parts of Asia, the thrust for nationalism in India was based on the anti-colonial struggle. More importantly, given the rich diversity of this country, the 
leaders of the national movement endorsed a pluralist and civic form of nationalism that transcended caste, class, language, religion, or any other form of ascriptive identity. Though in recent times we have witnessed a series of attacks on students, academics, journalists, and writers for not complying with accepted norms of "nationalistic behaviour", one cannot reasonably make the case that nationalism is therefore antithetical to freedom of speech and expression. A pluralist nationalism allows all citizens of the country, and not just the majority, the right to voice their dissent. But what about demands for territorial independence from India? Or advocating the use of violence against the State that characterize separatist language? How do Indians make sense of opinions that contradict an understanding of nationalism and patriotism? Do they feel that freedom of expression should be protected at any cost or do they think that only a particular "definition" of nationalism should triumph over all other kinds of liberties? Two questions used to identify public opinion on freedom of expression in its relation to sovereign nationalism are: (a) people should be allowed to express their opinion freely even if they promote the use of violence against the Indian State, (b) people should be allowed to express their opinion freely even if they demand independence for a certain part of India.

A greater proportion of respondents tend to disagree rather than agree on the right to express an opinion that promotes violence against the Indian State (Figure 3.1.12). Close to 50 percent of respondents from Bihar, Rajasthan, and Tamil Nadu tend to either fully or somewhat agree with the view that someone who advocates violence against the Indian State should be allowed to freely express that opinion. Between ten and 20 percent strongly agree in Kerala (18 percent), Madhya Pradesh (13 percent), Maharashtra (17 percent), Punjab (15 percent), Rajasthan (19 percent), Uttar Pradesh (16

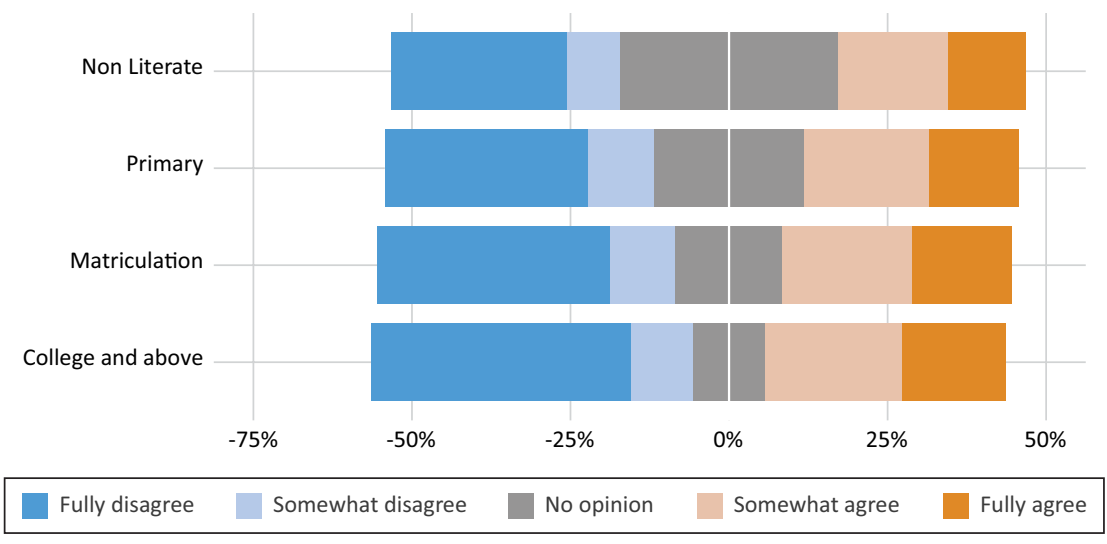

Figure 3.1.11 Promoting Violence Against Other Communities (by Education) 

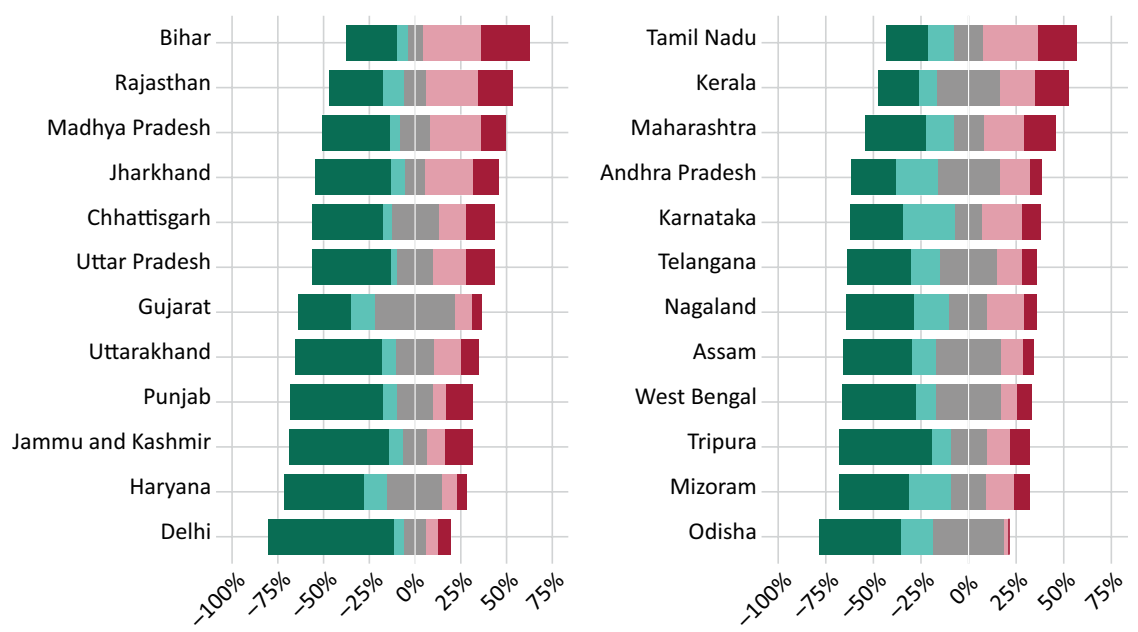

Fully disagree $\square$ Somewhat disagree $\square$ No opinion $\square$ Somewhat agree $\square$ Fully agree

Figure 3.1.12 Promoting Violence Against the Indian State (by State)

percent), Jharkhand (14 percent), and Chhattisgarh (16 percent). Between 30 to 40 percent respondents from Gujarat, Andhra Pradesh, and Assam do not have an opinion.

Here too we find only small differences across levels of education (Figure 3.1.13). About 27 percent of non-literate respondents either fully or somewhat agree with the statement, and the proportion increases to about

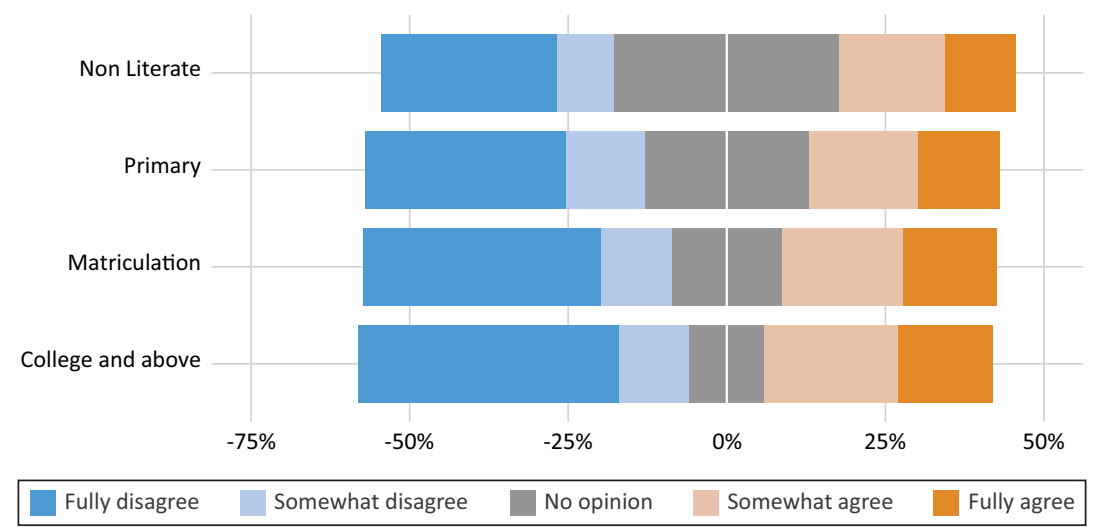

Figure 3.1.13 Promoting Violence Against the Indian State (by Education) 

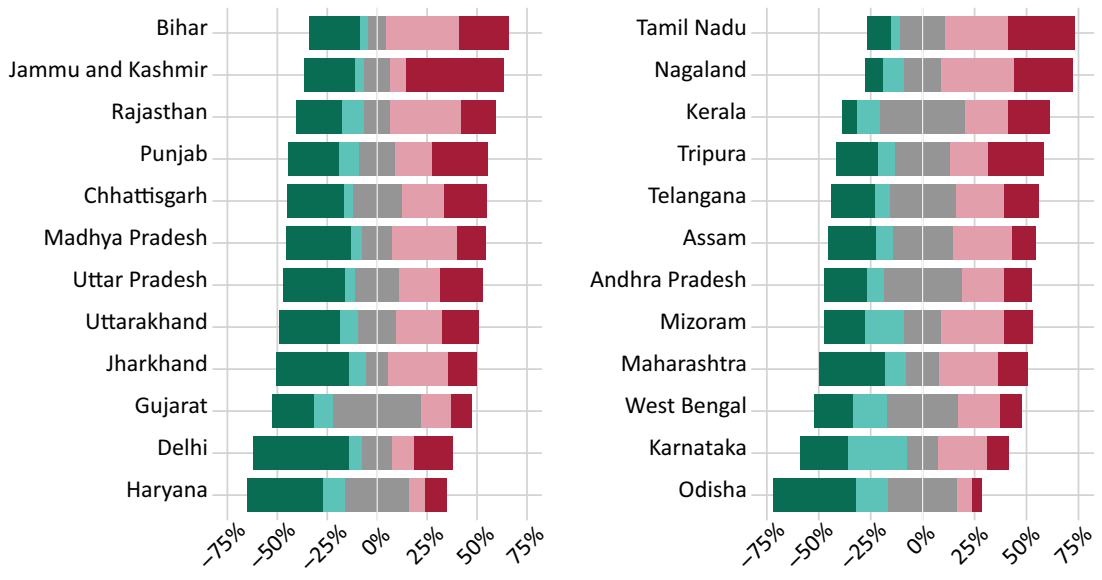

— Fully disagree $\square$ Somewhat disagree $\quad$ No opinion $\quad$ Somewhat agree

Fully agree

Figure 3.1.14 Independence for Certain Parts of India (by State)

37 percent for those with a college level of education. However, we find that 35 percent of non-literates have no opinion, compared to 13 percent for those with a college of higher level of education. About 46 percent of all respondents either fully or somewhat disagree while 33 percent of respondents agree.

A greater share of respondents fully disagrees than strongly agrees that views demanding independence in certain parts should be allowed. (Figure 3.1.14). The highest proportion of strongly agree is in Jammu and

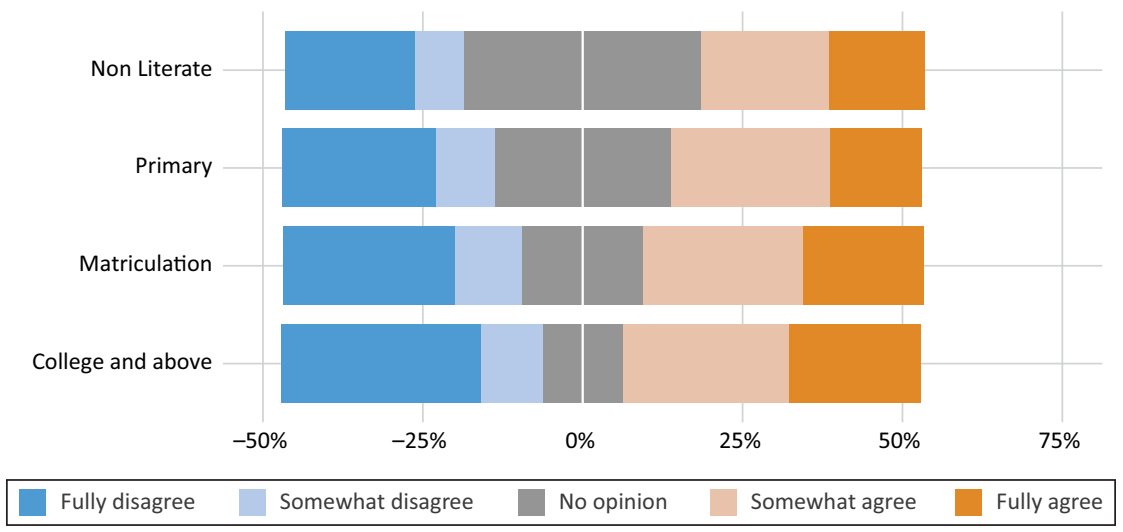

Figure 3.1.15 Independence for Certain Parts of India (by Education) 
Kashmir (49 percent) followed by Tamil Nadu (32 percent). In Kerala, Nagaland, Punjab, and Tripura a larger share of respondents fully agrees over strongly disagreeing. Close to 50 percent of respondents in Delhi strongly disagree. As with the other questions, Gujarat, Kerala, Andhra Pradesh, and Telangana record the highest proportion of non-responses between 32 percent and 45 percent.

We also see that across all levels of education the proportion of respondents who agree with allowing people to freely express independence for any part of India is greater than the proportion of respondents who disagree (Figure 3.1.15). Among non-literates, almost 25 percent of respondents either fully or somewhat agree, and among college-educated respondents this proportion increases to 47 percent. Once again, note that the proportion of non-responses is about 36 percent for non-literate respondents while this drops to 12 percent for those with college and above level of education. 


\subsection{NATIONAL AND REGIONAL IDENTITY}

National and subnational regional identities coexist in India's political universe. While a national identity is associated with nationalism and, historically, its origins can be traced to the anti-colonial national movement, the origins and forms of regional identities are varied. However, the creation of linguistic states, language policy and the role of Hindi, the growth of regional political parties, and election of regional governments have coalesced shared regional cultural identities into a significant political subnational identity. Yet, not much is known about subnational identities, both analytically and empirically, and the ways it differs from a national identity and what its drivers are (Singh 2015).

India also has a history of sub-national and regional movements with language and associated cultures as the focal point. Over the years, there have been popular movements that have pushed for primacy for the state language in public spaces. Support for the use of local language over any other language becomes an expression of linguistic sub-nationalism.

This section focuses on two dimensions of political identity: (a) self-identification as "national" versus "regional" and (b) linguistic preference i.e., a preference for which language should be used in public. We pose the following questions and empirically examine patterns across the states: What is the distribution of national and subnational identities across India today? Does one dominate the others? Is there subnational variation? Are there differences in identities across religious communities or across other socioeconomic dimensions such as education and media exposure? Are urban Indians more likely to adopt a national identity relative to rural India? And do Indians have a linguistic preference for the language to be used in public spaces?

\subsubsection{National or Regional}

We use the following question to explore the extent to which a respondent identifies as regional or national:

When we ask people how they would identify themselves, some say they are only (state identity) and others feel they are only Indian. While some feel they are more (state identity) and less Indian and other feel they are more Indian and less (state identity). How do you identify yourself?

The respondents are provided with six options to choose from: (a) Only (state identity), (b) More (state identity), less Indian, (c) More Indian, less (state identity), (d) Only Indian, and (e) Both Equally. We aggregate the responses into three categories: "More Regional", "Equal", and "More National". 
When we consider the distribution of a regional or national identity across the states, we find three distinct patterns (Figure 3.2.1). First, is a relatively equal distribution of responses across the three categories and/or the category that has the highest proportion of respondents an "equal" identity? In Karnataka and Andhra Pradesh we find about a third of respondents located in each group - a more or less even distribution. In Karnataka, a more national identity reaches about 35 percent and in Andhra Pradesh a more regional identity reaches 36 percent. In Kerala, Assam, Punjab, Chhattisgarh, and Uttarakhand, the proportion of respondents who feel equally national and regional is greater than the other two. In these states the proportion is about 40 percent or more, although in Punjab the proportion of those who express a regional identity is close to 40 percent and in Uttarakhand the proportion who express a national identity is also close to 40 percent. Second, states where a more national identity dominates over others include Bihar, Delhi, Haryana, Madhya Pradesh, Maharashtra, Rajasthan, and Uttar Pradesh. In these states, close to 50 percent or more respondents express a national identity. In Delhi and Haryana, close to 70 percent of respondents feel "national" while the number drops to about 50 percent in Rajasthan and Uttar Pradesh. States where national identity is the largest category but is still at less than 50 percent include Jharkhand, Tripura, Telangana, and West Bengal. The third state-wide pattern that we observe is the case where the regional identity dominates over others to various degrees. These include Tamil Nadu, Mizoram, Nagaland, Odisha, and Jammu and Kashmir, where 50 percent or more respondents profess having a more regional identity. In Gujarat we find that about 40 percent of respondents feel more "regional".

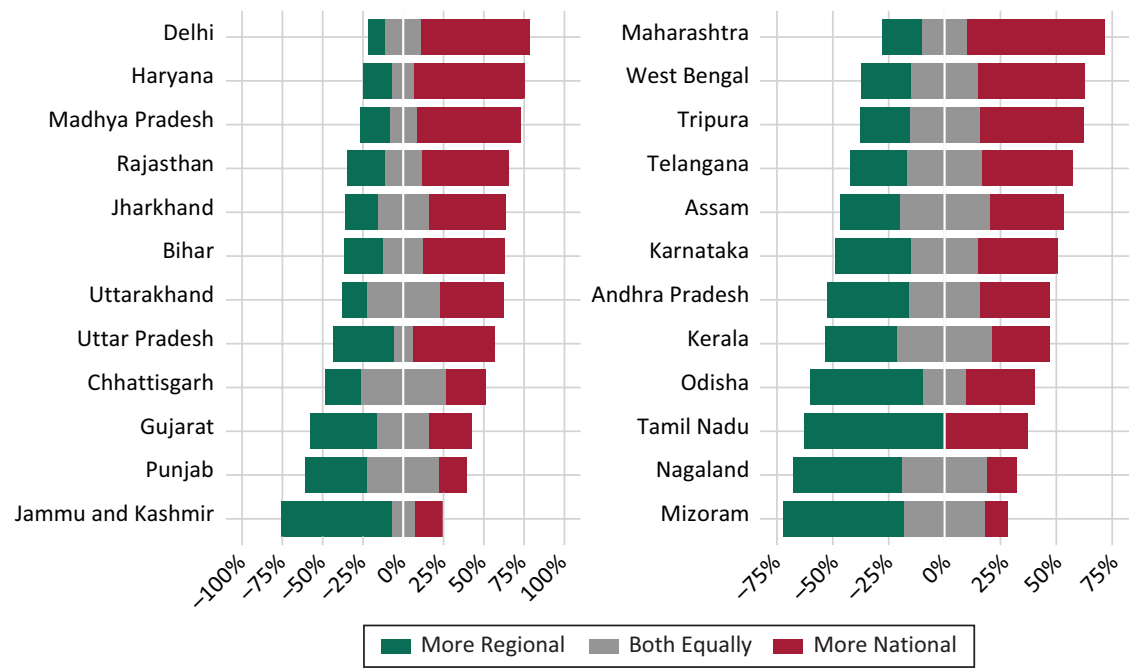

Figure 3.2.1 Regional and National Identity (by State) 


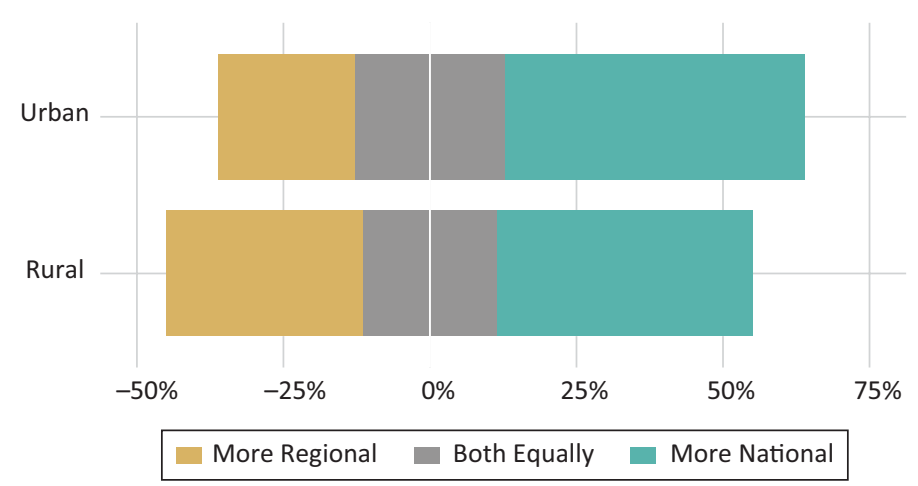

Figure 3.2.2 Regional and National Identity (by Rural-Urban)
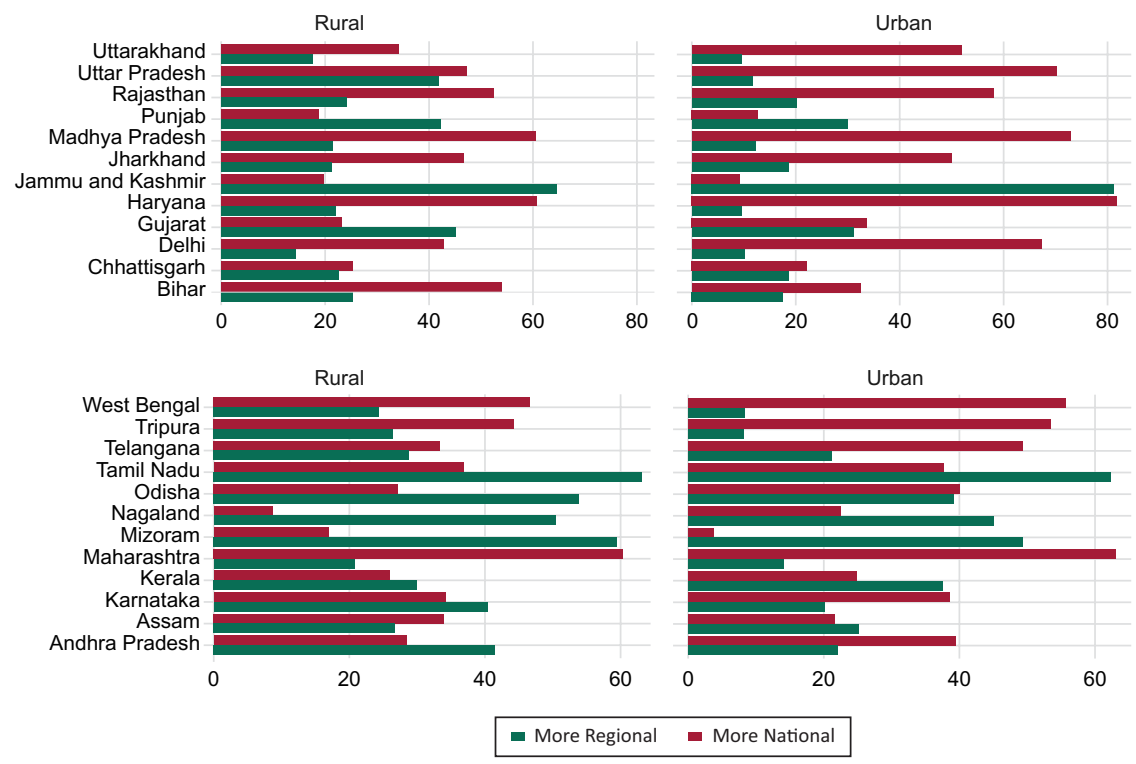

Figure 3.2.3 "More Regional” and "More National” (by State and Rural-Urban)

Across rural and urban locations, we find that more rural respondents claim to feel more regional (34 percent) and more urban respondents feel more national (51 percent) (Figure 3.2.2). The difference between those who say more national across rural and urban respondents is about 7 percentage points. About 23 percent rural and 26 percent urban respondents say they feel equally national and regional.

In most states, rural respondents tend to adopt a regional identity while urban respondents tend to be more national (Figure 3.2.3). There 
are exceptions to this - in Kerala and Jammu and Kashmir more urban respondents say they feel regional while in Tamil Nadu an equal number of urban and rural respondents express a regional identity. In the Hindi belt states (except Bihar, and including Maharashtra, Tripura, and Telangana) 50 percent or more of urban respondents express a "national" identity. In Mizoram, Nagaland, and Tamil Nadu, 50 percent or more rural respondents express a "regional" identity.

When considering the distribution of regional and national identity of religious communities across states, we find that Hindu respondents from the Hindi belt identify themselves as more national (Figure 3.2.4). The proportion of respondents varies from a high of 67 percent in Delhi and Haryana to about 40 percent in Uttarakhand. The rest - Bihar, Madhya Pradesh, Rajasthan, Jharkhand, and Uttar Pradesh - fall between this range. Other states where Hindus identify themselves as more national in identity include Assam, Jammu and Kashmir, Maharashtra, Nagaland, Tripura, West Bengal, and Telangana. Hindus in Andhra Pradesh, Gujarat, Karnataka, Kerala, Mizoram, Odisha, Punjab, and Tamil Nadu feel a stronger regional identity than a national one. With the exception of Jammu and Kashmir, Gujarat, and Punjab, a greater proportion of Muslim respondents also express a national identity. We also find that a majority of Christian respondents in Kerala, Mizoram, Nagaland, and Tamil Nadu adopt a more regional identity, while Christians in other states tend to adopt a more national identity.

Education level has an impact on people's responses of regional or national identity (Figure 3.2.5). As levels of education increase the proportion of respondents expressing a regional identity decreases. While 37 percent of non-literate respondents feel more regional, about 27 percent of college-educated respondents say they feel the same. Similarly, 41 percent of non-literate respondents say they feel more national and this increases to 50 percent among those with a college and above level of education. The number of respondents who feel equally national and regional in identity ranges from about 25 percent to 21 percent across education levels.

As levels of media exposure increase the proportion of respondents who express a regional identity decreases (Figure 3.2.6). This pattern holds in most states. In Uttar Pradesh and Jammu and Kashmir the proportion of respondents expressing a regional identity increases. In Bihar and Uttarakhand, the proportion of respondents who express a national identity decreases across increasing levels of media exposure. In Assam, Uttar Pradesh, Karnataka, Jammu and Kashmir, Nagaland, Punjab, and Delhi there is little difference across levels of media exposure in the proportion of respondents who feel more national. 

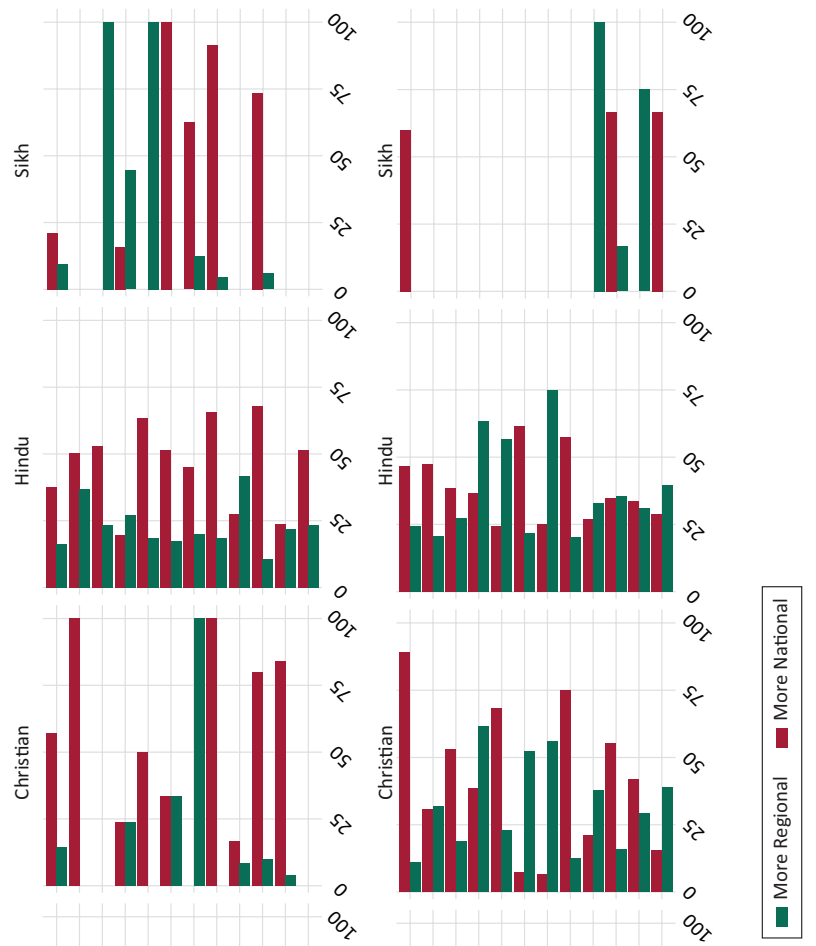

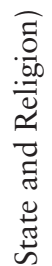
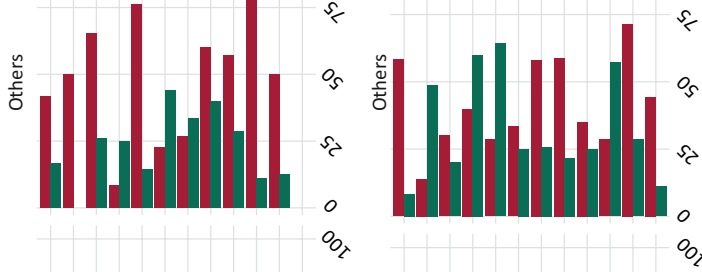

完

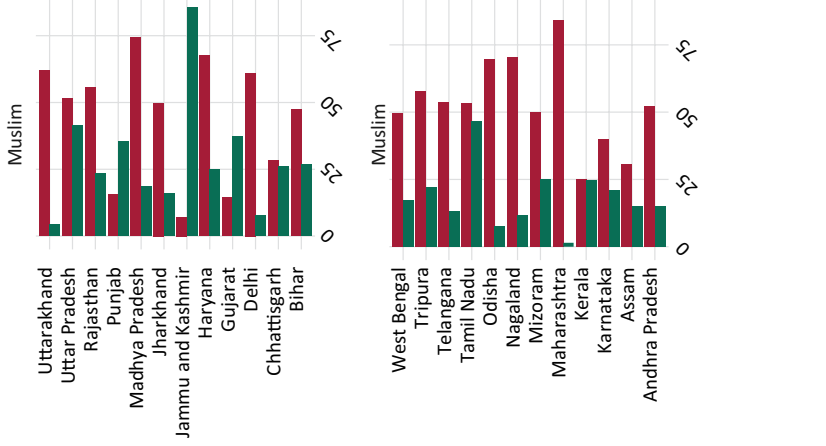

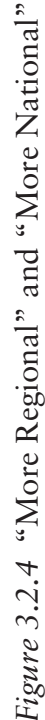




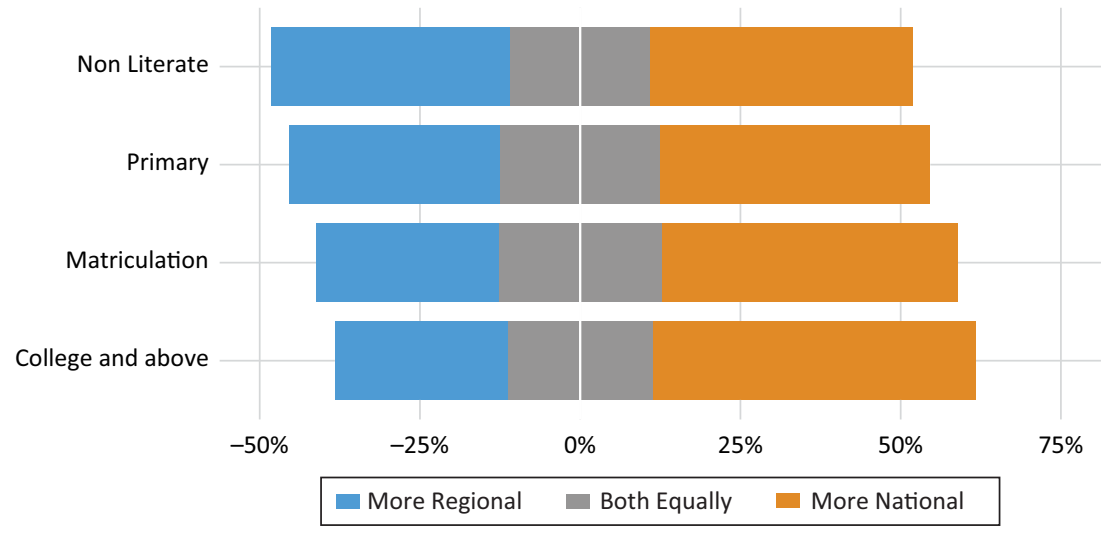

Figure 3.2.5 Regional and National Identity (by Education)

\subsubsection{Language Preference}

We explore whether citizens hold a preference in the languages that are used in public spaces. Respondents are posed the question: "Some people feel it is acceptable to speak in any language in public places while others feel that people should speak only in the local language in public places. What is your opinion on this issue?" The responses are (a) "Any Language", (b) "Local Language".

Fifty percent or more respondents in all the Hindi belt states, as well as Assam, Maharashtra, Mizoram, Punjab, and West Bengal, favour the local language over any language to be used in public places (Figure 3.2.7). There is strong support for any language in Andhra Pradesh, Tamil Nadu, Delhi, and Telangana.

Across most states, a larger share of urban respondents do not have a preferred language and support the use of any language (Figure 3.2.8). In Kerala, Nagaland, Tripura, Delhi, and Assam a greater proportion of rural respondents support the use of any language in public spaces. While the difference in support between urban and rural respondents is just four percentage points in Tripura, the same is as high as 20 percentage points in Kerala.

While the support for the use of any language in public spaces increases with education in most states, in Assam, Uttar Pradesh, West Bengal, Jharkhand, and Uttarakhand higher levels of education leads to a rise in respondents who feel that local language should be used in public spaces (Figure 3.2.9). In Kerala, Tripura, and Delhi there is no large change in the proportion of respondents likely to support the use of any language across the different levels of education. 

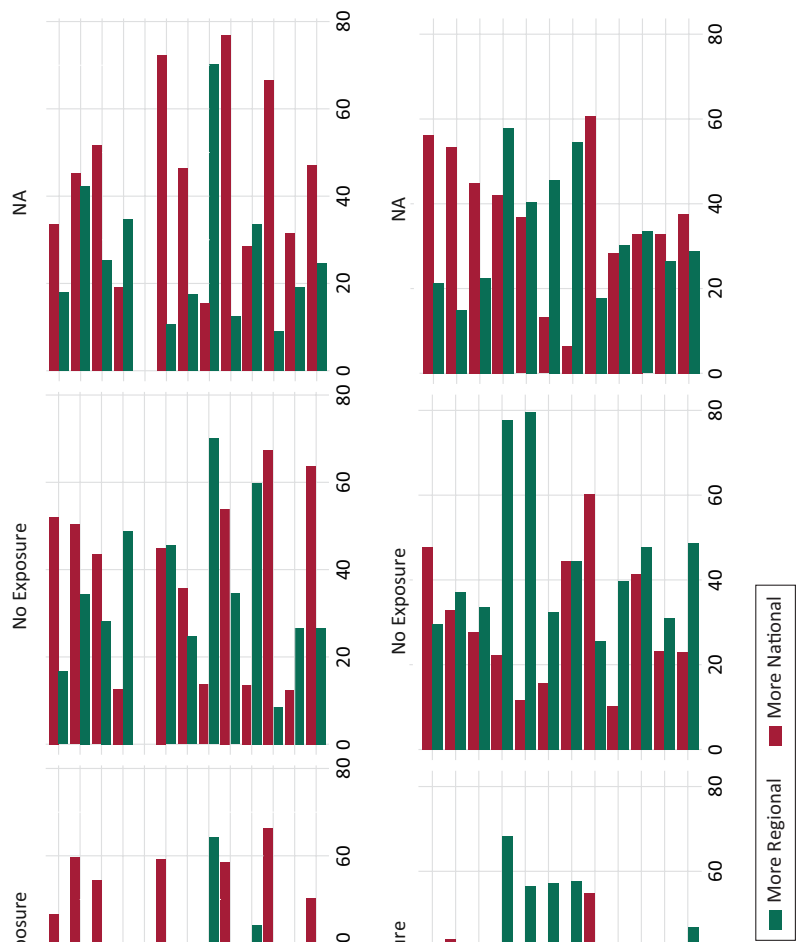

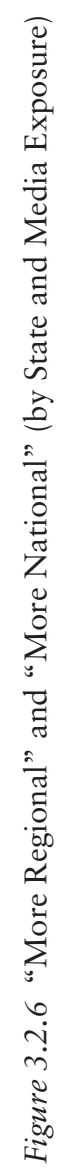
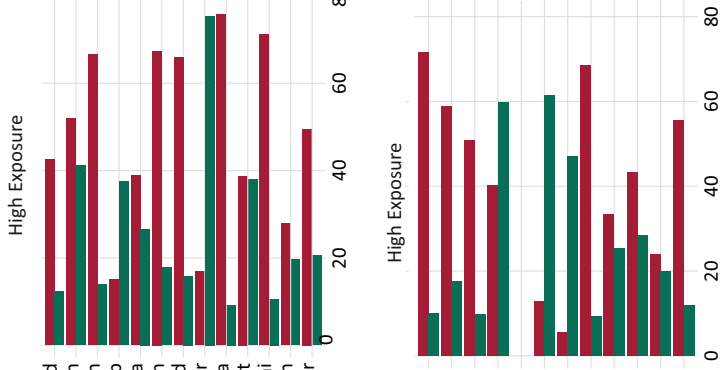

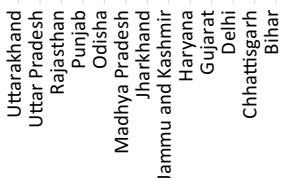

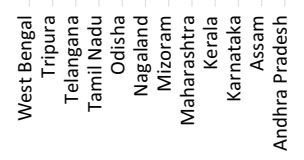


POLITICAL UNIVERSE
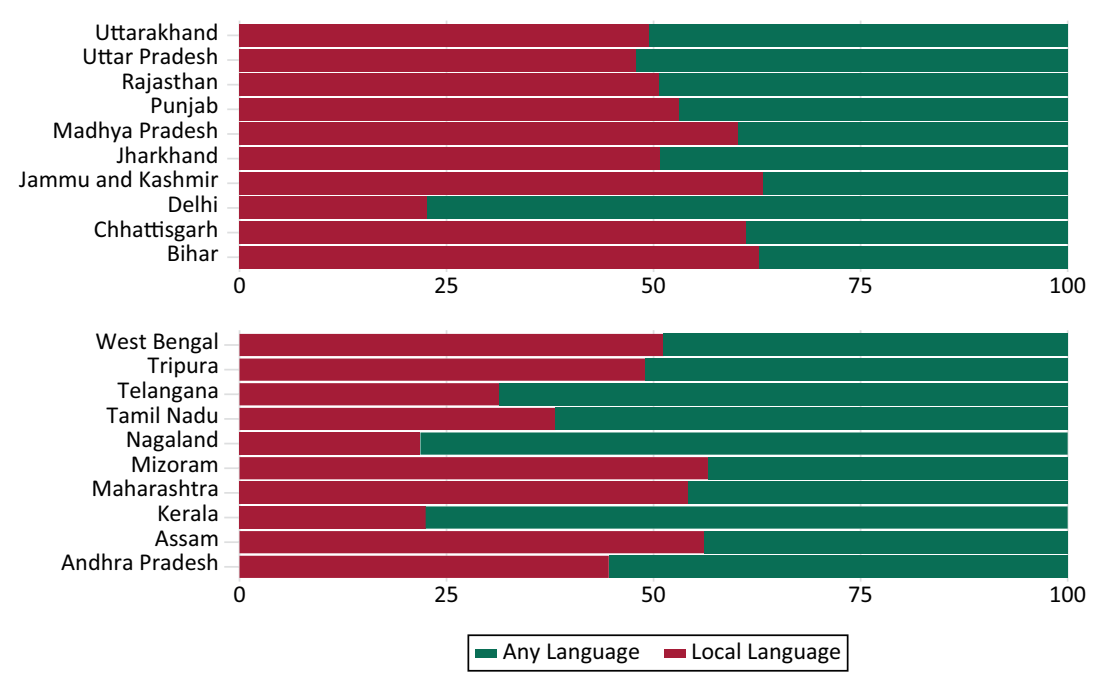

Figure 3.2.7 Preference for Local Language Versus Any Language in Public Spaces (by State)

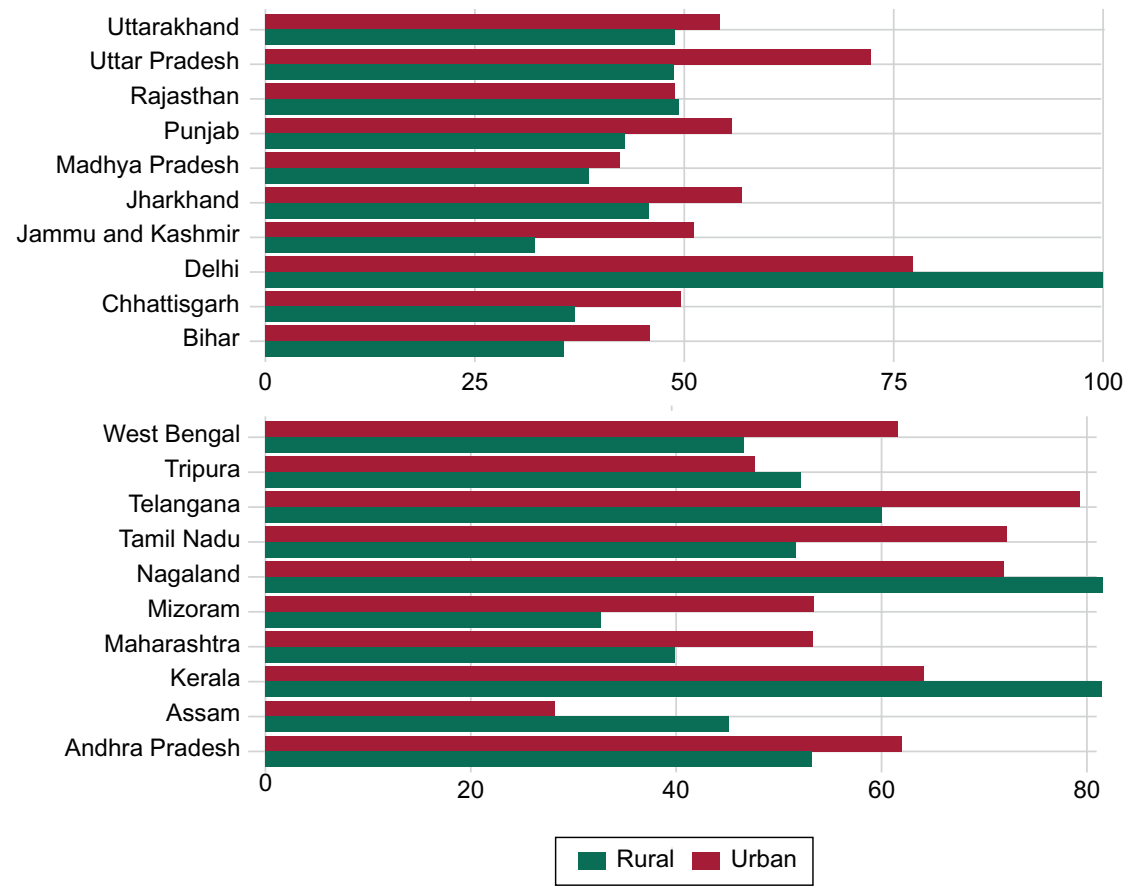

Figure 3.2.8 Preference for Any Language (by State and Rural-Urban) 

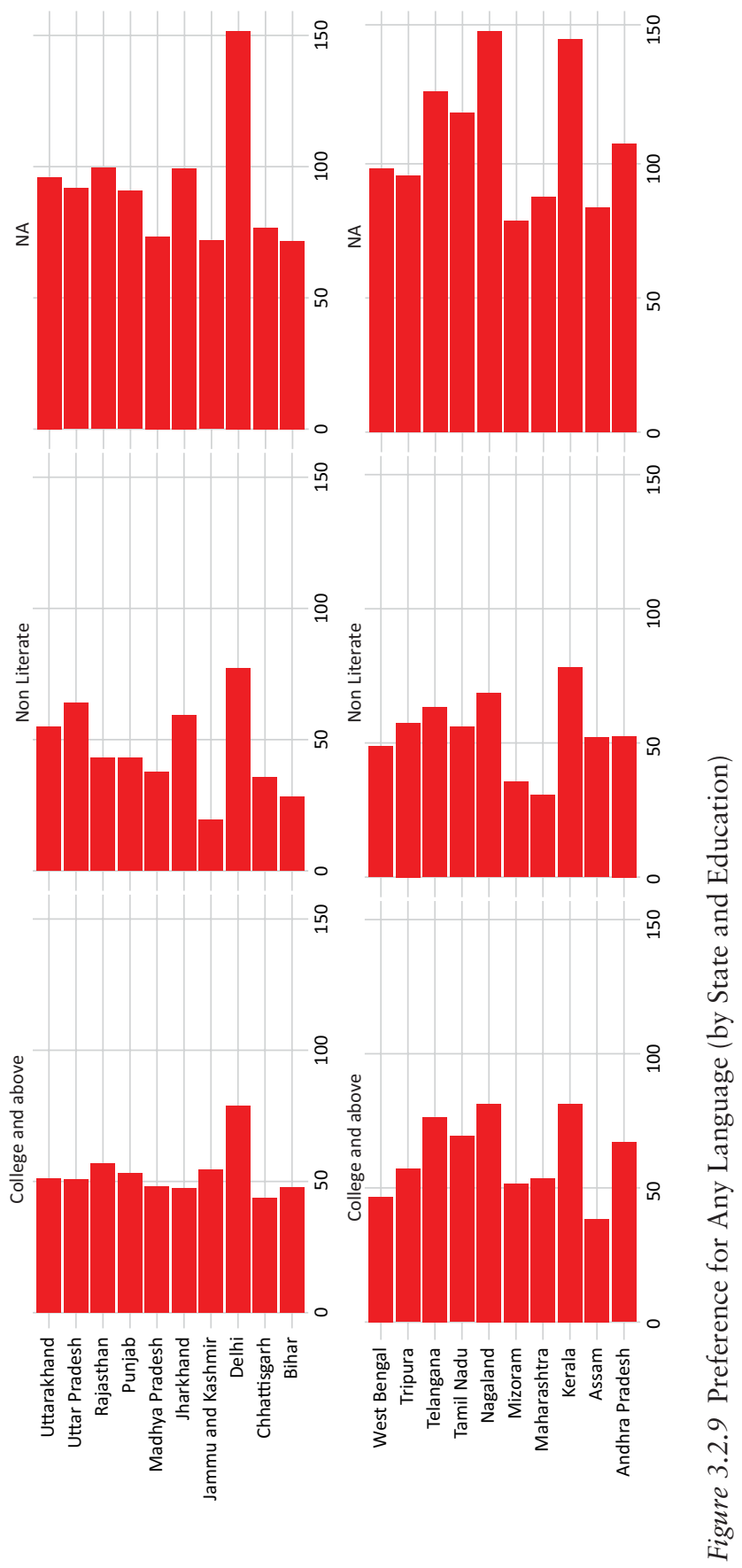


\subsection{NATIONALISM}

Nationalism is a significant element of India's political universe. Over the past decade the constituent ideas of Indian nationalism have been intensely and systematically contested in the public arena. Several events and campaigns in public spaces, universities and in civil society confirm this ongoing contest. Legislative actions that ban the consumption of certain foods (beef, for instance), arrests based on charges of sedition, public attacks on those who do not say "Bharat Mata ki Jai" or stand while the national anthem is played starkly demonstrate the divergent attitudes of what constitutes "national" and "anti-national" behaviour. In some instances, such as the Supreme Court ruling on respecting the national anthem or in interpreting certain political speeches as seditious, State institutions have actively intervened in defining, at least in part, what constitutes nationalism. At other times, lynchings, the physical assault on citizens who do not stand for the national anthem, the vigilante enforcement of cow protection by gaurakshaks, and ghar-wapsi rituals, the impetus for defining the terms of nationalism in public discourse arises from organized social and political groups seeking to enforce their version of nationalism. ${ }^{1}$

Scholars note that majoritarian cultural nationalism has firmly established itself in the past decade as the dominant narrative of Indian nationalism (Varshney 2014, Palshikar 2015, Jaffrelot 2017). To what extent has this majoritarian nationalism spread across India's social and political landscape? Does this majoritarian nationalism vary across subnational entities? Is it shared by all castes and community groups? Are majoritarian nationalist attitudes polarized or do they appear evenly spread? These are questions of fundamental importance for a constitutional democracy, especially one in a developing country that binds diverse social, religious, and linguistic communities.

In this section we examine responses to a set of four questions that measure the strength of support for State sanctions against what has been recently construed as "anti-national". They are:

Government should punish those who (a) do not stand while the national anthem is being sung, (b) do not say "Bharat Mata ki Jai" at public functions, (c) eat beef or cow meat, and (d) engage in religious conversions. The responses to this set of questions range from "fully agree" to "fully disagree".

The four questions are meant to identify how people think about nationalism and its majoritarian form. Standing during the national anthem is a standard protocol associated with the national anthem and we consider this as a form of civic nationalism. It does not have a cultural or ethnic 
ascription or value attached to it that would make the act of standing a violation of a cultural norm and hence controversial. Adding a cultural twist to standard national icons (as in "Bharat Mata ki Jai") or matters related to faith (religious conversions, for instance) and diet (beef consumption) produces majoritarian versions of nationalism (referred variously as "ethnic" or "religious" or "cultural" nationalism). Public opinion that tends toward protecting cultural or ethnic homogeneity and advocates State punishment for violation of its sanctity (or that of the State) is seen as majoritarian while pluralist opinions would instead find alternate ways to accommodate cultural diversity. We examine these questions using responses to questions that have animated politics and society recently such as not calling out "Bharat Mata ki Jai", or the consumption of beef (and the need to respect the cow) and religious conversions (ghar wapsi).

We also find that public opinion is particularly animated when questions of nationalism take on a cultural tone. For instance, while we find relative agreement on the question of standing during the national anthem (that is, most respondents agree that the national anthem should be respected), the responses to whether the State should punish someone for not saying "Bharat Mata ki Jai" is more polarized. Similarly, the question on beef consumption also elicits a greater polarization than do religious conversions. Spatially, we also find that the Hindi belt states cohere around similar positions on most questions tending to majoritarianism. States such as Maharashtra, Gujarat, Odisha, and Karnataka tend to also fall into this group. States with larger or significant minority populations such as Jammu and Kashmir, Mizoram, Nagaland, Kerala, West Bengal, and Tripura tend to adopt more pluralist positions. Castes and communities are clearly divided on the question of nationalism. While minority religious communities strongly disagree with State punishment, Hindus, across all castes, tend to strongly support State punishment. With the exception of the opinion on beef consumption, Hindu Dalits also tend to support a majoritarian position while Hindu Adivasis exhibit the least tendency toward a majoritarian nationalism.

\subsubsection{The National Anthem}

The national anthem, among other things, is a symbol of national unity and of India's geography (as a distinct territory with borders). In fact, the national anthem literally identifies a geography with the rivers and terrain associated with India generating a national spatial imagination that is also political. The Fundamental Duties under Article 51A of India Constitution states, "It shall be the duty of every citizen of India to abide by the Constitution and respect its ideals and institutions, the national Flag and the National Anthem". 
While legislation (The Prevention of Insult to National Honour Act, 1971) specifies protocols for singing the national anthem (Section 3) and states that

whoever intentionally prevents the singing of the Indian National Anthem or causes disturbances to any assembly engaged in such singing shall be punished with imprisonment for a term, which may extend to three years, or with fine, or with both

it does not clearly specify any punishment for not standing when the National Anthem is sung. For instance, in 2015 an order related to the National Anthem of India passed by Ministry of Home Affairs requires an audience shall stand to attention whenever the National Anthem is sung or played. In 2016, the Supreme Court (in Shyam Narayan Chouksey versus the Union of India) directed all cinema halls across India to play the National Anthem before every feature film. In 2017, the Supreme Court asked the Government of India to consider amending the rules for playing the national anthem in movie theatres, and in 2018 the Supreme Court changed the previous order and stated that playing the National Anthem prior to the screening of feature films in cinema halls is not mandatory, but optional or directory. Despite multiple legal opinions and government orders, none have prescribed punishment for not standing when the National Anthem is sung or played. Here, we are interested in citizens' opinion on whether someone who does not stand during the national anthem should be punished.

In most states, we find that a majority of respondents either fully or somewhat agree (Figure 3.3.1). The Hindi belt states demonstrate a high degree of support for punishing those who do not stand during the national anthem - 60 percent in Haryana, one in two respondents in Delhi and Uttar Pradesh, and forty percent or more in Chhattisgarh, Uttarakhand, Rajasthan, Madhya Pradesh, and Bihar. Karnataka, Maharashtra, and Odisha also indicate a high degree of support, about 60 percent of respondents fully agree. Least support, i.e., relatively lower proportions of fully agree are found in Andhra Pradesh and West Bengal, in addition to the states in the north-east. The largest proportion of respondents who fully disagree with State punishment for not standing during the national anthem comes from Jammu and Kashmir (about 50 percent) followed by Nagaland (30 percent).

Caste-community wise analysis indicates that among all castes within Hindus, a larger proportion of respondents fully agree than strongly disagree on the statement that the government should punish those who don't stand when the national anthem is played or sung (Figure 3.3.2). The difference ranges from 25 point (for Hindu Adivasis) to 35 points (for Hindu upper castes). Within Muslim communities, about equal proportions of Muslim Dalit and OBC respondents adopt fully agree and disagree position (about 26 percent). Christian communities tend to fully agree over disagree, but about 30 percent also somewhat agree. A larger proportion of Sikh respondents also fully agree. 


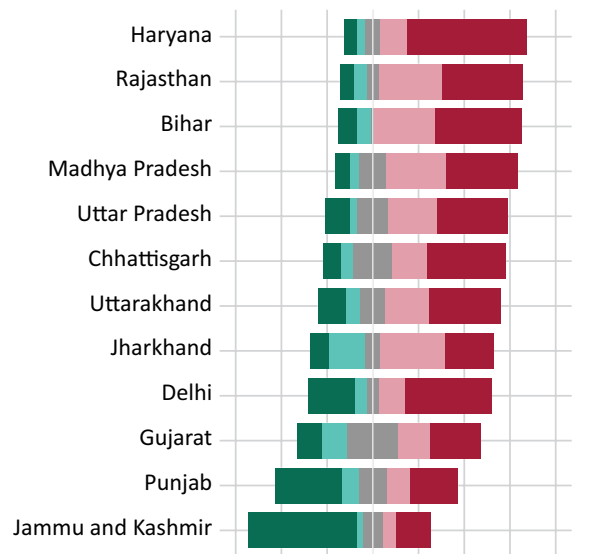

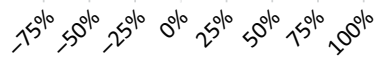

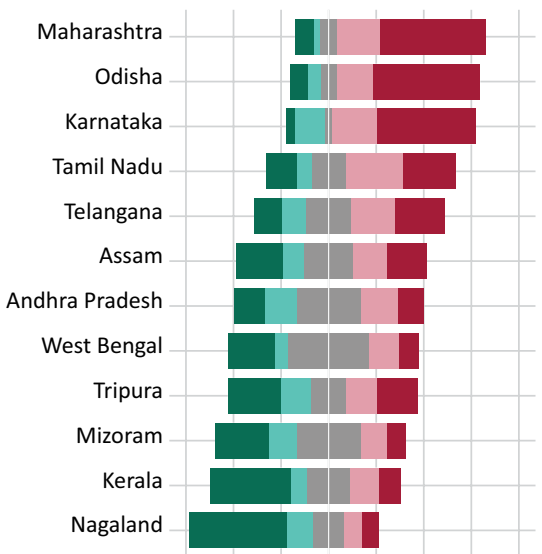

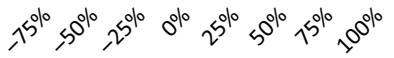

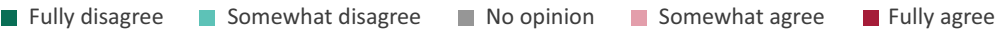

Figure 3.3.1 Opinion on Punishment to Those Who Don't Stand for National Anthem at Public Places (by State)

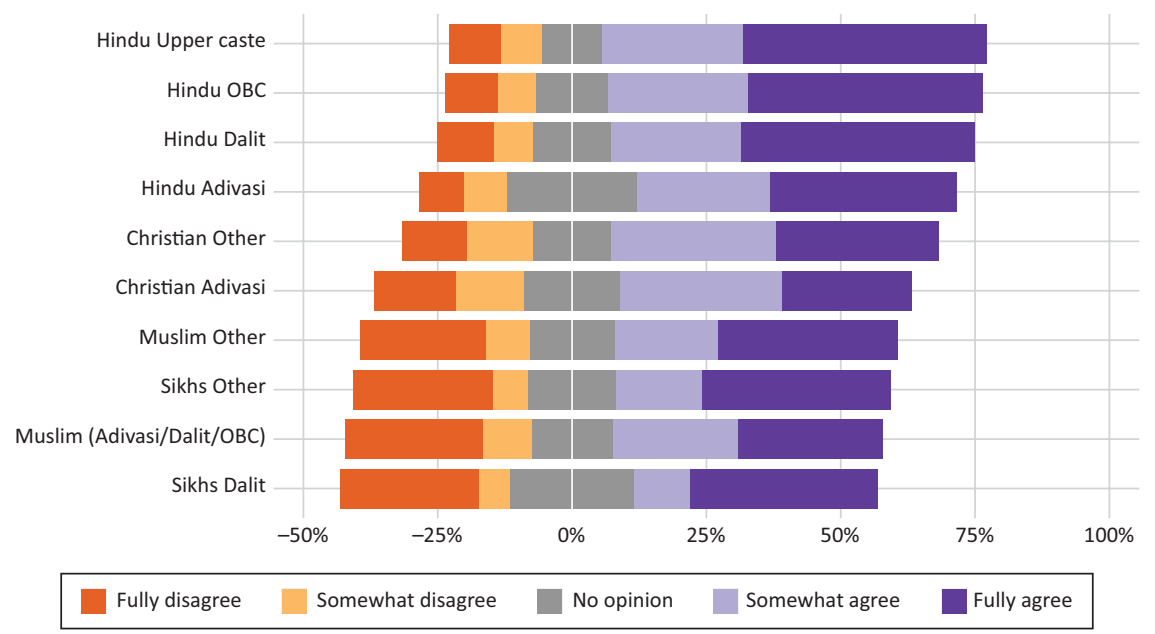

Figure 3.3.2 Opinion on Punishment to Those Who Don't Stand for National Anthem at Public Places (by Caste/Community) 


\subsection{2 "Bharat Mata ki Jai"}

Linked to nationalism is calling out or chanting "Bharat Mata ki Jai" during public gatherings and events. Once a clarion call to unite all Indians during the national movement for Indian independence it has morphed into a badge of Hindu nationalism. The image of "Bharat Mata" or "Mother India" of a woman draped in sari, wearing a crown, holding the national flag, and sometimes flanked by a lion is strikingly Hindu. This representation of India's geography and demands for the obligatory chanting of "Bharat Mata ki Jai" at public functions has generated resistance from nonHindu social groups. In the following section we examine the distribution of responses to whether the State should punish those who do not say "Bharat Mata ki Jai" at public functions across states and caste and religious identity. This question adds a cultural twist to nationalism by linking a religious image to the territorial identity of India.

In Assam, Jammu and Kashmir, Nagaland, Mizoram, Punjab, Kerala, and West Bengal, respondents are less likely to support State punishment for those who do not say "Bharat Mata ki Jai" at public functions (Figure 3.3.3). We find extensive support for punishing those who do not say "Bharat Mata ki Jai" at public functions across the Hindi belt states such as Bihar, Uttar Pradesh, Uttarakhand, Madhya Pradesh, Chhattisgarh, Rajasthan, Haryana, and Delhi, as well as in Karnataka, Maharashtra, and Odisha. In these states, 40 percent or more support the view that the State
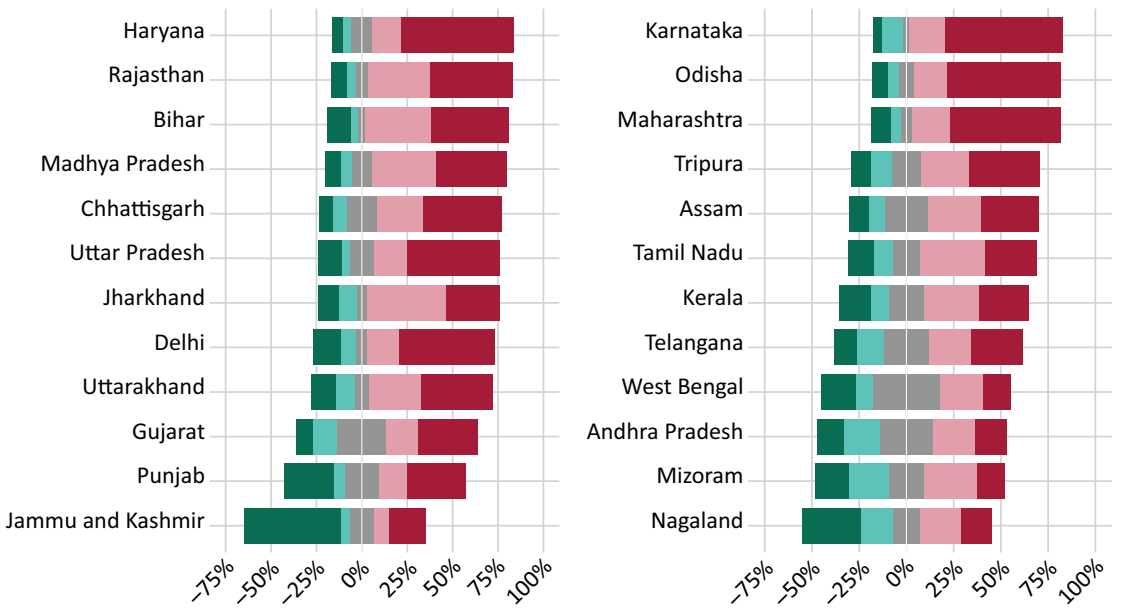

Fully disagree - Somewhat disagree

No opinion

Somewhat agree

Fully agree

Figure 3.3.3 Opinion on Punishment to Those Who Do Not Say "Bharat Mata ki Jai" at Public Functions (by State) 


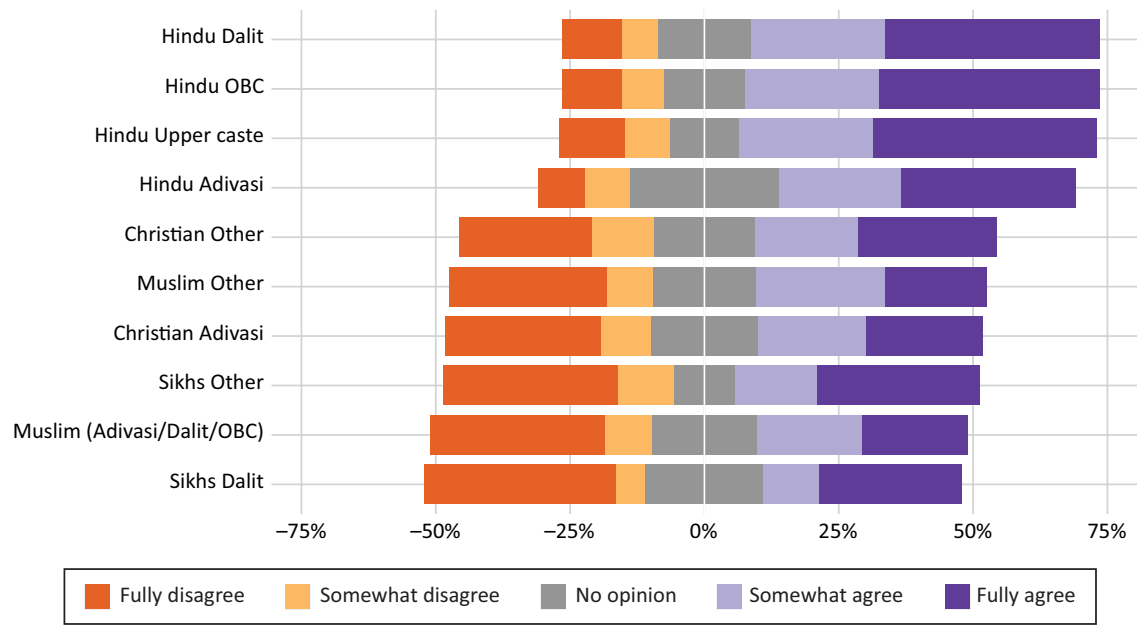

Figure 3.3.4 Opinion on Punishment for Those Who Do Not Say "Bharat Mata ki Jai" at Public Functions (by Caste/Community)

should punish those who do not say "Bharat Mata ki Jai" at public functions. In Gujarat and Tamil Nadu a little less than 30 percent fully agree. We also find greater support in Telangana compared to Andhra Pradesh, and in Bihar compared to Jharkhand. A large number of respondents, about 43 percent in West Bengal, a third of respondents in Andhra Pradesh and Mizoram, and about a quarter of respondents in Assam, Gujarat, Kerala, Mizoram, Chhattisgarh, and Telangana do not have an opinion.

Among Hindu caste groups, between 32 and 42 percent of respondents fully agree with State punishment for not chanting "Bharat Mata ki Jai" at public functions (Figure 3.3.4). Between 25 and 35 percent respondents from all minority caste communities fully disagree with this. However, for the same minority caste communities, between 19 and 30 percent also fully disagree. While Hindu caste groups tend to fully agree with the statement, and about ten percent fully disagree, the proportion of respondents fully agreeing within minority communities ranges from about 20 percent to 30 percent.

\subsubsection{Beef Consumption}

In the past years, there have been several incidents where some from minority communities have been attacked and in some instances lynched. ${ }^{2}$ There is no uniform law about eating beef across Indian states, but various Indian states have different laws regarding cow slaughter and eating cow meat 
including a complete ban on cow slaughter and cow meat consumption such as in Uttar Pradesh and Uttarakhand. Andhra Pradesh, Telangana, Assam, Bihar, Odisha and Tamil Nadu cow slaughter is regulated. And in Nagaland, West Bengal, Meghalaya, Mizoram, Tripura, Sikkim, and Kerala there is no law on beef consumption.

Across the states, we find that in Bihar, Haryana, Karnataka, Maharashtra, Odisha, Punjab, Rajasthan, Delhi, Chattisgarh, and Uttarakhand 50 percent or more respondents fully agree that the state should punish persons for beef consumption (Figure 3.3.5). In Haryana, 80 percent fully agree. Close to half the respondents fully agree in Uttar Pradesh, Madhya Pradesh - 46 and 48 percent respectively. In all of these states, the proportion of agreement far exceeds that of disagreement. In Mizoram and Nagaland about three percent fully agree while about seven percent do so in Kerala, 13 percent in Tripura, 15 percent in Assam, 16 percent in Tamil Nadu, and 18 percent in West Bengal. In all of these states, a quarter or more fully disagree. The proportion of those who disagree is greater than the proportion of those who agree. In the rest of the states, the proportion of respondents who fully agree ranges between 20 percent (Andhra Pradesh) and 37 percent (Gujarat). In Andhra Pradesh and Telangana the proportions of respondents who agree about equals the portion who disagree, while in Jharkhand and Gujarat, the proportion of agreement is greater than that of disagreement.

Close to 45 percent or more Muslims fully disagree with the idea of punishment for beef consumption (Figure 3.3.6). Christian respondents also
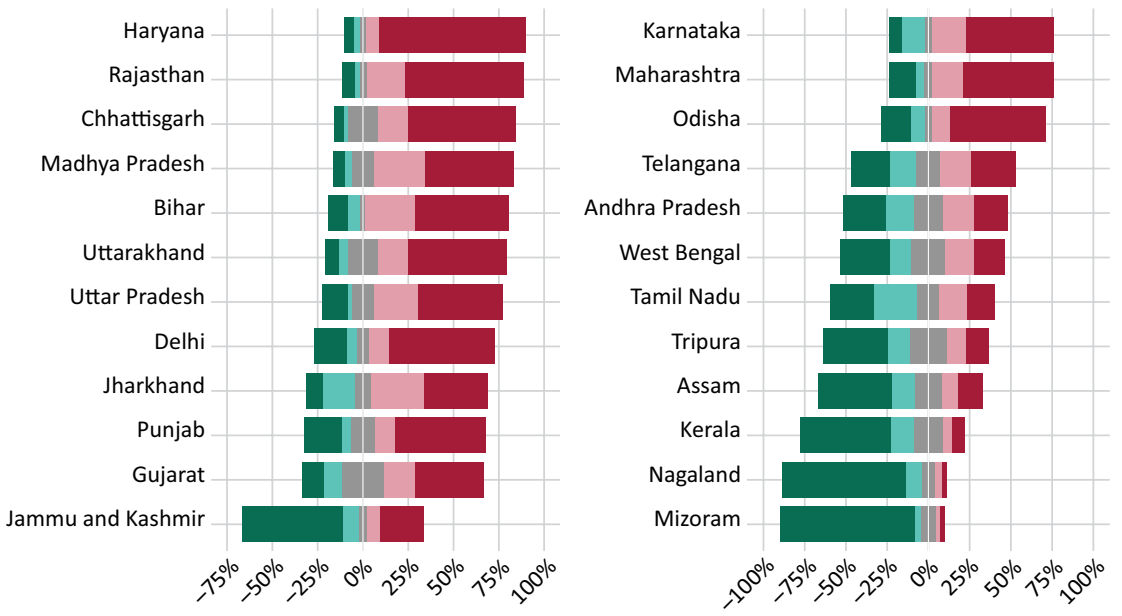

Fully disagree Somewhat disagree

No opinion

Somewhat agree

Fully agree

Figure 3.3.5 Opinion on Punishment to Those who Eat Beef/Cow Meat (by State) 


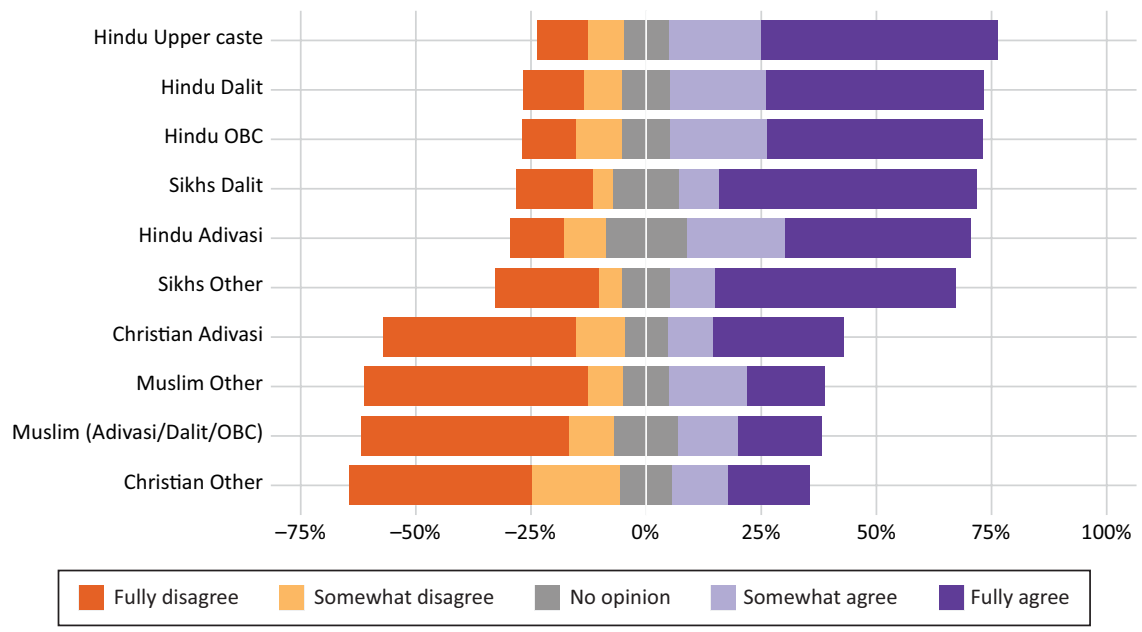

Figure 3.3.6 Opinion on Punishment to Those Who Eat Beef/Cow Meat (by Caste/ Community)

fully disagree (about 40 percent). Among Hindu respondents, a majority of upper castes respondents fully agree. Between 40 and 47 percent of Hindu Dalit, Adivasi, and OBC respondents also agree. Similarly, a majority of Sikh respondents also fully agree. Between ten and 13 percent of Hindu respondents fully disagree. The proportion of full disagreement for Muslim and Christian respondents ranges from between 17 to 28 percent.

\subsubsection{Religious Conversions}

The issue of religious conversion is an oft-debated one in India. In some states mass conversions have occurred to draw attention towards community-based problems. There is no national law to prevent religious conversion and many Hindu organizations demand a strong anti-conversion law. In 1954 a bill called Indian Conversion (Regulation and Registration) Bill was brought into the parliament but could not be passed due to significant opposition. ${ }^{3}$ At present, there are seven Indian states - namely Madhya Pradesh, Chhattisgarh, Odisha, Gujarat, Tamil Nadu, Rajasthan, and Himachal Pradesh - which have anti-conversion laws to stop forced and fraudulent conversion. Out of these seven states, Madhya Pradesh, Chhattisgarh, Odisha, Gujarat and Himachal Pradesh are the states where this act is in force. However, some Hindu organizations like Vishwa Hindu Parishad (VHP) and Rashtriya Swayamsewak Sangh (RSS) widely criticize religious conversions and have also launched a movement that they call 


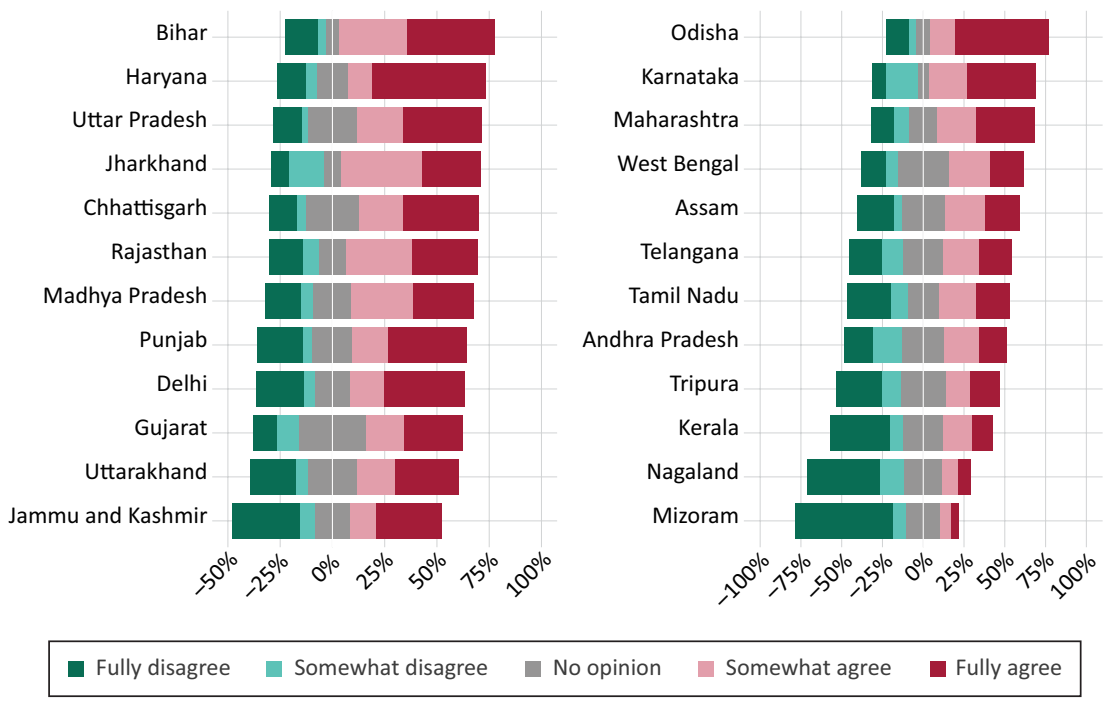

Figure 3.3.7 Opinion on Punishment to Those who Engaged in Religious Conversions (by State)

"Ghar Wapsi" to bring back the converted people into the Hindu religion. We asked our respondents their opinion on whether people engaged in religious conversions should be punished by the government.

We find only two states - Haryana and Odisha - with proportion of respondents fully agreeing greater than 50 percent (Figure 3.3.7). Only Mizoram has more than 50 percent respondents fully disagreeing. In Andhra Pradesh, Telangana, Assam, and Jammu and Kashmir equal proportions both fully agree and fully disagree. In Kerala, Mizoram, Nagaland, and Tamil Nadu the proportion of respondents who fully disagree is greater than those who fully agree. In the Hindi belt states and Karnataka, Maharashtra, Gujarat, we find the opposite - greater support for fully agree over strongly disagree. Yet, we find that responses to this question are less polarized compared to the previous ones. Though a greater proportion tend to agree than disagree, the distribution of responses within the agree category is apportioned relatively evenly.

About a third of respondents across all Hindu caste groups fully agree. Among Sikh respondents 42 percent strongly agree (Figure 3.3.8). A somewhat larger proportion of Muslim respondents (30 percent) tend to fully agree (the difference between those who fully agree and fully disagree is about 6 percentage points). About 30 percent of Christian respondents fully disagree and about 18 percent fully agree. We also find that about a third of Muslim respondents identifying as Dalit or OBC fully support this position 


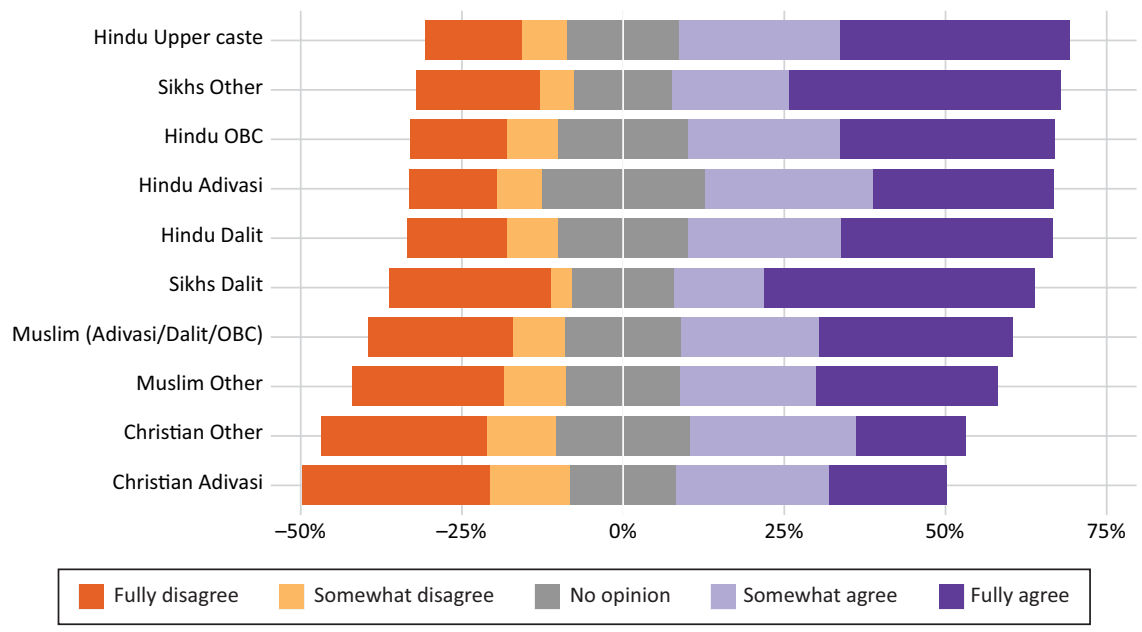

Figure 3.3.8 Opinion on Punishment to Those who engaged in Religious Conversion (by Caste/Community)

while almost a quarter fully disagree. Christian Adivasis and other Christians are the least likely to fully agree among all caste-community groups.

\subsubsection{Index of Nationalism}

These questions capture significant elements of nationalism. For instance, the idea of respecting the national flag is a reflection of civic or territorial nationalism, while adding a cultural inflection to India's geography with Bharat mata representing religious nationalism. Similarly, the sacred position occupied by the gan in Hinduism provides beef consumption with a religious flavour and points to a religious nationalism. In order to get an aggregate view of public opinion on nationalism we create an "index" of nationalism using the above four questions. Respondents are then grouped into one of three categories: liberal-nationalist, centrist, and conservativenationalist. Those who disagree with any three statements are classified as liberal nationalist and those who agree with any three are classified as conservative nationalist. The rest are categorized as "centrist". We understand that these terms have multiple and contested meanings, and we use them only as broad indicators to see the extent of a majoritarian nationalist sentiment in India.

We find that states fall distinctively into one of these three categories (Figure 3.3.9). First, there are the centrist states where close to or more than half the respondents locate themselves in the middle and the rest fall 
100

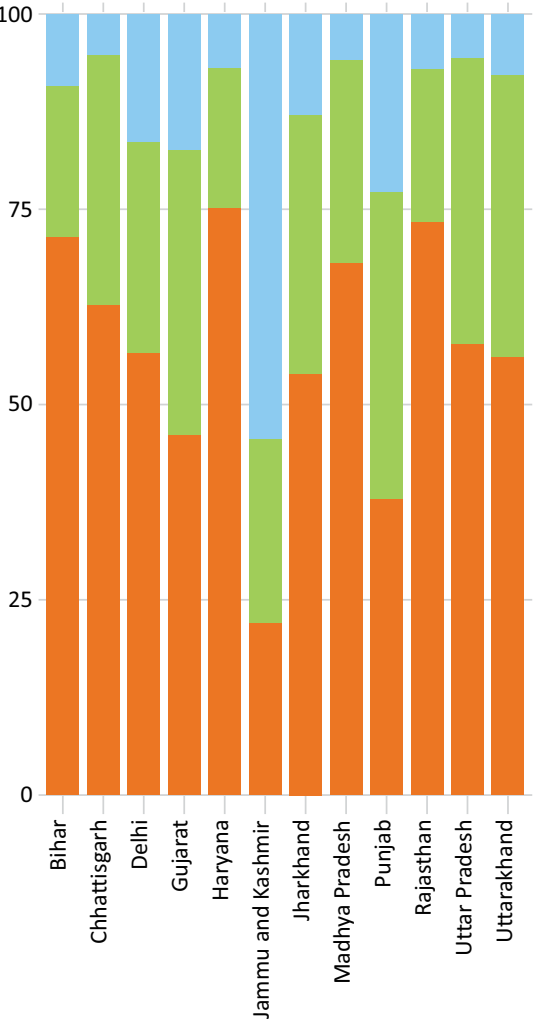

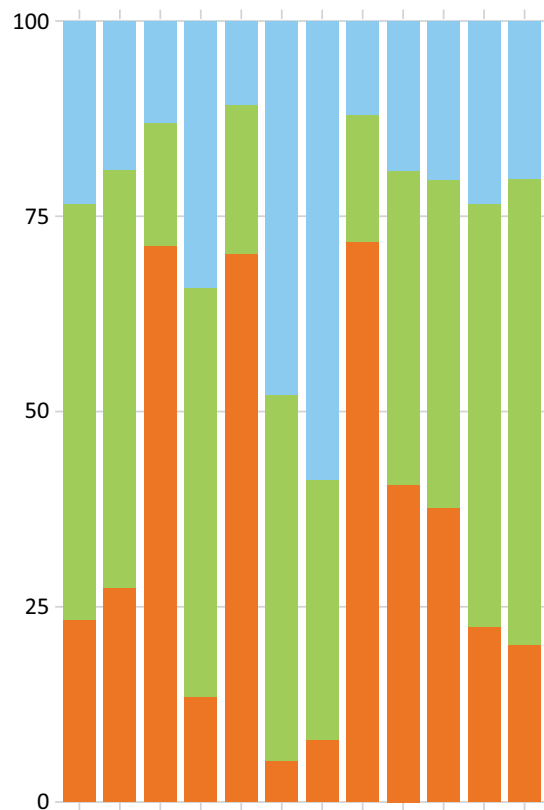

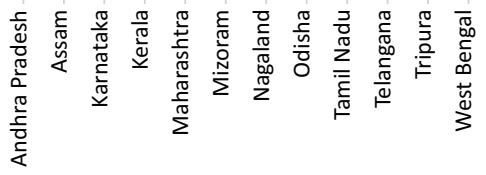

Liberal Nationalist

Centrist Nationalist

Conservative Nationalist

Figure 3.3.9 Index of Nationalism (by State)

on either side. These include Andhra Pradesh, Telangana, Assam, Kerala, Tripura, and West Bengal, and 50 percent or more respondents in these states adopt centrist positions on the questions of nationalism. Jammu and Kashmir and Nagaland have more than 50 percent respondents who take a liberal nationalist position. Bihar, Haryana, Maharashtra, Madhya Pradesh, Odisha, Rajasthan, Uttar Pradesh, Jharkhand, Chhattisgarh, and Uttarakhand have more than 50 percent of respondents who adopt positions that call for punishment. In fact, in some states (Haryana, Madhya Pradesh, Maharashtra, Karnataka, and Rajasthan) 70 percent or more support punishment. In Tamil Nadu while 40 percent of respondents adopt centrist position an equal proportion also hold conservative views. 


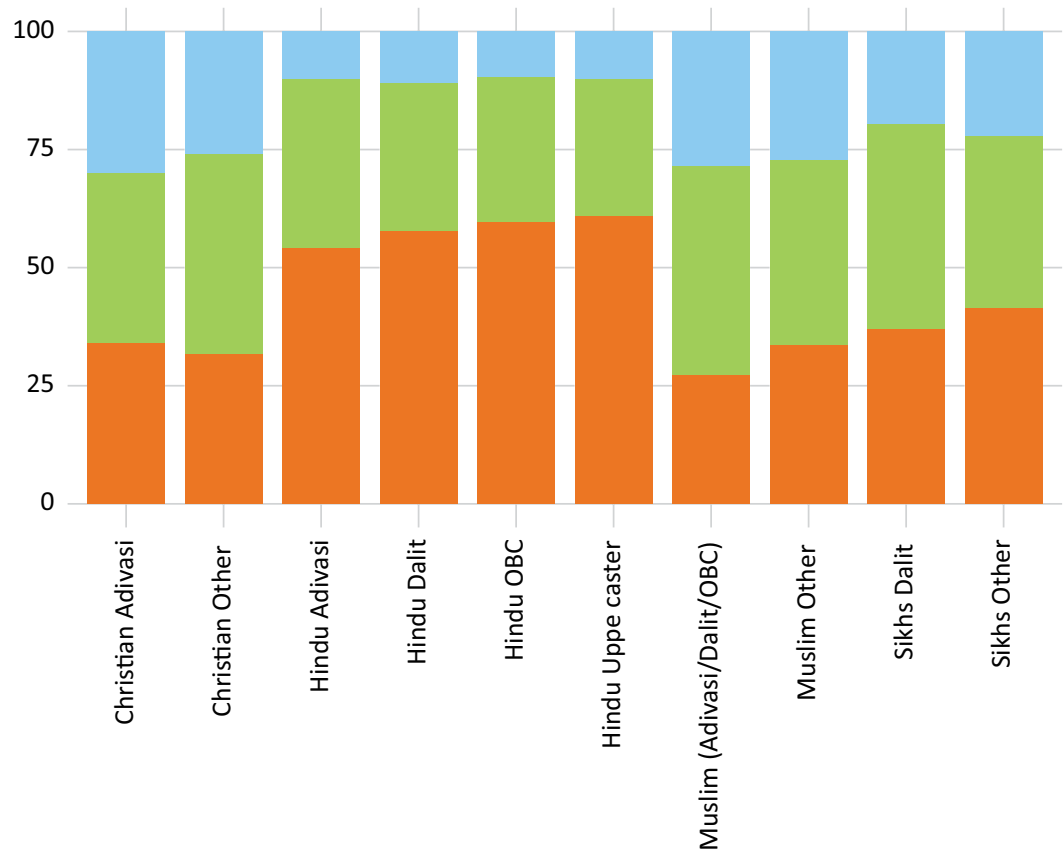

Liberal Nationalist

Centrist Nationalist

Conservative Nationalist

Figure 3.3.10 Index of Nationalism (by Caste/Community)

In Mizoram equal proportions (about 48 percent) adopt liberal and central positions.

Across caste/communities, we find a large proportion of all Hindu caste groups (upper caste, Dalit, Adivasi, and OBC) and including non-Dalit Sikhs, fall in the conservative nationalist category (Figure 3.3.10). This ranges from 54 percent among Hindu Dalit respondents to 61 percent among the Hindu upper caste. Ten percent or less among Hindu caste groups hold a position of no punishment. Several minority caste-community respondents, Muslims, Christians, and Sikhs have more respondents who fall into a centrist position. However, more or less equal proportions fall into the liberal and conservative categories among these groups.

A majority of both urban and rural respondents fall into the conservative nationalist category (Figure 3.3.11). Urban respondents are more likely to be liberal nationalists, relative to rural respondents, with a difference of about nine percentage points. Thirty percent of both rural and urban respondents are in the centrist position. 


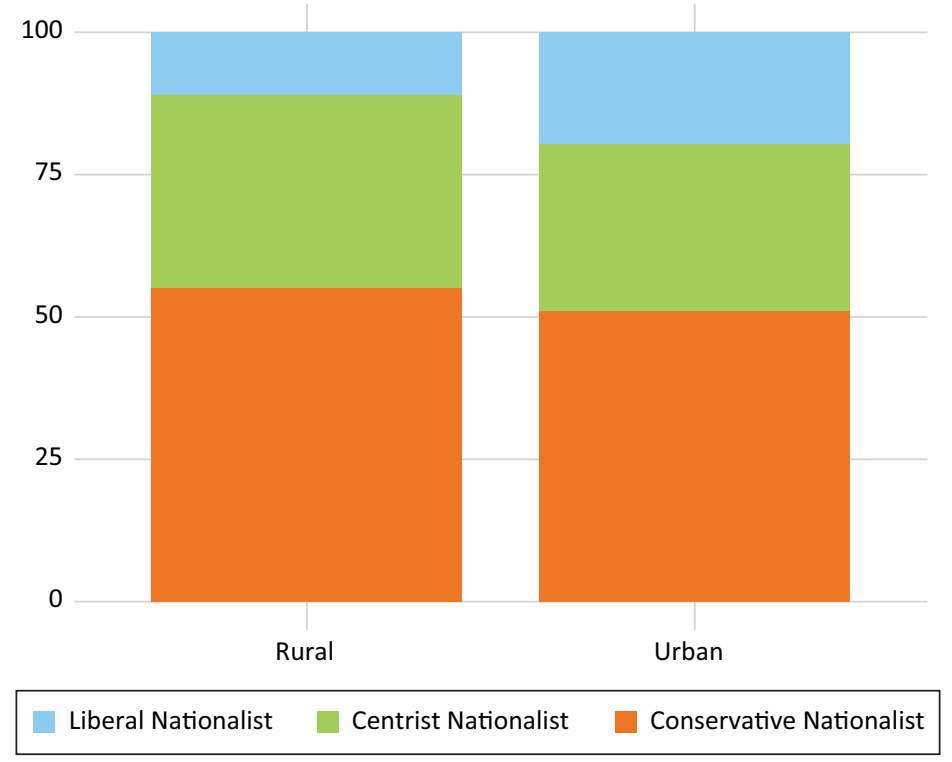

Figure 3.3.11 Index of Nationalism (by Rural-Urban)

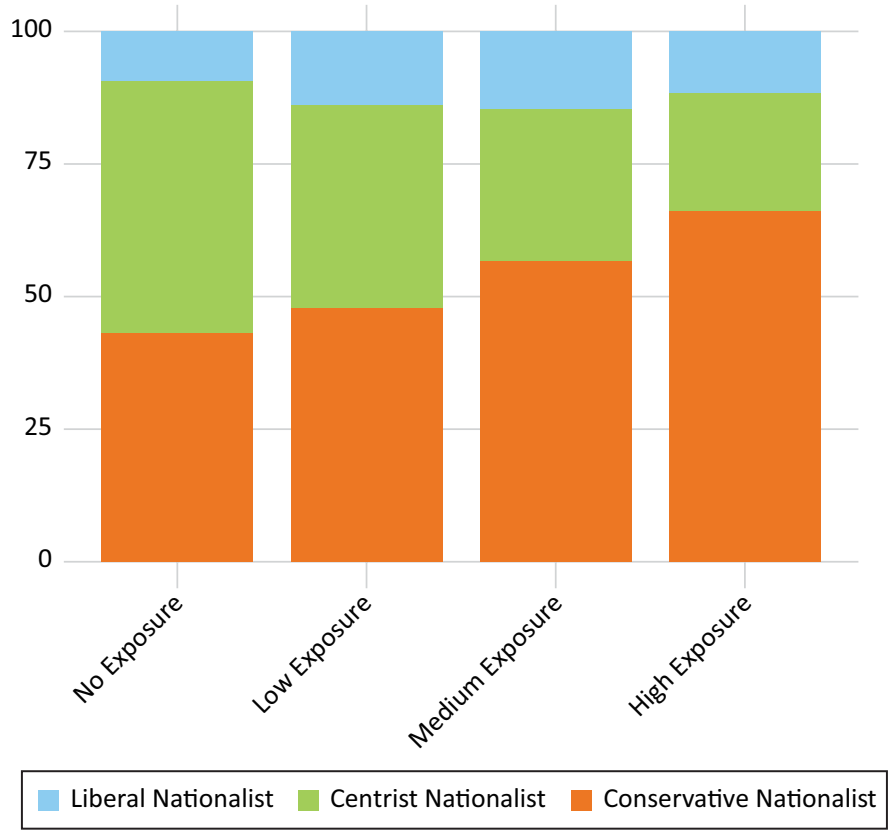

Figure 3.3.12 Index of Nationalism (by Media Exposure) 


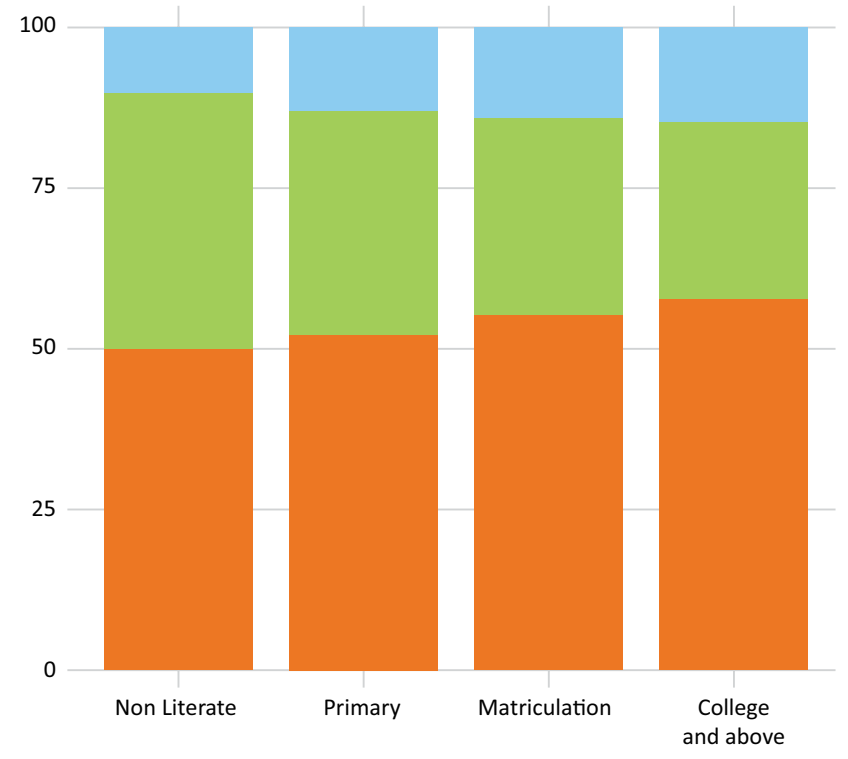

Liberal Nationalist Centrist Nationalist Conservative Nationalist

Figure 3.3.13 Index of Nationalism (by Education)

Increased levels of media exposure increases the likelihood of a respondent taking a conservative nationalist position (Figure 3.3.12). Forty three percent of respondents with no media exposure fall in the conservative category. This increases to 66 percent for respondents with high media exposure. Across these levels of media exposure, the proportion of respondents who fall in the centrist category decreases by approximately 25 percentage points. There is a two percentage point increase in the proportion of liberal nationalist respondents across media exposure levels.

Fifty eight percent of respondents with a college or higher level of education adopt a conservative nationalist position, and about 27 percent hold a centrist position (Figure 3.3.13). As levels of education increases the likelihood of holding conservative views also increases. The likelihood of being centrist declines by 12 percentage points. There is a five percent increase in the likelihood of being categorized as a liberal nationalist as the level of education increases. 


\subsection{POPULISM}

Has India turned populist? Personality-based politics and majoritarian nationalism have always been a part of the fabric of India's democracy, but the recent success of populists around the world, compels scholars to sharpen our understanding of these themes, and of populism, in India. We need to understand the nature, spread, and depth of populism in India better, as that has implications for democratic disenchantment - a consequence of politics between elections.

In this section, we summarize results from questions pertaining to three attributes of populism. We hope to understand what motivates the spread and depth of populist sentiments among respondents by exploring their individual attributes in terms of background characteristics such as state, age, religious and caste identity, and levels of education. Since the questions on populist attitudes is asked only in the following states: Assam, Delhi, Jammu and Kashmir, Kerala, Mizoram, Nagaland, Punjab, Tamil Nadu, Tripura, West Bengal, Uttar Pradesh, and Uttarakhand.

Much of the literature on populism in India is focused on understanding populism through electoral mobilization, political discourse and governance, but such a focus helps us to grapple with only the supply side. The demand side of looking at the scale and depth of populist attitudes in India can help us explain how ideas at the individual level can generate mass outcomes (Hawkins, Riding, Mudde 2012).

We adopt a conservative understanding of populism in this survey as there is scholarly consensus on these fundamental parameters to define populism (Mudde 2017, Mudde and Kaltwasser 2017, Weyland 2001). We understand populism to comprise of three attributes - popular sovereignty, the existence of a Manichean ethic, and an aversion to public institutions.

First, the defining feature of populism is the existence of a perceptible divide between the "people" and the "other". Populists typically believe that there is a community of people whose interests are not being served by some constructed "other" - both categories being fluidly defined but nevertheless existent. Our attempt through the survey is to understand who these "people" are and who the "other" is.

The question we ask is: "In your opinion, who is blocking progress of people like you?". The identified groups include: (a) Elites/Influential people, (b) Minorities, (c) Migrants/Outsiders, (d) Lower castes, and (e) Upper castes. Response categories are "yes" or "no".

Second, populist scholars agree that the division between the people and the "others" is necessarily a moral one wherein the people are considered virtuous and the other is considered self-serving at best or corrupt at worst. By extension, then, the relationship between them acquires a Manichean character whereby their relationship is antagonistic and not pluralist in nature and the will of the "people" (or popular sovereignty) is pitted against 
the "other". Our attempt through the survey is to understand whether respondents understand political contestations as essentially antagonistic or accommodative by nature.

The question we ask for this attribute is as follows: "Now I am going to read out two statements. Please tell me which statement you agree with most".

(Statement 1) Politics is ultimately a battle between good and bad.

(Statement 2) Politics is ultimately a compromise between good and bad.

Response categories include: "Agree with Statement 1" or "Agree with Statement 2".

And third, by implication, such people in an antagonistic relationship with the other, are averse to existing public institutions because they feel that the latter have been captured by the other, and therefore necessitates re-envisioning such institutions to live up to their original promise. It must be said here that in India, election is one such "institution" that escapes this aversion and indeed is seen as a pathway to better governance.

The question that captures this attribute is as follows: "Now I am going to read out two statements. Please tell me which statement you agree with most”.

(Statement 1) Elected leaders should be able to override the courts to serve the people better.

(Statement 2) Courts should be able to limit elected leaders to protect the people better.

Response categories include: "Agree with Statement 1" or "Agree with Statement 2".

\subsubsection{Anti-Elite Sentiment}

The first question related to populism is to ascertain if there is widespread disenchantment with a particular group. That is, who are the people against?

An anti-elite sentiment is concentrated in Jammu and Kashmir, Punjab, Tamil Nadu, Uttar Pradesh, and Delhi (Figure 3.4.1). Kerala stands out as a state that reflects a non-populist attitude, though it has the largest number of respondents who had "no opinion" on the question. A little more than 48 percent of all respondents reflected an anti-elite attitude, which is also more than twice that of any other cleavage (minorities, migrants, upper and lower castes), suggesting that the primary motivation behind populist attitudes is against elites more than traditional cleavages that typically influence politics in India.

An anti-elite sentiment seems to decrease quite substantially as the age of the respondents seem to increase (Figure 3.4.2). The younger population today is relatively more anti-elitist than the elder population, and that the latter is less certain as to where they stand on the "elite versus the people" divide. 


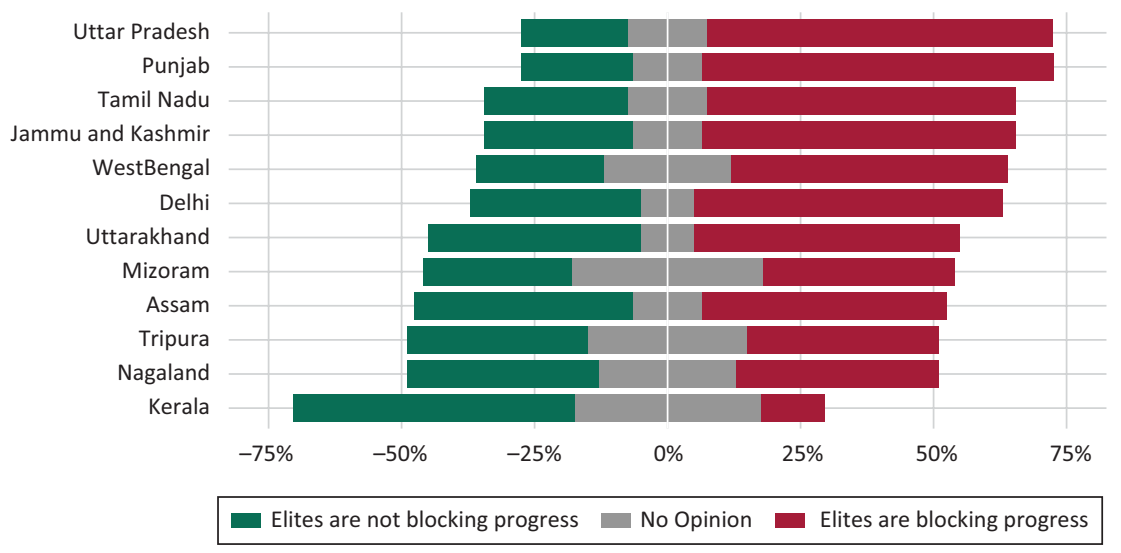

Figure 3.4.1 Anti-Elite Sentiment (by State)

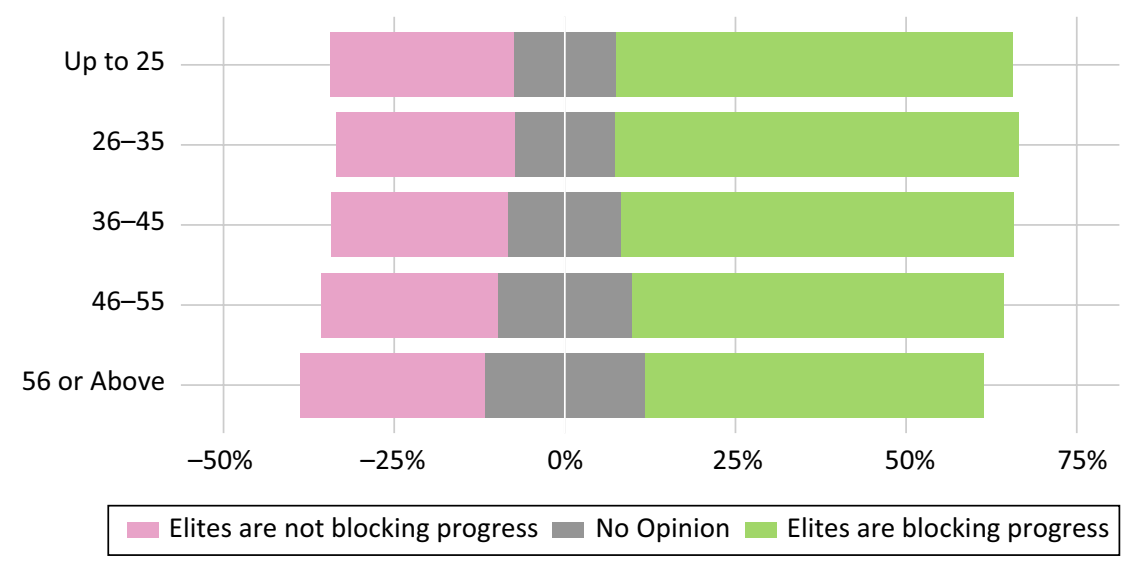

Figure 3.4.2 Anti-Elite Sentiment (by Age Group)

With the exception of Christians, a majority of respondents across all other communities hold an anti-elite attitude (Figure 3.4.3). Fifty six percent of Hindus, 57 percent Muslim, and 69 percent of Sikh respondents hold an anti-elite view. Approximately a third of Christian respondents also hold this view, and about 44 percent do not express an anti-elite sentiment. Twenty five percent of Christian respondents do not have an opinion.

Dalits within the Hindu population have a higher proportion of respondents (64 percent) who share an anti-elitist attitude compared to Adivasi (42 percent), OBC (55 percent), and upper caste (53 percent) respondents. 


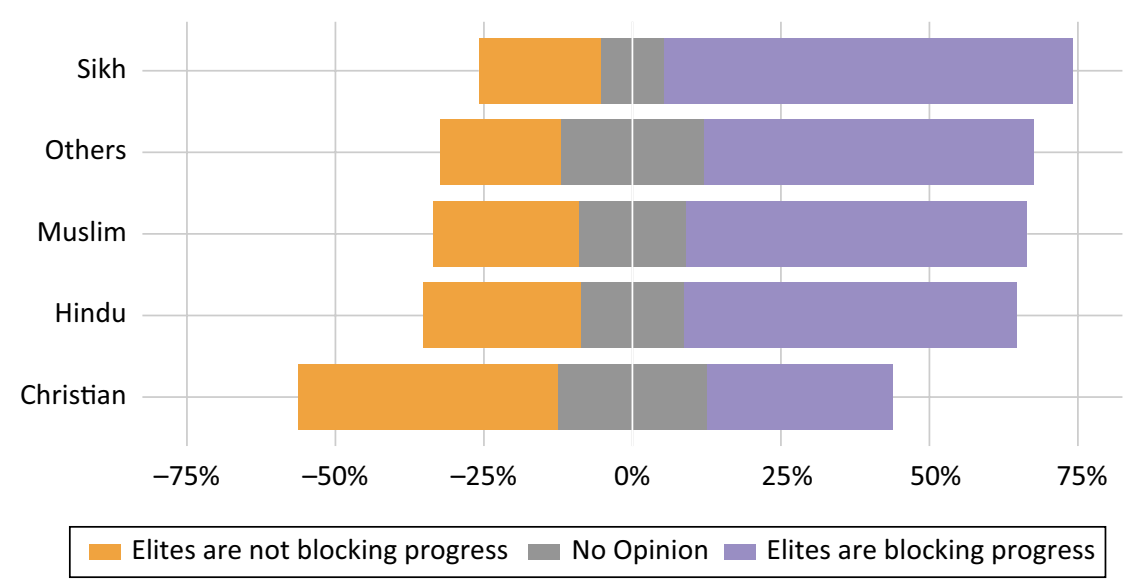

Figure 3.4.3 Anti-Elite Sentiment (by Religion)

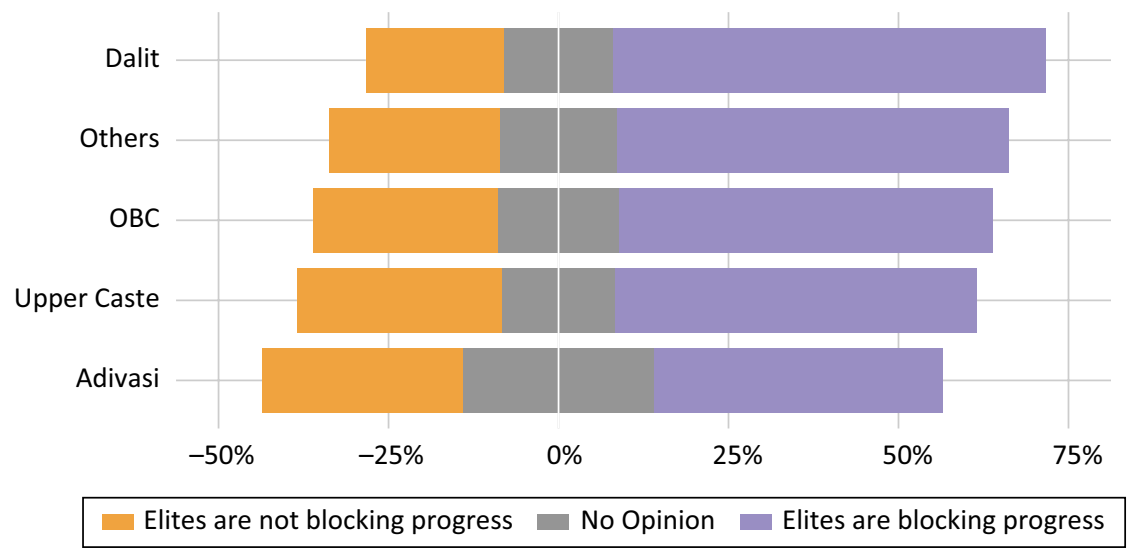

Figure 3.4.4 Anti-Elite Sentiment (by Caste)

(Figure 3.4.4). Adivasi respondents seems to be as divided as the Christians on this question. One could speculate that Dalits may be reflecting a sentiment against upper and OBC caste groups.

Education seems to play a role among those who feel that elites are blocking their progress, as college-educated respondents feel slightly less anti-elite compared to the non-literates (Figure 3.4.5). However, note that about 25 percent of non-literate respondents do not have an opinion. 


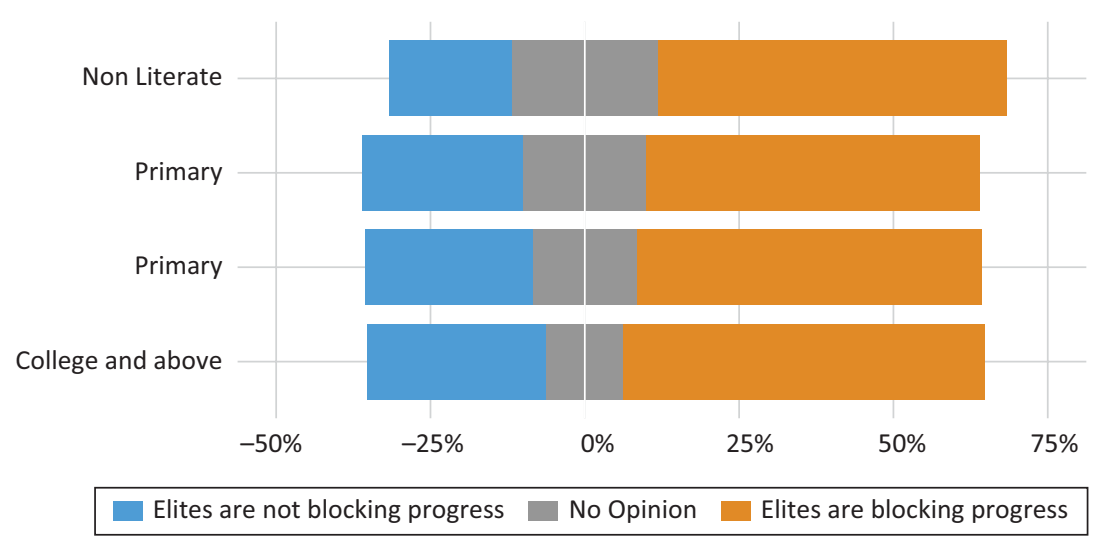

Figure 3.4.5 Anti-Elite Sentiment (by Education)

\subsubsection{Is Politics a Battle or Compromise Between Good and Bad?}

The second question related to populism focuses on the nature of politics: a battle or compromise between good and evil. While 48 percent believe that elites are blocking their progress, 47 percent believe that politics is ultimately a compromise between starkly divergent views on politics. Put another way, while an anti-elite-based antagonism is widespread, an almost equally substantial number believe that compromises more than "battles" lie at the core of political contestations. That being said, 29 percent believe that it is a battle.

An antagonistic relationship between political contestants seems to be a feeling concentrated in fewer states compared to an anti-elite attitude (Figure 3.4.6). Respondents in Jammu and Kashmir, Tamil Nadu, and Uttar Pradesh seem to have a stronger populist perception relative to other states, but respondents in Punjab seem to distinguish between anti-elite perceptions and the nature of political contestants and are less populist in comparison. Kerala seems to share this idea of antagonistic political contestants, whereas Nagaland is exactly on the opposite end. Respondents in Delhi overwhelmingly think that politics is a compromise and not a battle between good and bad.

Interestingly, while the idea of an antagonistic relationship is equally shared across all age groups, younger people seem to be marginally more persuaded by the idea of a compromise between good and bad political contestants (Figure 3.4.7). Support for this idea decreases as age increases. However, note that 35 percent respondents 56 years and above do not have an opinion. 


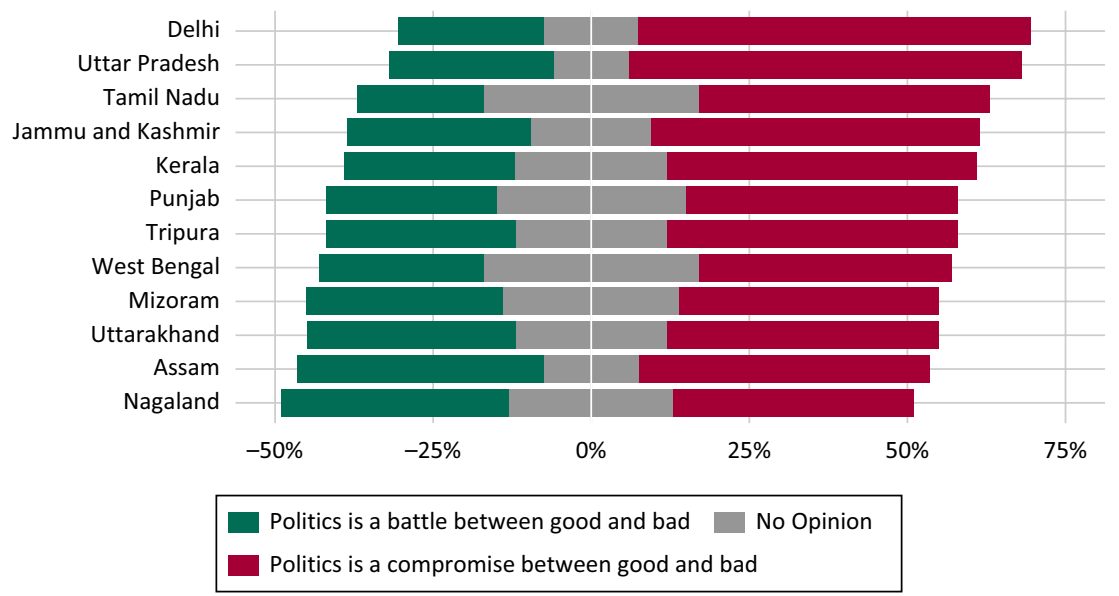

Figure 3.4.6 Battle or Compromise (by State)

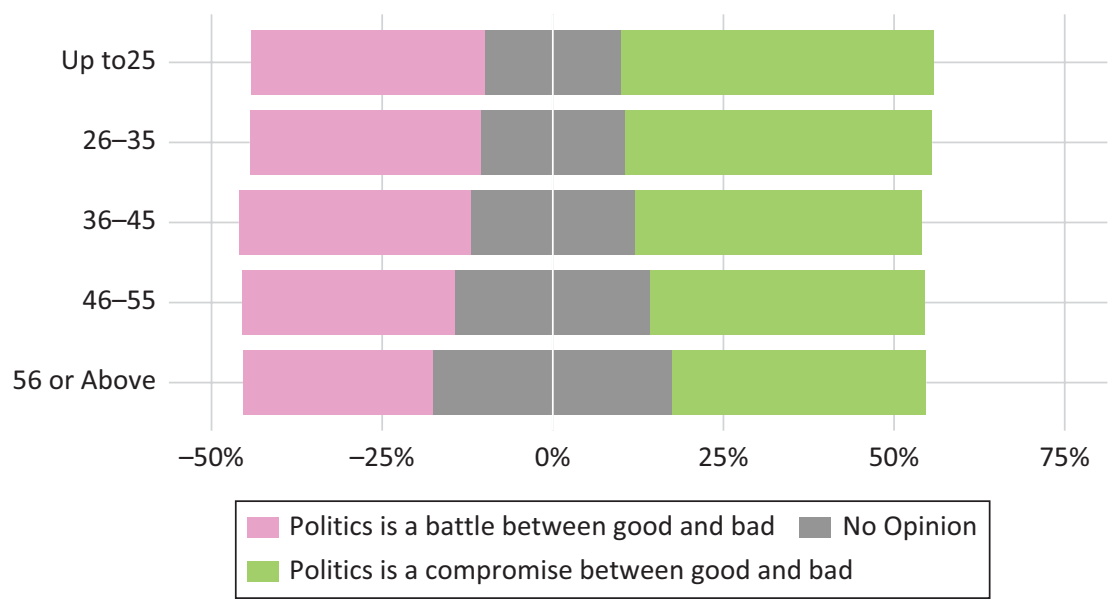

Figure 3.4.7 Battle or Compromise (by Age Group)

As levels of education increase a greater proportion of respondents believe that politics is a battle (Figure 3.4.8). Those who hold a college or above level education are more likely to have an opinion relative to those who have lower levels of education. About 42 percent of non-literate respondents do not express an opinion. 


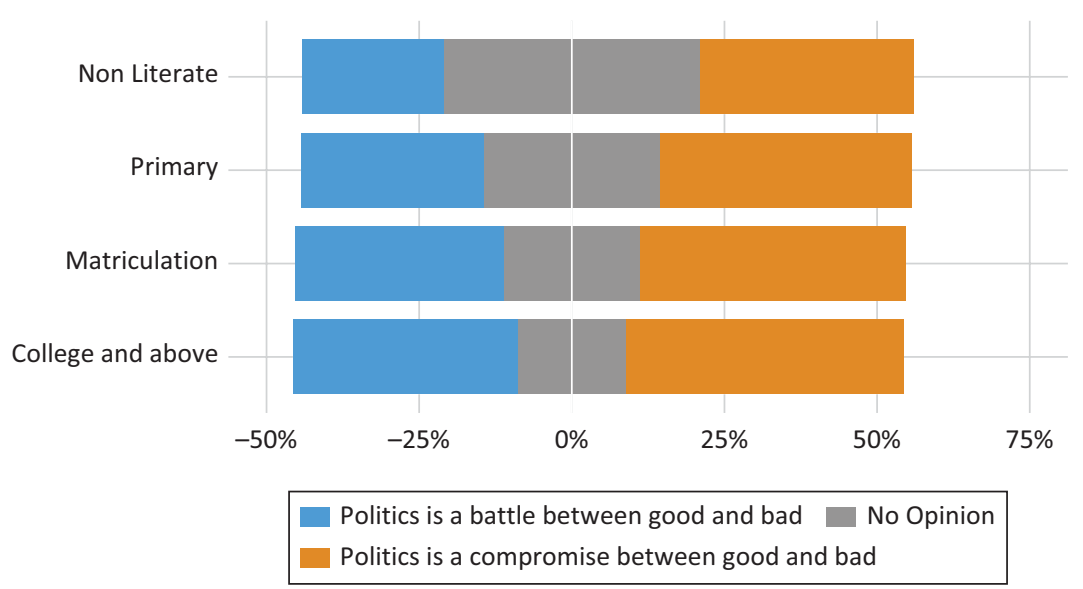

Figure 3.4.8 Battle or Compromise (by Education)

\subsubsection{Can Elected Leaders Override Courts on Behalf of the People?}

The third question related to populist attitudes is whether respondents believe that elected leaders should be able to override courts, reflecting an attitude that popular sovereignty can undermine public institutions because such institutions are in fact not representative of popular interests.

In West Bengal, Assam, Mizoram, Nagaland, and Tripura a majority of respondents do not feel that elected leaders can override courts (Figure 3.4.9). At the other end, Punjab, Tamil Nadu followed by Uttarakhand, Uttar Pradesh, and Jammu and Kashmir have more than a quarter of the respondents who think that elected leaders can override courts. In Delhi, 70 percent

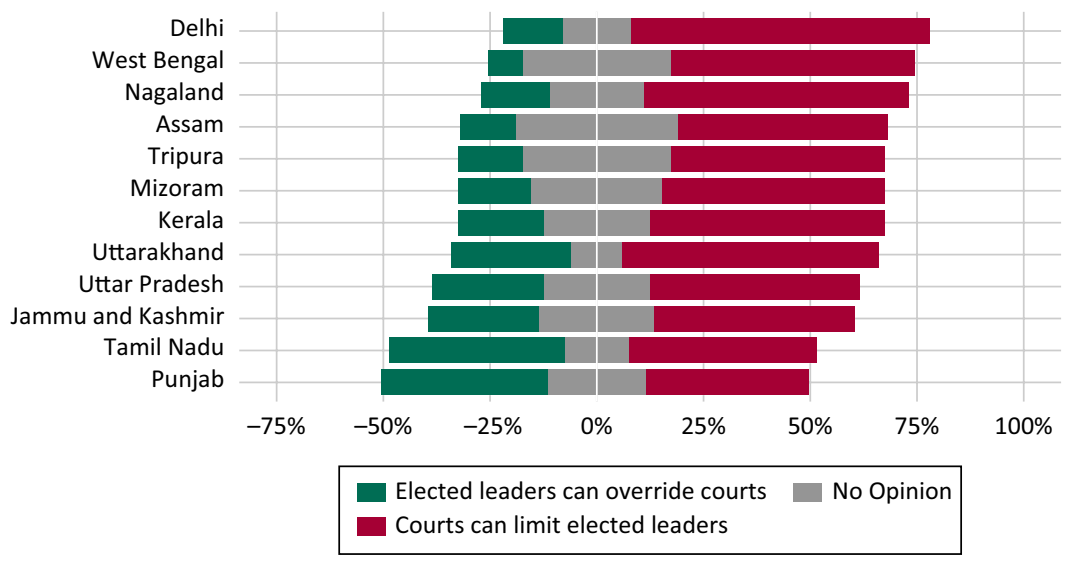

Figure 3.4.9 Elected Leaders can Override Courts (by State) 


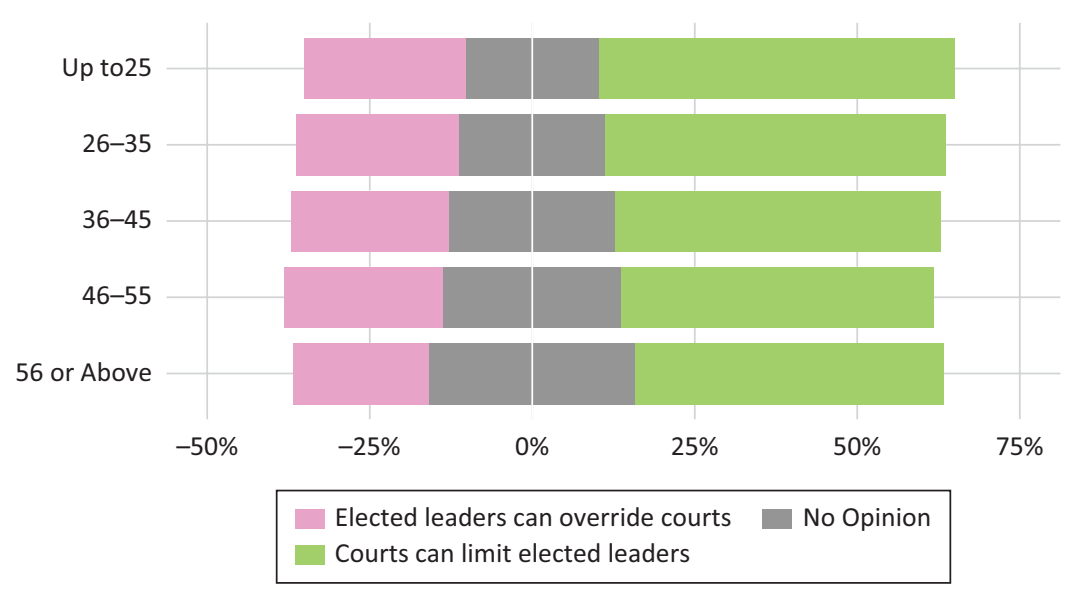

Figure 3.4.10 Elected Leaders can Override Courts (by Age Group)

of respondents feel that courts should be able to limit elected leaders against the opposite perception.

A substantial number of young respondents believe in the courts, and around one fourth of respondents across all age groups affirm the contrary. There are larger numbers of older groups who do not share an opinion about the relationship between the courts and the elected leaders (Figure 3.4.10).

A majority of respondents with college or above level of education affirm that courts should be able to limit elected leaders (Figure 3.4.11). However, while 39 percent non-literate respondents do not have an opinion this proportion drops to 15 percent for respondents with a college or above level of education.

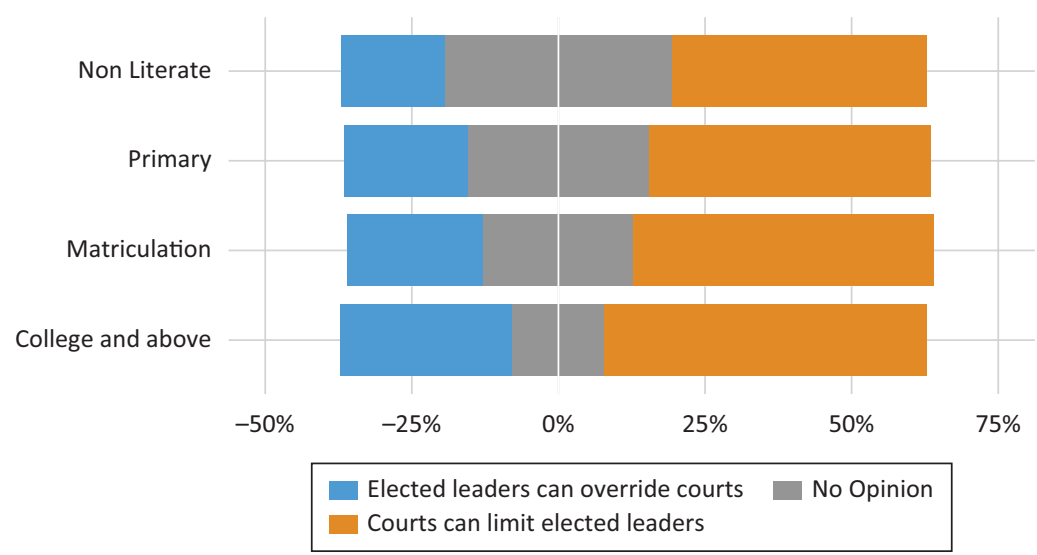

Figure 3.4.11 Elected Leaders can Override Courts (by Education) 


\subsubsection{Strong Populism}

Finally, to understand the prevalence of a populist attitude better, we present results below of respondents who affirm all three "populist" statements - that elites are blocking their progress, politics is a battle between good and bad, and that elected leaders should be able to override courts. We characterize those respondents - who affirm all three statements - as strong populists. Those respondents who affirm any two of the three statements are considered moderate populists.

Out of the total number of 24197 respondents in the sample 13269 answer all three questions. Among those that answered the questions, around ten percent affirmed all three statements, while almost 29 percent affirmed any two of the statements. Clear patterns can be seen in the case of state, levels of education, and religious and caste identities.

Strong populists are concentrated in the states of Punjab, Uttar Pradesh, Tamil Nadu, and Jammu and Kashmir (Figure 3.4.12). In all the other states, strong populists are less than ten percent with Kerala, Nagaland and Delhi below five percent. Further, more than 50 percent of the respondents are either strong or moderate populists in Punjab, Tamil Nadu, and Uttar Pradesh.

There does not appear to be a relationship between levels of education and strong populism. More or less equal proportions of strong populists are spread across levels of education (Figure 3.4.13).

Sikh and Muslim respondents hold stronger populist views relative to other religious groups with the Christian respondents being least persuaded by populist statements (Figure 3.4.14).

Dalit respondents are likely to have strong populist leanings relative to other groups (Figure 3.4.15). Adivasi respondents are least likely to be strong populist.

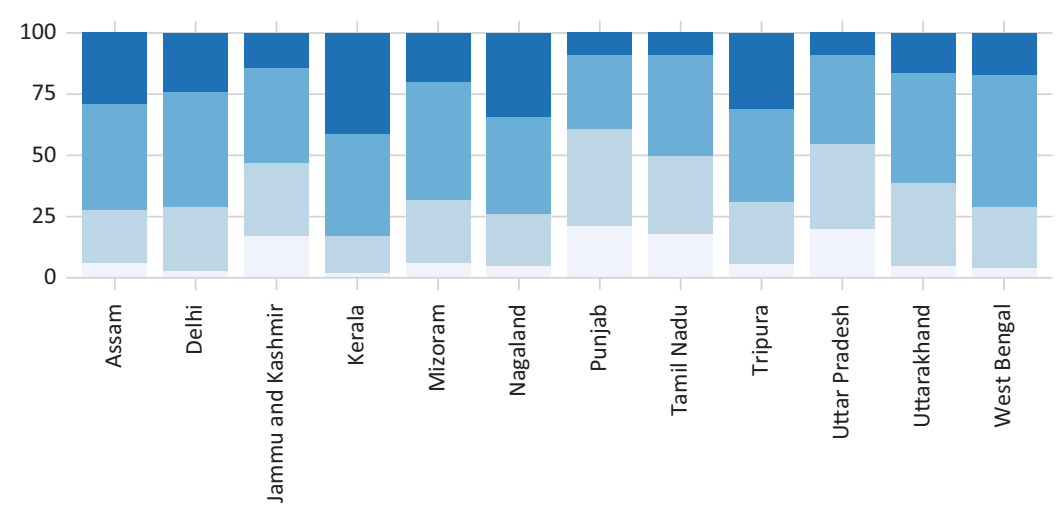

Non Populist Weak Populist $\quad$ Moderate Populist Strong Populist

Figure 3.4.12 Populism (by State) 


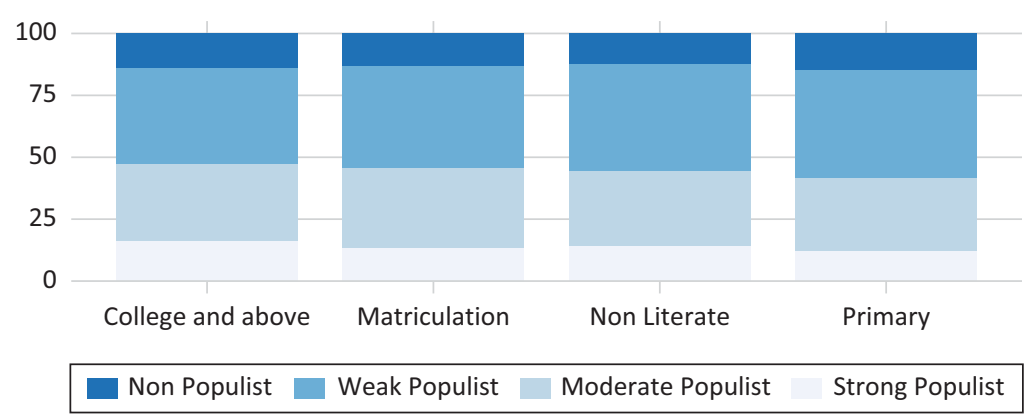

Figure 3.4.13 Populism (by Education)

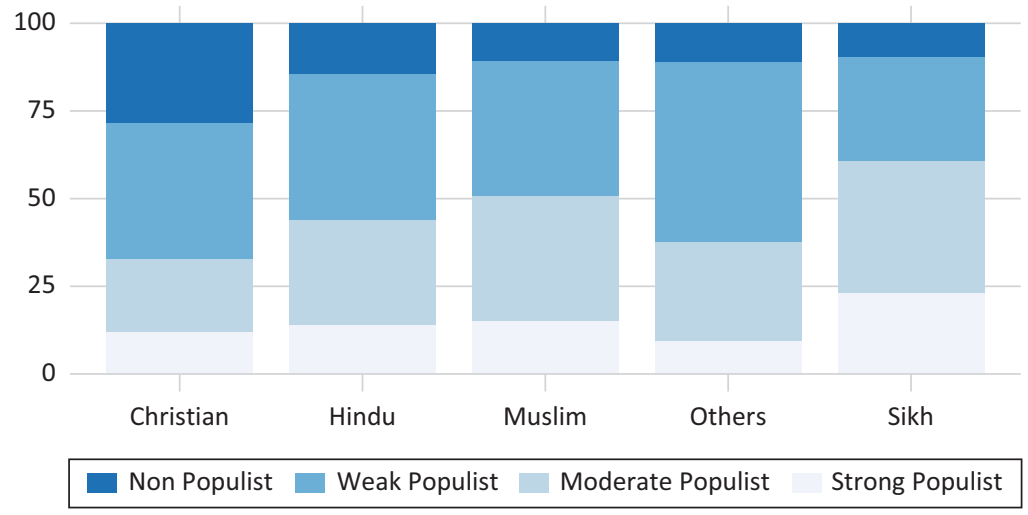

Figure 3.4.14 Populism (by Religion)

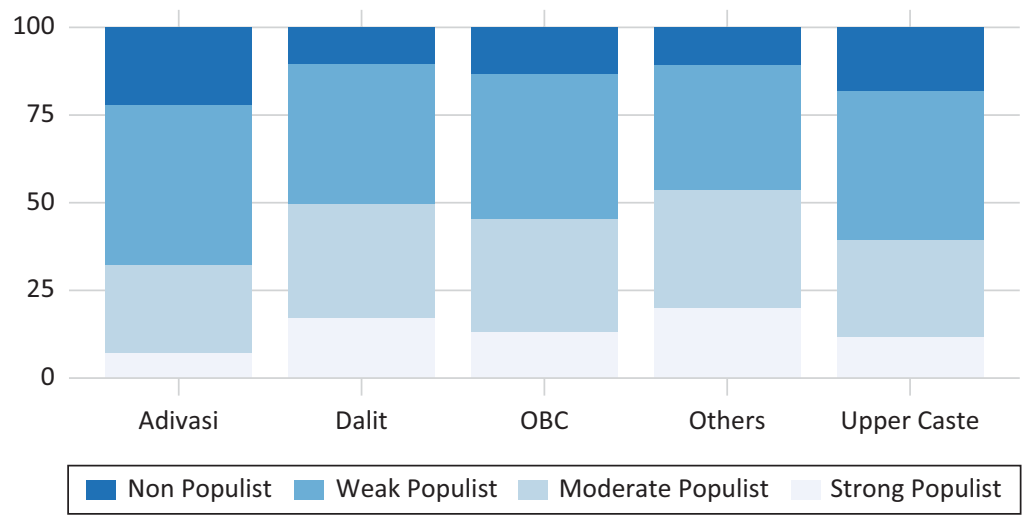

Figure 3.4.15 Populism (by Caste) 


\subsection{CONCLUSION}

Findings from the four sections on the political universe that citizens occupy display a kaleidoscopic view of public opinion on freedom of expression, regional and national identity, nationalism, and populism.

Opinions on freedom of expression vary across themes, states, and religious identity. Public opinion on freedom of expression varies across the three thematic clusters: democratic practice, secularism, and nationalism. Respondents are generally open, that is, agree to allow free expression of opinion that involves criticism of leaders, but less open to that involving regime and institutional replacement. However, we find that opinion tilts the other way, that is, toward strong disagreement when it involves making fun of or advocating hate speech or violence against others i.e. secularism. Responses to questions on nationalism again produce divergent opinions. While respondents agree with allowing a free expression of demands of independence for any part of India, they disagree when the same opinion involves the use of force against the Indian State. It appears that on some issues such as secularism, public opinion is consistent with the reasonable restriction imposed on freedom of expression, and the need to respect the rights of all religious communities. However, on questions of democratic practice and sovereign nationalism, public opinion is amenable to a more expansive view of what can be freely expressed by citizens.

While thematic variation in ideas pertaining to freedom of expression noted above is evident across all the states, we also observe a variation in the magnitude of responses across states. Public opinion appears to be very similar in certain states such as Tamil Nadu, Kerala, and, in some instances, Uttar Pradesh. Responses in Jammu and Kashmir are similar to those in Delhi on some questions and similar to those in Tamil Nadu on some other questions. Similarly, opinions on certain questions within states in the northeastern region reflect broad alignment within the region and cohere with opinions in states outside the region on some other questions. Surprisingly, the largest proportions of respondents without an opinion are from Andhra Pradesh, Assam, Gujarat, and West Bengal. The clustering of public opinion across states suggests that regional identities likely play a role in how freedom of expression is viewed across space, a relationship that calls for further empirical scrutiny.

Religious identity emerges as a key factor that differentiates public opinion on freedom of expression. Respondents considered a minority (Muslims, Christians, and others) tend to differ systematically from positions adopted by the Hindu majority. While the magnitude of differences observed across communities varies across the substantive dimensions of freedom of expression, (that is, whether making fun of religious practices or promoting violence against the Indian State) these differences persist. 
We also find clear spatial patterns in how national and subnational identities are distributed. In northern states with Hindi as their primary language respondents adopt a "national" identity. This identity is also found in large proportions in states from other regions such as Maharashtra, West Bengal, Tripura, and Telangana. A clear preference for a regional identity emerges in Tamil Nadu, Mizoram, Nagaland, Odisha, and Jammu and Kashmir and other states such as Punjab and Gujarat also have relatively high proportions of respondents who profess a regional identity over a national one. Social cleavages such as religious identity also impact political identity in interesting ways. While a greater proportion of Hindus tend to express a national identity over a subnational one, Hindus in the Hindi belt states tend to be more "national: than in other states such as Kerala, Tamil Nadu, and Punjab, that have witnessed significant politicalsocial movements in the past. Respondents who are urban, with higher levels of education or exposure to media tend to adopt a national identity relative to those in rural areas or with lower levels of education or exposure to media. Majoritarianism sits uneasy with persistent sub-nationalism (which is not anti-Indian but one that does not appear to prioritize Hindu nationalism), and an understanding of how these identities have shifted or are shifting is important in a developing multi-ethnic, federal, and pluralist democracy.

While the distribution of national and regional political identity reveals variation across subnational units, community, and other socio-economic factors, an analysis of linguistic preference does not produce very clear results. We find that urban respondents and respondents with higher levels of education are more likely to prefer any language and less likely to prefer the use of the local language in public spaces. More generally, respondents adopt the position that any language can be used in public spaces and do not appear tied to the local language.

Public opinion is particularly animated when questions of nationalism take on a cultural tone. For instance, while we find relative agreement on the question of standing during the national anthem (that is, most respondents agree that the national anthem should be respected), the responses to whether the state should punish someone for not saying "Bharat Mata ki Jai" are more polarized. Similarly, the question on beef consumption also elicits a greater polarization than questions on religious conversions. Spatially, we also find that the Hindi belt states cohere around similar positions on most questions tending towards majoritarianism - states such as Maharashtra, Gujarat, Odisha, and Karnataka tend to also fall into this group. States with larger or significant minority populations - such as Jammu and Kashmir, Mizoram, Nagaland, Kerala, West Bengal, and Tripura - tend to adopt more pluralist positions. Castes and communities are clearly divided on the question of nationalism. While minority religious communities strongly disagree with State punishment, Hindus, across all castes, tend to strongly support 
State punishment. With the exception of the opinion on beef consumption, Hindu Dalits also tend to support a majoritarian position while Hindu Adivasis exhibit the least tendency toward a majoritarian nationalism.

While populist ideas are clearly reflected in elite rhetoric, India is not overwhelmingly populist. Two thirds of the respondents appear to affirm ideas that are non-populist, but a third affirm questions that can be construed as very strong assertions of populism. Punjab, Tamil Nadu, and Uttar Pradesh are the three states where populist ideas resonate. This is not to say India is pluralist, only that it is essentially non-populist. It is clear that statelevel characteristics do seem to matter as much as individual characteristics - especially age, education, religion and caste.

While what we present here constitutes a preliminary examination of patterns, these results open up potential avenues of research on public opinion formation on freedom of expression, regional and national identity, nationalism, and populism, both theoretically and empirically.

\section{NOTES}

1 These events have been extensively reported across media outlets. For instance, mob violence protecting the cow has increased since 2014 (https://archive.ind iaspend.com/cover-story/86-dead-in-cow-related-violence-since-2010-are-musl im-97-attacks-after-2014-2014). Citizens have also been arrested for not standing during the national anthem (https://www.firstpost.com/india/national-ant hem-verdict-20-arrests-made-in-two-days-after-supreme-court-ruling-3155560. html), students (http://time.com/4224571/india-jnu-kanhaiya-kumar-arrest-pro tests-sedition/) and activists (https://www.hrw.org/news/2020/04/15/india-ac tivists-detained-peaceful-dissent) charged with sedition or anti-national activities (https://www.newsclick.in/anti-national-urban-naxal-trajectory-dissent-india), and leaders have sought to associate patriotism with chanting "Bharat Mata ki Jai" or "vande mataram" (https://www.outlookindia.com/newswire/story/those -who-dont-say-bharat-mata-ki-ja-have-no-right-to-stay-in-country-fadnavis/9 35430). Ban on the consumption of beef (https://www.forbes.com/sites/leeza mangaldas/2017/06/05/indias-got-beef-with-beef-what-you-need-to-know-a bout-the-countrys-controversial-beef-ban/\#15b1e4cd53c2) and religious conversions (https://www.financialexpress.com/india-news/ghar-wapsi-vhp-says-recon verted-25000-muslims-christians-in-2018/1746798/) have also contributed to a charged debate on nationalism.

2 For instance, online reportage of mob violence includes attempts to document the deaths resulting from such violence (https://www.thequint.com/quintlab/ lynching-in-india/).

3 Jayaram, N. (2004). "Emancipation through Proselytism: Some reflections on the marginal status of depressed classes" in R. Robinson, ed. (2004). Sociology of Religion in India. Sage Publishing. 


\section{POLITICAL INSTITUTIONS}

Moving away from attitudes and orientations typically associated with identities in social and political universes, Part 4 reports findings about the citizen interface with government institutions and citizens' perceptions about these institutions. Governance processes are examined in terms of citizen awareness of, and benefits from various welfare schemes of central and state governments and the institutions leaders approach to get work done or resolve disputes. The extent to which citizens find public institutions trustworthy, efficient, and distributively just is also explored. Findings suggest a wide but uneven distribution of information and benefits across schemes and states, and a widespread citizen preference of local government leader to approach in order to get work done. Public trust in institutions is robust enough to sustain democracy but low levels of citizen trust in key institutions such as the bureaucracy and political parties do not bode well for governance. 


\subsection{THE CITIZEN-STATE INTERFACE}

Public assessments about citizen-State interfaces are an important feature of politics between elections as they not only shape citizens attitudes toward parties and incumbents but also influence whether citizens view institutions as credible and efficacious. Engagement between the State and its citizens through political leaders and government officials, as well as through welfare schemes and public services provided by governments, is a critical governance process. Governance hinges on citizens being able to access basic services easily and benefit from welfare enhancing schemes. Local political actors, in many instances, also facilitate access to many resources (Sekhri, 2011; Auerbach and Thachil, 2018, 2020; Bussell, 2019). Governance also involves the ease with which citizens are able to approach leaders and government officials. Citizen experiences with State institutions in turn inform the trust citizens give to these institutions. However, are citizens aware of the opportunities provided by central and state governments? Lack of information about services and welfare schemes designed for poor and disadvantaged groups hinder their access to those services (Berry and Coffman, 2012). Improving stakeholders' awareness of entitlements and providing information on the quality of services can be an effective method of improving service delivery (Afridi, 2017). Despite having information about services and where to access these services, do citizens receive basic services? Do they have access to schemes that have the potential to improve livelihoods? And what sorts of institutions and leaders do citizens approach to get work done or for dispute resolution? These are critical to understanding the processes of routine governance that occurs in periods between elections.

We explore these questions in the following section through multiple lenses: across states, across caste and religious identities, levels of education, and class. We first examine citizen awareness of both central and state level schemes. These schemes cover four broad domains: agriculture, housing, employment, and health care. A list of state schemes across states is provided in the Appendix. Next we focus on the beneficiaries of these schemes. Do targeted groups benefit from these schemes? Then we consider the experiences of citizens in availing public services such as education, health services, sanitation, water, and electricity. Finally, we look at the sorts of institutions citizens approach to get important work done and for dispute resolution.

The questions asked in the survey that draw out this information are as follows:

(a) For awareness of central schemes, we ask: "Now I am going to name a few schemes (PM Fasal Bima Yojana, PM Jan Avas Yojana, PM Jan Aushadi Yojana, and MGNREGA) that the Central Government has initiated for the benefit of people. Have you or your family availed 
any benefit from these schemes?" The responses are "Benefitted", "Not benefitted", and "Not Heard".

(b) For awareness of state schemes, we ask: "Now I am going to name a few schemes (agriculture schemes, medical/health schemes, employment schemes, education schemes) which have been launched by the (state) government for the benefit of the people. Have you or anyone in your family benefitted from these schemes". The responses are "Benefitted", "Not benefitted" and "Not Heard". Note that the questions on central and state agricultural schemes are asked only of farmers. (The question is asked differently in four states: Gujarat, Karnataka, Odisha, and Haryana: "Government has initiated several schemes and programmes [Employment scheme, Pension scheme, Skill-development scheme, Accidental crop insurance scheme, Crop subsidy scheme, Fertilizer subsidy scheme, Housing scheme, Medical insurance scheme, Educational scholarship scheme] for the benefit of the people. Have you or your family ever availed any such benefits?" Whether the scheme was launched by the state or central government is not asked. Therefore we do not include Gujarat, Karnataka, Odisha and Haryana in the section on awareness and beneficiaries of central and State schemes, and experience with public services.)

(c) To gauge citizen experiences in availing public services like education, healthcare, electricity, water, and sanitation, we ask: "Based on your experience, how easy or difficult was it to obtain the following services - was it very easy, easy, difficult or very difficult?" followed by a list of public services: "Admission in a government school for a child", "Medical treatment at a nearby government hospital", "Garbage collection", "Electricity connection" and "Water connection". The response categories were: "Very Easy", "Easy", "Difficult", "Very Difficult", “ Never Tried" and "No response".

(d) In order to identify the institutions (political and non-political, formal and informal) and individual citizens' approaches to getting the services or to getting their important work done, we ask: "If you ever have difficulty in getting an important work done, whom will you first think of approaching for help?". The responses are placed in the following categories: "MP", "MLA", "Councillor/Sarpanch", "Government Official", "Local Political Leader", "Caste Leader", "Religious Leader", "Elder Outside the Family", "Dalals/Touts", "Non-Government Organizations", and "Others".

(e) Furthermore, in order to understand the sorts of institutions that citizens approach for resolving various types of disputes, we ask: "I will name a few methods through which it is possible to resolve a dispute between you and another party. Could you please tell me which one of these methods you are most likely to go to resolve the following disputes?" We ask this for four different types of disputes: "Property 
dispute", "Marriage dispute", "Neighbourhood dispute" and "Domestic violence". The responses are classified into the following seven categories: "Family member", "Neighbourhood/Village Elder", "Caste-Community Organization", "NGO", "Police", "Court", and "No Opinion".

\subsubsection{Awareness of Central and State Welfare Schemes}

We create a summative index of awareness merging all four schemes - agriculture, employment, housing, and health - that ranges from low awareness to high awareness for both central and state schemes. Those who are not at all aware or are aware of only one scheme are included in the category of "low awareness"; on the other hand, those who are aware of all four schemes are added in the category of "high awareness". Rest are in the category of "some awareness".

Awareness of central agriculture schemes is high in Bihar, Madhya Pradesh, Maharashtra, Punjab, Rajasthan, Uttar Pradesh, Chhattisgarh, Tripura, Jharkhand, and Uttarakhand; close to nine of the ten respondents (farmers) are aware of the central agricultural scheme (Figure 4.1.1). With the exception of Jammu and Kashmir, Jharkhand, West Bengal, and Tripura, the level of awareness about state agriculture schemes across the states is also high. There are a few states where awareness about the central agricultural scheme is higher than that of state schemes such as in Bihar, Madhya Pradesh, Jammu and Kashmir, Maharashtra, Rajasthan, West Bengal, Chhattisgarh, Tripura, Jharkhand, and Uttarakhand. On the other hand, in Andhra Pradesh, Kerala, Mizoram, Tamil Nadu, Uttar Pradesh, Punjab, and Telangana awareness about state agriculture schemes is higher than central agriculture scheme.

In Assam, Bihar, Madhya Pradesh, Rajasthan, Tripura, Uttar Pradesh, Jharkhand, Chhattisgarh, and Uttarakhand, approximately nine in every ten respondents are aware of the central housing scheme, Pradhan Mantri Jan Avas Yojna. In Bihar, Punjab, Rajasthan, and Delhi, the level of awareness about central and state housing schemes is about the same. In Andhra Pradesh, Kerala, Mizoram, Tamil Nadu, and Telangana, we find more respondents aware of state housing schemes compared to central housing schemes.

More than 80 percent of respondents are aware of central employment schemes. The Mahatma Gandhi National Rural Employment Guarantee, a central scheme, is widely recognized compared to state employment schemes across most the states. In Tamil Nadu and Punjab, however, more respondents are aware of state employment schemes. However, Kerala and Maharashtra, Telangana, and Delhi's awareness of both schemes is more or less the same. 
POLITICAL INSTITUTIONS
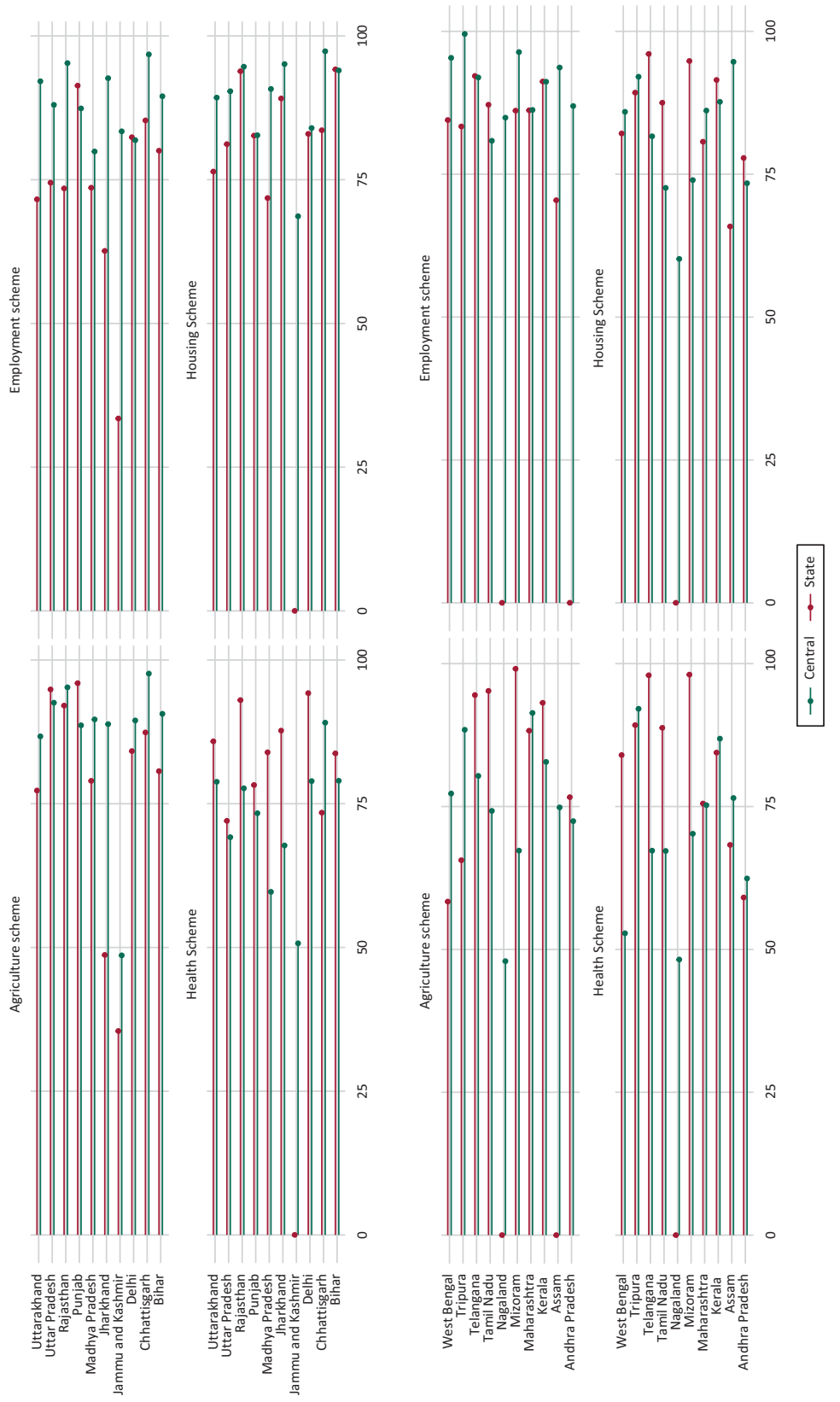

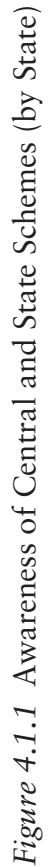


With health schemes, the awareness about state health schemes is higher than the central health scheme, Pradhan Mantri Jan Aushadhi Yojna. Overall, 85 percent of the respondents are aware of state health schemes, whereas 73 percent are aware of central health scheme. In Bihar, Madhya Pradesh, Mizoram, Punjab, Rajasthan, Tamil Nadu, Uttar Pradesh, West Bengal, Delhi, Jharkhand, Uttarakhand, and Telangana, there is greater awareness of state health schemes relative to central health schemes. In Andhra Pradesh, Assam, Kerala, Tripura, Chhattisgarh, however, the central health scheme is recognized more than state heath scheme. In Maharashtra, awareness of the both central and state health schemes is about equal.

In Andhra Pradesh, Bihar, Kerala, Madhya Pradesh, Maharashtra, and Uttar Pradesh, similar proportions (a majority in all of the above except Madhya Pradesh) of respondents indicate high awareness of both central and state schemes (Figure 4.1.2). In Assam, Jammu and Kashmir, Rajasthan, Tripura, Chhattisgarh, Jharkhand, Delhi, and Uttarakhand respondents reveal a high level of awareness across central schemes relative to state schemes. In Mizoram, Punjab, Tamil Nadu, West Bengal, and Telangana, there is a high level of awareness regarding state schemes relative to central schemes. About 30 percent and 42 percent respondents in Jammu and Kashmir and Nagaland, respectively, indicate a low level of awareness of central schemes. In Andhra Pradesh and Tamil Nadu the proportion is 27 percent. In Andhra Pradesh, Assam, Jammu and Kashmir, between 30 percent and 58 percent respondents indicate a low awareness of state schemes.

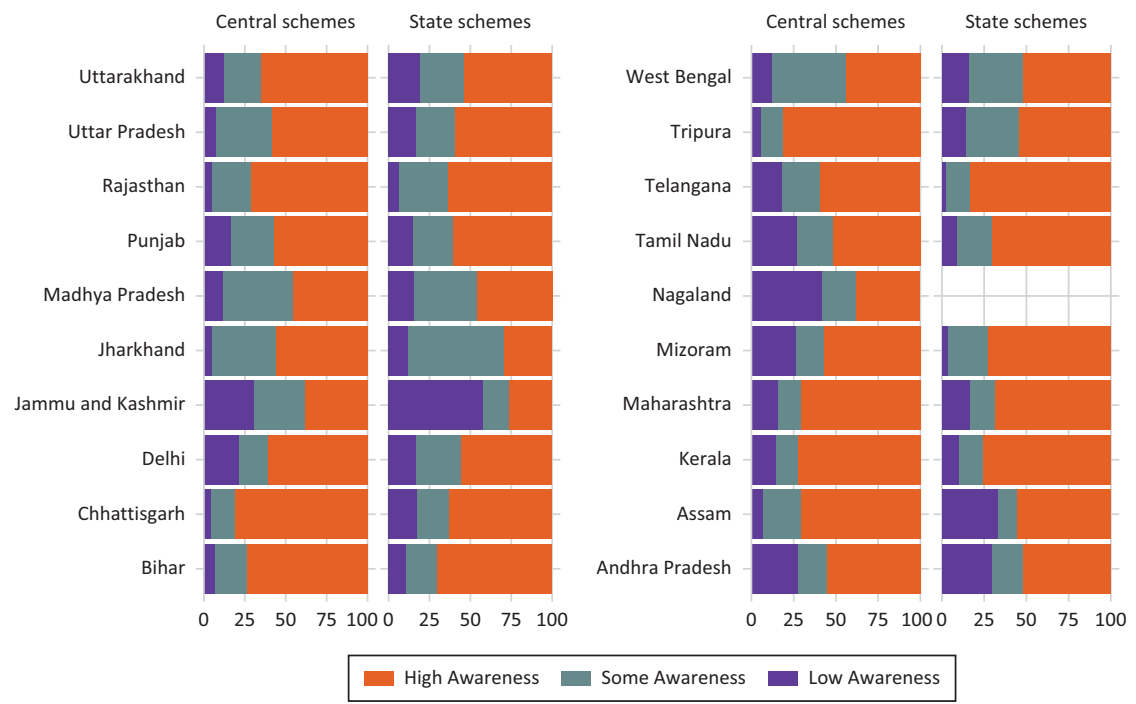

Figure 4.1.2 Index of Awareness of Central and State Schemes (by State) 
When we examine levels of awareness across caste and religion, we find that Christian Adivasi respondents have the lowest levels of awareness of schemes introduced by the central and state governments (Figure 4.1.3). Approximately 33 percent of Christian Adivasi respondents are very aware of central schemes and 35 percent of state schemes. On the other hand, 12 percent of Hindu Adivasis exhibit a low awareness of central schemes, while 62 percent indicate high awareness of state schemes. A majority of respondents from other caste-community groups show a high level of awareness of both central and state schemes

As levels of education increase, we find that the proportion of respondents who have a low level of awareness of either central or state schemes decreases (Figure 4.1.4). At the same time, the proportion of respondents

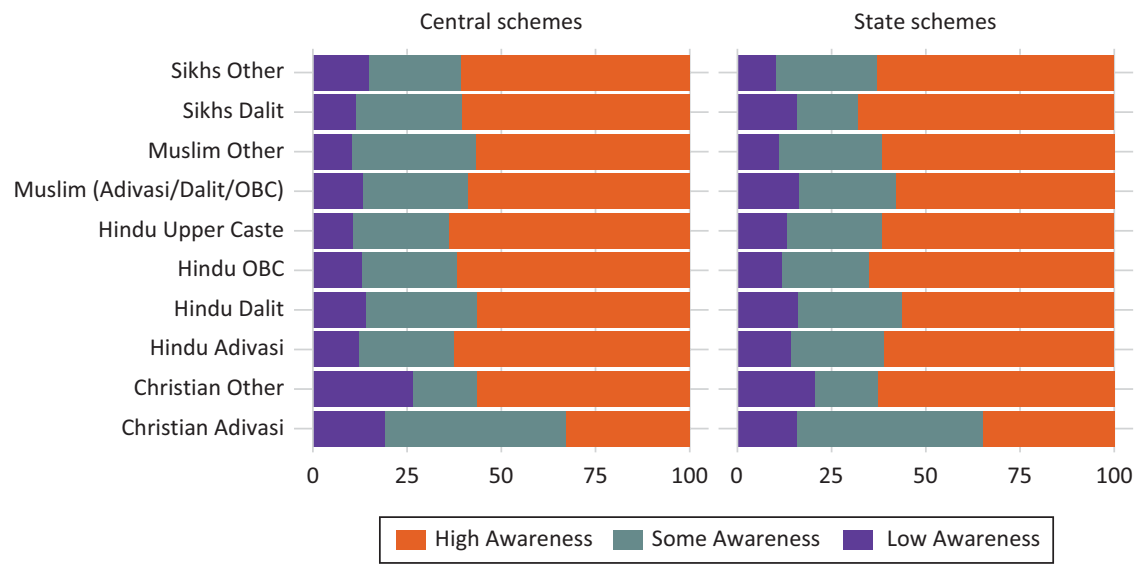

Figure 4.1.3 Index of Awareness of Centraland StateSchemes (by Caste-Communities)

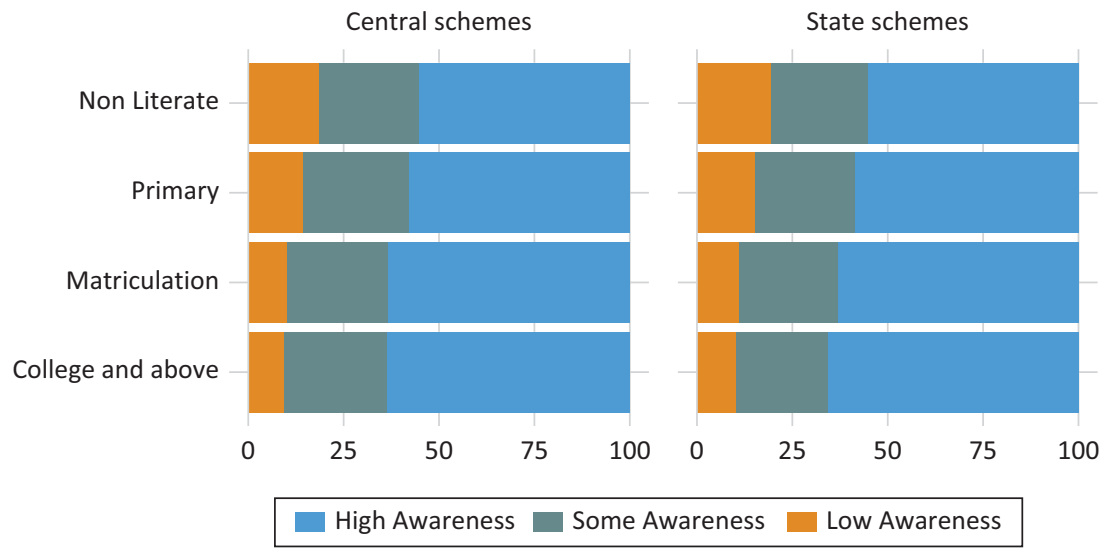

Figure 4.1.4 Index of Awareness of Central and State Schemes (by Education) 
who exhibit higher awareness about central and state schemes increases. About 19 percent of non-literate respondents have a low level of awareness of central and state schemes, while the number drops to ten percent among respondents with a college education for both central and state schemes. While 55 percent of non-literate respondents have a high level of awareness about central schemes, the proportion increases to 63 percent among respondents who have a college education. A similar change across levels of education occurs for higher awareness of state schemes as well.

\subsubsection{Beneficiaries of the Central and State Welfare Schemes}

We find that a slightly higher number of respondents benefit from state agricultural schemes (13 percent) than central agricultural schemes (Figure 4.1.5). A large proportion of farmers from Madhya Pradesh (27 percent), Rajasthan (29 percent), Jharkhand (24 percent), and Chhattisgarh (24 percent) are beneficiaries of the central agricultural schemes. On the other hand, a large share of farmers in Mizoram and Tamil Nadu are beneficiaries of state agricultural schemes. Close to half of the farmers in Mizoram and 22 percent of the farmers in Tamil Nadu report benefits of state agricultural schemes.

We find that central housing schemes has a greater proportion of beneficiaries (13 percent) relative to state housing schemes (ten percent). More respondents in Assam, Bihar, Madhya Pradesh, Rajasthan, Jharkhand, Uttarakhand, and Chhattisgarh are beneficiaries of central housing schemes. A little over a third of the respondents in Jharkhand report being beneficiaries of a central housing scheme. In rest of the states, differences in the proportions of the beneficiaries of central and state housing schemes are small.

A greater difference in beneficiaries is observed across states with respect to employment schemes. Overall, only nine percent of the respondents claim receiving benefits of state employment scheme, but 32 percent report having availed the central employment scheme, NREGA. A quarter or more respondents in Andhra Pradesh, Assam, Jammu and Kashmir, Madhya Pradesh, Nagaland, Rajasthan, Tamil Nadu, West Bengal, Jharkhand, Chhattisgarh, Uttarakhand, and Telangana report themselves as beneficiaries. In Mizoram and Tripura, close to two-thirds of the respondents indicate benefitting from NREGA, and in Nagaland and Jharkhand, close to half of the respondents claim benefitting from NREGA. The proportion of the beneficiaries of NREGA is also substantially large in Rajasthan (43 percent), West Bengal (43 percent), and Chhattisgarh (44 percent).

Unlike the employment scheme, a higher share of respondents claims to benefit from state health schemes in comparison to central health scheme. Only ten percent of the respondents report availing of benefits from a 
POLITICAL INSTITUTIONS

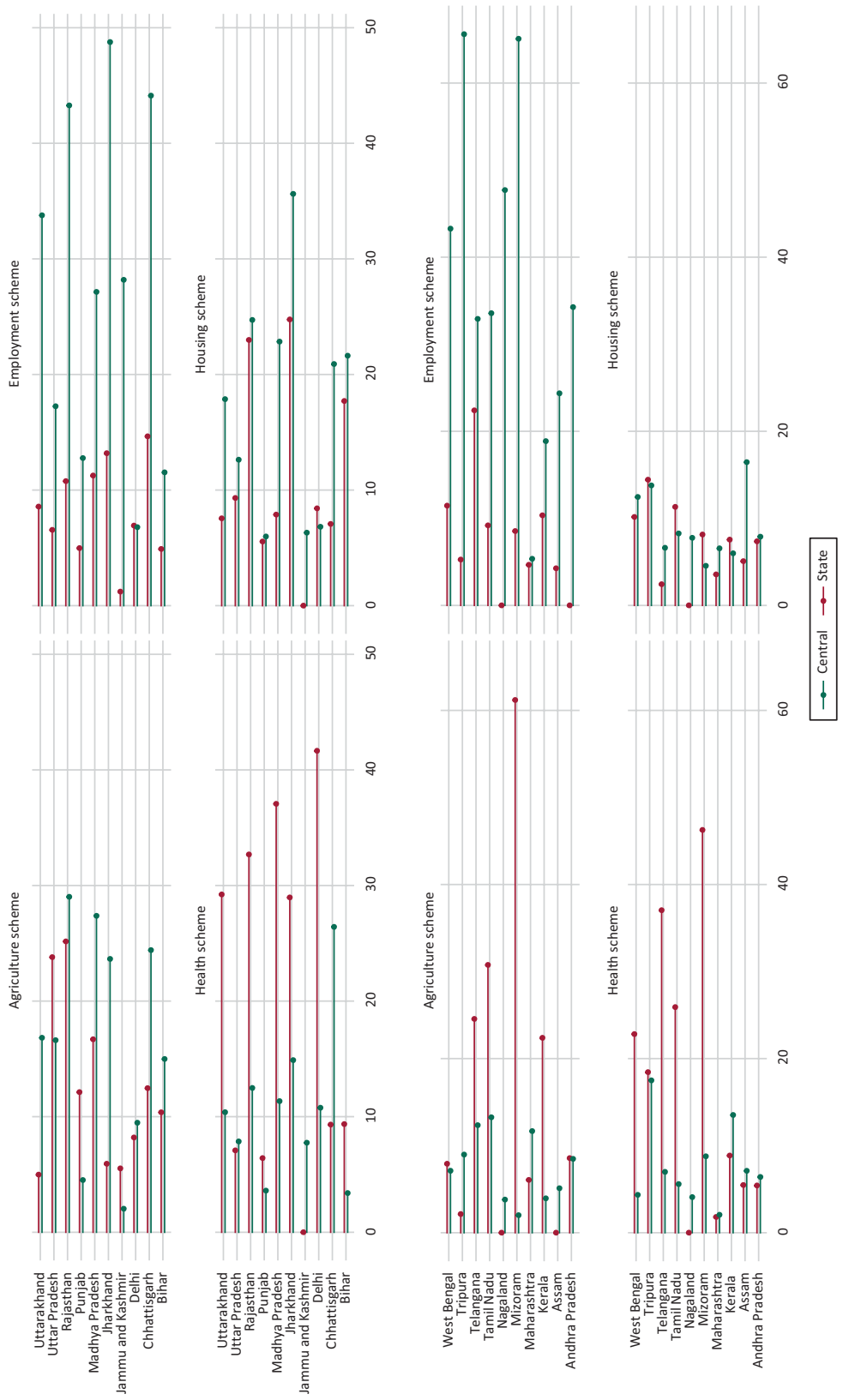

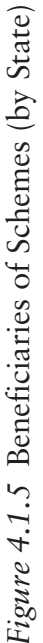


central health scheme, whereas when it comes to the state health schemes, one out of every five respondents avail of benefits. More respondents in Chhattisgarh (26 percent), Tripura (17 percent), and Kerala (13 percent) record having benefitted from central health scheme. Forty-six percent in Mizoram, 42 percent in Delhi, and 37 percent each in Madhya Pradesh and Telangana claim benefits of the state health schemes. Tamil Nadu, Uttarakhand Jharkhand, and West Bengal also report close to a quarter of respondents as benefiting from state health schemes.

We find no difference in the numbers of farmers who have availed of the benefits from the central agriculture scheme, Pradhan Mantri Fasal Bima Yojana (PMFBY), introduced by the central government in 2016 as crop insurance for farmers in India and the state agriculture schemes launched by their respective state governments (Figure 4.1.6). However, big and small farmers have benefitted more from the agricultural schemes (both central and state) compared to tenant cultivators and agricultural labourers.

When viewed through the lens of caste, Hindu Adivasis (19 percent) report the highest percentage of beneficiaries of housing schemes at the central level followed by Hindu Dalits at 18 percent (Figure 4.1.7). Dalit Sikhs have the lowest percent of respondents who benefit from central or state housing scheme at only four percent. At the state level, Hindu Dalits have the highest percentage of people who benefitted from housing schemes at 13 percent. Hindu Adivasi and Hindu $\mathrm{OBC}$ are marginally lower at 12 percent and ten percent, respectively.

We find that across caste and religious groups, Christian Adivasis (56 percent) seem to benefit the most from the central employment scheme, NREGA, followed by Hindu Dalit respondents (30 percent) (Figure 4.1.8). Hindu Adivasis ( 37 percent) and $\mathrm{OBC}$ respondents (35 percent) also benefit

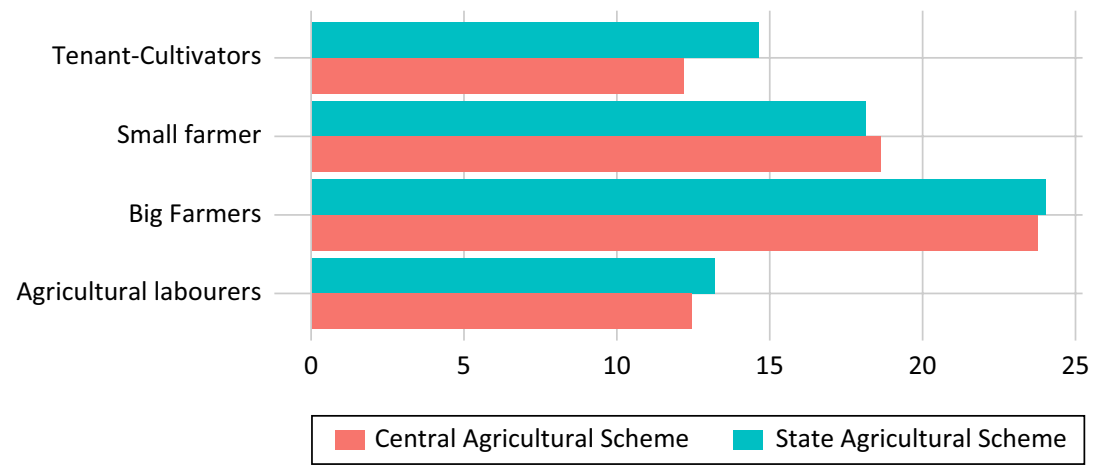

Figure 4.1.6 Beneficiaries of Central and States' Agricultural Schemes (by Type of Farmer) 


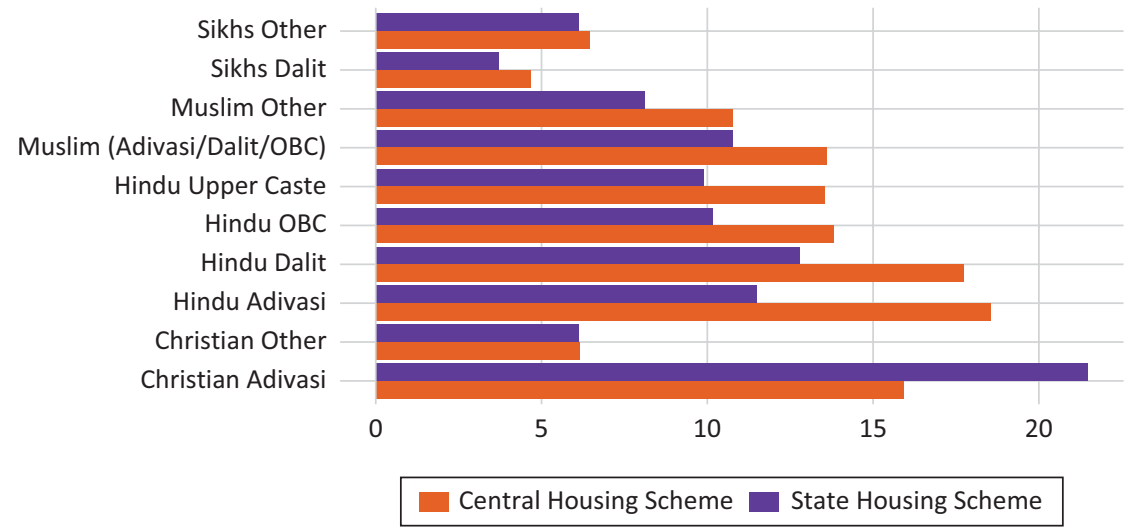

Figure 4.1.7 Beneficiaries of Central and States' Housing Schemes (by Caste/ Communities)

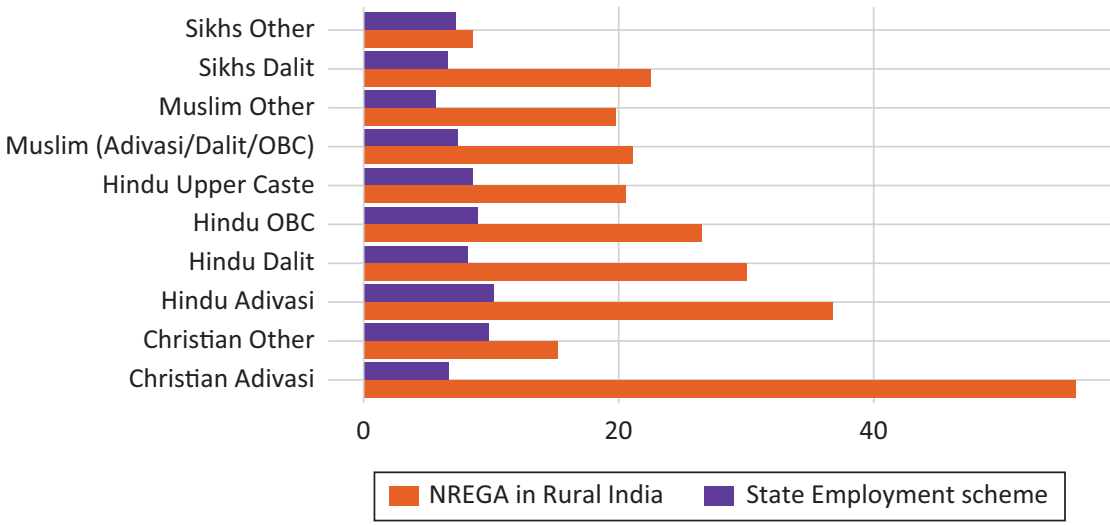

Figure 4.1.8 Beneficiaries of Central and States' Employment Schemes (by Caste/ Communities)

from the central scheme. "Other Sikhs" and "Other Christians" are the castes that benefit the least with only eight and 15 percent respectively. The state employment schemes have relatively low percentages of beneficiaries across all castes and religions (ten percent or less).

Across caste and religion groups, the Pradhan Mantri Jan Aushadhi Yojana does not appear to find much support (Figure 4.1.9). In general, a greater share of respondents seems to benefit from state health schemes, 


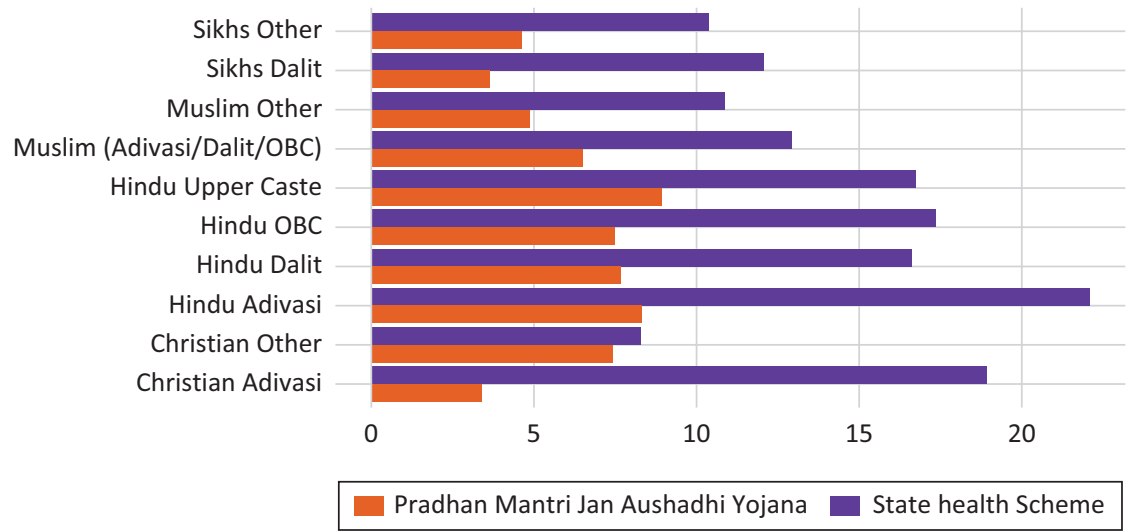

Figure 4.1.9 Beneficiaries of Central and States' Health Schemes (by Caste/ Communities)

especially Hindu and Christian Adivasi respondents $(22$ percent and 18 percent, respectively).

\subsubsection{Citizens' Experience in Availing of Public Services}

A heat map of ease of availing various services - with darker shades representing a higher share of respondents who find it easy to avail a service, shows that admission to government schools is seen as very accessible in Assam, Bihar, Kerala, Madhya Pradesh, Odisha, Tamil Nadu, Jharkhand, Chhattisgarh, and Uttarakhand (Figure 4.1.10). Nine out of every ten respondents in these states say it is easy for them to avail the education services. On the contrary, respondents in Delhi don't find government school education to be as accessible and only three-fifths of the respondents in Delhi report finding it easy to avail government school admission. Four out of every five respondents in Kerala, Madhya Pradesh, and Tamil Nadu report finding admission to government hospitals to be easy. On the other hand, less than 50 percent of the respondents in Haryana, Delhi, and West Bengal report finding it easy. More than seven out of every ten respondents in Andhra Pradesh, Kerala, Mizoram, and Delhi find it easy to access electricity connection. However, in Haryana, Rajasthan, and West Bengal the proportions drop to 43 percent, 45 percent and 39 percent respectively. Both water connection and garbage collection services are not as easy to access as other services. While respondents in Kerala, Maharashtra, Mizoram, Punjab, Delhi, and Uttarakhand find it easy to avail water connection, less than 30 percent of the respondents in Assam, Odisha, Uttar Pradesh, West Bengal, and Jharkhand feel the same. Availing garbage collection service was 

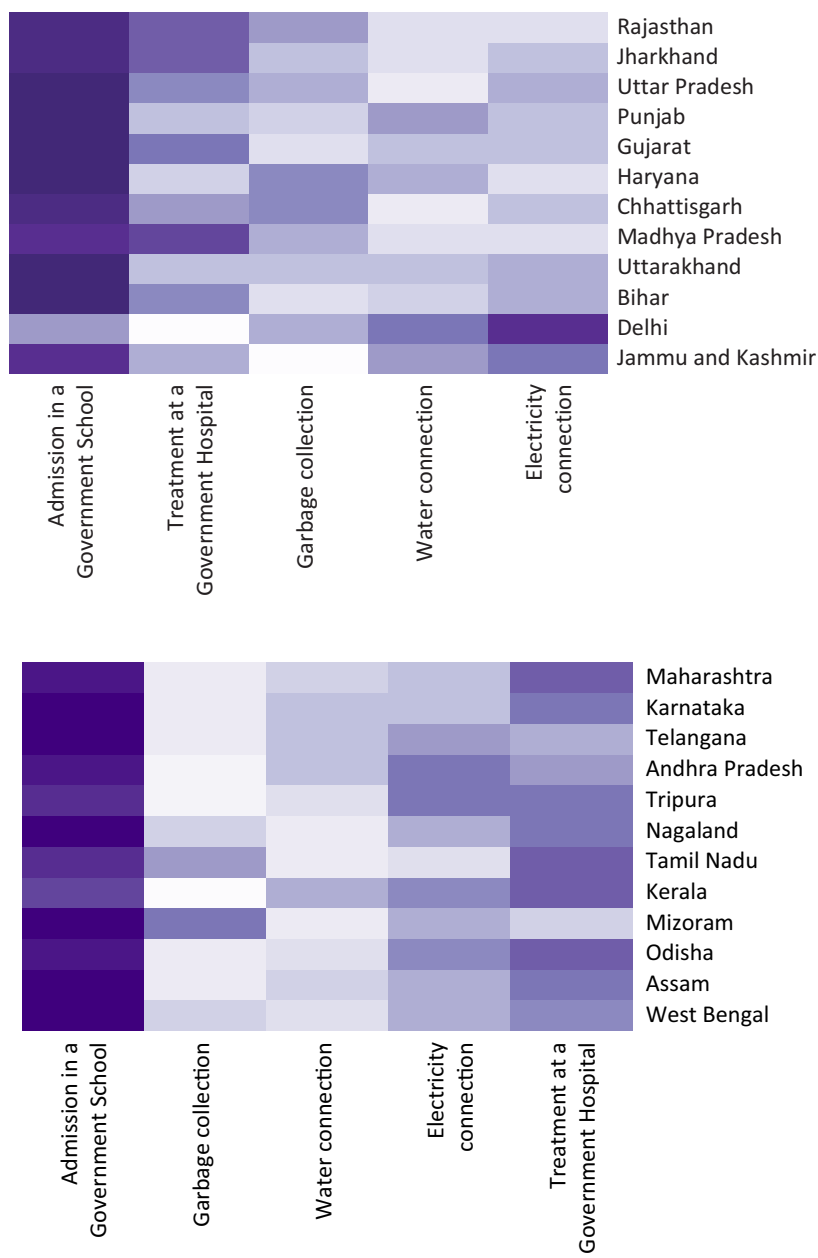

Figure 4.1.10 Experience Availing of Public Services (by State)

the easiest in Mizoram, 80 percent, followed by Chhattisgarh, Tamil Nadu, Madhya Pradesh, and Haryana with 76 percent, 68 percent, 66 percent, and 64 percent respectively.

Caste and religious identity of respondents shapes the experience of availing the public services (Figure 4.1.11). Hindu upper caste, OBC, and, to some extent non-Adivasi Christians, find it largely easy to avail of all services. Large proportions of respondents across caste-communities find it easy to access education in government schools. Similarly, relatively large proportions report easy access to treatment at a government hospital. Less 


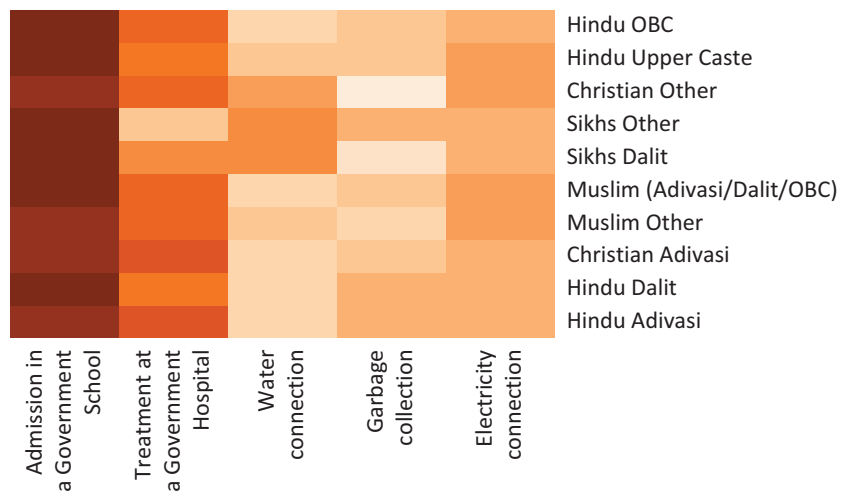

Figure 4.1.11 Experience Availing of Public Services (by Caste/Communities)

than a majority of Hindu Dalit, Hindu Adivasi, Muslim communities, and Christian Adivasi find it easy to receive water connections. Additionally, less than a majority of Hindu Adivasi, Muslim communities, Sikh Dalit, and Christian Adivasi respondents find it easy to access garbage collection services. Generally, Hindu and Sikh Dalits as well as Muslims do not find it easy to avail public services (with the exception of education and health).

\subsubsection{Institutions Preferred by Citizens}

A heat map of the institutions that citizens approach in order to get important work done across states - where darker shades represent a greater share of citizens who approach a particular institution or person - shows that in Chhattisgarh and Punjab more than eight out of every ten respondents report that they will approach the councillor to get important work done (Figure 4.1.12). In Andhra Pradesh, Assam, Haryana, Madhya Pradesh, Odisha, and Telangana about one in every two respondents state that they will approach a councillor to get important work done. Across most states we find that the preference for approaching a councillor or sarpanch is the highest. In Tripura and Karnataka, one out of every three respondents report approaching local political leaders to get their important work done more than any other state. In Nagaland and Mizoram, preference to approach elders outside the family is the highest. In Mizoram, 18 percent of respondents report that they will approach religious leaders and 16 percent prefer to approach NGOs.

In rural areas, a greater number of respondents (42 percent) report that they will approach the sarpanch or the councillor, followed by local 


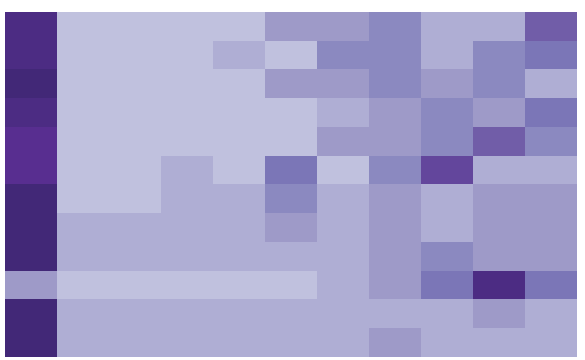

Bihar

Uttar Pradesh

Jharkhand

Uttarakhand

Jammu and Kashmir

Gujarat

Rajasthan

Madhya Pradesh

Haryana

Delhi

Punjab

Chhattisgarh

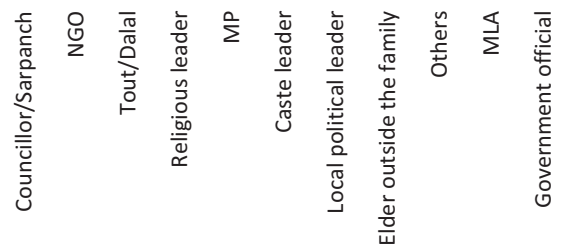

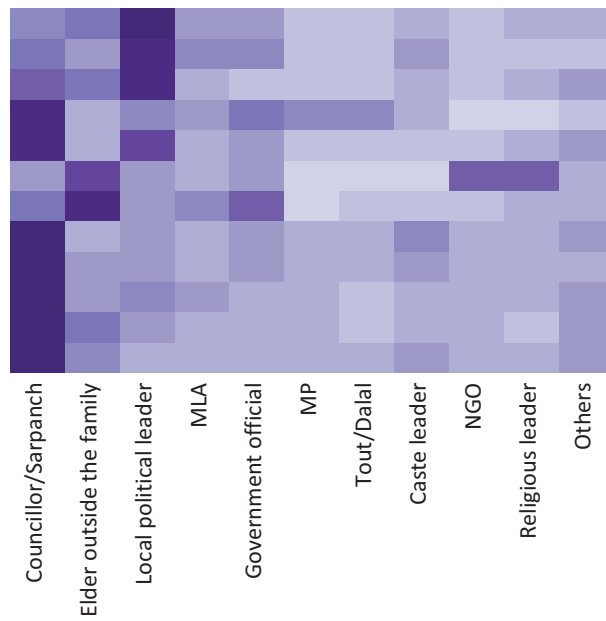

Tripura

Karnataka

West Bengal

Tamil Nadu

Kerala

Mizoram

Nagaland

Telangana

Andhra Pradesh

Assam

Maharashtra

Odisha

Figure 4.1.12 Institutions to Approach to Get an Important Work Done (by State)

political leaders (12 percent), to get their work done (Figure 4.1.13). In the urban localities, 35 percent of the respondents claim that they will approach a councillor to get their work done, followed by 13 percent of respondents preferring to approach government officials, and nine percent who will approach an MLA to get their work done. Compared to rural areas (12 percent) a marginally lower proportion of respondents in urban areas (11 percent) report that they would approach elder outside family. 


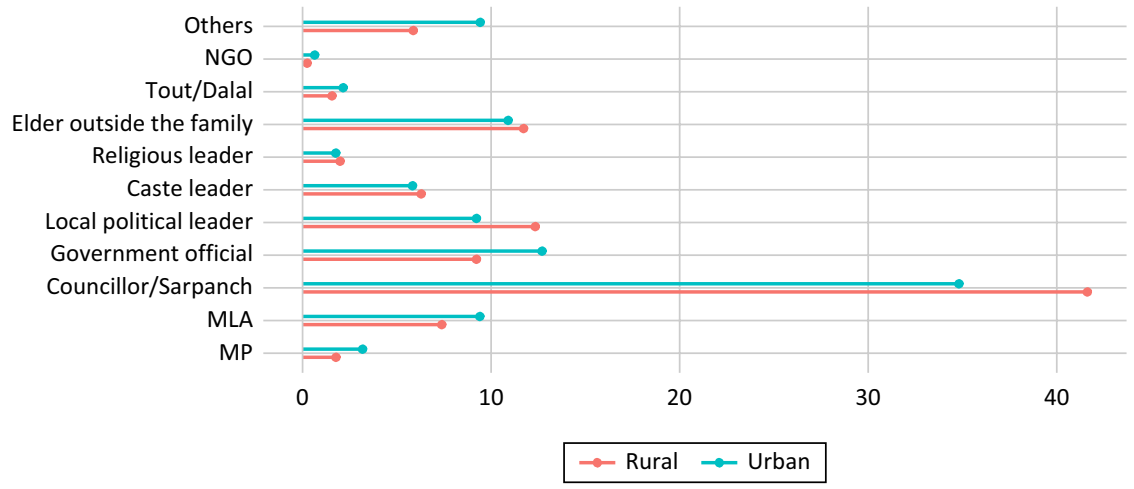

Figure 4.1.13 Institutions to Approach to Get Important Work Done (by RuralUrban)

Across levels of education, we find that most of the respondents prefer to approach a councillor or sarpanch to get important work done (Figure 4.1.14). A larger share of non-literate respondents (50 percent), compared to their college educated counterparts (32 percent), prefer approaching sarpanch or councillors. Fifteen percent of the college educated respondents also report that they approach government officials and this proportion declines to about six percent as level of education decreases. The likelihood of approaching a local political leader also increases marginally with the level of education.

\subsubsection{Dispute Resolution}

In Punjab, 62 percent of respondents prefer family members as the forum to resolve property disputes (Figure 4.1.15). In Jammu and Kashmir, Kerala, Madhya Pradesh and Maharashtra, Uttar Pradesh, and Delhi, more than 50 percent of respondents prefer to resolve property disputes through family. In Mizoram, 52 percent of the respondents prefer to approach the court to resolve their property related disputes while in Assam, (39 percent), Rajasthan (38 percent), Jharkhand (34 percent), West Bengal (32 percent), and Tripura (30 percent) respondents prefer neighbourhood or village elders. Caste and community organizations are found to be an important forum in Nagaland (16 percent) and Jammu and Kashmir (15 percent) to resolve property disputes, whereas 22 percent in Kerala and 16 percent in Tamil Nadu prefer resolving disputes through the police.

In most states, greater proportions of citizens prefer family members to resolve marital disputes (Figure 4.1.16). In Nagaland (69 percent), Punjab (66 percent), and in Jammu and Kashmir (66 percent) respondents prefer to 


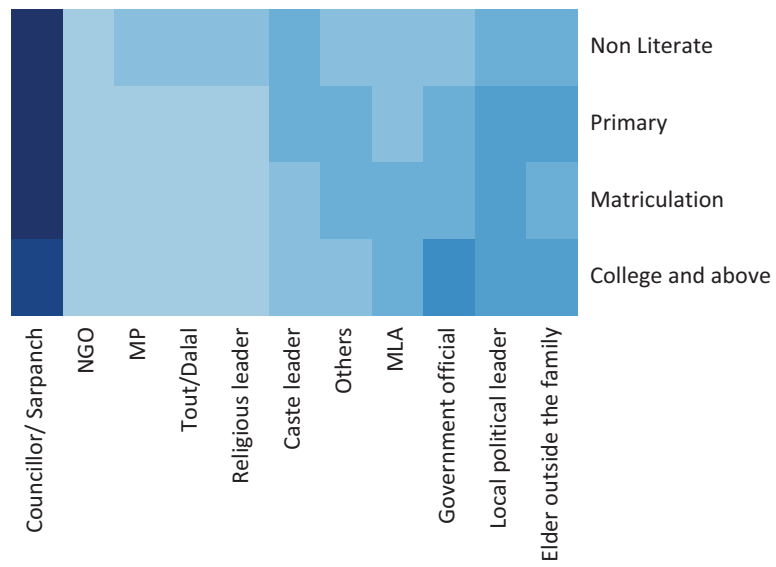

Figure 4.1.14 Institutions to Approach to Get Important Work Done (by Education)

resolve marital disputes through family members. However, in Jharkhand, neighbourhood and village elders are the most preferred institution to resolve marital disputes. One third of the respondents in Andhra Pradesh, Assam, Chhattisgarh, Rajasthan, and Uttar Pradesh prefer to resolve marital disputes through neighbourhood and village elders. In Mizoram, other than family members, respondents prefer to resolve marital disputes through courts. In Kerala (23 percent) and Tamil Nadu (17 percent) respondents also prefer approaching the police to resolve their marital disputes. In Rajasthan (24 percent), Telangana (22 percent), Andhra Pradesh (19 percent), and Bihar (18 percent) respondents prefer working with caste and community organizations to resolve marital disputes.

Most respondents in the states prefer to resolve neighbourhood disputes through neighbourhood or village elders (Figure 4.1.17). This is higher in Assam (70 percent) and Nagaland (58 percent). In Punjab, a little over one third of respondents prefer to resolve neighbourhood disputes with family members. One in five respondents in Jammu and Kashmir, Nagaland and Telangana also prefer to resolve neighbourhood disputes through caste community organizations. In Delhi, Kerala, and Andhra Pradesh, a little more than one fourth of respondents say they would approach the police to resolve neighbourhood disputes. One fifth of respondents in Mizoram prefer to resolve neighbourhood disputes through the courts.

Over 60 percent of respondents in Madhya Pradesh, Punjab, and Jammu and Kashmir prefer to approach family members to resolve disputes related to domestic violence (Figure 4.1.18). In Kerala (49 percent) and Mizoram (54 percent) and between 20 and 38 percent respondents in Andhra Pradesh, 

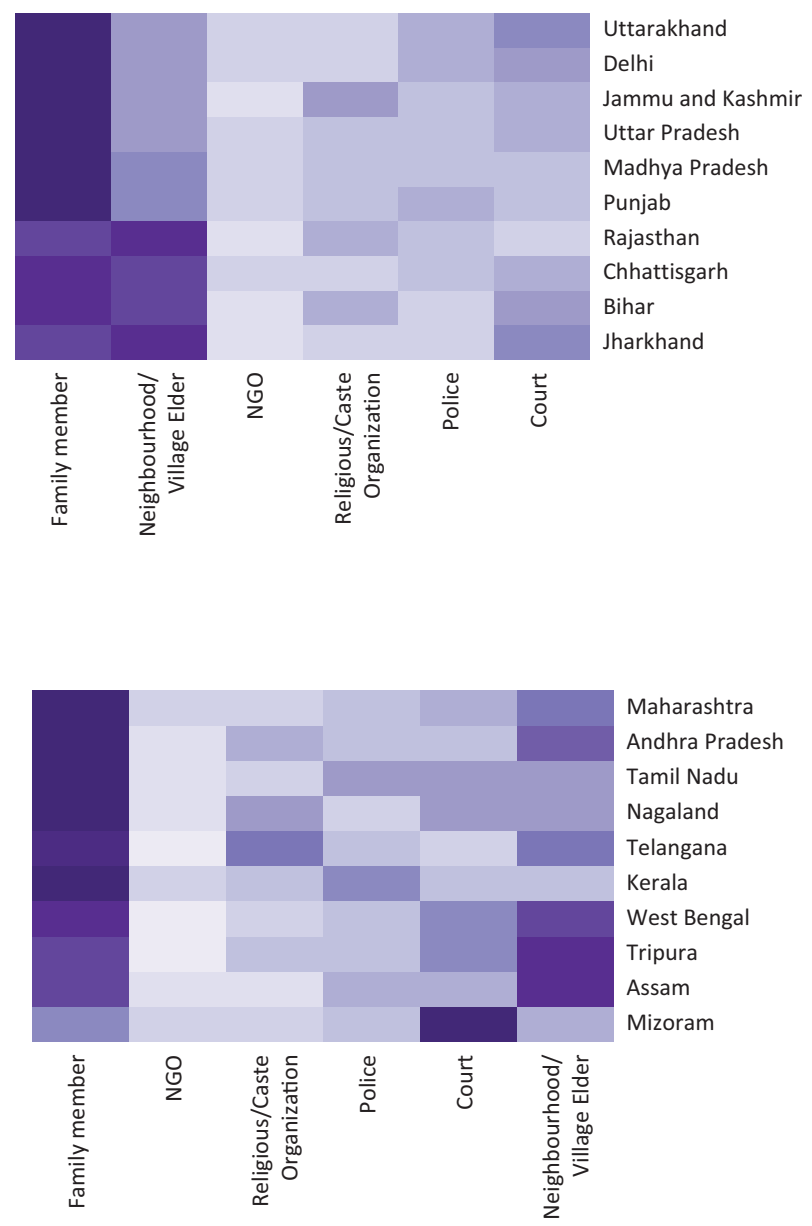

Figure 4.1.15 Preferred Forums to Resolve Property Disputes (by State)

Tamil Nadu, Tripura, West Bengal, Delhi, Chhattisgarh, Uttarakhand, and Telangana state that they would like to approach the police to resolve disputes related to domestic violence. In Nagaland and Telangana, preferences for caste or community organizations to resolve domestic violence disputes is higher than in any other state. Furthermore, in Mizoram (16 percent), Jharkhand (11 percent), and Maharashtra (ten percent) people prefer to approach courts to resolve disputes related to domestic violence. 

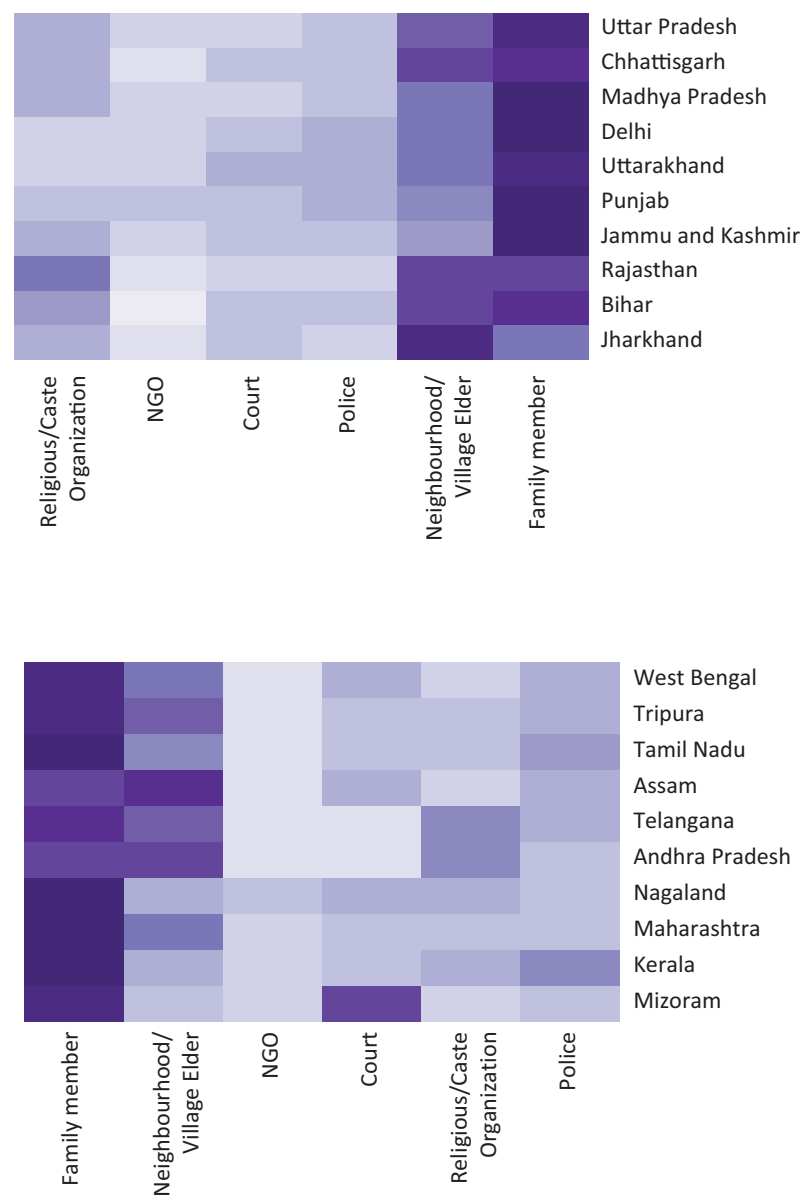

Figure 4.1.16 Preferred Forums to Resolve Marital Disputes (by State) 


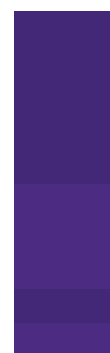

Rajasthan

Bihar

Madhya Pradesh

Jharkhand

Uttar Pradesh

Punjab

Jammu and Kashmir

Uttarakhand

Chhattisgarh

Delhi
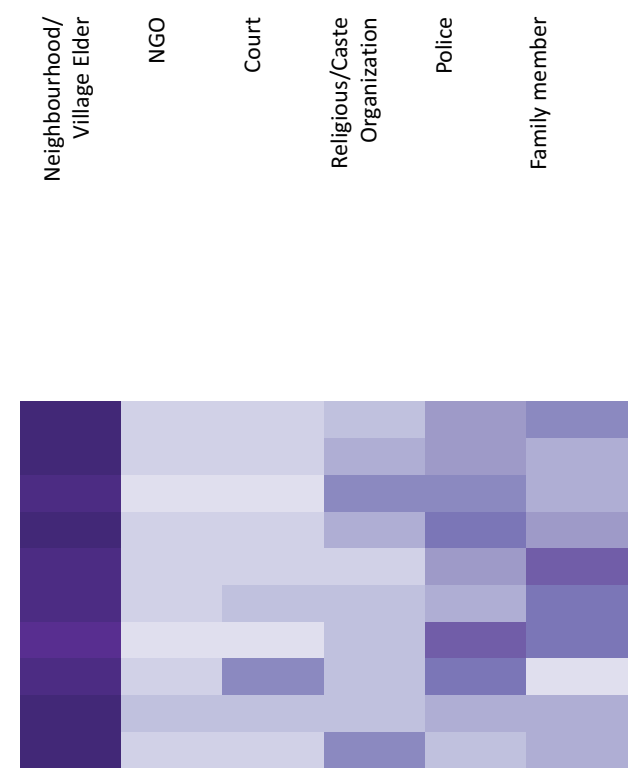

West Bengal

Tripura

Telangana

Andhra Pradesh

Tamil Nadu

Maharashtra

Kerala

Mizoram

Assam

Nagaland

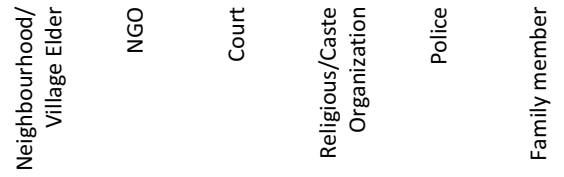

Figure 4.1.17 Preferred Forums to Resolve Neighbourhood Dispute (by State) 


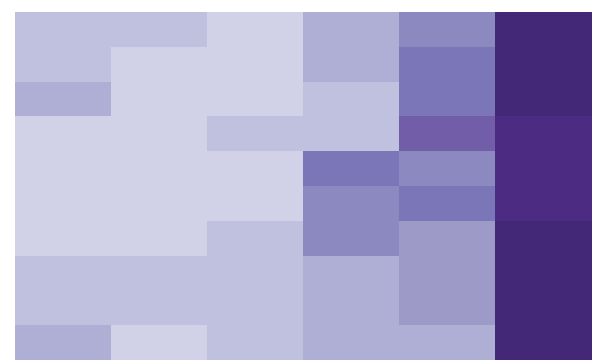

Uttar Pradesh

Rajasthan

Bihar

Jharkhand

Uttarakhand

Chhattisgarh

Delhi

Madhya Pradesh

Punjab

Jammu and Kashmir
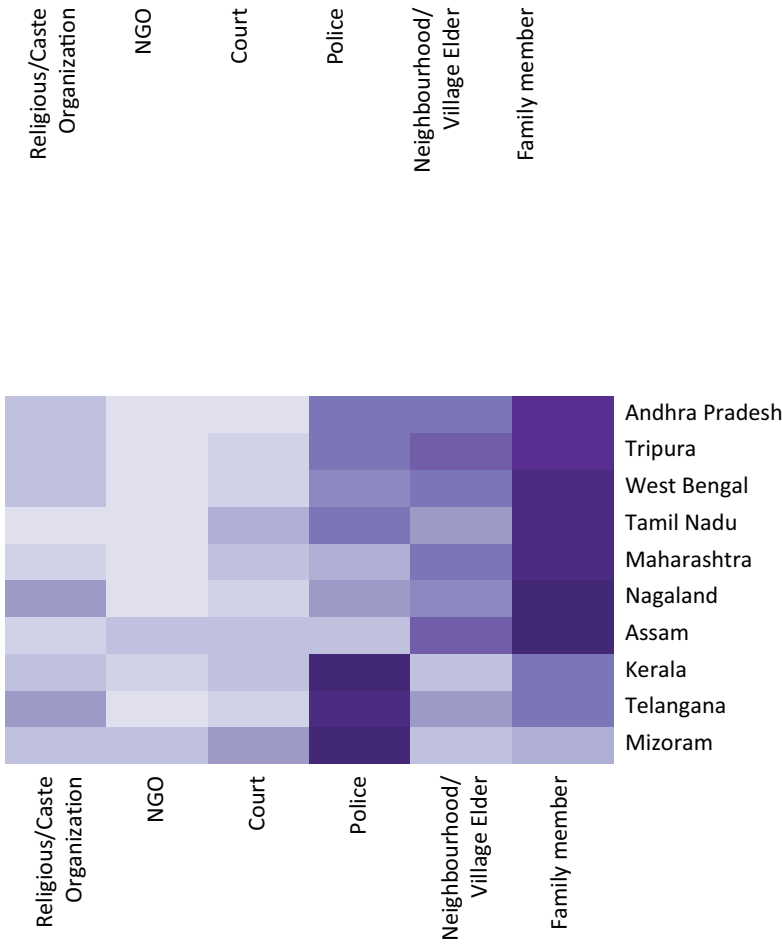

Figure 4.1.18 Preferred Forums to Resolve Dispute Related to Domestic Violence (by State) 


\subsection{GOVERNING LAND}

In the post-reform era, no policy issue has come to dominate the political landscape as has the economic governance of land. The constant demand for land in order to build large scale infrastructure projects such as roads, railways, waterways, dams, power plants, and other forms of physical capital - such as factories - generally considered to generate employment and increase standards of living, often contends with the willingness of farmers to give up their land. Given the economic dependence on land for a significant populace and the symbolic attachment of farmers to their land as well as the significance of rural constituencies to political leaders during elections, addressing the issue of rights over (agricultural) land, and the boundaries of eminent domain emerge as central tasks of economic governance between elections.

At the heart of the debates on land acquisition lies the scope of eminent domain powers exerted by the State. Should the State have extensive powers to acquire the land deemed necessary for development? Or does democratic governance imply self-imposed limits to the boundaries of eminent domain? Does the State have the rights to acquire, without consent, privately owned land for projects deemed "developmental" or in the "national interest"? In India, comprehensive reform in land acquisition was passed in the form of the Right to Fair Compensation and Transparency in Land Acquisition, Rehabilitation and Resettlement Act (2013), replacing the a colonial era law, the Land Acquisition Act (1894). In contrast to the 1894 law, the 2013 Act narrowly defined "public purpose", or the types of projects for which land (including multi-cropped land) could be acquired. It required the consent of 70-80 percent of landowners if the project was for a private company or a public-private partnership.

The level of compensation was set at two to four times the prevailing market prices, and the 2013 Act also prescribed a set of minimum norms for the resettlement and rehabilitation of displaced persons. Additionally, a social impact assessment (SIA) was made mandatory in order to determine the potential benefits and the social costs. A recent amendment, The Right to Fair Compensation and Transparency in Land Acquisition, Rehabilitation and Resettlement (Second Amendment) Bill, introduced in 2015 modifies certain provisions of the 2013 Act. Most significantly, the Amendment exempts the following categories of projects from certain provisions of the 2013 Act: (i) defence, (ii) rural infrastructure, (iii) affordable housing, (iv) industrial corridors, and (v) infrastructure - including PPPs where the government owns the land. While the 2013 Act greatly curtailed the powers of eminent domain, the 2015 Amendment seeks to expand the same.

Since land acquisition is a concurrent subject, several states have also enacted laws to regulate land acquisition. Gujarat, for instance, was one of the first states to modify the 2013 Act in line with provisions in the 
2015 Amendment. Between 1992 and 2016, there were about 102 laws that were legislated with regard to land acquisition, and 87 of these were legislated by state assemblies (Wahi et al., 2017). Yet, a succession of protests across states by local farmers, unions, and activists suggests significant opposition to the proposed amendment(s), limiting the ability of several other states that have actively sought to bring changes to the laws governing land acquisition.

While there are multiple accounts of popular opposition to land acquisition by the State across the states in India, little is known about how citizens perceive the validity of actions undertaken by the State, what they think are legitimate forms of popular resistance toward State action that involves land appropriation, and acceptable State responses to such opposition.

In this section, we look at the responses of citizens on three issues: a) whether the use of force by State is preferable or should the landowners voluntarily give up the land, b) whether the landowners should be allowed to resist the government in peaceful manner or by violent methods, and c) whether the court has any role in settling the disputes over land acquisition. We ask three sets of two forced-choice questions (consisting of two opposing statements) and three response categories: "Agree with (1)" meaning agree to the first statement, "Agree with (2)" meaning agree with the second statement, and "No Opinion" if the respondent does not wish to the answer the question for any reason. Broadly, these questions measure opinions on the State's rights of land acquisition, peaceful and violent forms of resistance to land acquisition, and finally, the mechanisms of conflict resolution - be it institutional or use of force.

\subsubsection{Modes of Land Acquisition}

On the mode of land acquisition, we ask a pair of forced choice statements as follows:

Statement 1. "Landowners should give up their land in the larger interest of development".

Statement 2. "The government should be allowed to use force to displace local villagers/ landowners".

(In Haryana, Karnataka, Odisha, and Gujarat the questions are asked in a different format. Instead of forced choice, the same statements are read separately and respondents asked to agree or disagree.)

Across the states, there is majority support for voluntarily giving up land except in Andhra Pradesh (39 percent), Tamil Nadu (43 percent), and Telangana (44 percent) (Figure 4.2.1). More than one in four respondents in Bihar (30 percent), Tamil Nadu (27 percent), Jharkhand ( 23 percent), and Uttar Pradesh (23 percent) support the use of force by the State to displace landowners. 


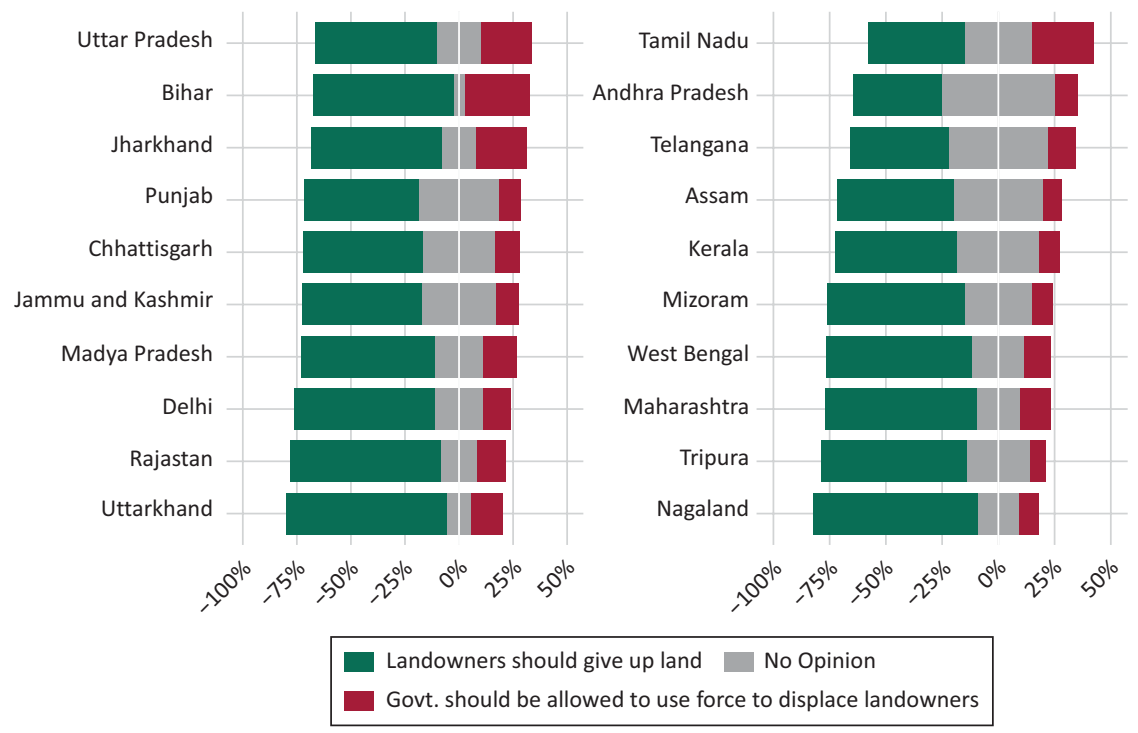

Figure 4.2.1 Modes of Land Acquisition (by State)

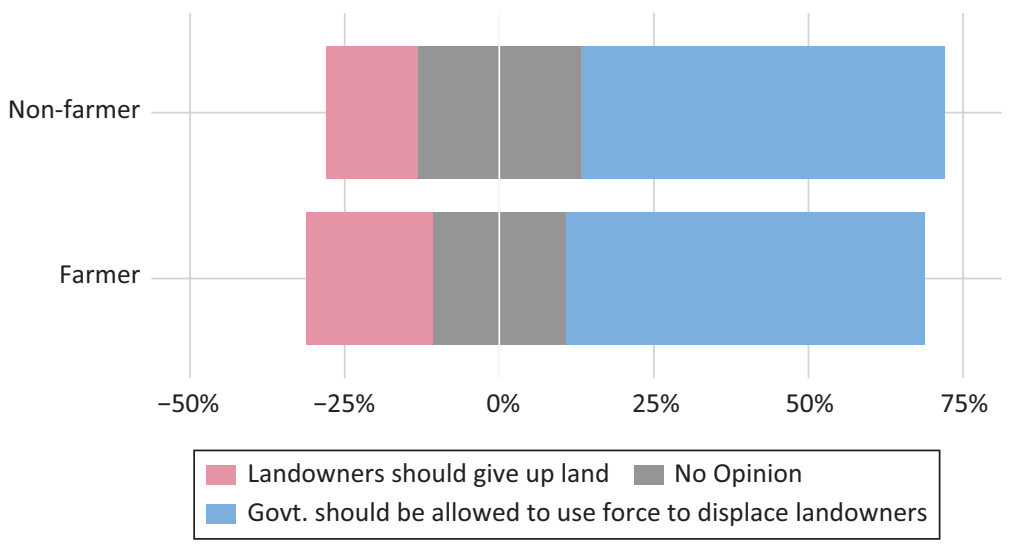

Figure 4.2.2 Modes of Land Acquisition (by Farmer-Non-Farmer)

There is no difference between the broader categories of farmers and non-farmers on the mode of land acquisition but farmers are marginally more likely to support the use of force by the State to displace landowners. However, 26 percent of non-farmers do not have an opinion (Figure 4.2.2). 


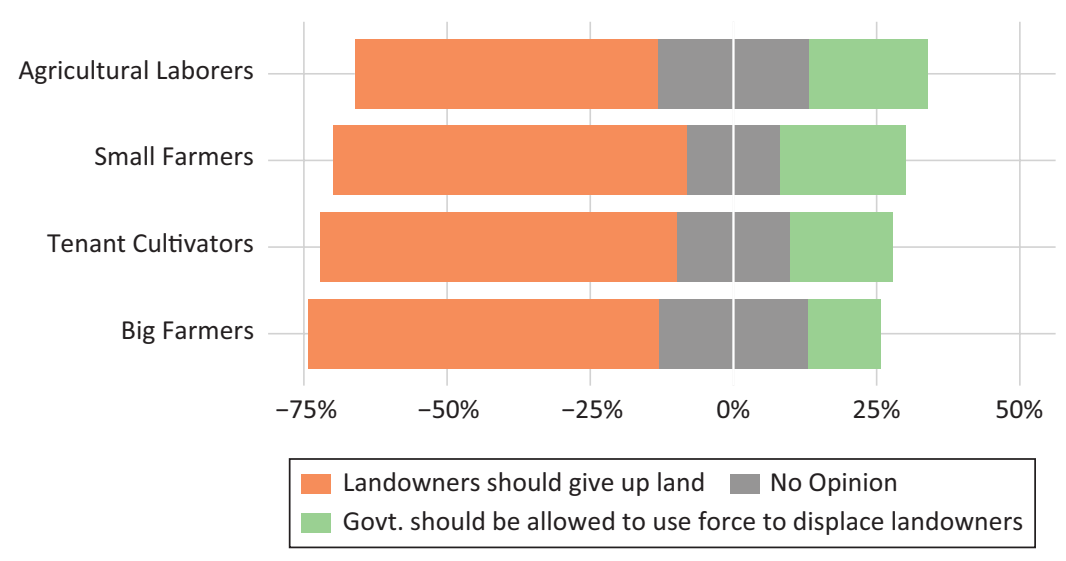

Figure 4.2.3 Modes of Land Acquisition (by Type of Farmer)

Both large and small farmers, and tenant cultivators, are marginally more likely to hold the view that land should be given up willingly as compared to agricultural labourers (Figure 4.2.3). Around 20 percent of small farmers and agricultural labourers also support the use of force by the State to displace landowners.

\subsubsection{Responses to Land Acquisition}

What are perceptions about the options citizens possess in response to land acquisition? We ask the respondents to choose between two statements:

Statement 1. "Villagers/Landowners should be allowed to continue their protest in a peaceful manner".

Statement 2. "Villagers/Landowners should be allowed to resist the government by violent methods".

(In Haryana, Karnataka, Odisha and Gujarat the questions are asked in a different format. Instead of forced choice, the same statements are read separately, and respondents asked to agree or disagree.) 


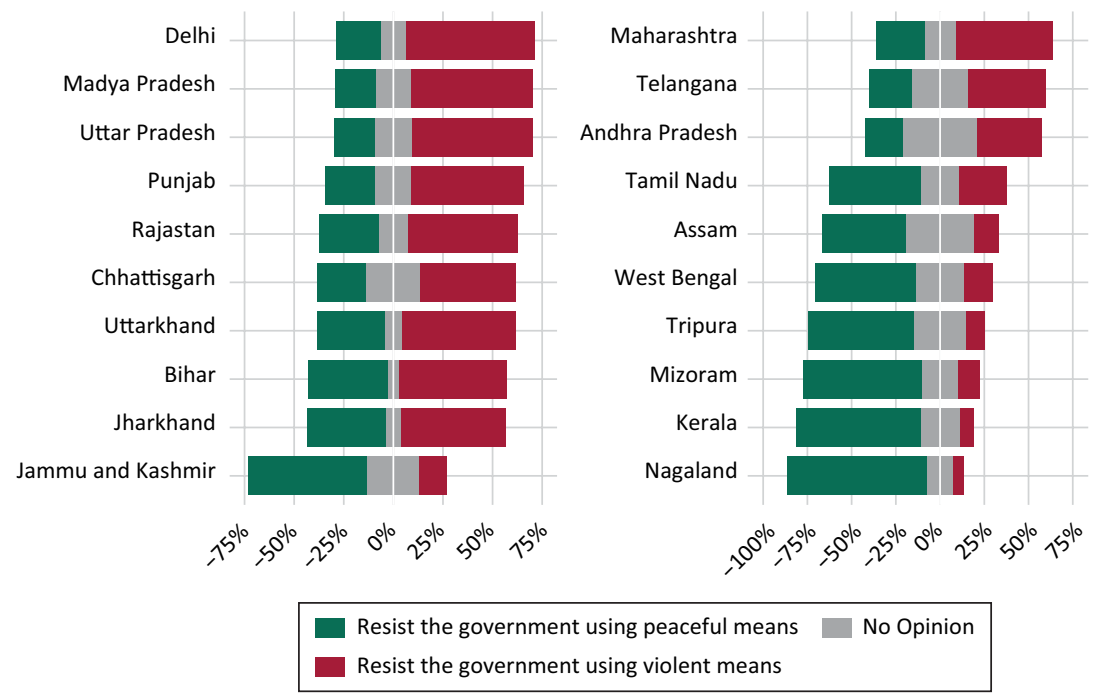

Figure 4.2.4 Response to Land Acquisition (by State)

A majority of respondents in Nagaland, Kerala, Mizoram, Tamil Nadu, Jammu and Kashmir, West Bengal, and Tripura support resistance by violent means over peaceful protests (Figure 4.2.4). In Bihar, Delhi, Madhya Pradesh, Maharashtra, Rajasthan, Uttar Pradesh, Punjab, and Uttarakhand a majority show support for peaceful protests over violent methods. In Telangana, Chhattisgarh, and Andhra Pradesh there is greater support for peaceful protests over violence and the difference is between five and 20 percentage points.

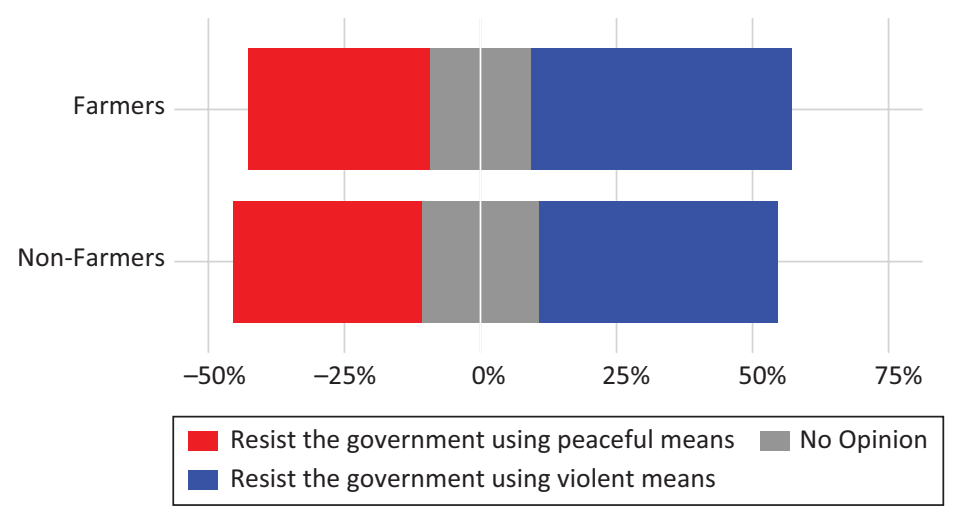

Figure 4.2.5 Response to Land Acquisition (by Farmer-Non-Farmer) 
There are no large differences between farmers and non-farmers (Figure 4.2.5). About two in five respondents among farmers and non-farmers support peaceful means. Generally, more respondents prefer peaceful means of resistance.

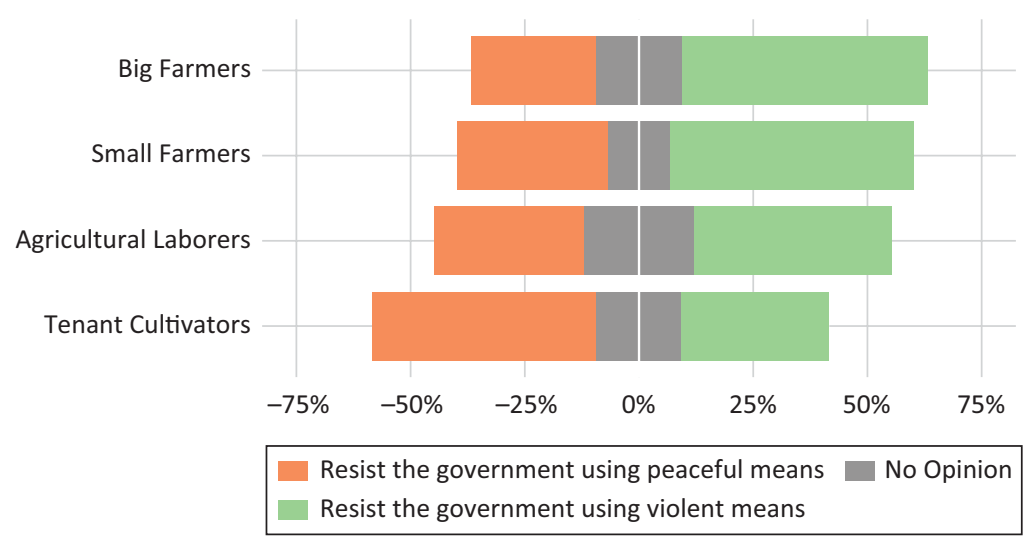

Figure 4.2.6 Response to Land Acquisition (by Type of Farmer)

A majority of big and small farmers are more likely to support peaceful resistance relative to tenant cultivators and agricultural labourers (Figure 4.2.6). About 49 percent tenant cultivators and 33 percent agricultural labourers support violent means of resistance.

\subsubsection{Dispute Resolution Over Land Acquisition}

With respect to dispute resolution in land acquisition, we ask the respondents to choose one of the two statements:

Statement 1. "Dispute over land between the government and local villagers/landowners should be settled by the court".

Statement 2. "The courts have no role to play in these disputes over land between the government and the local villagers/landowners".

(In Haryana, Karnataka, Odisha, and Gujarat the questions are asked in a different format. Instead of forced choice, the same statements are read separately, and respondents asked to agree or disagree.) 

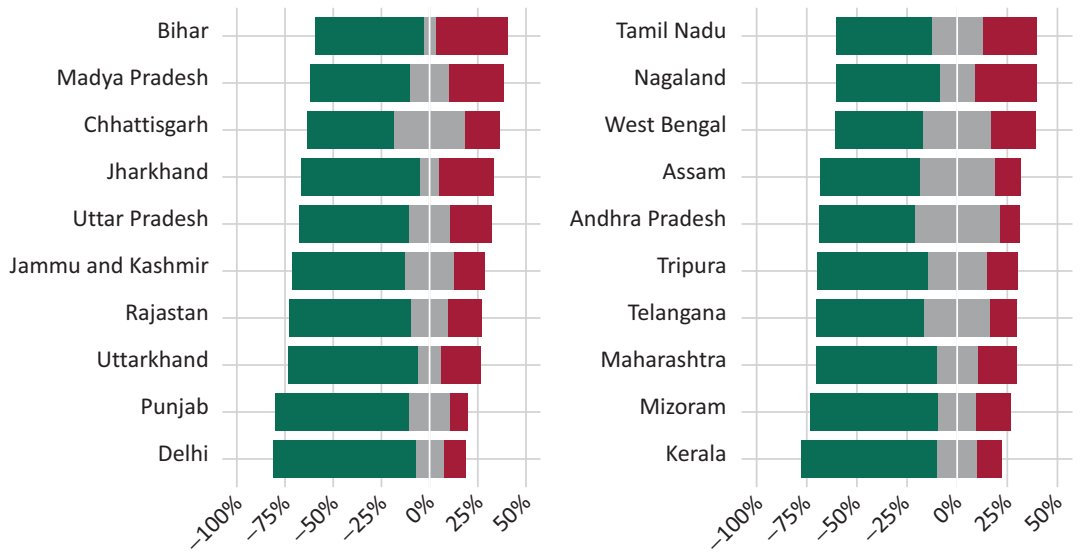

Land disputes should be settled by the Court

No Opinion

Courts have no role to play in land disputes

Figure 4.2.7 Modes of Dispute Resolution (by State)

We find that across states more respondents support the view that the courts should settle the disputes between the government and the landowners and villagers as opposed to not perceiving a role for the judiciary (Figure 4.2.7). Least support for institutional dispute resolution is seen in Andhra Pradesh (48 percent), Chhattisgarh (45 percent), Tamil Nadu (47 percent), and West Bengal (44 percent). However, support for institutional justice is higher. In Delhi, Kerala, Punjab, Uttarakhand, Rajasthan, Mizoram, Jharkhand, and Maharashtra two in three respondents support court driven dispute resolution. In Jharkhand, Tamil Nadu, and Madhya Pradesh a third respondents also state that courts have no place in dispute resolution. 


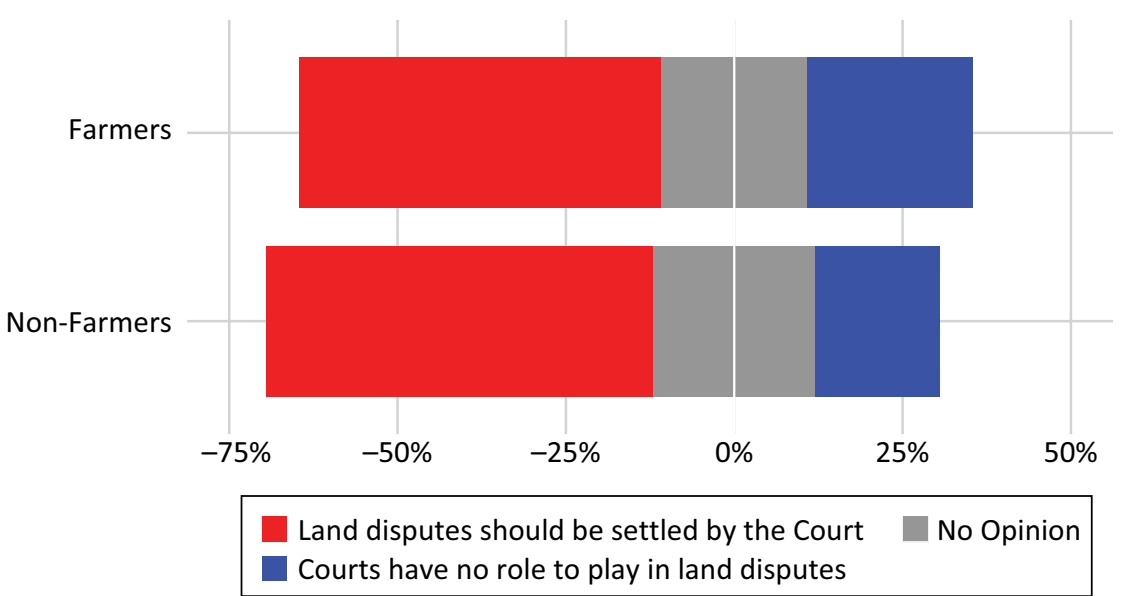

Figure 4.2.8 Modes of Dispute Resolution (by Farmer-Non-Farmer)

Non-Farmers are more likely to hold the view that land disputes should be settled by courts compared to farmers (Figure 4.2.8).

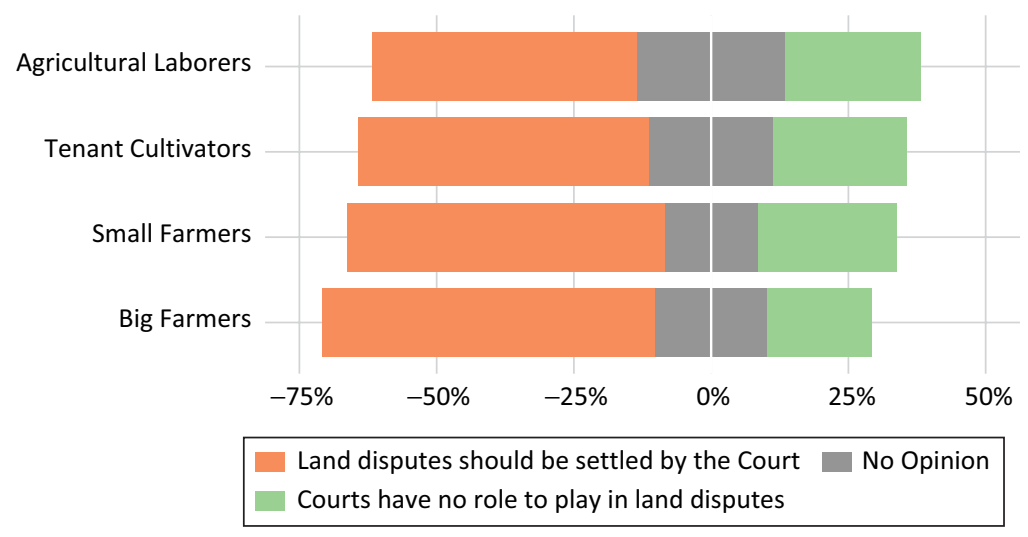

Figure 4.2.9 Modes of Dispute Resolution (by Type of Farmer)

There is broad agreement among all groups that land disputes should be resolved by courts (Figure 4.2.9). While 61 percent of big farmers believe this, 48 percent of agricultural labourer feel the same. Large farmers are also less likely to say that courts have no role to play (19 percent) compared to 25 percent for the other three categories. 


\subsection{TRUST IN INSTITUTIONS}

Constitutional democracies thrive when their institutions enjoy high levels of popular trust. An erosion of trust in public institutions can have serious repercussions for the quality of democracy and governance. Trust underpins all interactions between citizens and State institutions. Political trust is "a central indicator of public's underlying feeling about its polity" (Newton and Norris, 2000) and reflects a belief that "the system and the political incumbents are responsive and will do what is right even in the absence of constant scrutiny" (Miller and Listhaug, 1990). Empirically, studies examine trust at both the aggregate (Chanley et al., 2000) and individual levels (Mansbridge, 1997; Pew Research Center, 1998) of analysis, and focus mostly on developed nations (Cook and Gronke, 2005) with little attention paid to South Asian nations (Ramesh, 2017). In addition, citizen trust in institutions overseeing law and order (the police and the courts) is influenced by subjective perceptions of how effective and fair these institutions are in exercising authority (Lind and Tyler, 1988; Tyler and Lind, 1992, Tyler, 1990; Tyler and Huo, 2002) and allocating outcomes (Tyler et al., 1985). Whether citizens see their political institutions as effective, procedurally fair, and distributively just has a critical impact on governance as well.

This section explores citizen trust in political institutions and actors in India, perceptions of procedural fairness, distributive fairness, and the effectiveness of three important non-elected institutions - the police, government officials, and the courts.

\subsubsection{Trust in Institutions}

In order to examine public trust in various elected and non-elected political institutions, respondents are asked:

"How much trust do you have in the following institutions?" the institutions being: president, prime minister, chief minister, parliament, state assembly, Gram Panchayat/Nagar Palika, district collector, Tehsildar, military/national army, election commission, political parties, police, Supreme Court, High Court, District Court, and government officials. The respondents were given a range of response categories: "A great deal of trust", "Quite a lot of trust", "Not a lot of trust", "Not trust at all", "No Opinion".

The army, the Supreme Court and the High Court are the institutions that enjoy the highest level of trust in the country (Figure 4.3.1). Over 70 percent of the respondents express a great deal of trust in the army, followed by 54 percent in the Supreme Court and 46 percent in the High Court. Seventy five percent respondents trust (combining a great deal of trust and quite a lot of trust) the district collector. With respect to the prime minister and the chief minister, 72 percent and 69 percent of the respondents respectively, generally trust these institutions. Between 60 and 70 percent respondents 


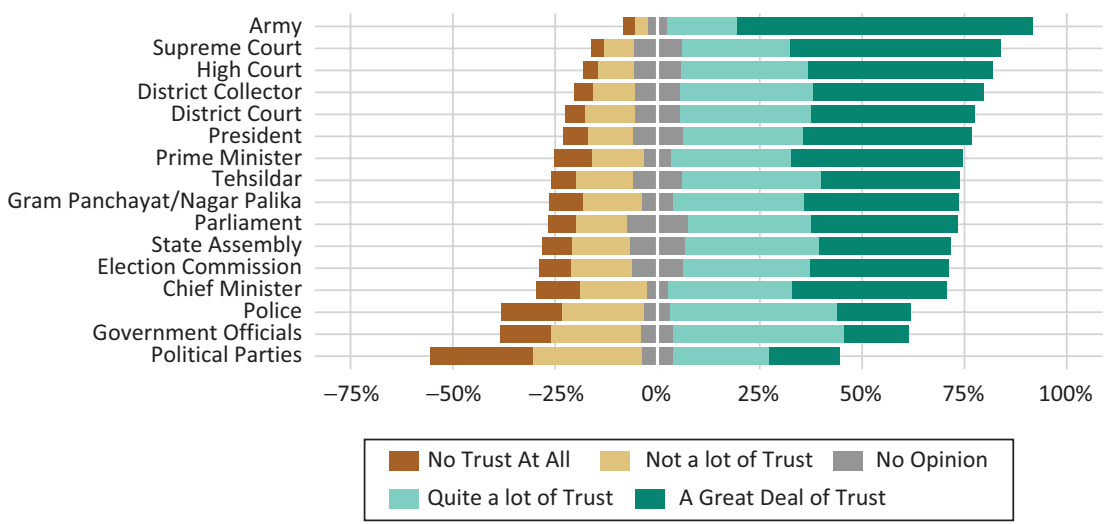

Figure 4.3.1 Trust in Institutions

trust other institutions such as the president, parliament, state assembly, Gram Panchayat/Nagar Palika, the election commission, district courts, and Tehsildar. The least trusted institutions are the police, government officials, and political parties. Fifty seven percent respondents trust the police and government officials, but this proportions falls to 42 percent in case of political parties. Close to 50 percent of respondents either have little or no trust in political parties.

We construct a measure of "effective trust" by subtracting the share of respondents who state either "No trust at all" or "Not a lot of trust" from those who say either "Great deal of trust" or "Quite a lot of trust". Positive values of effective trust signifies that more number of respondents trust than distrust the institution, and the negative values signify a net distrust of the institution (i.e., a larger proportion of respondents distrust than trust the institution).

The army enjoys the highest levels of effective trust (86 percent), followed by the Supreme Court (69 percent), High Court (64 percent), and district collector (61 percent), consistent with the earlier result (Figure 4.3.2). At the other end of the radial histogram, political parties record effective trust in the negative range i.e. this institution is distrusted more than trusted. The institutions with lowest levels of effective trust include political parties ( -9 percent), government officials ( 23 percent), and police ( 21 percent). The remaining institutions fall between the 40-59 percent range of effective trust. These include: president (55 percent), District Court (53 percent), the prime minister (48 percent), Tehsildar (48 percent), the parliament (46 percent), Gram Panchayat/Nagar Palika (45 percent), state assembly (43 percent), election commission, and the chief minister (42 percent).

We use heat maps to show effective trust across states (Figure 4.3.3). Note that the darker shades of the heat map represent a higher share of 


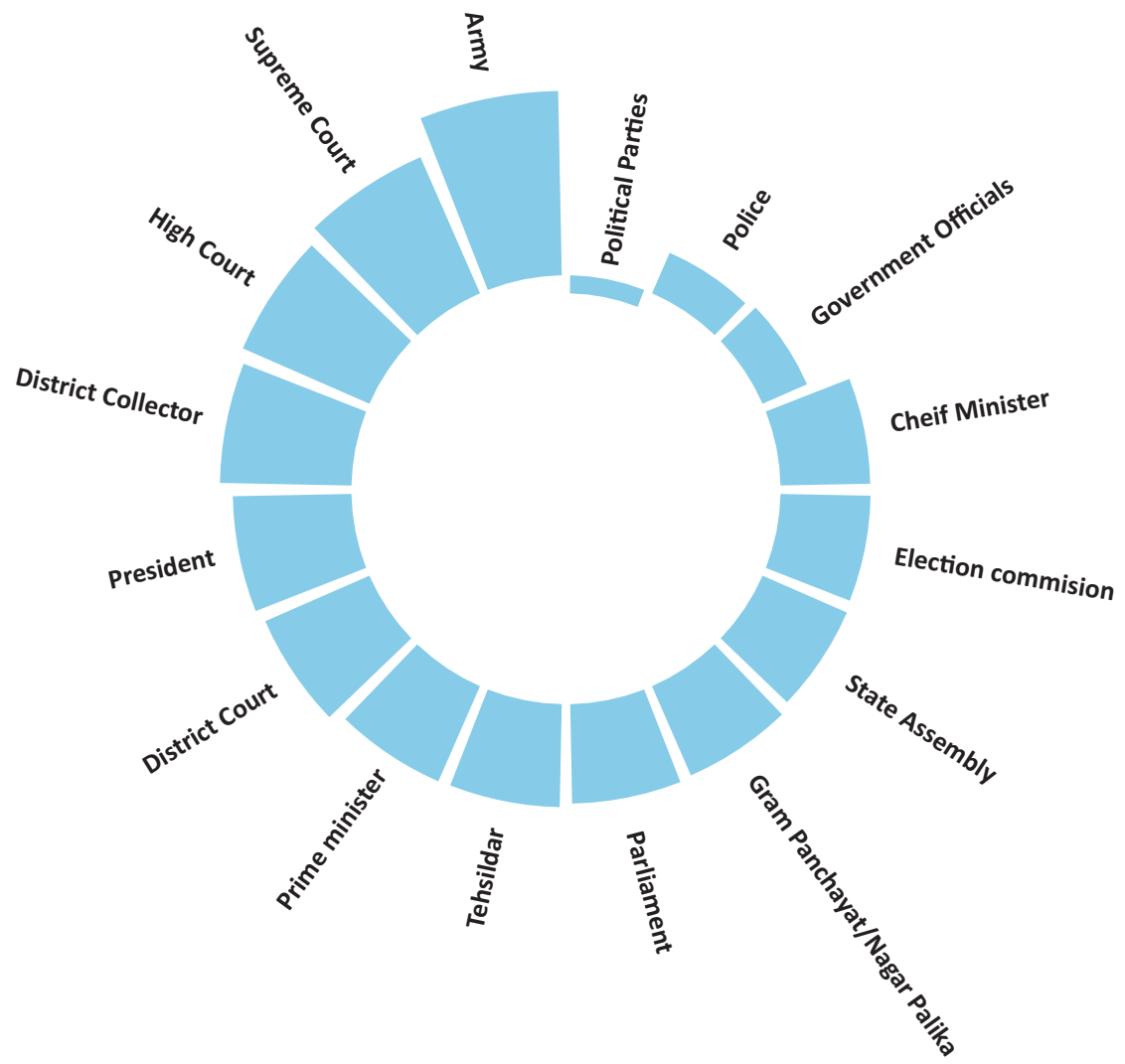

Figure 4.3.2 Effective Trust in Institutions

effective trust in a particular institution. Across most states, the army is held at the highest levels of trust and the political parties at the lowest effective trust. In Jammu and Kashmir, however, the army is among the least trusted institutions ( -12 percent) and this former state also records the lowest effective trust in political parties (-52 percent). Other than the district collector, Tehsildar, and the courts, none of the institutions in Jammu and Kashmir enjoy positive effective trust.

The second most trusted institution in most states is either the Supreme Court or the District Court. In Kerala, the effective trust in the district collector (91 percent) is similar to the army (92 percent). The prime minister enjoys high levels of effective trust in Haryana (75 percent), Karnataka (78 percent) and Chhattisgarh (80 percent), Assam (75 percent), Mizoram (77 percent), Odisha (76 percent), Tripura (81 percent), Jharkhand (78 percent), and Uttarakhand (75 percent). There is however extremely low 

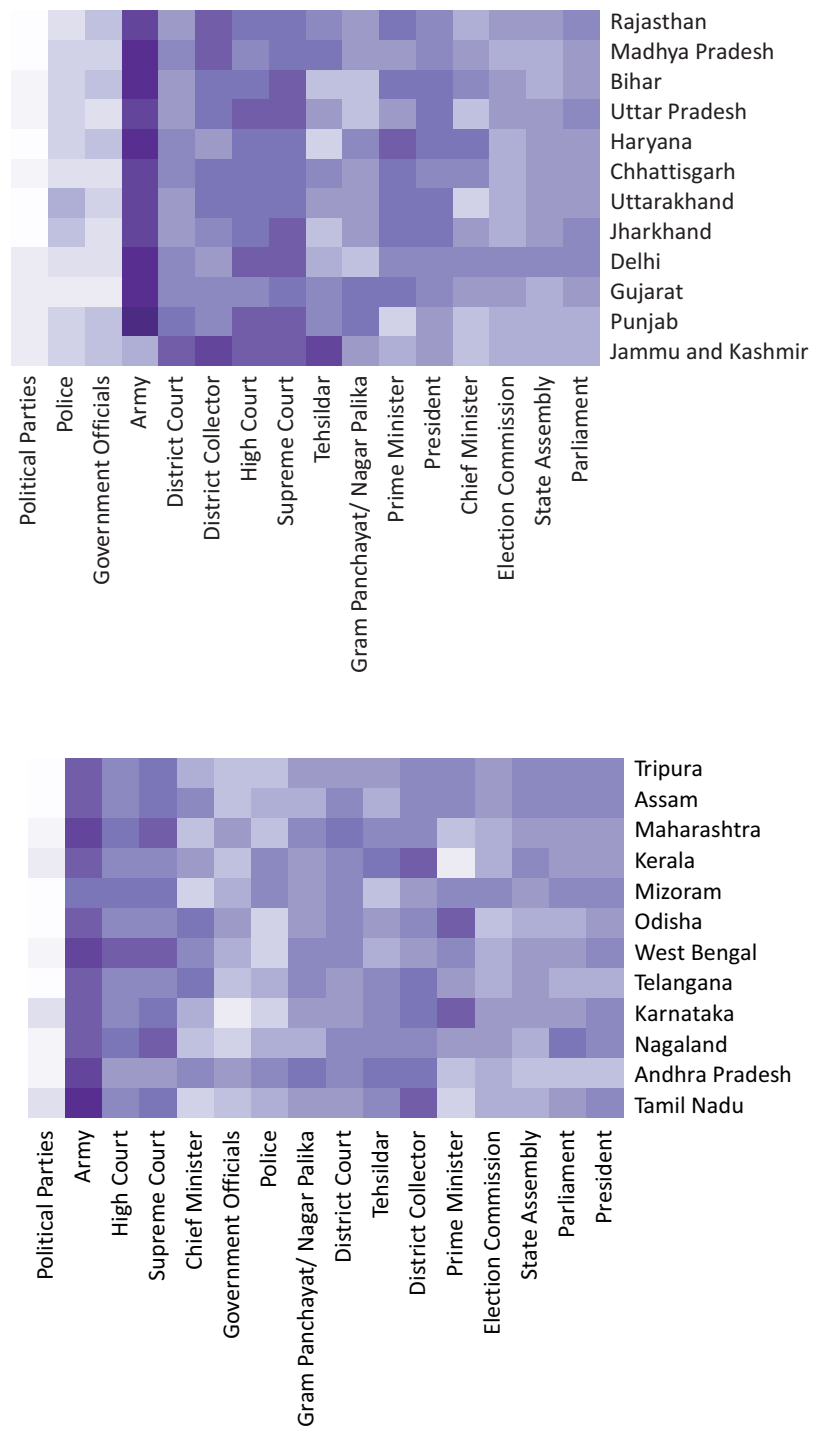

Figure 4.3.3 Effective Trust in Institutions (by State) 


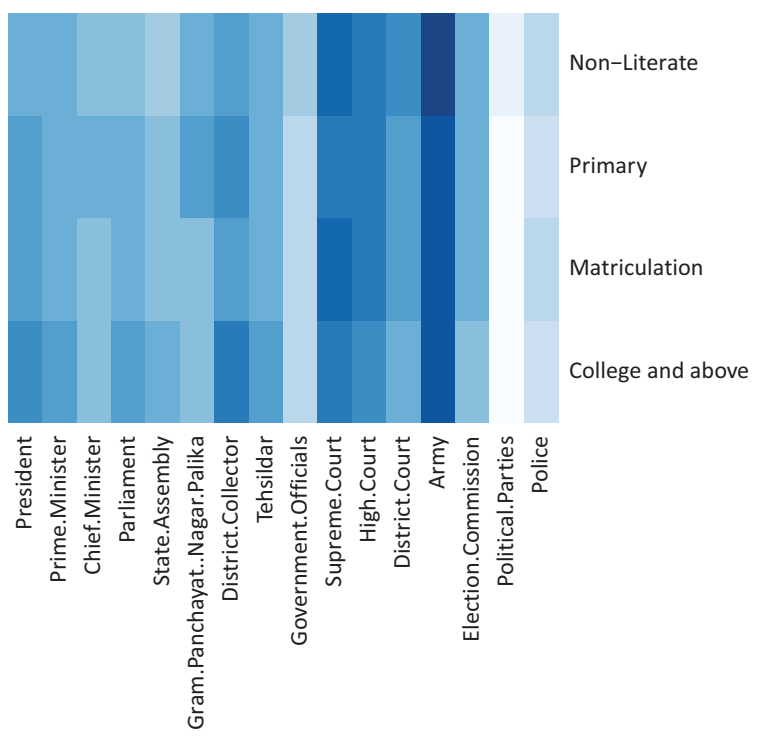

Figure 4.3.4 Effective Trust in Institutions (by Education Level)

effective trust in the prime minister in Andhra Pradesh (11 percent) and net distrust in Tamil Nadu ( -14 percent), Jammu and Kashmir ( -19 percent), and Punjab (-27 percent). Similarly, the Chief Minister also faces distrust in Jammu and Kashmir ( -28 percent), Tamil Nadu ( -24 percent) and Punjab (-17 percent). These states, along with Delhi, also record the highest distrust in political parties; over half of the respondents in Punjab and Jammu and Kashmir distrust the political parties.

Effective trust increases with levels of education for certain institutions (Figure 4.3.4). These are the president, prime minister, parliament, state assembly, chief minister, district collector, and Tehsildar. For a number of other institutions the proportion of respondents increases with education until matriculation level, and drops for those with college or above level. This is seen with Gram Panchayats, government officials, police, the Supreme Court, High Court, and the election commission. There are no large differences for the army. Distrust in political parties also appears to increase with levels of education.

Across different religious communities the army enjoys comparatively high effective trust ranging from 75 to 90 percent (Figure 4.3.5). Next come the Supreme Court and High Court with 60 percent or more effective trust. The district collector also enjoys relatively high effective trust among Hindu, Christian, and Muslim respondents (56 percent to 65 percent). Sikh respondents in general express low levels of effective trust for all 


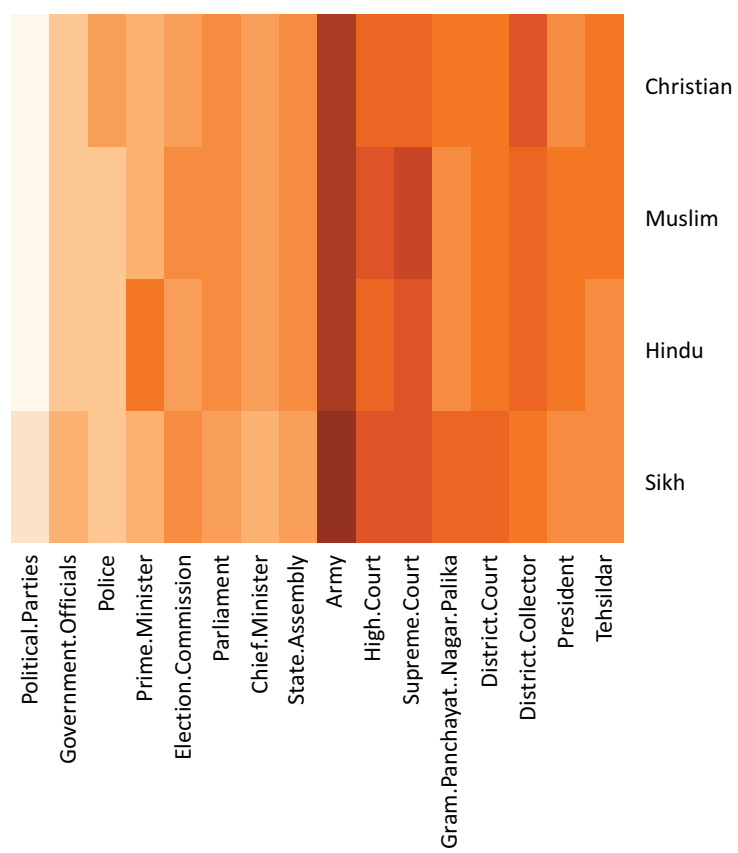

Figure 4.3.5 Effective Trust in Institutions (by Religion)

institutions. Fifty four percent of Hindu respondents express effective trust in the prime minister but the proportion of other religious minorities doing so drops sharply. Other institutions such as the parliament, chief minister, state assembly, Gram Panchayat/Nagar Palika, election commission, and Tehsildar record effective trust in the range of 35 to 53 percent among Hindu, Muslim, and Christian respondents. Government officials and the police show lower levels of effective trust, between 18 to 35 percent, but is negative for Sikh respondents. Political parties record negative effective trust across all groups.

\subsubsection{Institutional Effectiveness and Procedural Fairness}

In order to measure perceptions of effectiveness in decision making and procedural fairness, respondents are asked to what extent they agree or disagree on a battery of four statements pertaining to three institutions - police, government officials, and courts. The questions state:

"I am now going to read out some statements about the police/courts/ government officials and the nature of the decisions made by them. Please tell me how much you agree or disagree with the following statements". 


\section{Police}

a. If a citizen were to report a crime to the police, quick action would be taken.

b. The police in the (state) generally take bribes.

c. The decisions made by the police are unduly influenced by political parties/ politicians.

d. Police generally treats people with respect.

\section{Government Officials}

a. If a citizen approached with a problem, quick action would be taken.

b. The government officials in (state) generally take bribes.

e. The decisions taken by the government officials are unduly influenced by political parties/ politicians.

f. Government officials generally treats people with respect.

\section{Courts}

a. It is highly likely that an innocent person will be convicted.

g. It is highly likely that a guilty person will be acquitted.

h. The decisions made by the court are unduly influenced by political parties/politicians.

i. Court officials in (state) generally take bribe.

Figure 4.3.6 Statements on Effectiveness and Procedural Fairness

These statements consist of positive and negative assertions that point to the quality of decision making i.e., effectiveness in action, and the quality of decision making i.e., fairness in procedure. The response categories include: "Strongly Agree", "Somewhat Agree", "Somewhat Disagree", "Strongly Disagree" and "No Opinion".

For the police and government officials, the statements consist of two positive assertions on respectful interaction and quick action, and two negative assertions on bribery and political influence (Figure 4.3.6). For courts, four negative assertions on effectiveness were measured by respondents' opinion of whether individuals would be wrongly convicted or acquitted. Similarly, procedural fairness for the courts focuses on the perceived level of corruption and political influence.

We create an index of effectiveness and procedural fairness by recoding and summing the positive and negative statements. For instance, for a positive assertion, "Strongly Agree" and "Somewhat Agree" are coded as " 1 " and "Strongly Disagree and "Somewhat Disagree" are coded "0". The opposite coding scheme is used for negative assertions about the institution. The responses are then summed into three categories "Largely Positive" (if the resulting value is 3 or 4), "Neutral" (if the value is 2), and "Largely negative" (if the value is 0 or 1 ).

In Andhra Pradesh (42 percent), Haryana (48 percent), Jammu and Kashmir (54 percent), Punjab (63 percent), West Bengal (64 percent), and 
Delhi (65 percent) the police are seen as ineffective and procedurally unfair, while a majority hold a neutral view in the other states (Figures 4.3.7- 4.3.9). Similarly, more respondents in Andhra Pradesh (42 percent), Nagaland (46 percent), Punjab (57 percent), West Bengal (59 percent), and Delhi (64 percent) consider government officials to be ineffective and procedurally unfair, while others hold a mostly neutral view. Most respondents from all states see the courts as ineffective and procedurally unfair.

Between 45 percent and 57 percent Hindu, Christian, and Muslim respondents, hold a neutral perception about the police and government officials (Figures 4.3.10-4.3.12). Among these groups the proportion of respondents having a positive view is 20 percent or less. A third of these respondents also have a negative view of the Police and government officials. However, a majority of the Sikh respondents consider the police (57 percent) and government officials (52 percent) to be ineffective and
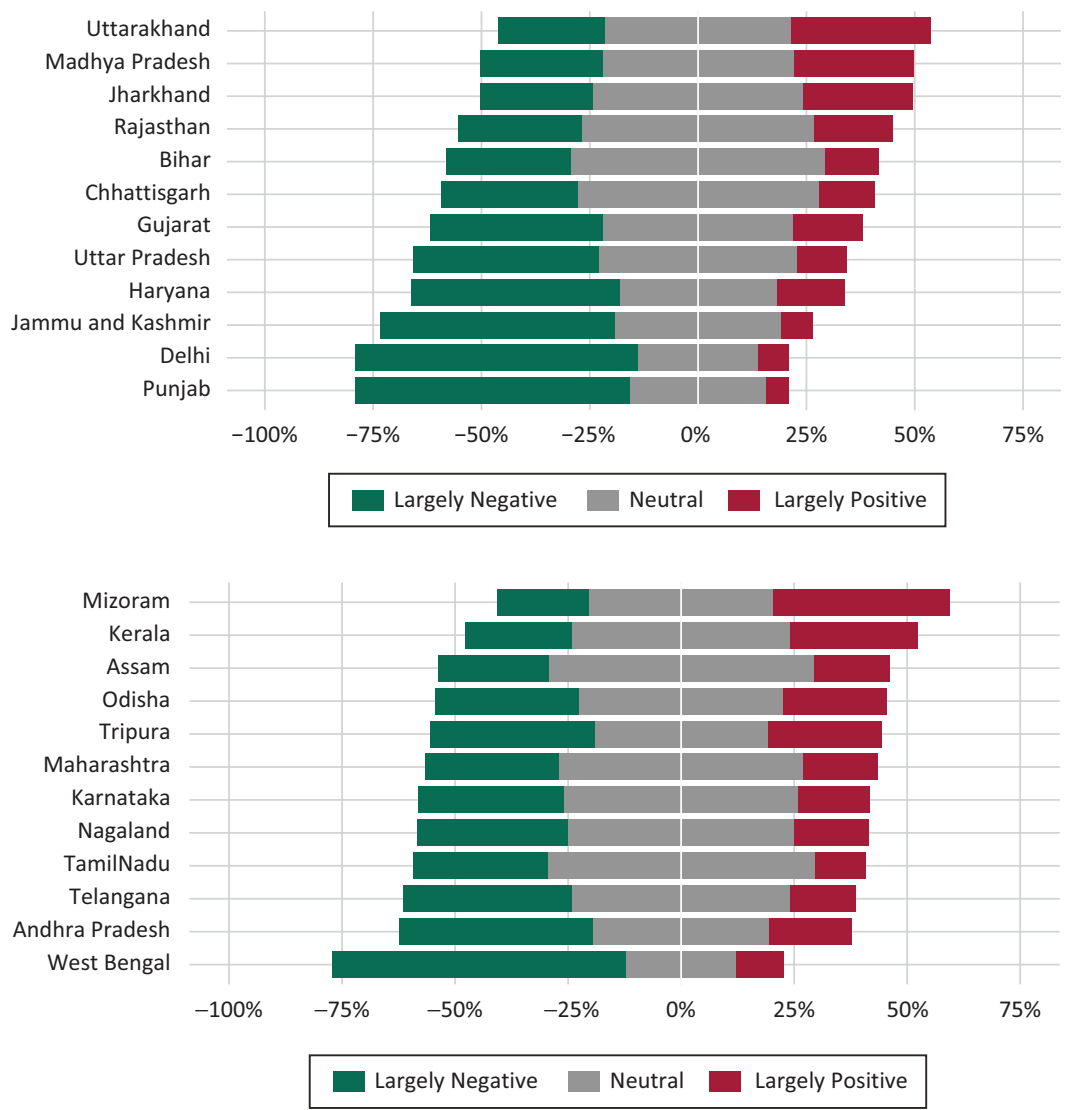

Figure 4.3.7 Effectiveness and Procedural Fairness of Police (by State) 

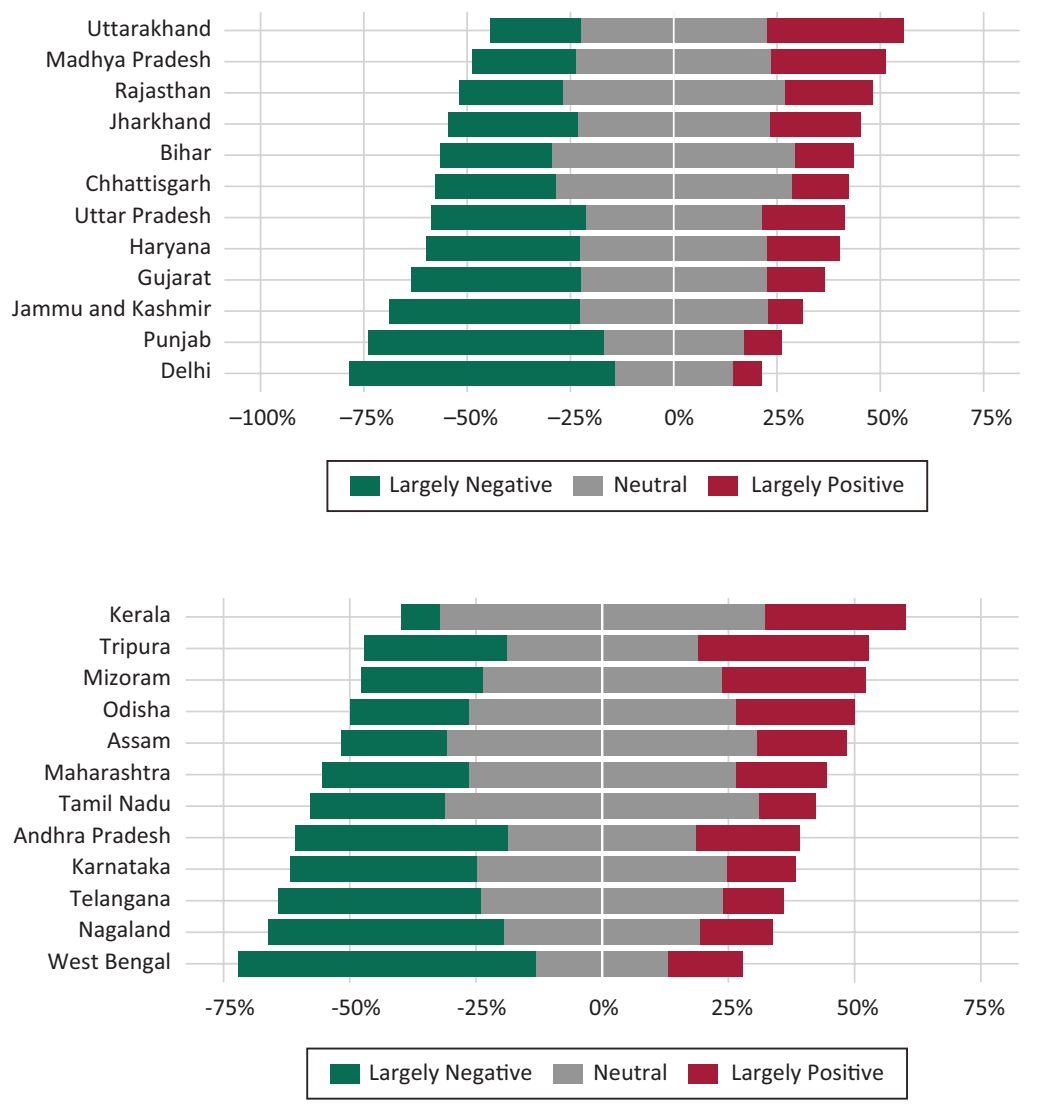

Figure 4.3.8 Effectiveness and Procedural Fairness of Government Officials (by State)

procedurally unfair. With respect to the courts, most of the Hindus (60 percent), Muslims (59 percent), and Sikhs (47 percent) hold a negative view about judicial effectiveness and procedural fairness.

Across caste groups close to a majority of respondents view the police and government officials in a neutral light (Figures 4.3.13-4.3.15). The courts, however, are perceived in a negative way by over half of the respondents who are upper caste (60 percent), Dalit (61 percent), Adivasi (58 percent), and $\mathrm{OBC}$ (64 percent). However, the proportion of respondents who view the courts positively is greater than that of those who see the police and government officials the same way. 

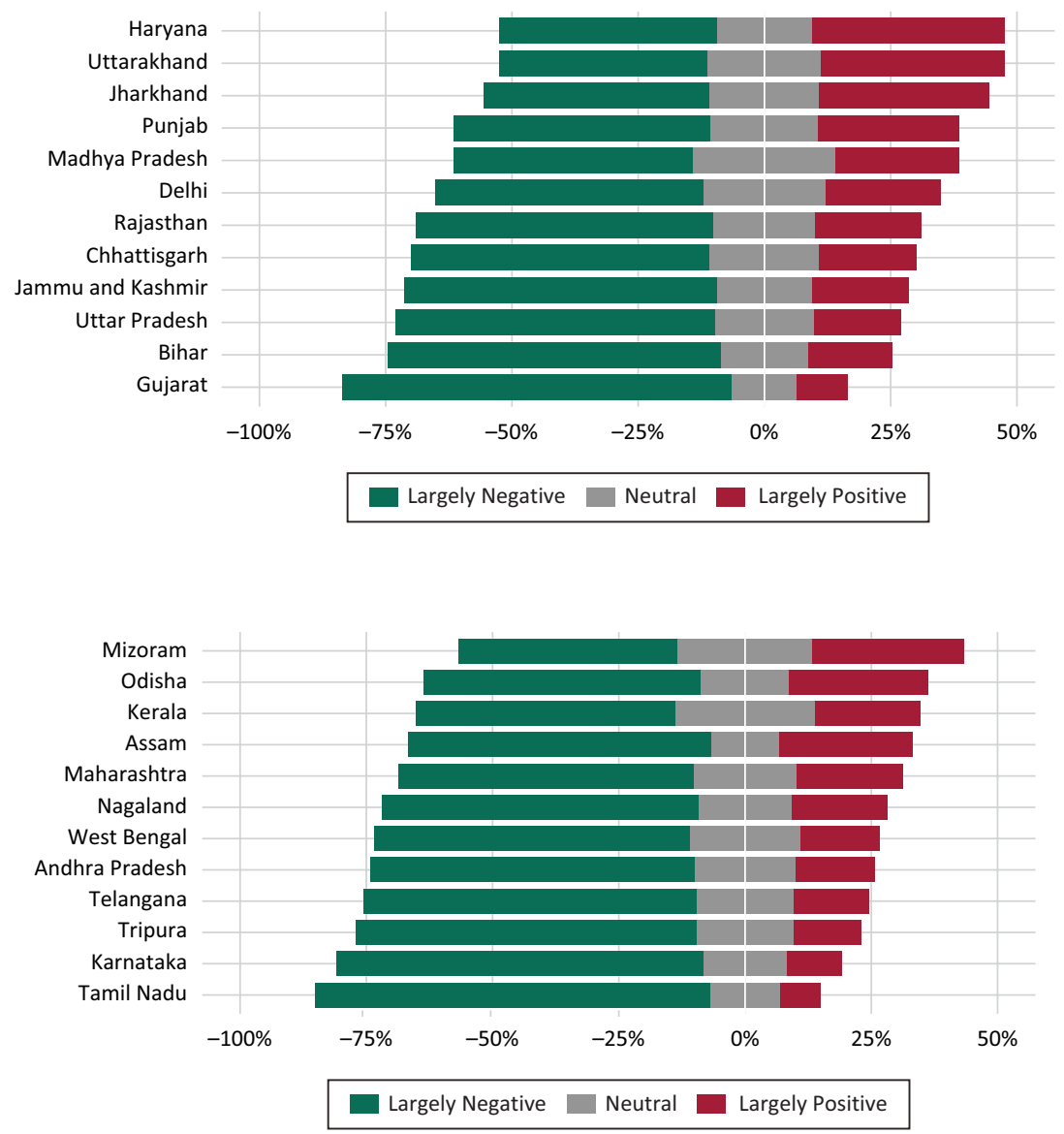

Figure 4.3.9 Effectiveness and Procedural Fairness of Courts (by State)

\subsubsection{Distributive Fairness}

Distributive or outcome fairness is captured here using questions on preferential or equal treatment by State officials - the police, the courts, and the government officials. The question asks:

"Which group do you think the police will treat better? a) A Rich Person or a Poor Person? b) An Upper Caste or a Dalit? c) A Hindu or a non-Hindu? d) A Man or a Woman?" The same is repeated for courts and government officials. 


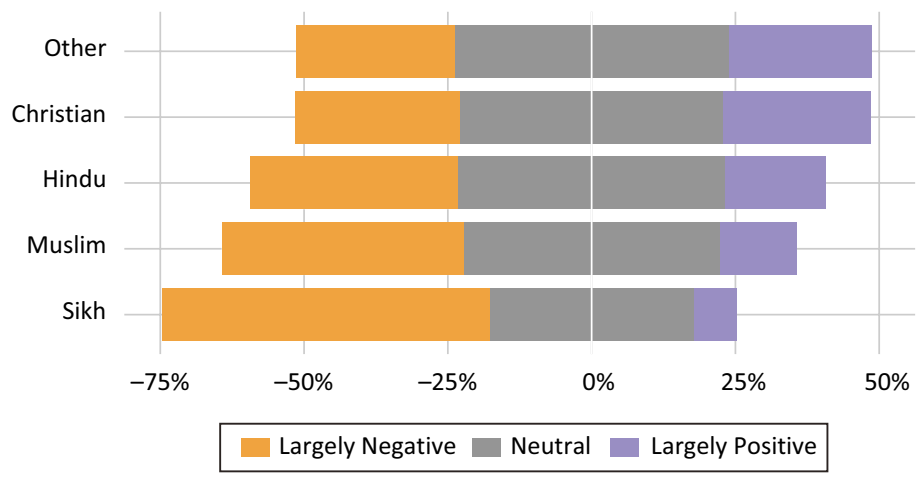

Figure 4.3.10 Effectiveness and Procedural Fairness of Police (by Religion)

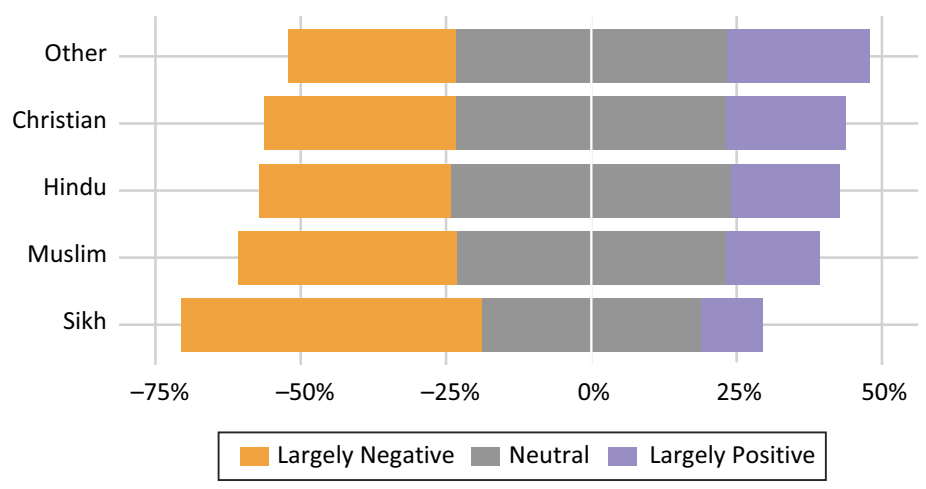

Figure 4.3.11 Effectiveness and Procedural Fairness of Government Officials (by Religion)

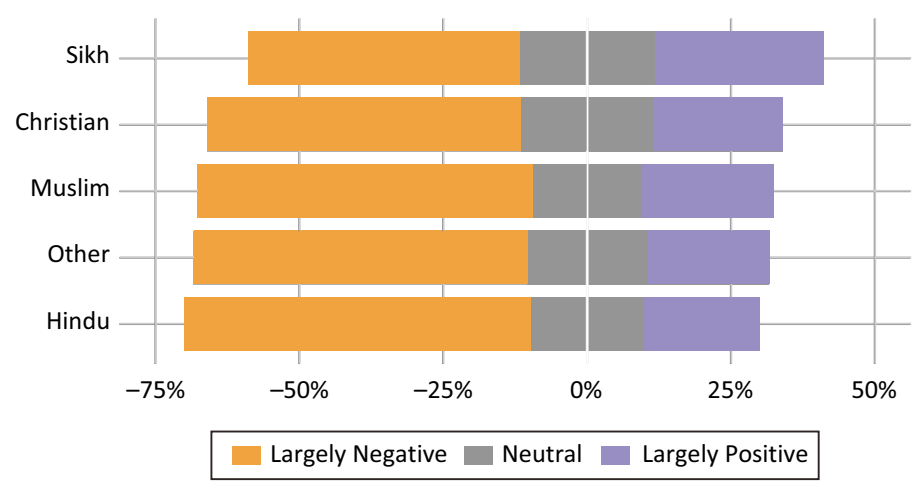

Figure 4.3.12 Effectiveness and Procedural Fairness of Courts (by Religion) 
POLITICAL INSTITUTIONS

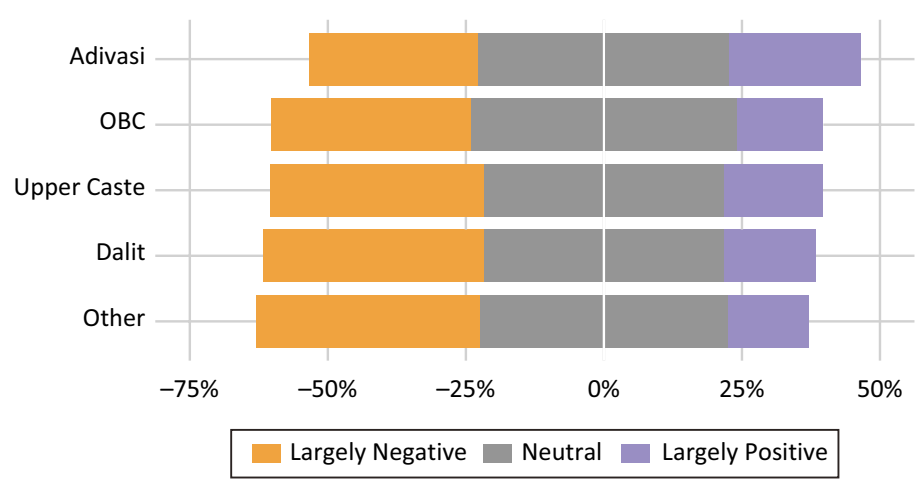

Figure 4.3.13 Effectiveness and Procedural Fairness of Police (by Caste)

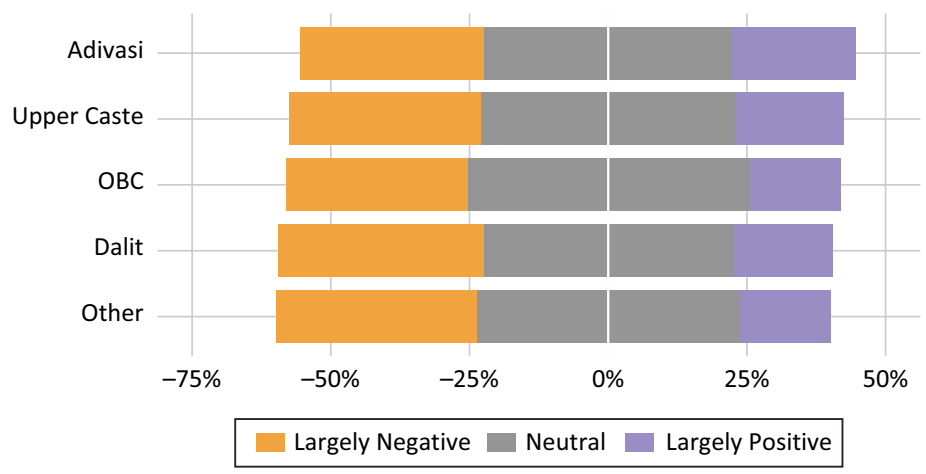

Figure 4.3.14 Effectiveness and Procedural Fairness of Government Officials (by Caste)

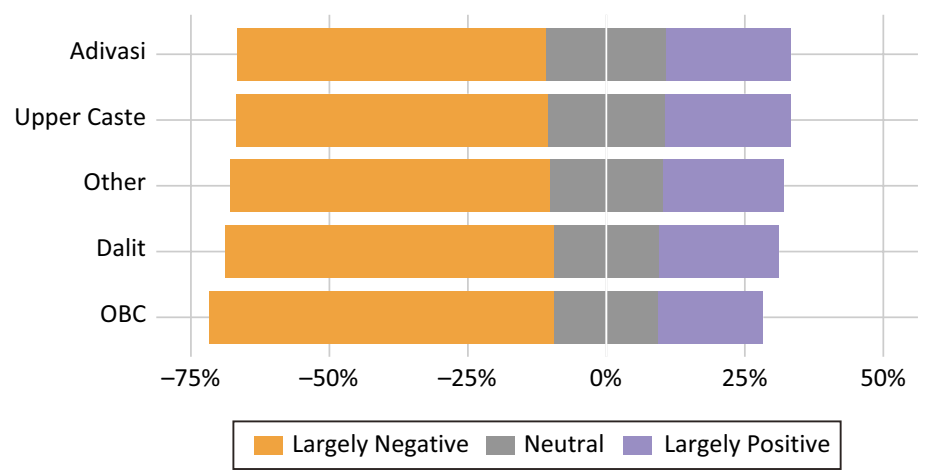

Figure 4.3.15 Effectiveness and Procedural Fairness of Courts (by Caste) 


\subsubsection{Rich or Poor}

Over 50 percent of the respondents from all states feel that the police would treat the rich better than the poor especially in Haryana (81 percent), Jammu and Kashmir (81 percent), and Delhi (83 percent) (Figure 4.3.16). Exceptions are Kerala and Uttarakhand where 54 percent and 55 percent of respondents, respectively, hold the view that the police are fair and treat both the rich and the poor equally.

The same can be seen with respect to perceptions about government officials (Figure 4.3.17). A majority of the respondents in all states, except for Kerala and Uttarakhand, see government officials as favouring the rich. In Delhi, Punjab, and Jammu and Kashmir, over 80 percent of respondents hold this view. Nevertheless, 52 percent of the respondents in Kerala and 55 percent of the respondents in Uttarakhand feel that the government officials treat the rich and the poor equally.

Unlike, the results seen for the police and the government officials, over 50 percent of the respondents in Rajasthan (52 percent), Madhya Pradesh (53 percent), Maharashtra (60 percent), Jharkhand (63 percent), Uttarakhand (70 percent), and Kerala (78 percent) support the view that the courts are fair and treat both the rich and the poor equally (Figure 4.3.18). In the other states courts are seen as unfair and as treating the rich better. This sentiment is especially so in Karnataka (66 percent), Tamil Nadu (64 percent), Jammu and Kashmir (63 percent), and West Bengal (61 percent).

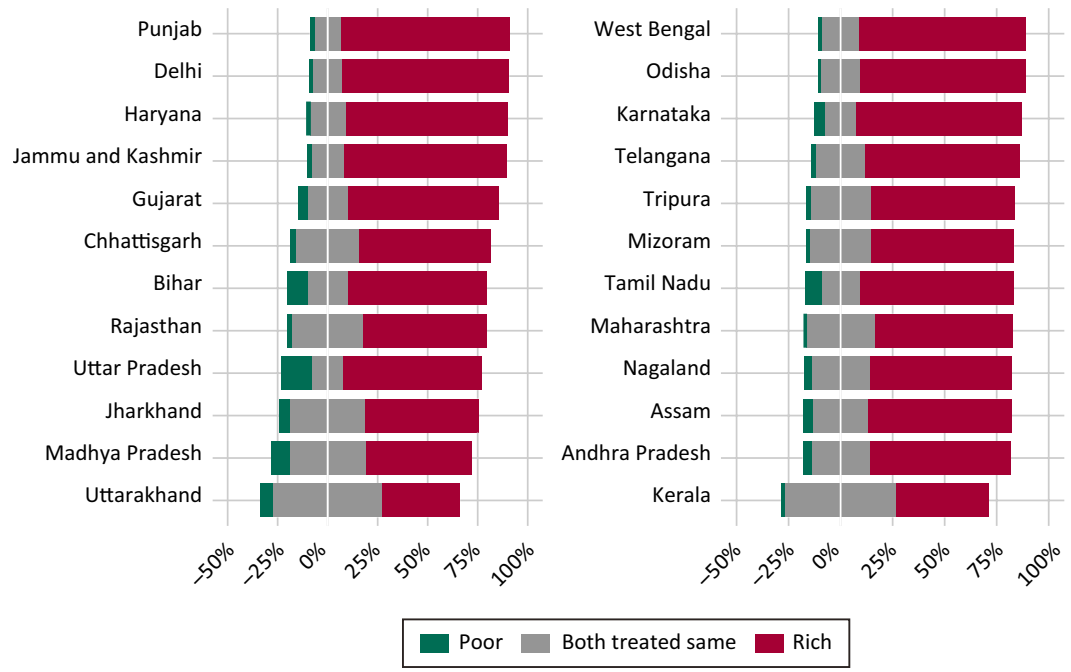

Figure 4.3.16 Rich or Poor - Who Will the Police Favour? (by State) 

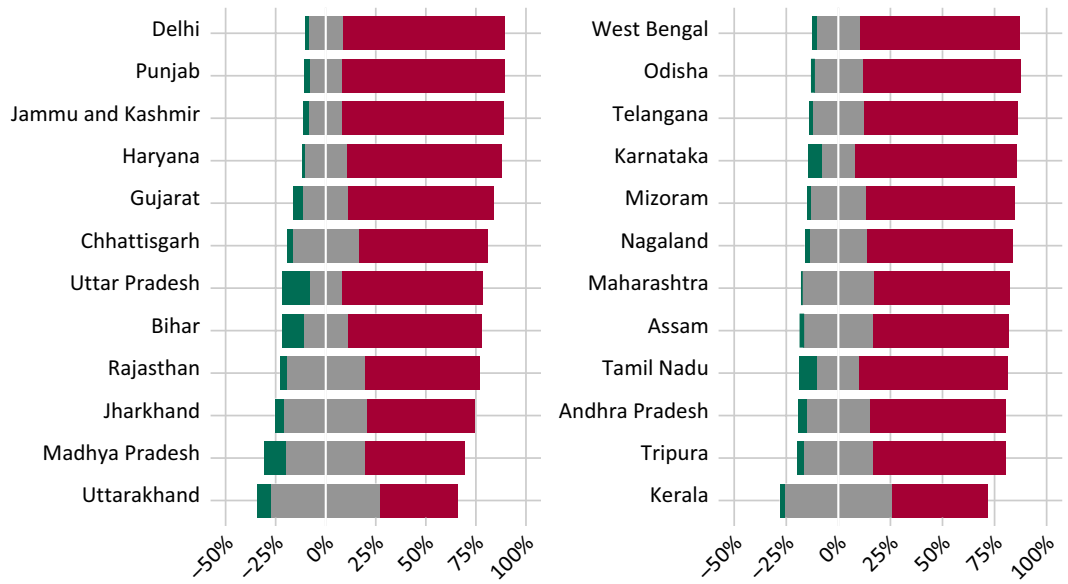

Poor Both treated same

Rich

Figure 4.3.17 Rich or Poor - Who Will the Government Officials Favour? (by State)

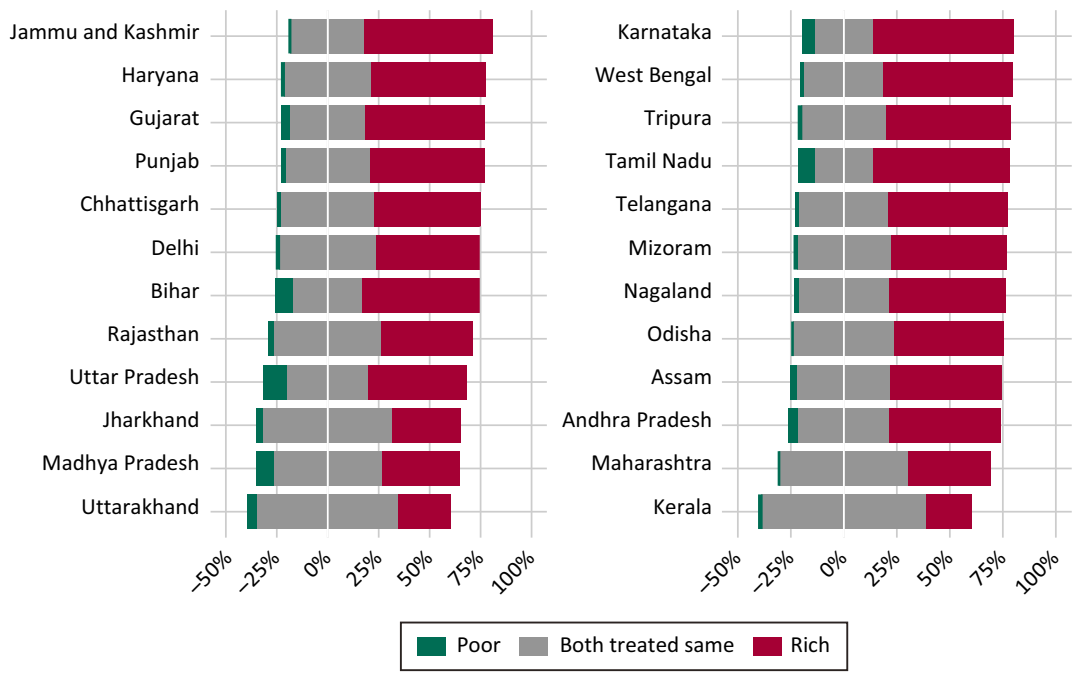

Figure 4.3.18 Rich or Poor - Who Will the Courts Favour? (by State) 


\subsubsection{Upper Caste or Dalits}

Greater proportions of respondents feel that the police treat upper caste citizens better, especially in Telangana (63 percent), Punjab (67 percent), and Haryana (67 percent) (Figure 4.3.19). Over half of the respondents in Assam (54 percent), Tripura (57 percent), Uttarakhand (69 percent), and Kerala ( 72 percent) feel that the police treat both equally. Equal shares of respondents in Maharashtra feel that the police favour the upper caste (48 percent) and treat all the castes the same (48 percent).

Similar to the results for the police, most respondents find the government officials to favour upper castes - over 60 percent in Haryana (63 percent) and 65 percent in Punjab (Figure 4.3.20). Kerala and Uttarakhand again have over 70 percent of respondents who feel that the government officials treat both equally, and an equal share of respondents in Gujarat and Nagaland find the government officials to support the upper castes and treat both castes equally.

Over half of the respondents in all states, except Bihar, Karnataka, and Tamil Nadu, support the view that the courts treat both upper caste and Dalit citizens same (Figure 4.3.21). While a marginally higher share of respondents in Bihar (3 percentage points) and Karnataka (three percentage points) feel that the courts favour the upper caste members, equal shares of respondents support both views in Tamil Nadu.

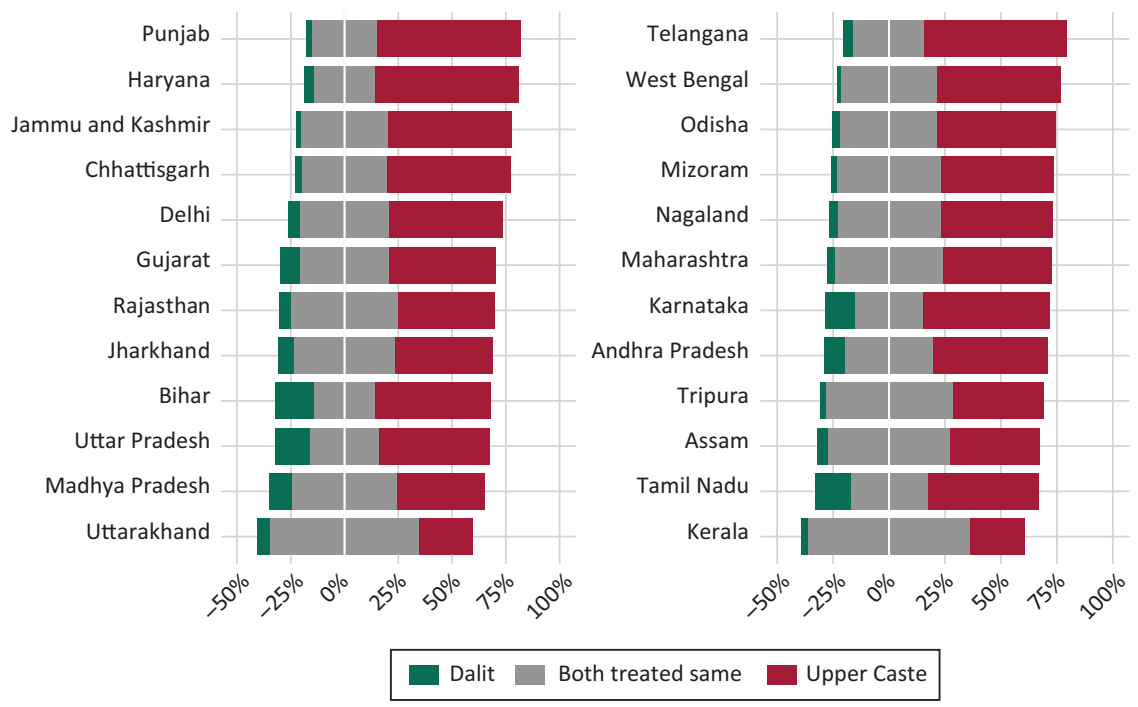

Figure 4.3.19 Upper Caste or Dalit - Who Will the Police Favour? (by State) 

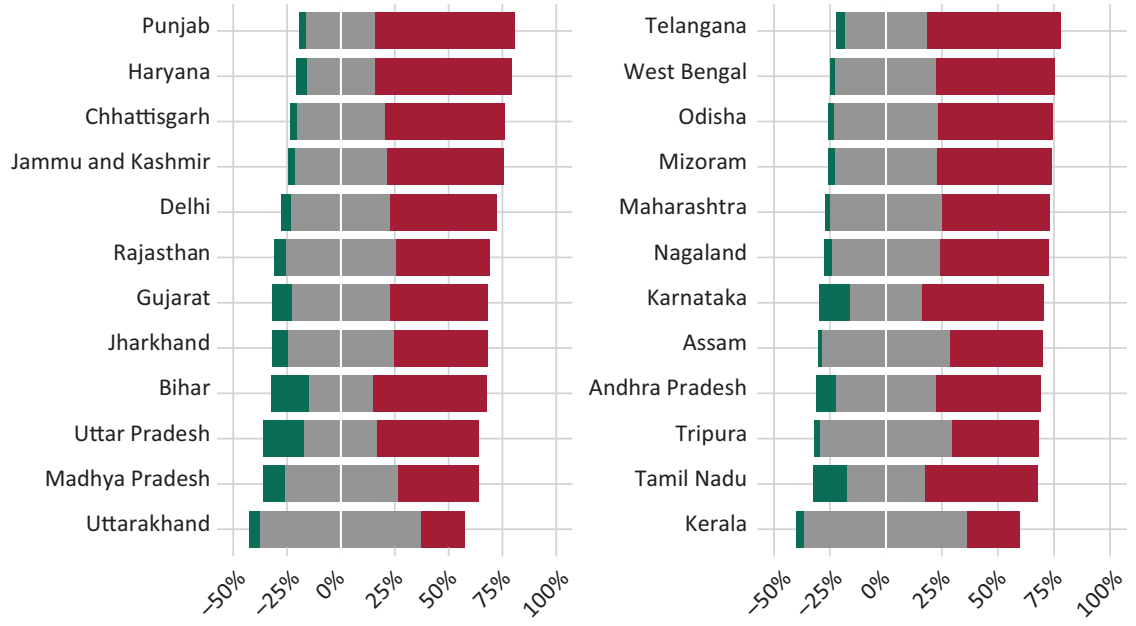

Dalit Both treated same $\square$ Upper Caste

Figure 4.3.20 Upper Caste or Dalit - Who Will the Government Officials Favour? (by State)

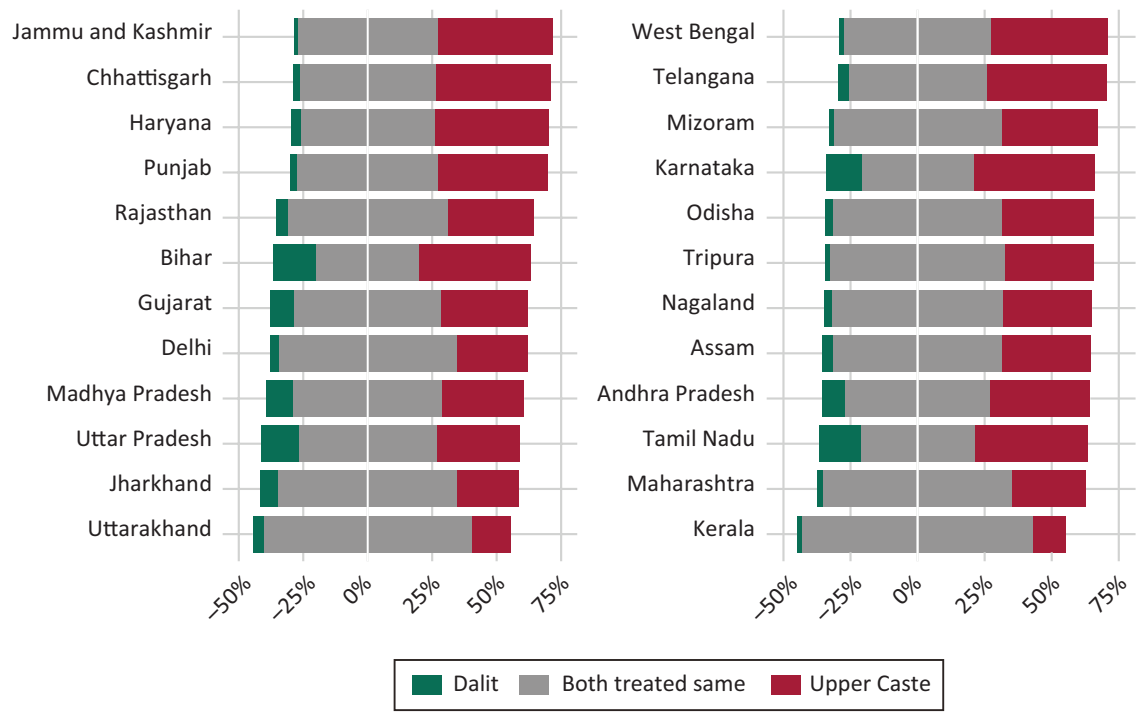

Figure 4.3.21 Upper Caste or Dalit - Who Will the Courts Favour? (by State) 


\subsubsection{Hindu or Non-Hindu}

Across states, over 50 percent of the respondents feel that Hindus and NonHindus will be treated equally by the police, the courts and the government officials (Figures 4.3.22-4.3.24). This view is especially prominent in Kerala (more than 90 percent) and Tripura (more than 85 percent), with respect to the police and the government officials. Over 85 percent of the respondents in Andhra Pradesh, Punjab, Uttarakhand, and Telangana support the view that the judiciary treats Hindus and Non-Hindus equally, and is highest in Kerala (94 percent). Thirty percent or more respondents in Bihar, Haryana, Karnataka, Nagaland, Tamil Nadu, Uttar Pradesh, and Delhi state that Hindus will be treated better by the police. Similarly, 30 percent or more feel that government officials will treat Hindus better. In Bihar (30 percent) and Tamil Nadu (35 percent) respondents also feel Hindus will be treated better.

\subsubsection{Men or Women}

Over 50 percent of the respondents in most of the states feel that both men and women will be treated the same by the Police. In Haryana, Jammu and Kashmir, Tamil Nadu and Delhi between 40 percent and 49 percent respondents support this view and less than 40 percent in Bihar and Uttar Pradesh (Figure 4.3.25). Mizoram (79 percent) and Nagaland (77 percent) record the highest levels of support for distributive fairness of the Police.

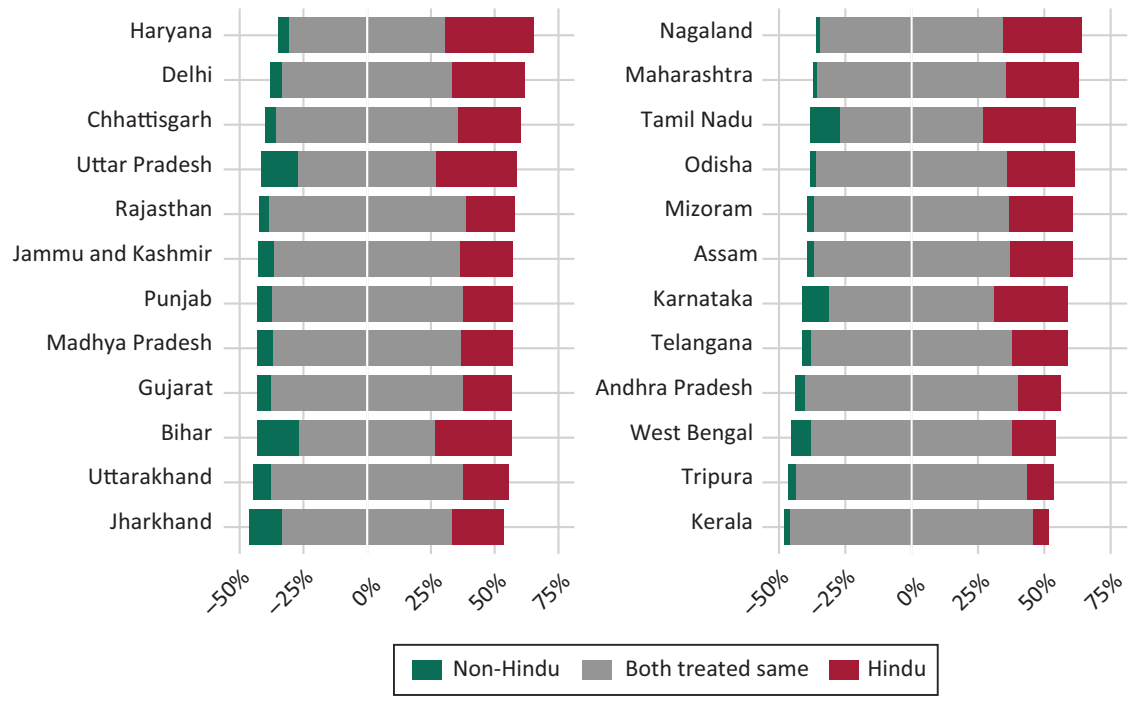

Figure 4.3.22 Hindu or Non-Hindu - Who Will the Police Favour? (by State) 


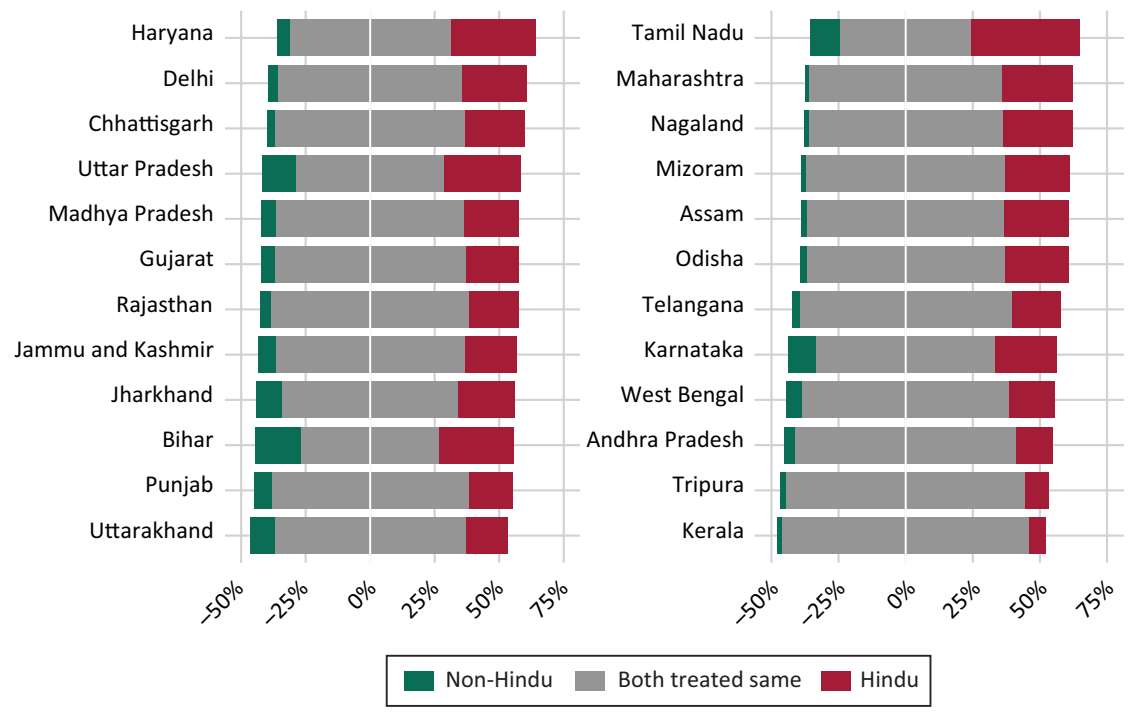

Figure 4.3.23 Hindu or Non-Hindu - Who Will the Government Officials Favour? (by State)

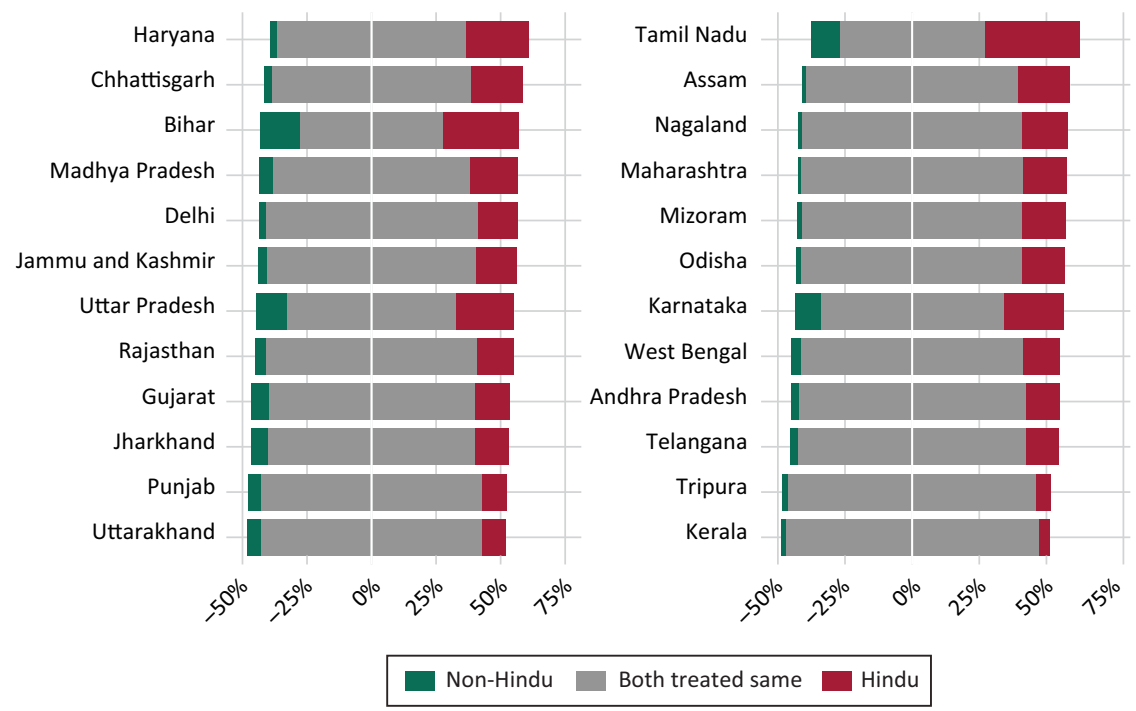

Figure 4.3.24 Hindu or Non-Hindu - Who Will the Courts Favour? (by State) 


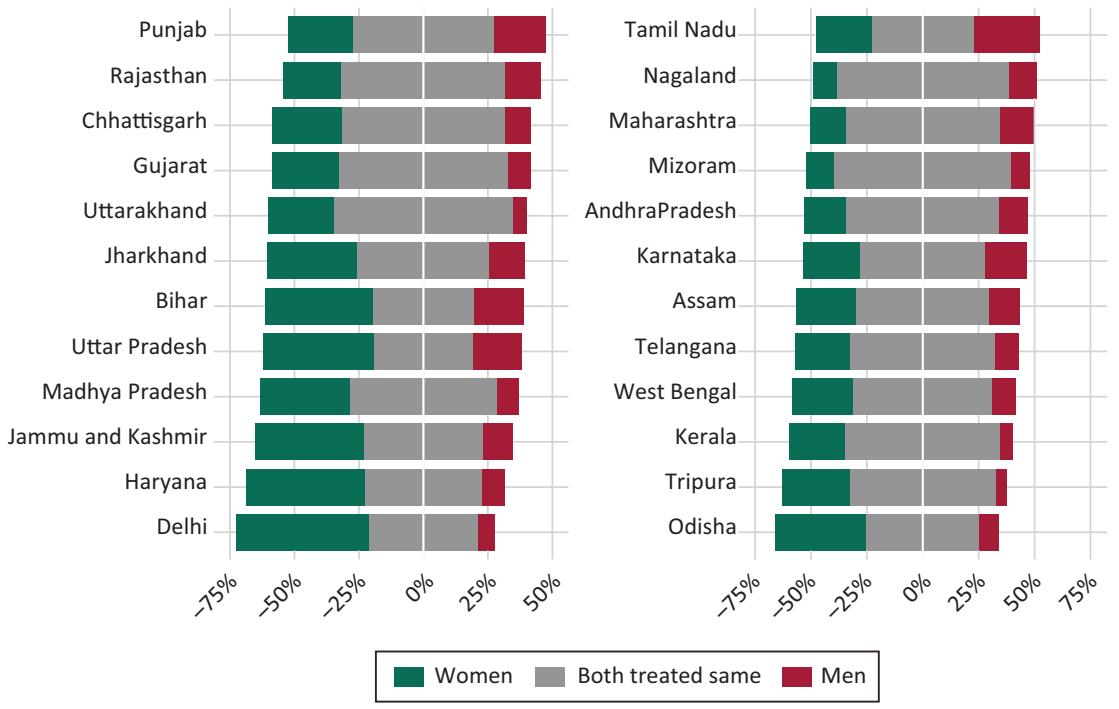

Figure 4.3.25 Men or Women - Who Will the Police Favour? (by State)

However, over half of the respondents in Delhi (51 percent) feel that women are favoured. This view also finds support in Bihar (41 percent), Jammu and Kashmir (41 percent), Uttar Pradesh (42 percent), and Haryana (45 percent). Almost 30 percent of the respondents in Tamil Nadu feel that men will be treated better by the Police.

The results are similar with respect to the government officials (Figure 4.3.26). Over half of the respondents in all states, except for Bihar (41 percent), Uttar Pradesh (42 percent), Tamil Nadu (47 percent), and Jammu and Kashmir (48 percent), support the view that women and men will be treated the same by the bureaucrats. Highest support for distributive fairness of the government officials come from north-eastern states of Mizoram (79 percent), Nagaland (75 percent), Tripura (75 percent), and Kerala (75 percent). Tamil Nadu (31 percent), again, registers a relative large share of the respondents who feel that men are favoured. On the other hand, over 40 percent of the respondents in Delhi (42 percent), Uttar Pradesh (40 percent), and Jammu and Kashmir (40 percent) feel that women are treated better.

The court also enjoys support for their distributive fairness in all states, except for Bihar (Figure 4.3.27). Over 30 percent of the respondents in Bihar (35 percent), Haryana (30 percent), Jammu and Kashmir (30 percent), and Delhi (30 percent) find the courts to show favour for women. On the other hand, 30 percent of the respondents in Tamil Nadu 


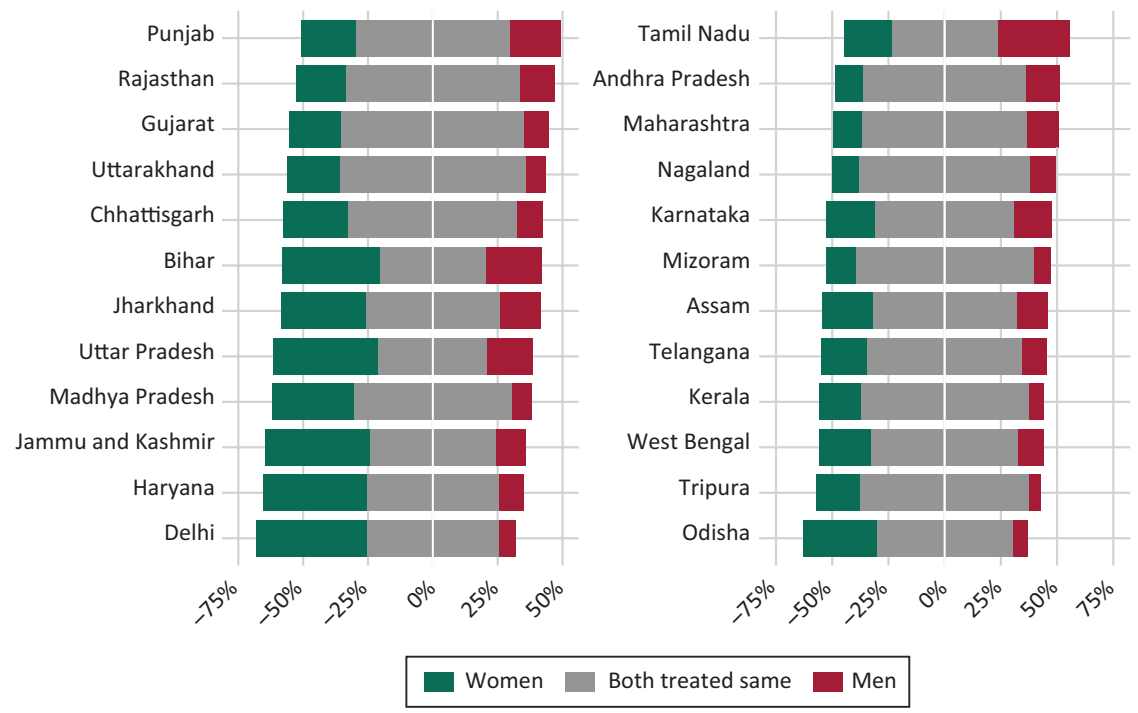

Figure 4.3.26 Men or Women - Who Will the Government Officials Favour? (by State)

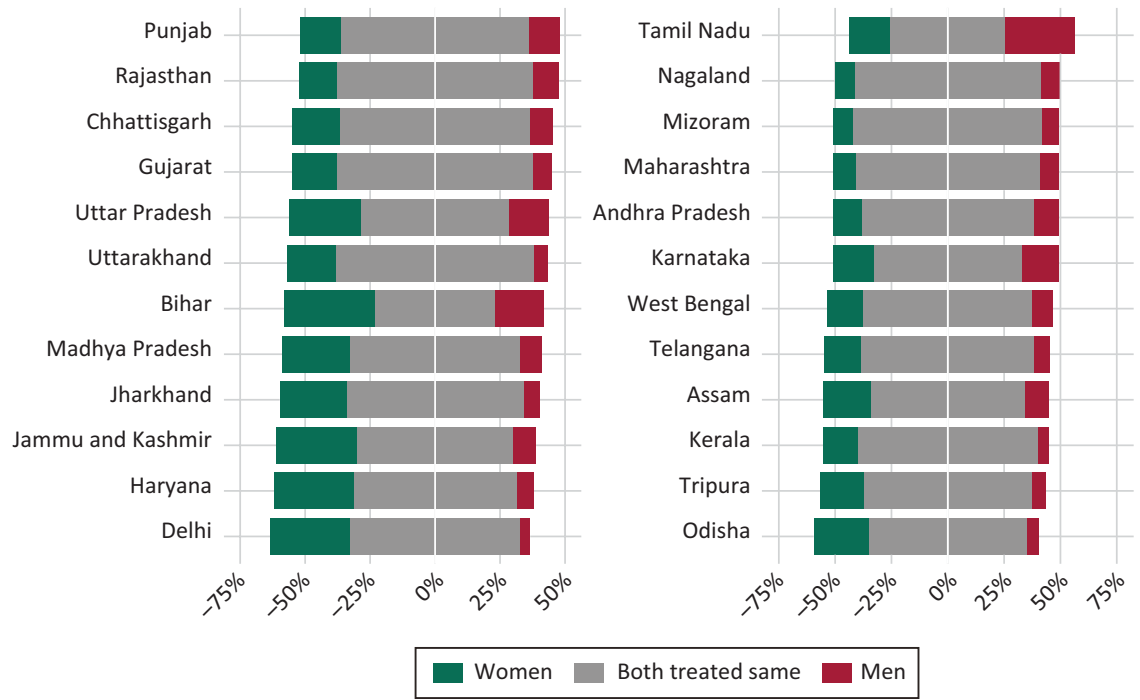

Figure 4.3.27 Men or Women - Who Will the Courts Favour? (by State) 


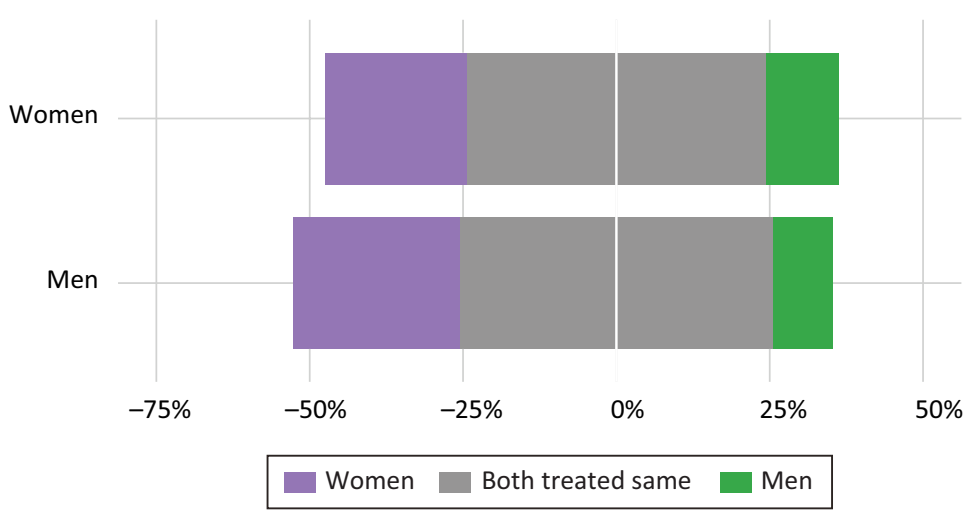

Figure 4.3.28 Men or Women - Who Will the Police Favour? (by Gender)

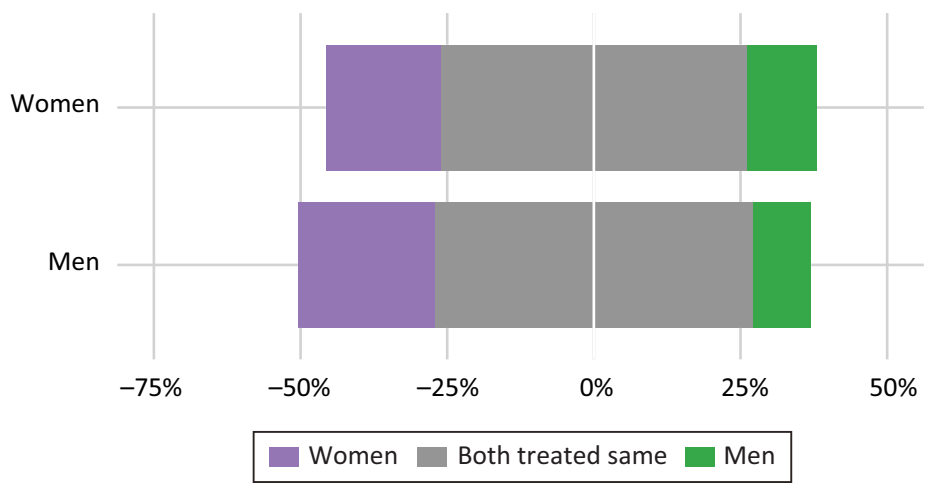

Figure 4.3.29 Men or Women - Who Will the Government Officials Favour? (by Gender)

support the view that men are treated better by the courts. Mizoram ( 84 percent), Nagaland (82 percent), Maharashtra (81 percent), and Kerala ( 80 percent) record the highest levels of trust in distributive fairness of the judiciary.

Across men and women, almost equal shares of respondents feel that all three institutions treat men and women equally, though men are slightly more likely to hold this view but the differences are small (Figures 4.3.284.3.30). We also find that a marginally higher percent of both men and women believe that the opposite sex is treated better by all three institutions. 
POLITICAL INSTITUTIONS

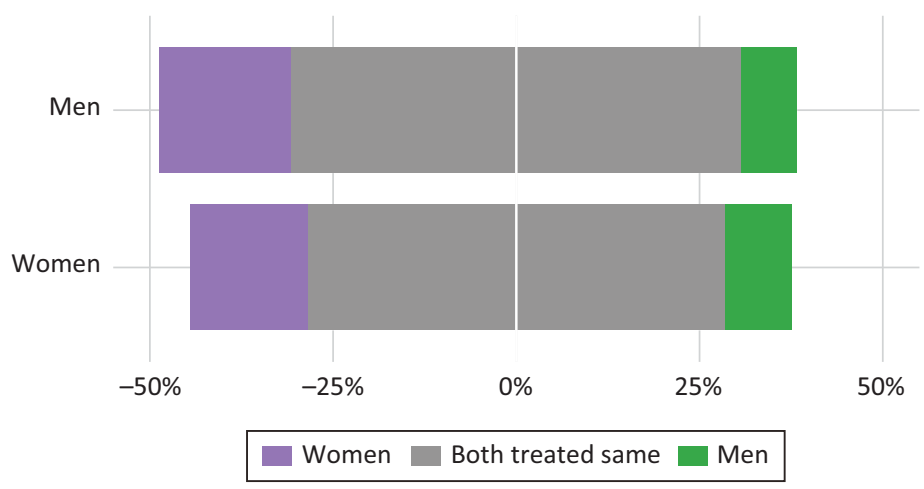

Figure 4.3.30 Men or Women - Who Will the Courts Favour? (by Gender) 


\subsection{CONCLUSION}

Findings from citizen perceptions about governance and public institutions suggest the diversity of opinion on the extent of awareness of welfare schemes and the receipt of benefits from these schemes, accessibility of services, preferred fora for dispute resolution and trust in institutions.

When examined across states, we find that there are states where awareness of central schemes is greater than that of state schemes, states where awareness of both are equal, and those where there is greater awareness of state schemes over central schemes. When disaggregated by scheme across states we find similar patterns. Larger proportions of respondents are aware of central employment schemes compared to state employment schemes. The opposite is true while comparing central and state health schemes. Respondents are more aware of central housing schemes over state ones, and both proportions are about equal for agricultural schemes. We also find that Adivasis (especially Christian Adivasis) exhibit the lowest level of awareness of welfare schemes. Awareness increases with levels of education. While a larger share of respondents benefit from state agriculture and health schemes compared to their central counterparts, more report benefits from central employment and young schemes over the state schemes. Benefits across schemes are also widely distributed across castecommunity groups.

In terms of access to services, citizens find accessing the education system the easiest followed by treatment in government hospitals and to a lesser extent power. Access to a water connection is seen as the most difficult. Minority caste-communities also find it the most difficult to access water services compared to upper caste or OBC respondents.

When it comes to getting important work done most respondents approach elected local government leaders such as the sarpanch or councillors followed by the government officials or local political leaders. This pattern is replicated across states. Respondents generally prefer to resolve marital and domestic violence issues within the family, though respondents across some states say they will approach the police for the latter. For neighbourhood disputes, they tend to prefer elders of the family. In case of property disputes, there is a division between resolving it within the family and approaching courts.

Land is one issue that brings the State and citizen into conflict, and as India continues to urbanize and grow - fuelled by greater demand for land - conflict over land will only decrease if norms acceptable to citizens are set in place. Across states, most respondents prefer a voluntary handing of land over forced acquisition, prefer peaceful resistance over the use of violent methods, and prefer dispute settlement through courts. However, we also observe states where there is some support for a forcible acquisition of land, use of violent methods of resistance, and non-institutional forms of dispute 
settlement. We do not find large differences in farming and non-farming respondents on the mode, response, and dispute resolution over land acquisition. Large and farmers support giving up land voluntarily, peaceful forms of resistance, and are more likely to approach courts to settle the land disputes. Cultivators and agricultural labour are more likely to support violent resistance to acquisition, and the latter also more likely to support forced acquisition.

Elected and non-elected institutions of governance are trusted by citizens to varying degrees. Broadly, we find that there are clusters of institutions those that are highly trusted, those that are somewhat trusted that is, where effective trust is positive but proportions are lower, and those that are less trusted where effective trust is still positive but proportions are much lower and those that are distrusted. The army, and to lesser extent the Supreme Court and High Court, and the district collector are highly trusted. The president, prime minister, chief minister, parliament, state assembly, local governments, Tehsildar, district courts, and election commissions form the next cluster as trusted institutions with relatively large proportions of respondents, in the 40 percent to 59 percent range expressing effective trust but not as high as for the previously noted institutions. Then comes the next cluster with institutions that are far less trusted, such as the police and government officials. The police and government officials - both key institutions responsible for governance - elicit low levels of trust among citizens. Proportions are typically less than 25 percent. Finally, political parties are distrusted.

We find that this pattern is replicated in most states however with varying proportions within each of these clusters. With a few exceptions, the army is consistently the most trusted institution across states followed by the Supreme Court, High Court, and district collector. There is greater variation within the second cluster across the states. In some states, the prime minister registers high proportions of effective trust but distrust in a few states. Similarly, other institutions such as state assembly, district courts, and chief minister among others, are trusted in high proportions in some states but register much lower levels of effective in other states. The police and government officials are trusted by significantly fewer respondents. Political parties are consistently distrusted across most states.

Variation in effective trust in institutions across religious community groups also follows a similar pattern. The army, followed by the Supreme Court, High Court and district collector are trusted by high proportions across all community identities. The next set cluster of institutions exhibit greater variation across community groups, and the police and government officials register lower proportions of effective trust, and political parties distrusted across all communities. Levels of education increase effective trust up to a certain level but drops for the most educated group. 
Where effectiveness and procedural fairness are concerned, most citizens hold largely neutral or negative views about the police and government officials. While the former is the case in many states, a few have relatively high numbers of respondents that view the police and government officials largely negatively. In rare instance, a quarter of respondents view the police and government officials positively. With the court, a larger share of respondents view them negatively i.e., ineffective and procedurally unfair, followed by neutral views. However, there are also states where the courts are seen in a more positive light. A similar pattern is seen in the distribution of effectiveness and procedural fairness across caste and religious identities. Views on the police and government officials are neutral, followed by a largely negative one. Additionally, courts are seen negatively followed by neutral views.

In terms of distributive fairness, courts are seen as generally fair in comparison to the police and government officials. More respondents see the courts as treating members from different castes, communities, classes, and genders equally. The police and government officials are seen as favouring the wealthy and upper castes, and while seen as treating both Hindus and non-Hindus equally, there are respondents who also feel that Hindus are treated better. The judiciary is perceived as distributively fair but at the same time as procedurally unfair and ineffective, while the police and government officials are seen as effective and procedurally fair but favouring of a particular class, caste, and in some cases, religious identity. Citizens trust political institutions to varying degrees and as a result of several factors. Next steps should aim to explain these differences and more systematically open up the black box of trust. 


\section{5 \\ CONCLUSION}

This report does three things: First, it allows students of Indian society and politics to connect the seemingly contingent processes obtaining around elections when citizens make political choices within the confines of available menu of candidates and parties but also make those political choices within a much broader context of how their political and social attitudes are shaped between two elections. Second, the report draws attention to key features of public opinion that might be more durable and form the basis for politics in the coming decade. Third, by identifying state-level patterns, the report significantly contributes to the field of comparative study of politics and public opinion across the states of India.

How do interactions between the State and the citizen unfold in periods between elections? What characterizes interactions between citizens across states? Across economic class, caste, and community? And what sorts of perceptions, attitudes, and opinions do everyday forms of governance engender within society? This report explores such questions that are of importance in a democracy undergoing a significant political and social transformation.

Politics and Society between Elections surveys public opinion, social attitudes, and political subjectivities in times between elections across 23 Indian states and the National Capital Region of Delhi. This report summarizes respondent opinions on multiple dimensions of social and political life in India focusing on friendship ties across social groups, perceptions of social community, citizens' trust in political institutions, preferences of leader identity, awareness of public services and ease of access, citizen-State institutional and other interfaces, land governance, gender roles and relationships, nationalism and political identity, freedom of expression, and populism. As noted earlier we explore the data in three ways: through a mapping of the variation in public opinion across ideas, states, and to a lesser extent individual caste-community identities and other socio-economic characteristics of respondents.

Many themes explored in this report are not new. Caste and community relationships, gender roles, and other social attitudes have been shaped over long periods of time. Some others such as nationalism, attitudes toward 
democracy and constitutional practices, and populism are relatively recent, gaining strength in post-independence India. Regardless, what we find is that many of these ideas persist and co-exist with newer forms of political rhetoric that emerge in periods between elections. While the period during which this study was undertaken might be seen as somewhat extraordinary in the sense of emergence of a new party system and possibly a new regime, we would argue that rather than that extraordinariness, this report brings home the more general point that between elections, routine politics and governance shape citizen attitudes and that this is an almost routine process. It is only coincidental that this study happens at a particular point in time and, therefore, may also help throw light on how the attitudes that sustain an emergent regime might actually pre-exist the rise of the regime.

But beyond this more temporal context, the study has larger lessons for students of Indian politics and society. The sections in Part 2 examine the diverse social universe Indian citizens live in. We find that social bridging is limited. Weak cross-caste and cross-community personal friendships characterize the social world. However, ties within communities are strong and intra-community friendships tend to reflect these bonds. This has implications for inclusion/exclusion and the constitution of civil society. Spatial variation in friendship ties indicates a few regions that exhibit high crossgroup friendships, but for most part social lives remain insular. A narrow social universe reinforces stereotypical views of others. We find that perceptions about certain identity communities mildly follow stereotypes that could prove to be potentially problematic. Formal support for greater agency for women stands in contradiction to gendered expectations of a woman's role at home and work. These findings highlight the paradoxical nature of the social universe, a mix of authoritarian-democratic, traditional-modern, and exclusive-inclusive opinions. The presence of opposing impulses leaves behind an ambivalence as to where social process will lead to in the future. It also perhaps indicates that the direction of social processes may critically depend on the agency of politics more than anything else.

In Part 3 we cover opinions on four dimensions of India's political universe: freedom of speech, a national or a regional identity, nationalism, and populism. We find that there exists relatively weak to mixed support for free expression, an overarching national identity co-existing with strong pockets of regional identity, a definitive tilt in opinion toward majoritarian nationalism, and an ambivalence between populist and pluralist attitudes. We also observe variation across states for each of these dimensions and this reveals a strong spatial clustering of attitudes on nationalism and choice of identity as national. Populist attitudes in politics exist strongly in a few states but weak in most others. Similarly, opinions on freedom of expression favour a more expansive view in a few states compared to most others. Preferences for a majoritarian nationalism are polarized across community identities, and cohere within, rather than being defined by economic class or levels of 
education. While spatial differences are clear in whether individuals identify themselves as regional or national, caste-community differences do not appear to matter.

In Part 4 we focus on citizen awareness of welfare schemes and their status as beneficiaries, opinions on land governance, and public trust in institutions. We find both citizen awareness and beneficiary status to be fairly high but unevenly spread across schemes and states. Citizens tend to be aware or beneficiaries of either central or state schemes conditional on regional location. Citizens' ease of accessing services varies and certain basic services are hard to reach. Caste-community differences in accessing benefits of welfare schemes shows that State institutions fail in delivering to minority groups. However, the successes of local governments in connecting citizens with local elected officials are undeniable. Finally, we find high to middling public trust across institutions that suggest citizens view institutions with sufficient credibility for democracy to sustain, but low levels of trust in key institutions are a cause for concern for governance.

Our mapping exercise also suggests that citizens converge in agreement or disagreement on certain issues and are highly polarized on other issues. For instance, there is convergence on the growing importance of local governments in India given that a large number of respondents place faith in the district collector, and a significant number approach municipal corporator or sarpanch in order to get important work done. Similarly, citizens are also surprisingly united on their trust in institutions. While the army and the judiciary are uniformly among the most trusted institutions, governance institutions that directly interact with citizens such as the police and the bureaucracy are among the least trusted. On the other hand, there is a sharp division, that is, opinions are highly polarized on matters related to nationalism, freedom of expression, and regional identity, and to some extent on how social communities view one another. That citizen opinions diverge on some issues and cohere on others is a feature of all societies, neither unexpected nor unique to India, but the magnitude of polarization on issues that have engendered violent conflicts in the past must be taken very seriously as they are likely to dominate both public discourse and our collective lives in the near future.

For students of society and politics, this has a few lessons. The initial results presented here open possibilities for empirically testing theoretically driven hypotheses relating to the horizontal and vertical citizenship in politics and society in times between elections. Further, the results also point to interesting and complex spatial patterns that beg further systematic investigation. Cross-state comparisons of social and political relationships over space and time will help us better understand how politics between elections unfold in the many regions across India and allow us to arrive at broad generalisations about state politics. 


\section{CONCLUSION}

What do these findings portend for democracy in India? Is India headed on a path of democratic deepening or is a democratic slide imminent? Results point to a mixed future. The strong tilt toward a majoritarian nationalist identity - across space and community, that threatens minorities and critics, suppresses freedoms of expression, and fosters mostly negative stereotypes about others signals a regression away from constitutional values and democracy acquiring an illiberal hue. Uneven distribution of welfare and citizen difficulties in accessing basic services, in addition to relatively low levels of public trust in institutions that citizens routinely deal with, suggest governance links continue to remain weak - this also undermines a democratic commitment to welfare. High public trust in political institutions that guard against constitutional breaches, indicates the huge burden institutions will have to carry in sustaining and strengthening democracy. This complex mix of attitudes, however, also suggests that an authoritarian turn overnight is unlikely. While this might be sufficient to sustain democracy, a significant democratic deepening appears uncertain. What looked like the "democratic upsurge" at the turn of the century and what was reported as expansion of democracy that might lead to deepening of democracy (SDSA, 2008), both seem to have been arrested. Two decades down the line, India's democracy appears to be facing fundamental questions about its nature, reach, and impact. This should surely be a sobering finding, although not exactly alarming. 


\section{APPENDIX}

\subsection{SAMPLING AND DATA COLLECTION}

The data collection for "Politics and Society between Elections (PSBE)" was conducted in three rounds between 2016-2018, covering 24 Indian states. This note provides details relating to the spatial and temporal coverage of the surveys as well as the sampling method used in the selection of respondents.

The survey was conducted in 524 assembly constituencies (AC) across 24 states resulting in a sample size of 48542 respondents. Twenty-one ACs (in the first round) and 22 ACs (in the second and third rounds) were randomly selected in each state using the probability proportionate to size method. Four polling stations within each of the sampled constituencies were then selected through systematic random sampling. Finally, 30 respondents were randomly selected using the same method from the latest electoral rolls of the sampled polling stations. Table A1 shows the rounds and coverage of the study. Table A2 details the achieved sample. Table A3 compares the achieved sample with 2011 census figures.

The primary data collection instrument was a structured questionnaire with a few open-ended questions. The entire questionnaire is available section 6.4 in the Appendix. The questionnaire was translated into the language mainly spoken in a state. The translation process was monitored to ensure that a question in one state did not have a different meaning in another. While the main language of the state is used in each state, in some cases, field investigators are provided with questionnaires in languages other than state language, for example, Hindi in Maharashtra and Bengali in Assam. Table A4 provides details on the languages into which the questionnaire was translated.

A fieldwork manual was specially designed for field investigators with general instructions on how to conduct standard interviews. It also contained question-specific instructions explaining skips patterns in questions and probing levels for correct responses. The manual also had numerical 
Table A1 Politics and Society between Elections (Rounds and Coverage)

\begin{tabular}{|c|c|c|c|c|}
\hline Rounds & $\begin{array}{l}\text { Nos. of } \\
\text { states }\end{array}$ & $\begin{array}{l}\text { Nos. of } \\
\text { Assembly } \\
\text { Constituencies }\end{array}$ & Name of the states & Field work \\
\hline 1 & 4 & 84 & $\begin{array}{l}\text { Gujarat, Odisha, Karnataka, and } \\
\text { Haryana }\end{array}$ & $\begin{array}{l}\text { November- } \\
\text { December } \\
2016\end{array}$ \\
\hline 2 & 8 & 176 & $\begin{array}{l}\text { Bihar, Jharkhand, Madhya } \\
\text { Pradesh, Chhattisgarh, Andhra } \\
\text { Pradesh, Telangana, Rajasthan, } \\
\text { and Maharashtra }\end{array}$ & $\begin{array}{l}\text { November- } \\
\text { December } \\
2017\end{array}$ \\
\hline 3 & 12 & 264 & $\begin{array}{l}\text { Assam, Delhi, Jammu and } \\
\text { Kashmir, Kerala, Mizoram, } \\
\text { Nagaland, Punjab, Tamil } \\
\text { Nadu, Tripura, Uttar Pradesh, } \\
\text { Uttarakhand, and West Bengal }\end{array}$ & $\begin{array}{l}\text { September- } \\
\text { October } \\
2018\end{array}$ \\
\hline
\end{tabular}

Table A2 Distribution of the Achieved Sample

\begin{tabular}{|c|c|c|c|c|}
\hline & $\begin{array}{l}\text { Sampled Assembly } \\
\text { Constituencies }\end{array}$ & $\begin{array}{l}\text { Sampled } \\
\text { Polling Station }\end{array}$ & $\begin{array}{l}\text { Sampled } \\
\text { Respondents }\end{array}$ & $\begin{array}{l}\text { Achieved } \\
\text { Sample }\end{array}$ \\
\hline \multicolumn{5}{|l|}{ Round 1} \\
\hline Gujarat & 21 & 84 & 2520 & 2044 \\
\hline Haryana & 21 & 84 & 2520 & 1789 \\
\hline Karnataka & 21 & 84 & 2520 & 1873 \\
\hline Odisha & 21 & 84 & 2520 & 2064 \\
\hline \multicolumn{5}{|l|}{ Round 2} \\
\hline Andhra Pradesh & 22 & 88 & 2640 & 2108 \\
\hline Bihar & 22 & 88 & 2640 & 1956 \\
\hline Chhattisgarh & 22 & 88 & 2640 & 1998 \\
\hline Jharkhand & 22 & 88 & 2640 & 2144 \\
\hline Madhya Pradesh & 22 & 88 & 2640 & 2073 \\
\hline Maharashtra & 22 & 88 & 2640 & 2122 \\
\hline Rajasthan & 22 & 88 & 2640 & 2099 \\
\hline Telangana & 22 & 88 & 2640 & 2180 \\
\hline \multicolumn{5}{|l|}{ Round 3} \\
\hline Assam & 22 & 88 & 2640 & 2095 \\
\hline Delhi & 22 & 88 & 2640 & 2098 \\
\hline Jammu and Kashmir & 22 & 88 & 2640 & 2011 \\
\hline Kerala & 22 & 88 & 2640 & 1943 \\
\hline Mizoram & 22 & 88 & 2640 & 2199 \\
\hline Nagaland & 22 & 88 & 2640 & 1886 \\
\hline Punjab & 22 & 88 & 2640 & 2041 \\
\hline Tamil Nadu & 22 & 88 & 2640 & 2028 \\
\hline Tripura & 22 & 88 & 2640 & 1717 \\
\hline Uttar Pradesh & 22 & 88 & 2640 & 2151 \\
\hline Uttarakhand & 22 & 88 & 2640 & 2063 \\
\hline West Bengal & 22 & 88 & 2640 & 1860 \\
\hline Overall & 524 & 2096 & 62880 & 48542 \\
\hline
\end{tabular}




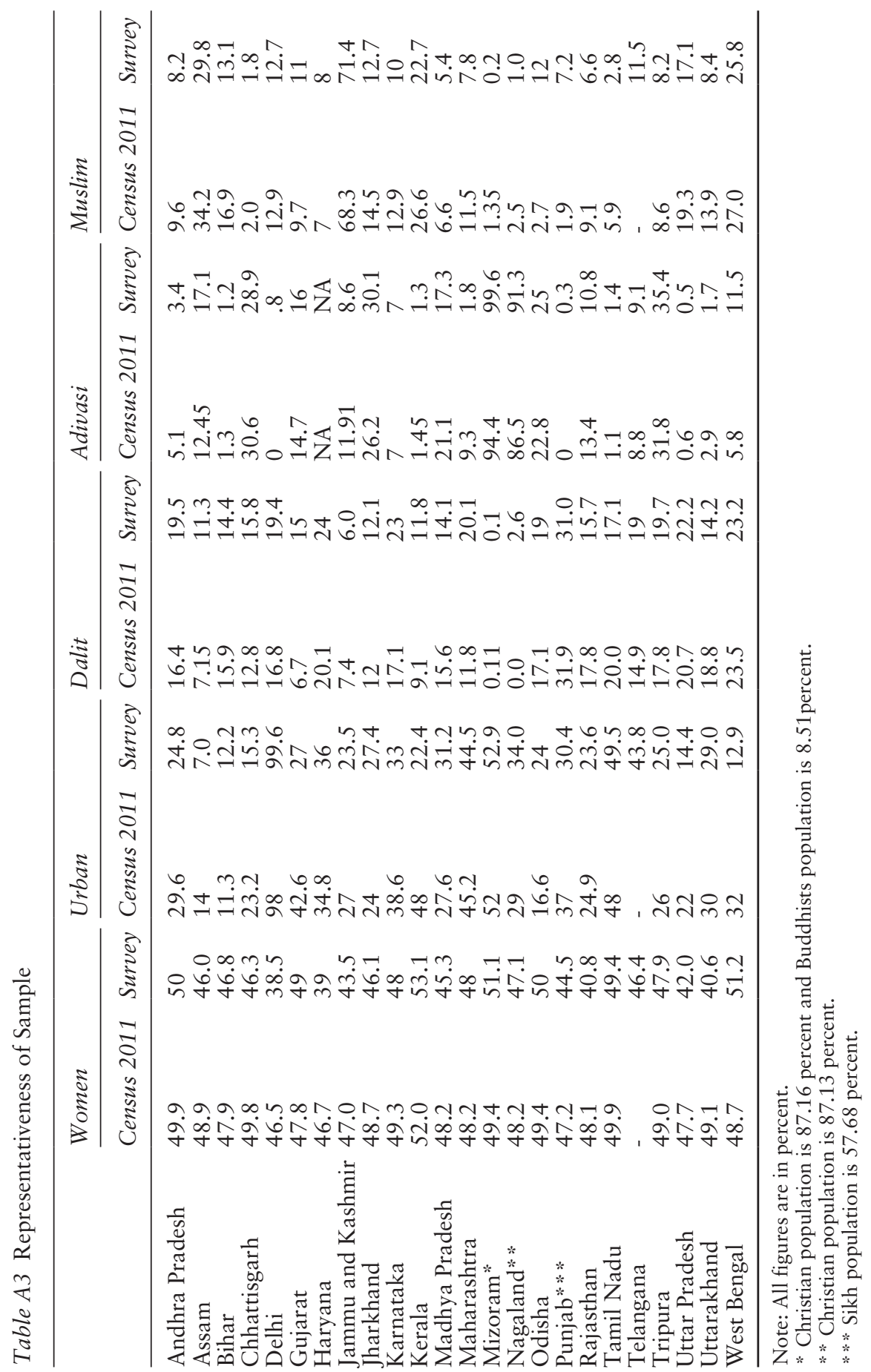


Table A4 Languages Used for Translation

\begin{tabular}{lll}
\hline Sr. No. & Language & States \\
\hline 1 & Assamese & Assam \\
2 & Bengali & West Bengal, Tripura \\
3 & English & Nagaland \\
4 & Gujarati & Gujarat \\
5 & Hindi & Haryana, Uttar Pradesh, Delhi, Uttarakhand, Bihar, \\
& & Chhattisgarh, Jharkhand, Madhya Pradesh, Rajasthan \\
6 & Kannada & Karnataka \\
7 & Malayalam & Kerala \\
8 & Marathi & Maharashtra \\
9 & Mizo & Mizoram \\
10 & Oriya & Odisha \\
11 & Punjabi & Punjab \\
12 & Tamil & Tamil Nadu \\
13 & Telugu & Andhra Pradesh, Telangana \\
14 & Urdu & Jammu and Kashmir \\
\hline
\end{tabular}

codes for background variables like education, occupation, caste, etc., with pre codes for some open-ended questions.

Training workshops were organised before the survey fieldwork to train the field investigators and supervisors who carried out the fieldwork operations. State coordinators, across all states, conducted intensive and interactive workshops for training field investigators on conducting face-to-face interviews based on the questionnaire. The investigators underwent an orientation programme and trained rigorously about interviewing techniques and communication protocols with the respondents. A comprehensive and detailed interviewing guide, designed on the basis of the questionnaire and survey methodology, was prepared for the interviewers.

The interviews of the selected respondents were conducted at their residence or place of work (such as a farm field or small shops near residence). Field investigators, on meeting the respondents, explained the purpose of the interview, established their identity, and informed them about the expected research output of the study. The field investigators conducted the interview of the selected respondent in face-to-face interaction that took up to 35 minutes. The investigators followed the standard and accepted practices of fieldwork and the information collected has been kept strictly confidential.

All questionnaires were manually screened for consistency and quality prior to data entry. A data checking team ensured the codes and made corrections in case of investigator errors during coding. 


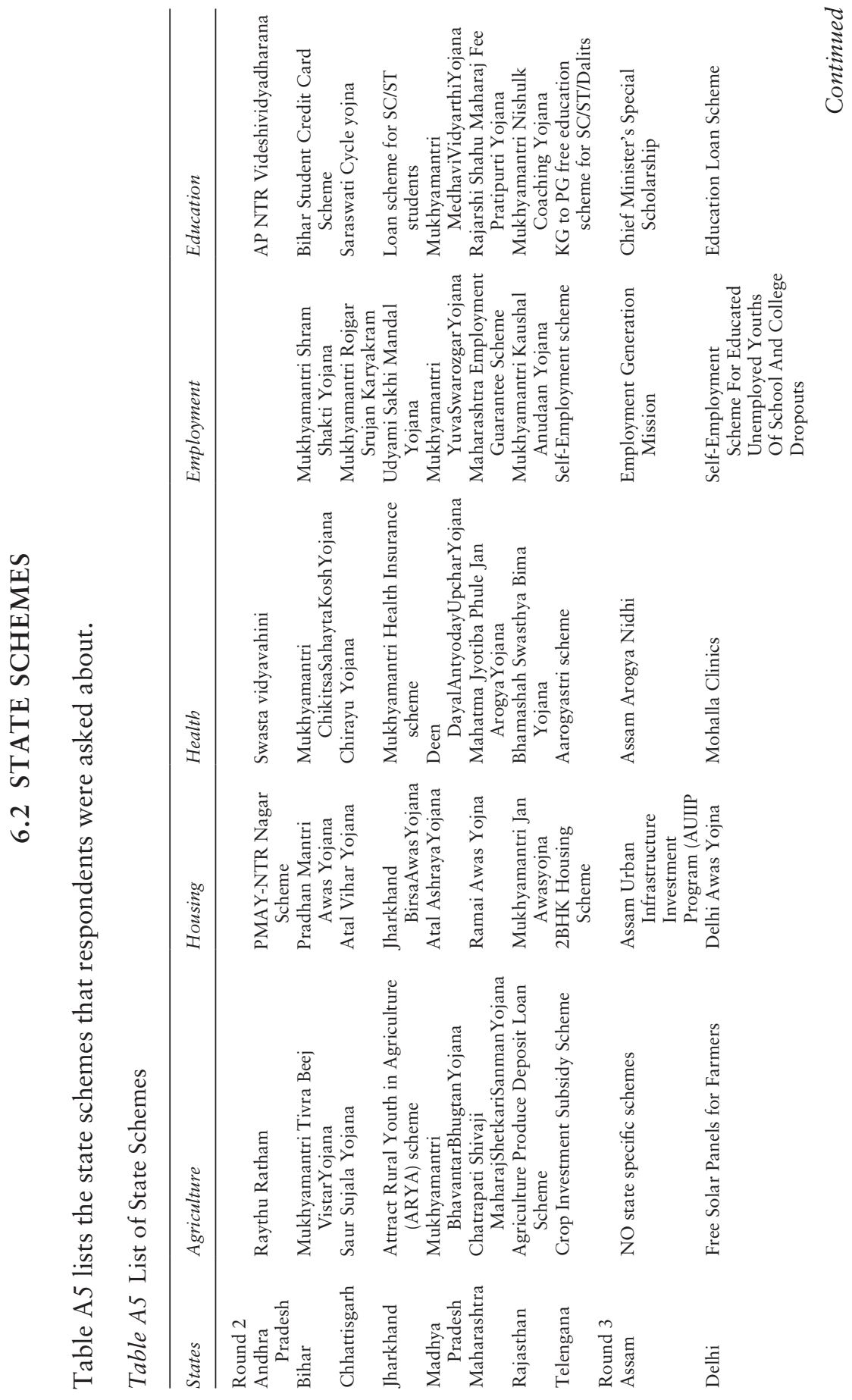




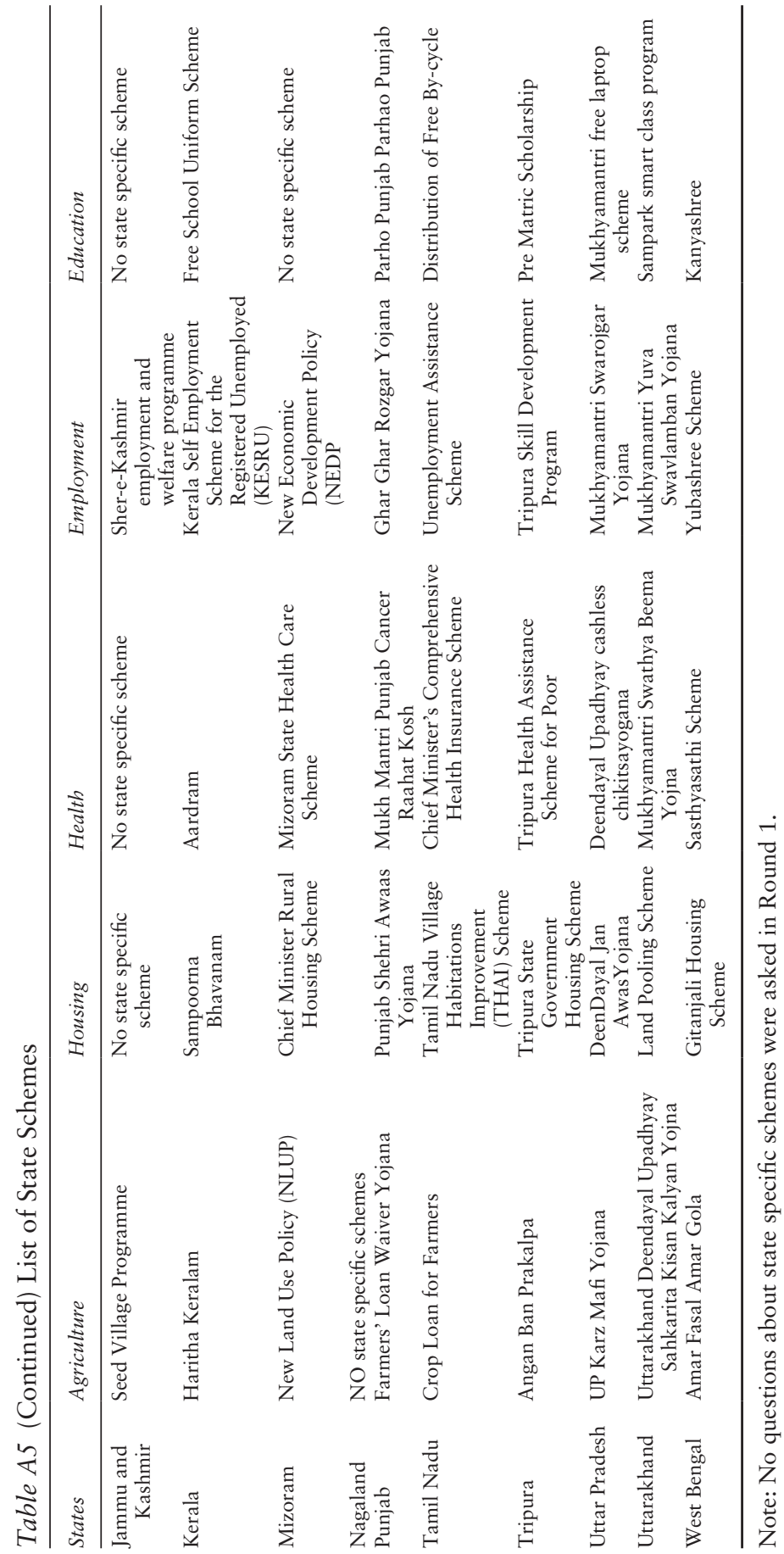




\subsection{INDEX CONSTRUCTION METHOD}

\subsubsection{Index of Nationalism}

This index is constructed by taking into account the following four questions from the survey:

1. The government should punish those who do not say "Bharat Mata ki Jai" at public functions. Do you agree or disagree with this statement?

2. The government should punish those who eat beef/cow meat. Do you agree or disagree with this statement?

3. The government should punish those who don't stand for national anthem at public places. Do you agree or disagree with this statement?

4. The government should punish those who engage in religious conversions. Do you agree or disagree with this statement?

In each question, the response options offered to the respondent were "1. Fully Agree", "2. Somewhat Agree", "3. Somewhat Disagree", "4. Fully Disagree", “8. Don't know”.

The response options of "Fully Disagree" and "Somewhat Disagree" are recoded as 1; and "Fully Agree" and "Somewhat Agree" as 2; Nonresponses are coded as 0 . An additive score is created from the set of the four questions. These scores are then distributed across three categories. Those scoring zero were set as missing since there is no response to these questions. Those who disagree with at least three statements are labelled as "liberal-nationalist"; those who agree with at least three statements are labelled as "conservative nationalist" and the rest as "centrist nationalist".

\subsubsection{Index of Awareness About Central Government Schemes}

This index is constructed by taking into account the following four questions from the survey:

1. Now I am going to name a few central government schemes and programmes which central government has initiated for the benefit of the people. Have you or your family ever availed any benefit of central government schemes?

a. Pradhan Mantri Fasal Bima Yojana

b. Pradhan Mantri Awas Yojana

c. Mahatma Gandhi National Rural Employment Guarantee Act (MGNREGA)

d. Pradhan Mantri Jan Aushadhi Yojana

The response options "Not heard" and "Don't know" are scored as 0 and labelled "not aware" and the responses to "benefitted" and "not benefitted" 
are coded as " 1 " and labelled as "aware" for each of the four listed central government scheme. An additive score (ranging from 0 to 4 ) is created from this set of questions. The scores are then distributed across three categories. The scores of 0 and 1 are categorised as "Low Awareness". Scores ranging from 2 to 3 are labelled as "Some Awareness", and 4 as "High Awareness".

\subsubsection{Index of Awareness About State Government Schemes}

The index is constructed with the following four questions from the survey:

1. Now I am going to name a few schemes and programmes which have been launched by state government for the benefit of the people. Have you or your family ever availed any benefit of these schemes?
a. State Agriculture Scheme
b. State Housing Scheme
c. State Health Scheme
d. State Employment Scheme

The response options "Not heard" and "Don't know" are scored as 0 and labelled as "not aware" and the responses to benefitted and not benefitted as " 1 " and labelled as "aware" for each of the four listed state schemes. An additive score (ranging from 0 to 4 ) is created from this set of questions. The scores are then distributed across three categories. The scores of 0 and 1 are categorised as "Low Awareness". Scores ranging from 2 to 3 are labelled as "Some Awareness", and 4 as "High Awareness".

\subsubsection{Index of Populism}

The following questions from the survey are used to construct an index of populism:

1. In your opinion, who is blocking progress of people like you? a) Elites/ Influential people

2. Now I am going to read out two statements. Please tell me which statement you agree with most?

Statement 1: Politics is ultimately a battle between good and bad.

Statement 2: Politics is ultimately a compromise between good and bad.

3. Now I am going to read out two statements. Please tell me which statement you agree with most?

Statement 1: Elected leaders should be able to override the Courts to serve the people better.

Statement 2: Courts should be able to limit elected leaders to protect the people better. 
Respondents who affirm all three 'populist' statements - a) that elites are blocking their progress, b) that politics is a battle between good and bad, and c) that elected leaders should be able to override courts are characterised as strong populists. Those respondents who affirm any two of the three statements are considered moderate populists. Respondents who affirm any one of the three statements are considered weak populists, and those who do not affirm any of the three are non-populists. 


\subsection{QUESTIONNAIRE}
State Code
A.C. Code
P.S. Code
Respondent S.No.

\section{Politics and Society Between Elections}

\section{Azim Premji University and Lokniti (2016-2018)}

F1. State Name:

F2. A.C. Name:

F3. P.S. Name:

F4. Name of the Respondent:

F5. Address of the respondent (Give landmark):

F6. Date of interview (dd/mm/yyyy):

F7. Name of the Investigator (Code Roll No.):

\section{INVESTIGATOR'S INTRODUCTION AND STATEMENT OF INFORMED CONSENT}

My name is and I have come from Centre for the Study of Developing Societies (also give your University's reference), a social science research organization in Delhi. The study aims to capture public opinion between elections. It covers various aspects related to delivery of public services, law and order, identities, discrimination and violence, economic processes and the perception of on the state at various levels the citizens interact with.

Every person over the age of 18 has an equal chance of being included in this study. You have been selected by chance. There is no risk and also no benefit in participating in this survey. But if you answer our questions, you will help us in understanding how the public feels about issues facing the country today.

This survey is an independent study and is not linked to any political party or government agency. Whatever information you provide will be kept strictly confidential. The findings of this survey will be used for research work.

Participation in this survey is voluntary and it is entirely up to you to answer or not answer any question that I ask. We hope that you will take part in this survey since your participation is important. It usually takes 40 to 45 minutes to complete this interview. Please spare some time for the interview and help me in successfully completing the survey.

F8. May I begin the interview now? 1. Respondent agrees to be interviewed

2. Respondent does not agree to be interviewed

Q1. What is your age? (in completed years) 98. No Response (Code 95 for 95 yrs and above)
Q2. Gender: 1. Male
2. Female
3. Other 
Q3. Up to what level have you studied? (Record exactly and consult code book)

9. No

response

Q3a. Up to what level have your father and mother studied? (Record exactly and consult code book)

Father:

Mother:

9. No response

Q4. In your opinion, what is the most important issue facing India today? (Record the answer and consult the codebook for coding) 98. Don't Know

Q5. Now I am going to name a few central government schemes and programmes which central government has initiated for the benefit of the people. Have you or your family ever availed any benefit of central government schemes?

Benefitted Not Not NR

a. Pradhan Mantri Fasal

$\begin{array}{llllll}\text { Bima Yojana } & 1 & 2 & 3 & 8\end{array}$

b. Pradhan Mantri Awas

Yojana

benefitted heard

c. Mahatma Gandhi National

Rural Employment

$\begin{array}{lllll}\text { Guarantee Act (MGNREGA) } & 1 & 2 & 3 & 8\end{array}$

d. Pradhan Mantri Jan Aushadhi

$\begin{array}{llllll}\text { Yojana } & 1 & 2 & 3 & 8\end{array}$

Q6. If you ever have difficulty in getting an important work done, whom will you first think of approaching for help? (Do NOT read answer categories)

01. MP 02. MLA 03. Councillor/sarpanch

04. Government official 05. Local political leader

06. Caste leader

07. Religious leader

08. Elder outside your family 09. Dalals/Touts

10. NGOs

11. Any other 98. DK

Q7. Based on your experience, how easy or difficult was it to obtain the following services - was it very easy, easy, difficult or very difficult?

Very Easy Difficult Very Never NR easy difficult tried

a. Admission in a

Govt. school

$\begin{array}{llllllll}\text { for a child. } & 1 & 2 & 3 & 4 & 5 & 8\end{array}$

b. Medical

treatment at a

nearby government

$\begin{array}{llllllll}\text { Hospital. } & 1 & 2 & 3 & 4 & 5 & 8\end{array}$

$\begin{array}{lllllll}\text { c. Garbage collection. } & 1 & 2 & 3 & 4 & 5 & 8\end{array}$ 

d. Electricity connection. $\begin{array}{llll}1 & 2 & 3 & 4\end{array}$ 5
4

Q8. In your opinion, who is blocking progress
of people like you? (Only in
a. Elites/Influential people
b. Minorities
c. Migrants/Outsiders
d. Lower castes
e. Upper castes

$\begin{array}{llll}\text { Yes } & \text { No } & \text { DK } & \\ 2 & 1 & 8 & \\ & 2 & 1 & 8 \\ & 2 & 1 & 8 \\ & 2 & 1 & 8 \\ & 2 & 1 & 8\end{array}$

Q9. Total No. of family members living in the household:

Above 18 years:

Below 18 years:

(If more than 9, Code 9)

Q10. (If below 18 years) Do your children go to government school or private school?

1. Government School 2. Private school

3. Some schooling from government schools and some from private schools

4. Few children go to government schools and few go to private school

5. Does not go to school any more 6. No children of school going age 9. NA

Q10a. (If respondent answers with 1, 2, 3 or 4) What are the reasons for current choice of school for your child?

(Check all applicable)

a. It is closer than other schools

b. It is more affordable than other schools

c. It has better facilities compared to other schools

d. It has better teachers compared to other schools

e. It has better discipline compared to other schools

f. It has mid-day meal scheme

g. It is the only school here

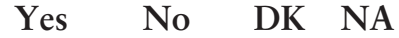

$\begin{array}{llll}2 & 1 & 8 & 9\end{array}$

$\begin{array}{llll}2 & 1 & 8 & 9\end{array}$

$\begin{array}{llll}2 & 1 & 8 & 9\end{array}$

$\begin{array}{llll}2 & 1 & 8 & 9\end{array}$

$\begin{array}{llll}2 & 1 & 8 & 9\end{array}$

$\begin{array}{llll}2 & 1 & 8 & 9\end{array}$

$\begin{array}{llll}2 & 1 & 8 & 9\end{array}$

Q10b. (If child does not go to school any more) Grade/class completed before discontinuance/dropping out? 99. NA

Q11. If you had a choice, would you send your child to a private school or a government school?

1. Private School 2. Government School 8. Don't Know/Can't Say

Q12. I will read out a few statements that people often make about getting work done in government offices. Please tell me which statement you agree with the most? (If no answer then code 8) 
1. Proper documents and information are not enough, proper connections/networks are important to get work done in a government office/department.

2. Proper documents and information are not enough; bribes are important to get work done in a government office/department

3. It is possible to get work done in a government office, if one has all documents and information, without paying bribe or having connection/network

Q13. On a ladder of 10 steps where the 1st step at bottom stands for extremely unpatriotic and the 10th step at the top stands for extremely patriotic, on which step from 1 to 10 would you place the following communities? (SHOW THE LADDER AND EXPLAIN (If no answer is given code 98)

\begin{tabular}{llllllllllll}
\hline \multicolumn{1}{c}{} & \multicolumn{1}{c}{ Extremely unpatriotic } \\
\hline a. Muslims & 01 & 02 & 03 & 04 & 05 & 06 & 07 & 08 & 09 & 10 \\
b. Christians & 01 & 02 & 03 & 04 & 05 & 06 & 07 & 08 & 09 & 10 \\
c. Hindus & 01 & 02 & 03 & 04 & 05 & 06 & 07 & 08 & 09 & 10 \\
d. Sikhs & 01 & 02 & 03 & 04 & 05 & 06 & 07 & 08 & 09 & 10 \\
\hline
\end{tabular}

Q14. How much trust do you have in the following institutions - a great deal of trust, quite a lot of trust, not a lot of trust, no trust at all?

\begin{tabular}{llllll}
\hline & & $\begin{array}{l}\text { Quite } \\
\text { a lot of } \\
\text { trust }\end{array}$ & $\begin{array}{l}\text { Not a lot trust of } \\
\text { of trust }\end{array}$ & $\begin{array}{l}\text { DK at } \\
\text { trust }\end{array}$ & all \\
\hline a. President & 1 & 2 & 3 & 4 & 8 \\
b. Prime Minister & 1 & 2 & 3 & 4 & 8 \\
c. Chief Minister & 1 & 2 & 3 & 4 & 8 \\
\hline
\end{tabular}

Q15. How much trust do you have in the following institutions?

\begin{tabular}{llllll}
\hline & $\begin{array}{l}\text { A great } \\
\text { deal }\end{array}$ & $\begin{array}{l}\text { Quite } \\
\text { a lot of } \\
\text { trust }\end{array}$ & $\begin{array}{l}\text { Not a lot } \\
\text { of trust }\end{array}$ & $\begin{array}{l}\text { No trust DK } \\
\text { of trust at all }\end{array}$ \\
\hline $\begin{array}{l}\text { a. Parliament } \\
\text { b. State Assembly (Vidhan } \\
\quad 1\end{array}$ & 1 & 2 & 3 & 4 & 8 \\
$\begin{array}{l}\text { Sabha) } \\
\text { c. Gram Pachayat/Nagar } \\
\quad \text { Palika (MCD) }\end{array}$ & 1 & 2 & 3 & 4 & 8 \\
$\begin{array}{l}\text { FOR NAGALAND } \\
\text { d. Village council }\end{array}$ & 1 & 2 & 3 & 4 & 8 \\
\hline
\end{tabular}


Q16. I will now name a few government officials. Please tell me how much trust do you have in them: a great deal of trust, quite a lot of trust, not a lot of trust, no trust at all?

\begin{tabular}{llllll}
\hline & $\begin{array}{l}\text { A great } \\
\text { deal }\end{array}$ & $\begin{array}{l}\text { Quite a lot } \\
\text { of trust }\end{array}$ & $\begin{array}{l}\text { Not a lot } \\
\text { of trust }\end{array}$ & $\begin{array}{l}\text { No trust } \\
\text { of trust }\end{array}$ & $\begin{array}{l}\text { DK at } \\
\text { all }\end{array}$ \\
\hline $\begin{array}{l}\text { a. District } \\
\begin{array}{l}\text { Collector } \\
\text { b. Tehsildar }\end{array}\end{array}$ & 1 & 2 & 3 & 4 & 8 \\
\hline
\end{tabular}

Q17. How much trust do you have in the following institutions?

\begin{tabular}{llllll}
\hline & $\begin{array}{l}\text { A great } \\
\text { deal }\end{array}$ & $\begin{array}{l}\text { Quite } \\
\text { a lot of } \\
\text { trust }\end{array}$ & $\begin{array}{l}\text { Nota } \\
\text { lot of } \\
\text { trust }\end{array}$ & $\begin{array}{l}\text { No trust } \\
\text { of trust }\end{array}$ & $\begin{array}{l}\text { DK at } \\
\text { all }\end{array}$ \\
\hline $\begin{array}{l}\text { a. The military/National } \\
\quad 1\end{array}$ & 2 & 3 & 4 & 8 \\
$\begin{array}{l}\text { Army } \\
\text { b. Election Commission }\end{array}$ & 1 & 2 & 3 & 4 & 8 \\
c. Political Parties & 1 & 2 & 3 & 4 & 8 \\
\hline
\end{tabular}

Q18. The government should punish those who do not say "Bharat Mata ki Jai" at public functions. Do you agree or disagree with this statement? (Probe further whether 'fully' or 'somewhat' agree or disagree)
1. Fully Agree
4. Fully Disagree
2. Somewhat Agree
8. Don't know

Q19. Now I am going to name a few schemes and programmes which have been launched by state government for the benefit of the people. Have you or your family ever availed any benefit of these schemes?

\begin{tabular}{lllll}
\hline & Benefitted & $\begin{array}{l}\text { Not } \\
\text { benefitted }\end{array}$ & $\begin{array}{l}\text { Not } \\
\text { heard }\end{array}$ & NR \\
\hline a. State Agriculture & 1 & 2 & 3 & 8 \\
$\quad \begin{array}{l}\text { Scheme } \\
\text { b. State Housing Scheme }\end{array}$ & 1 & 2 & 3 & 8 \\
$\begin{array}{l}\text { c. State Health Scheme } \\
\text { d. State Employment }\end{array}$ & 1 & 2 & 3 & 8 \\
$\quad 1$ & 2 & 3 & 8 \\
e. State Education Scheme & 1 & 2 & 3 & 8 \\
\hline
\end{tabular}


Q20. Now I am going to read out two statements. Please tell me which statement you agree with most?

Statement 1: People, not governments, should punish those who commit rape.

Statement 2: Governments, not people, should punish those who commit rape.

\section{$\begin{array}{lll}1 \text { 1. Agree with Statement } 1 & \text { 2. Agree with Statement } 2 \quad 8 \text {. DK }\end{array}$}

Q21. People should be allowed to express their opinion freely even if they promote dictatorship over democracy in India. Do you agree or disagree with this statement? (Probe further whether "fully" or "somewhat" agree or disagree)
1. Fully Agree
2. Somewhat Agree
3. Somewhat Disagree
4. Fully Disagree
8. Don't know

Q22. On a ladder of 10 steps where the 1st step at bottom stands for extremely lazy and the 10th step at the top stands for extremely hardworking, on which step from 1 to 10 would you place the following communities? SHOW THE LADDER AND EXPLAIN (If no answer is given code 98)

\begin{tabular}{|c|c|c|c|c|c|c|c|c|c|c|}
\hline \multirow[b]{2}{*}{ a. Dalits/SCs } & \multicolumn{9}{|c|}{ Extremely Lazy } & \multirow{2}{*}{$\begin{array}{l}\text { Extremely } \\
\text { hardworking } \\
10\end{array}$} \\
\hline & 01 & 02 & 03 & 04 & 05 & 06 & 07 & 08 & 09 & \\
\hline b. Adivasis/STs & 01 & 02 & 03 & 04 & 05 & 06 & 07 & 08 & 09 & 10 \\
\hline c. Upper Caste & 01 & 02 & 03 & 04 & 05 & 06 & 07 & 08 & 09 & 10 \\
\hline $\begin{array}{l}\text { d. Dominant } \\
\text { Caste } 1\end{array}$ & 01 & 02 & 03 & 04 & 05 & 06 & 07 & 08 & 09 & 10 \\
\hline $\begin{array}{l}\text { e. Dominant } \\
\text { Caste } 2\end{array}$ & 01 & 02 & 03 & 04 & 05 & 06 & 07 & 08 & 09 & 10 \\
\hline
\end{tabular}

Q23. How worried do you feel about the way things are going in the country these days - very worried, somewhat worried, or not at all worried?
1. Very worried
2. Somewhat worried
3. Not worried
8. DK

Q24. How much trust do you have in police - a great deal of trust, quite a lot of trust, not a lot of trust, no trust at all?
1. A great deal of trust
2. Quite a lot of trust
3. Not a lot of trust
4. No trust at all
8. Don't know

Q25. In the last 2-3 years have you or your family ever been in a situation where you needed to contact the police, or the police contacted you? 2. Yes 1. No 8. DK

Q25a. (If yes) Did they come to your home/workplace or did you go to them?
1. I went to the police station
2. Police came to my home/workplace

3. They called me

8. DK 9. Not Applicable/NA 
Q26. Now I am going to read out two statements. Please tell me which statement you agree with most? (Only in 2018)

Statement 1: Politics is ultimately a battle between good and bad.

Statement 2: Politics is ultimately a compromise between good and bad.

$\begin{array}{lll}1 \text { 1. Agree with Statement } 1 & 2 \text {. Agree with Statement } 2 & 8 \text {. DK }\end{array}$

Q27. I am now going to read out some statements about the police and the nature of the decisions made by them. Please tell me how much you agree or disagree with the following statements. (Probe further whether 'strongly' or 'somewhat' agree or disagree)

\begin{tabular}{llllll}
\hline & \multicolumn{1}{c}{ Agree } & \multicolumn{3}{c}{ Disagree } \\
\cline { 2 - 5 } & Strongly & Somewhat & Somewhat & Strongly & DK \\
\hline $\begin{array}{l}\text { a. If a citizen were to report a crime } \\
\text { to the police, quick action would } \\
\text { be taken. }\end{array}$ & 1 & 2 & 3 & 4 & 8 \\
$\begin{array}{l}\text { b. } \begin{array}{l}\text { The police in State generally take } \\
\text { bribes. }\end{array} \\
\begin{array}{l}\text { c. The decisions made by the police } \\
\text { are unduly influenced by political } \\
\text { parties/politicians. }\end{array}\end{array}$ & 1 & 2 & 3 & 4 & 8 \\
$\begin{array}{l}\text { d. Police generally treats people with } \\
\text { respect. }\end{array}$ & 1 & 2 & 3 & 4 & 8 \\
\hline
\end{tabular}

Q28. Now I will read out a few situations of people from different social backgrounds going to the police. Which group do you think the police will treat better? (Ask questions one by one)

\begin{tabular}{|c|c|c|c|c|}
\hline $\begin{array}{l}\text { a. A Rich person or a } \\
\text { Poor person? }\end{array}$ & 1. Rich & 2. Poor & $\begin{array}{l}\text { 3. Both treated } \\
\text { same }\end{array}$ & 8. DK \\
\hline $\begin{array}{l}\text { b. An Upper Caste or } \\
\text { a Dalit? }\end{array}$ & $\begin{array}{l}\text { 1. Upper } \\
\text { Caste }\end{array}$ & 2. Dalit & $\begin{array}{l}\text { 3. Both treated } \\
\text { same }\end{array}$ & 8. DK \\
\hline $\begin{array}{l}\text { c. A Hindu or a } \\
\text { non-Hindu? }\end{array}$ & 1. Hindu & $\begin{array}{l}\text { 2. Non- } \\
\text { Hindu }\end{array}$ & $\begin{array}{l}\text { 3. Both treated } \\
\text { same }\end{array}$ & 8. DK \\
\hline $\begin{array}{l}\text { d. A Man and a } \\
\text { Woman? }\end{array}$ & 1. Man & 2. Woman & $\begin{array}{l}\text { 3. Both treated } \\
\text { same }\end{array}$ & 8. DK \\
\hline
\end{tabular}

Q29. The government should punish those who eat beef/cow meat. Do you agree or disagree with this statement? (Probe further whether 'fully' or 'somewhat' agree or disagree)
1. Fully Agree
2. Somewhat Agree
4. Fully Disagree
8. DK

Q30. How safe is to live in this city/town/village - very safe, safe or unsafe.
1. Very safe
2. Safe
3. Unsafe
8. DK

Q31. How much trust do you have in the different level of judiciary - a great deal of trust, quite a lot of trust, not a lot of trust, no trust at all? 


\begin{tabular}{llllll}
\hline & A great deal & $\begin{array}{l}\text { Quite a lot of Not a lot } \\
\text { trust }\end{array}$ & $\begin{array}{l}\text { No trust } \\
\text { of all }\end{array}$ & DK \\
\hline $\begin{array}{lllll}\text { a. Supreme } \\
\quad \text { Court }\end{array}$ & 1 & 2 & 3 & 4 & 8 \\
b. High Court & 1 & 2 & 3 & 4 & 8 \\
c. District Court & 1 & 2 & 3 & 4 & 8 \\
\hline
\end{tabular}

Q32. I am now going to read out some statements about the courts and the nature of the decisions made by them. Please tell me how much you agree or disagree with the following statements. (Probe further whether strongly or somewhat agree or disagree).

\begin{tabular}{|c|c|c|c|c|c|}
\hline & Agree & & Disagree & & $D K$ \\
\hline & Strongl & Somewhat & Somewhat & Strongly & \\
\hline $\begin{array}{l}\text { a. It is highly likely that an } \\
\text { innocent person will be } \\
\text { convicted }\end{array}$ & 1 & 2 & 3 & 4 & 8 \\
\hline $\begin{array}{l}\text { b. It is highly likely that } \\
\text { a guilty person will be } \\
\text { acquitted }\end{array}$ & 1 & 2 & 3 & 4 & 8 \\
\hline $\begin{array}{l}\text { c. The decisions made by } \\
\text { the court are unduly } \\
\text { influenced by political } \\
\text { parties/politicians. }\end{array}$ & 1 & 2 & 3 & 4 & 8 \\
\hline $\begin{array}{l}\text { d. Court officials in Jammu } \\
\text { \& Kashmir generally } \\
\text { take bribes. }\end{array}$ & 1 & 2 & 3 & 4 & 8 \\
\hline
\end{tabular}

Q33. In the past five years have you or your family been in any situation that could have involved the court system or where you could have gone to the court to resolve matter/ dispute?
2. Yes
1. No
8. DK

Q33a. (If yes) Did they contact you or did you go to the court?

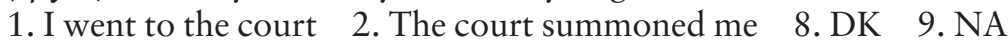

Q34. Now I will read out a few situations of people from different social backgrounds going to the court. Which group do you think the court will treat better? (Ask questions one by one)

\begin{tabular}{|c|c|c|c|c|}
\hline $\begin{array}{l}\text { a. A Rich person or a } \\
\text { Poor person? }\end{array}$ & 1. Rich & 2. Poor & $\begin{array}{l}\text { 3. Both treated } \\
\text { same }\end{array}$ & 8. DK \\
\hline $\begin{array}{l}\text { b. An Upper caste or } \\
\text { a Dalit? }\end{array}$ & $\begin{array}{l}\text { 1. Upper } \\
\text { Caste }\end{array}$ & 2. Dalit & $\begin{array}{l}\text { 3. Both treated } \\
\text { same }\end{array}$ & 8. DK \\
\hline $\begin{array}{l}\text { c. A Hindu or a } \\
\text { non-Hindu? }\end{array}$ & 1. Hindu & 2. Non-Hindu & $\begin{array}{l}\text { 3. Both treated } \\
\text { same }\end{array}$ & 8. DK \\
\hline $\begin{array}{l}\text { d. A Man and a } \\
\text { Woman? }\end{array}$ & 1. Man & 2. Woman & $\begin{array}{l}\text { 3. Both treated } \\
\text { same }\end{array}$ & 8. DK \\
\hline
\end{tabular}


Q35. The government should punish those who don't stand for national anthem at public places. Do you agree or disagree with this statement? (Probe further whether "fully" or "somewhat" agree or disagree)
1. Fully Agree
2. Somewhat Agree 3. Somewhat Disagree
4. Fully Disagree
8. Don't know

Q36. Now I am going to read out two statements. Please tell me which statement you agree with most?

Statement 1: People, not governments, should punish those who kill cows.

Statement 2: Governments, not people, should punish those who kill cows.

\section{$\begin{array}{lll}\text { 1. Agree with Statement } 1 & 2 \text {. Agree with Statement } 2 \text { 8. DK }\end{array}$}

Q37. How much trust do you have in government officials - a great deal of trust, quite a lot of trust, not a lot of trust or no trust at all?

1. A great deal of trust 2. Quite a lot of trust
3. Not a lot of trust
4. No trust at all
8. Don't know

Q38. In the past two years have you or your family contacted government officials to resolve matter/ dispute?
2. Yes
1. No
8. DK

Q39. I am now going to read out some statements about the government officials and the nature of the decisions taken by them. Please tell me how much you agree or disagree with the following statements. (Probe further whether "strongly" or "somewhat" agree or disagree).

\begin{tabular}{|c|c|c|c|c|c|}
\hline & Agree & & Disagree & & $D K$ \\
\hline & Strongly & Somewhat & Somewhat & Strongly & \\
\hline $\begin{array}{l}\text { a. If a citizen approached } \\
\text { with a problem, quick } \\
\text { action would be taken. }\end{array}$ & 1 & 2 & 3 & 4 & 8 \\
\hline $\begin{array}{l}\text { b. The government } \\
\text { officials in the state } \\
\text { generally take bribes. }\end{array}$ & 1 & 2 & 3 & 4 & 8 \\
\hline $\begin{array}{l}\text { c. The decisions taken } \\
\text { by the government } \\
\text { officials are unduly } \\
\text { influenced by political } \\
\text { parties/politicians. }\end{array}$ & 1 & 2 & 3 & 4 & 8 \\
\hline $\begin{array}{l}\text { d. Government officials } \\
\text { generally treats people } \\
\text { with respect. }\end{array}$ & 1 & 2 & 3 & 4 & 8 \\
\hline
\end{tabular}

Q40. Now I will read out a few situations of people from different social backgrounds going to the government officials. Which group do 
you think the government officials will treat better? (Ask questions one by one)

\begin{tabular}{|c|c|c|c|c|}
\hline $\begin{array}{l}\text { a. A Rich person or a } \\
\text { Poor person? }\end{array}$ & 1. Rich & 2. Poor & $\begin{array}{l}\text { 3. Both treated } \\
\text { same }\end{array}$ & 8. DK \\
\hline $\begin{array}{l}\text { b. An Upper Caste or a } \\
\text { Dalit? }\end{array}$ & $\begin{array}{l}\text { 1. Upper } \\
\text { Caste }\end{array}$ & 2. Dalit & $\begin{array}{l}\text { 3. Both treated } \\
\text { same }\end{array}$ & 8. DK \\
\hline $\begin{array}{l}\text { c. A Hindu or a } \\
\text { non-Hindu? }\end{array}$ & 1. Hindu & 2.Non-Hindu & $\begin{array}{l}\text { 3. Both treated } \\
\text { same }\end{array}$ & 8. D \\
\hline d. A Man and a Woman? & 1. Man & 2. Woman & $\begin{array}{l}\text { 3. Both treated } \\
\text { same }\end{array}$ & 8. D \\
\hline
\end{tabular}

Q41. Now I am going to read out two statements. Please tell me which statement you agree with most?

Statement 1: It is more important for a politician to have a clean image than to deliver public services.

Statement 2: It is more important for a politician to deliver public services than to have a clean image.

\section{$\begin{array}{lll}1 \text {. Agree with Statement } 1 & 2 \text {. Agree with Statement } 2 \text { 8. DK }\end{array}$}

Q42. I will name a few methods through which it is possible to resolve a dispute between you and another party. Could you please tell me which one of these methods you are most likely to go to resolve the following disputes?

\begin{tabular}{|c|c|c|c|c|c|c|c|}
\hline & Family & Neighbor & urhood & $\begin{array}{l}\text { Caste/ } \\
\text { Community }\end{array}$ & NGO & $\begin{array}{l}\text { Police } \\
\text { Court }\end{array}$ & DK \\
\hline & & member & $\backslash$ village elder & & organi & & \\
\hline $\begin{array}{l}\text { a. Property } \\
\text { dispute }\end{array}$ & 1 & 2 & 3 & 4 & 5 & 6 & 8 \\
\hline $\begin{array}{l}\text { b. Marriage } \\
\text { dispute }\end{array}$ & 1 & 2 & 3 & 4 & 5 & 6 & 8 \\
\hline $\begin{array}{l}\text { c. Neighbourhood } \\
\text { dispute }\end{array}$ & 1 & 2 & 3 & 4 & 5 & 6 & 8 \\
\hline $\begin{array}{l}\text { d. Domestic } \\
\text { violence }\end{array}$ & 1 & 2 & 3 & 4 & 5 & 6 & 8 \\
\hline
\end{tabular}

Q43. The government should punish those who engage in religious conversions. Do you agree or disagree with this statement? (Probe further whether "fully" or "somewhat" agree or disagree)
1. Fully Agree
2. Somewhat Agree
3. Somewhat Disagree
4. Fully Disagree 8. Don't know

Q44. Is any of your close friends a

\begin{tabular}{llll}
\hline & Yes & No & DK \\
\hline a. Dalit & 2 & 1 & 8 \\
b. Adivasi & 2 & 1 & 8 \\
c. OBC & 2 & 1 & 8 \\
d. Upper caste & 2 & 1 & 8
\end{tabular}



e. Muslim
f. Christian
g. Hindu
h. Of the opposite gender

$\begin{array}{lll}2 & 1 & 8 \\ 2 & 1 & 8 \\ 2 & 1 & 8 \\ 2 & 1 & 8\end{array}$

Q45. What is the most important responsibility of a government towards its citizens? (Record exact answer options) 98. Don't Know

Q46a. Now I am going to read out two statements. Please tell me which statement you agree with most?

Statement 1: Generations of unfair treatment has made it difficult for Dalits to improve their economic conditions

Statement 2: Dalits are not trying harder; if they try hard enough they will be well off.

\section{$\begin{array}{lll}\text { 1. Agree with Statement } 1 & 2 \text {. Agree with Statement } 2 & 8 . \text { DK }\end{array}$}

Q46b. Now I am going to read out two statements. Please tell me which statement you agree with most?

Statement 1: Generations of unfair treatment have made it difficult for Adivasis to work their way out of the lower class.

Statement 2: Adivasi are not trying harder; if they try hard enough they will be well off.
1. Agree with Statement 1
2. Agree with Statement 2
8. DK

Q46c. Now I am going to read out two statements. Please tell me which statement you agree with most?

Statement 1: Over the last 50 years, Dominant caste has acquired large political and economic power hence they should not be given any special assistance.

Statement 2: Only few from Dominant caste have acquired large political and economic power, while a majority among them are not as privileged. Hence they should be given more privileges in society

\section{$\begin{array}{lll}1 \text {. Agree with Statement } 1 & 2 \text {. Agree with Statement } 2 \text { 8. DK }\end{array}$}

Q47. People should be allowed to express their opinion freely even if they are making fun of religious communities other than their own. Do you agree or disagree with this statement? (Probe further whether "fully" or "somewhat" agree or disagree)
1. Fully Agree
2. Somewhat Agree
3. Somewhat Disagree
4. Fully Disagree
8. Don't know

Q48. On a ladder of 10 steps where the 1st step at bottom stands for extremely violent and the 10th step at the top stands for extremely peaceful, on which step from 1 to 10 would you place the following communities? SHOW THE LADDER AND EXPLAIN (If no answer is given code 98) 


\begin{tabular}{|c|c|c|c|c|c|c|c|c|c|c|}
\hline a. Dalits/SCs & 01 & 02 & 03 & 04 & 05 & 06 & 07 & 08 & 09 & 10 \\
\hline b. Adiv & 01 & 02 & 03 & 04 & 05 & 06 & 07 & 08 & 09 & 10 \\
\hline c. Upp & 01 & 02 & 03 & 04 & 05 & 06 & 07 & 08 & 09 & 10 \\
\hline Cas & 01 & 02 & 03 & 04 & 05 & 06 & 07 & 08 & 09 & \\
\hline $\begin{array}{l}\text { e. Dominant } \\
\text { Caste } 2\end{array}$ & 01 & 02 & 03 & 04 & 05 & 06 & 07 & 08 & 09 & 10 \\
\hline f. Muslims & 01 & 02 & 03 & 04 & 05 & 06 & 07 & 08 & 09 & \\
\hline g. $\mathrm{Ch}$ & 01 & 02 & 03 & 04 & 05 & 06 & 07 & 08 & 09 & \\
\hline h. $\mathrm{Hi}$ & 01 & 02 & 03 & 04 & 05 & 06 & 07 & 08 & 09 & \\
\hline i. Sikhs & 01 & 02 & 03 & 04 & 05 & 06 & 07 & 08 & 09 & \\
\hline
\end{tabular}

Q49. People should be allowed to express their opinion freely even if they are criticizing elected leaders. Do you agree or disagree with this statement? (Probe further whether "fully" or "somewhat" agree or disagree)

1. Fully Agree 2. Somewhat Agree 3. Somewhat Disagree

4. Fully Disagree 8. Don't Know

Q50. How regularly do you do the following for News - daily, sometimes, rarely or never?

\begin{tabular}{llllll}
\hline & Daily & \multicolumn{2}{l}{ Sometimes } & Rarely & Never DK \\
\hline a. Watch Doordarshan & 1 & 2 & 3 & 4 & 8 \\
b. Watch Private News Channels & 1 & 2 & 3 & 4 & 8 \\
c. Watch Local language television & 1 & 2 & 3 & 4 & 8 \\
$\quad$ channel & & & & & \\
d. Read Hindi Newspapers & 1 & 2 & 3 & 4 & 8 \\
e. Read English Newspapers & 1 & 2 & 3 & 4 & 8 \\
f. Read Local language newspaper & 1 & 2 & 3 & 4 & 8 \\
g. Facebook & 1 & 2 & 3 & 4 & 8 \\
h. Whatsapp & 1 & 2 & 3 & 4 & 8 \\
i. Twitter & 1 & 2 & 3 & 4 & 8 \\
\hline
\end{tabular}

Q51. How much trust do you have in them? Is it a great deal of trust, quite a lot of trust, not a lot of trust or no trust at all?

\begin{tabular}{llllll}
\hline & $\begin{array}{l}\text { Great deal } \\
\text { of trust }\end{array}$ & $\begin{array}{l}\text { Quite a lot } \\
\text { of trust }\end{array}$ & $\begin{array}{l}\text { Not a lot } \\
\text { of trust }\end{array}$ & $\begin{array}{l}\text { No trust } \\
\text { at all }\end{array}$ & DK \\
\hline a. Doordarshan & 1 & 2 & 3 & 4 & 8 \\
$\begin{array}{l}\text { b. Private news channels } \\
\text { c. Local language }\end{array}$ & 1 & 2 & 3 & 4 & 8 \\
$\begin{array}{l}\text { television channel } \\
\text { d. Hindi newspapers }\end{array}$ & 1 & 2 & 3 & 4 & 8 \\
\end{tabular}




\begin{tabular}{llllll} 
e. English newspapers & 1 & 2 & 3 & 4 & 8 \\
$\begin{array}{l}\text { f. Local language } \\
\quad \text { newspaper }\end{array}$ & 1 & 2 & 3 & 4 & 8 \\
g. Facebook & 1 & 2 & 3 & 4 & 8 \\
h. WhatsApp & 1 & 2 & 3 & 4 & 8 \\
i. Twitter & 1 & 2 & 3 & 4 & 8 \\
\hline
\end{tabular}

Q52. Now I am going to read out two statements. Please tell me which statement you agree with most? (Only in 2018)

Statement 1: Elected leaders should be able to override the Courts to serve the people better.

Statement 2: Courts should be able to limit elected leaders to protect the people better.

$\begin{array}{lll}1 . & \text { Agree with Statement } 1 & 2 \text {. Agree with Statement } 2 \text { 8. DK }\end{array}$

Q53. People should be allowed to express their opinion freely even if they are promoting violence against people from other communities. Do you agree or disagree with this statement? (Probe further whether 'fully' or 'somewhat' agree or disagree)
1. Fully Agree
2. Somewhat Agree
3. Somewhat Disagree
4. Fully Disagree
8. Don't know

Q54. When we ask people how they would identify themselves, some say they are only State identity and others feel they are only Indian. While some feel they are more State identity and less Indian and other feel they are more Indian and less State identity. How do you identify yourself?
1. Only State identity
2. Only Indian
3. More State identity less Indian
4. More Indian less State identity 5. Both equally $\quad 8$. DK

Q55. Suppose there are two leaders from same political party and equally competent to get your work done. If one is from your caste while the other from a different caste. Whom would you be willing to contact first?

1. Leader from same caste

2. Leader from different caste

3. Will not make any difference

8. DK

Q56. Suppose there are two leaders from same political party and equally competent to get your work done. If one is from your religion while the other from a different religion. Whom would you be willing to contact first?

1. Leader from same religion 2. Leader from different religion

3. Will not make any difference 8 . DK

Q57. Some people feel it is acceptable to speak in any language in public places while others feel that people should speak only in the local language in public places. What is your opinion on this issue? 
1. Speak any language 2. Speak local language 8 . Can't say

Q58. People should be allowed to express their opinion freely even if they promote the use of violence against the Indian state. Do you agree or disagree with this statement? (Probe further whether 'fully' or 'somewhat' agree or disagree)
1. Fully Agree
2. Somewhat Agree
3. Somewhat Disagree
4. Fully Disagree
8. DK

Q59. In many parts of India, large parts of agricultural and forest land are acquired to build a factory, a road, railway lines, bus stand, airport, pipelines, dams. Often local villagers protest against these acquisitions: Now, I am going to read out pairs of statements. Please tell me which statement you agree with the most.

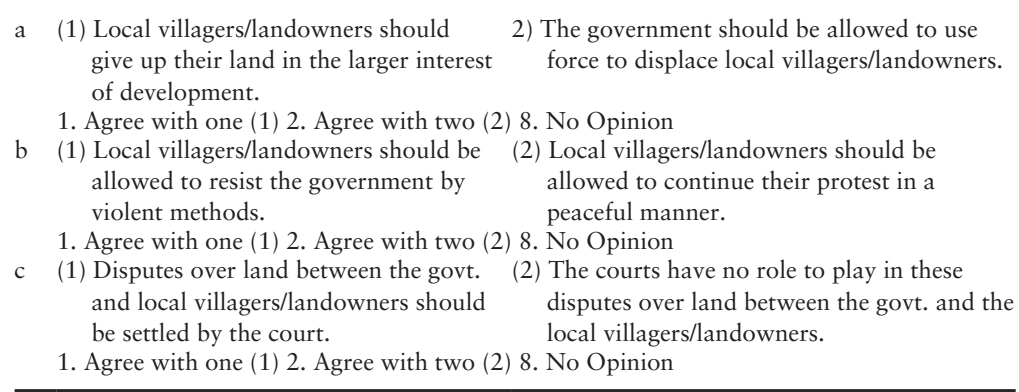

Q60. The government should punish individuals or groups that use violence or violent means against others in the name of cow protection. Do you agree or disagree with this statement? (Probe further whether "fully" or "somewhat" agree or disagree)
1. Fully Agree
2. Somewhat Agree
3. Somewhat Disagree
4. Fully Disagree
8. Don't Know

Q61. How would you describe your social class? Are you in the lower class, the working class, the middle class, or the upper class?
1. Lower class
2. Working class
3. Middle class
4. Upper class
8. DK

Q62. Now I am going to read out a few statements. Please tell me which statement you agree with most?

Statement 1: Elected leaders should be able to override the bureaucrats to serve the people better.

Statement 2: Bureaucrats should be able to limit elected leaders to protect the people better.

$\begin{array}{lll}1 \text { 1. Agree with Statement } 1 & \text { 2. Agree with Statement } 2 \quad 8 \text {. DK }\end{array}$

Q63. Compared to your parents, do you think it is easy or hard for you to move up the income ladder? (Probe whether a great deal easier, moderately easier or a great deal harder or moderately harder) 
1. A great deal easier

3. A great deal harder

5. Neither easier nor harder
2. Moderately easier

4. Moderately harder

8. DK

Q64. People should be allowed to express their opinion freely even if they demand independence for a certain part of India. Do you agree or disagree with this statement? (Probe further whether 'fully' or 'somewhat' agree or disagree)

1. Fully Agree 2. Somewhat Agree 3. Somewhat Disagree

4. Fully Disagree 8. Don't know

Q65. I am now going to read out some statements about men and women and their place in the family. Please tell me how much you agree or disagree with the following statements. (Probe further whether "strongly" or "somewhat" agree or disagree)

\begin{tabular}{|c|c|c|c|c|c|}
\hline & Agree & & Disagree & & DK \\
\hline & Strongly & Somewhat & Somewhat & Strongly & \\
\hline $\begin{array}{l}\text { a. A woman should } \\
\text { prioritise managing home } \\
\text { over outside work. }\end{array}$ & 1 & 2 & 3 & 4 & 8 \\
\hline $\begin{array}{l}\text { b. It is up to women to } \\
\text { decide whom to get } \\
\text { married to. }\end{array}$ & 1 & 2 & 3 & 4 & 8 \\
\hline $\begin{array}{l}\text { c. Educating boys is more } \\
\text { important then educating } \\
\text { girls. }\end{array}$ & 1 & 2 & 3 & 4 & 8 \\
\hline $\begin{array}{l}\text { d. Men should be paid more } \\
\text { than women even if it's } \\
\text { the same job. }\end{array}$ & 1 & 2 & 3 & 4 & 8 \\
\hline $\begin{array}{l}\text { e. Women should have } \\
50 \text { percent reservations of } \\
\text { all jobs. }\end{array}$ & 1 & 2 & 3 & 4 & 8 \\
\hline $\begin{array}{l}\text { f. Women should have the } \\
\text { right to decide to get } \\
\text { married or not. }\end{array}$ & 1 & 2 & 3 & 4 & 8 \\
\hline $\begin{array}{l}\text { g. Women and men should } \\
\text { have equal responsibility } \\
\text { for child rearing. }\end{array}$ & 1 & 2 & 3 & 4 & 8 \\
\hline
\end{tabular}

Q66. Sexual relationship between two men or two women should be accepted in society. Do you agree or disagree with this statement? (Probe further whether "fully" or "somewhat" agree or disagree)
1. Fully Agree
2. Somewhat Agree
3. Somewhat Disagree
4. Fully Disagree
8. Don't know 


\section{Only 2016 and 2017}

P4. How hopeful do you feel about the way things are going in the country these days - very hopeful, somewhat hopeful or not at all hopeful?
1. Very hopeful
2. Somewhat hopeful
3. Not at all hopeful
8. Don't know/DK

P25. There are different reasons why people avoid interacting with the police, even when they have been in situations where they could have interacted with the police. Please tell me about yourself, what was the main reason for you or your family for not interacting with the police? (Don't read out answer categories)

01. Problem could be resolved by community elders

02. Lawyers/ friends. associates suggested not to go to police

03. Didn't go to police, because it complicates the matter

04. Previous experience with police was bad

05. Police is not fair to everyone

06. Police extracts money

07. It is not good for the family name and prestige to be involved with the police

08. There is No Point in going to the police

09. Never gone/contacted police

10. Others (specify) 98. DK

P49. Of the different sources of information such as TV, newspaper, internet and radio, which source would you refer to first for reliable and accurate information?
1. TV
2. Newspaper
3. Internet
4. Radio
5. All
6. None
8. DK

P63. How safe are women in this city (city/town/village) in the following situations? Would you say that women are safe or unsafe? (Probe further whether "very" or "somewhat" safe or unsafe)

\begin{tabular}{lllllll}
\hline & Safe & & Unsafe & & DK \\
\hline & Very & Somewhat & Somewhat & Very \\
\hline $\begin{array}{l}\text { a. When they go out after } \\
\begin{array}{l}\text { sunset. } \\
\text { b. How safe are women at the }\end{array}\end{array}$ & 1 & 2 & 2 & 3 & 4 & 8 \\
$\begin{array}{l}\text { place where they work. } \\
\text { c. How safe are women from } \\
\text { beating etc. (maar/pit) from } \\
\text { their family members inside } \\
\text { their home. }\end{array}$ & 1 & 2 & 3 & 4 & 8 \\
\hline
\end{tabular}




\section{Only 2016}

N7. Government has initiated several schemes and programmes for the benefit of the people. Have you or your family ever availed any such benefits?

\begin{tabular}{llll}
\hline & Yes & No & Not heard \\
\hline a. Employment scheme & 2 & 1 & 0 \\
b. Pension scheme & 2 & 1 & 0 \\
c. Skill-development scheme & 2 & 1 & 0 \\
d. Accidental crop insurance scheme & 2 & 1 & 0 \\
e. Crop subsidy scheme & 2 & 1 & 0 \\
f. Fertilizer subsidy scheme & 2 & 1 & 0 \\
g. Housing scheme & 2 & 1 & 0 \\
h. Medical insurance scheme & 2 & 1 & 0 \\
i. Educational scholarship scheme & 2 & 1 & 0 \\
\hline
\end{tabular}

N8. Now I am going to name a few government policies. Please tell me whether it is good for you or bad for you. (Probe further whether "very" or "somewhat" good or bad)

\begin{tabular}{|c|c|c|c|c|c|c|c|}
\hline & Gooc & & Bad & & $\begin{array}{l}\text { Neither } \\
\text { good nor } \\
\text { bad }\end{array}$ & $\begin{array}{l}\text { Not } \\
\text { heard }\end{array}$ & $D K$ \\
\hline & Very & Somewhat & Somewhat & Very & & & \\
\hline $\begin{array}{l}\text { a. Right to } \\
\text { Information }\end{array}$ & 1 & 2 & 3 & 4 & 5 & 6 & 8 \\
\hline $\begin{array}{l}\text { b. Right to } \\
\text { Education }\end{array}$ & 1 & 2 & 3 & 4 & 5 & 6 & 8 \\
\hline $\begin{array}{l}\text { c. Mahatma } \\
\text { Gandhi } \\
\text { National Rural } \\
\text { Employment } \\
\text { Guarantee Act. } \\
\text { (NREGA) }\end{array}$ & 1 & 2 & 3 & 4 & 5 & 6 & 8 \\
\hline $\begin{array}{l}\text { d. Atal Pension } \\
\text { Yojana }\end{array}$ & 1 & 2 & 3 & 4 & 5 & 6 & 8 \\
\hline $\begin{array}{l}\text { e. Deen Dayal } \\
\text { Upadhyaya } \\
\text { Grameen } \\
\text { Kaushal Yojna }\end{array}$ & 1 & 2 & 3 & 4 & 5 & 6 & 8 \\
\hline $\begin{array}{l}\text { f. Swachh Bharat } \\
\text { Abhiyan }\end{array}$ & 1 & 2 & 3 & 4 & 5 & 6 & 8 \\
\hline $\begin{array}{l}\text { g. Pradhan } \\
\text { Mantri } \\
\text { Suraksha Bima } \\
\text { Yojana }\end{array}$ & 1 & 2 & 3 & 4 & 5 & 6 & 8 \\
\hline
\end{tabular}


N11. I will read out a few statements that people often make about getting work done in government offices/ departments. Please tell me whether you agree or disagree with these statements? (Probe further whether "strongly" or "somewhat" agree or disagree)

\begin{tabular}{|c|c|c|c|c|c|}
\hline & Agree & & Disagree & & $D K$ \\
\hline & Strongly & Somewhat & Somewhat & Strongly & \\
\hline $\begin{array}{l}\text { a. It is possible to get work } \\
\text { done in a government } \\
\text { office/department if one } \\
\text { has all documents and } \\
\text { information. }\end{array}$ & 1 & 2 & 3 & 4 & 8 \\
\hline $\begin{array}{l}\text { b. Proper documents and } \\
\text { information is not } \\
\text { enough, to get work } \\
\text { done in a government } \\
\text { office/department, } \\
\text { bribes are important. }\end{array}$ & 1 & 2 & 3 & 4 & 8 \\
\hline $\begin{array}{l}\text { c. If one has proper } \\
\text { connections/ networks } \\
\text { (pahuch/pehchaan), } \\
\text { documents and } \\
\text { procedures do not } \\
\text { matter, one can any way } \\
\text { get their work done. }\end{array}$ & 1 & 2 & 3 & 4 & 8 \\
\hline
\end{tabular}

N16. Please tell me whether you agree or disagree with the following issues? (Probe further whether "fully" or "somewhat" agrees or disagrees)

\begin{tabular}{llllll}
\hline & Agree & Disagree & & DK \\
\hline & Fully & Somewhat & Somewhat & Fully & \\
\hline $\begin{array}{l}\text { a. Voting must be made } \\
\text { mandatory for all Indian. }\end{array}$ & 1 & 2 & 3 & 4 & 8 \\
$\begin{array}{l}\text { b. Government should punish } \\
\text { those who do not respect } \\
\text { the cow. }\end{array}$ & 2 & 3 & 4 & 8 \\
\hline
\end{tabular}

N44. Some people feel it is okay to speak in State language in public places while others feel that there is no problem in speaking in Hindi or English in public places. What is your opinion on this issue?

1. State language

2. No problem speaking in Hindi or English
3. Hindi but not English
4. English but not Hindi
5. I don't know both Hindi/English
8. DK 
N45. In many parts of India, large parts of agricultural and forest land are acquired to build a factory, a road, railway lines, bus stand, airport, pipelines, dams. Often local villagers protest against these acquisitions. Should they: (Probe further whether "strongly" or "somewhat" agree or disagree)

\begin{tabular}{|c|c|c|c|c|c|}
\hline & Agree & & Disagree & & $D K$ \\
\hline & Strongly & Somewhat & Somewhat & Strongly & \\
\hline $\begin{array}{l}\text { a. Give up their land in } \\
\text { the larger interest of } \\
\text { development. }\end{array}$ & 1 & 2 & 3 & 4 & 8 \\
\hline $\begin{array}{l}\text { b. Be allowed to } \\
\text { continue their protest } \\
\text { in a peaceful manner. }\end{array}$ & 1 & 2 & 3 & 4 & 8 \\
\hline $\begin{array}{l}\text { c. Be allowed to resist } \\
\text { the government by } \\
\text { violent methods. }\end{array}$ & 1 & 2 & 3 & 4 & 8 \\
\hline $\begin{array}{l}\text { d. These disputes should } \\
\text { be settled by the } \\
\text { court. }\end{array}$ & 1 & 2 & 3 & 4 & 8 \\
\hline $\begin{array}{l}\text { e. The government } \\
\text { should be allowed to } \\
\text { use force to displace } \\
\text { locals. }\end{array}$ & 1 & 2 & 3 & 4 & 8 \\
\hline $\begin{array}{l}\text { f. The government } \\
\text { should be allowed } \\
\text { to acquire fertile } \\
\text { agricultural land. }\end{array}$ & 1 & 2 & 3 & 4 & 8 \\
\hline
\end{tabular}

N49. I am going to read out three statements about same sex relationship. Which one do you agree with Most?

1. Same sex relationships should be punished

2. It is a medical problem that needs to be treated

3. It should be treated the same as different sex relationships 8 . D.K.

NZ9. Livestock Total Number

a. Goat/sheep/pig:

b. Cow/Oxen/buffalo/Camel:

c. Any other:

\section{Only 2017}

R10b1. (If child does not go to school any more) Grade/class completed before discontinuance/dropping out? 99. NA 
R10b2. (If child does not go to school any more) Grade/class completed before discontinuance/dropping out? 99. NA

\section{BACKGROUND DATA}

\section{Personal Information}

Z1. Now let us talk about this village/ town you live in. How long have you lived here? (If not all life, probe for number of years lived here) 1. Less than 5 years 2.5 to 10 years 3 . More than 10 years 4. Entire life

Z1a. (If Not all life) Where did you come from? Name of state: 99. Not answer

Z2. Occupation? (Record exactly and consult codebook of if retired, try to ascertain his/her previous occupation. If student or housewife, then note down that as well)

a. What is your occupation? 98. No response

b. What is your mother's occupation? 98. No response

c. What is your father's occupation? 98. No response

Z3. How is payment for your work calculated? Do you have an hourly wage, a daily wage, fixed weekly salary, or a fixed monthly salary or is it calculated some other way?
1 . Hourly wage 2. Fixed daily wage
3. Fixed weekly salary
4. Fixed monthly 5. In another way
6. I am not working 8. D.K.

Z4. What is your Caste/Jati-biradari/Tribe name? (Consult code book for code)

Z4a. And what is your caste group? (Double check and consult code book)
1. Scheduled Caste (SC)
2. Scheduled Tribe (ST)
3. Other Backward Classes (OBC)
4. Other

Z5. What is your religion?
1. Hindu
2. Muslim
3. Christian 4. Sikh
5. Buddhist/Neo Buddhist
6. Jain
7. No religion
9. Others (Specify)

Z5a. (If Hindu) To which sect do you belong Shaiva or Vaishnava?
1. Shaiva
2. Vaishnava
8. Can't say
9. NA

Z5b. (If Muslim) To which sect do you belong Shia or Sunni?
1. Shia
2. Sunni8. Can't say
9. NA

Z6. Which ration card do you have?

1. Above Poverty Line 2. Below Poverty Line 3. Antyodaya

4. Annapurna

5. Do not have

6. Had, but lost it

7. Any other (Specify)

Z7. Do you have an Aadhar card? 2. Yes 1. No 8. NR 
Z8. Which language do you use the most for the following? (Record answer and consult language codes from codebook for coding)

a. For conversing at home/speaking with family members _ 98 . N.R.

b. For watching TV news 98. N.R. 99. Do not watch TV/news

c. For reading the newspaper 98. N.R. 99. Do not read newspaper

Z9. Area/Locality:
1. Village
2. Town
3. City 4. Metropolitan City

Z9a. (If Town/City/Metropolitan) Type of house where Respondent lives

1. House/Flat/Bunglow

2. House/Flat with

5 or more rooms

3. House/Flat with 4 rooms

4. Houses/Flat with 3 rooms

5. Houses/Flat with 2 rooms

6. House with 1 room

7. Mainly Kutcha house

8. Slum/Jhuggi Jhopri

9. NA

Z9b. (If village) Type of house where Respondent lives

1. Pucca (both wall and roof made of pucca material)

2. Pucca-Kutcha (Either wall or roof is made of pucca material and other of kutcha material)

3. Kutcha/Mud houses (both wall and roof are made of kutcha material)

4. Hut (both wall and roof made of grass, leaves, un-burnt brick or bamboo) 9. NA.

Z10. Total agricultural land including orchard and plantation owned by your household (as on date of survey): (Ask in local units, but record in standard acres. If more than 99, Code 99. If no answer does not own land code 00)

Z11. Do you or members of your household have the following:

\begin{tabular}{lll}
\hline & Yes & No \\
\hline a. Car/Jeep/Van & 1 & 2 \\
b. Scooter/Motorcycle/Moped & 1 & 2 \\
c. Airconditioner & 1 & 2 \\
d. Computer/laptop & 1 & 2 \\
e. Washing machine/Microwave/Fridge & 1 & 2 \\
f. Fan/Cooler & 1 & 2 \\
g. TV & 1 & 2 \\
h. Mobile phone & 1 & 2 \\
i. LPG gas & 1 & 2 \\
j. Motorised pumping set for irrigation & 1 & 2 \\
k. Tractor & 1 & 2 \\
l. Handpump inside the house & 1 & 2 \\
m. Power back up (Invertor/Generator, etc.) & 1 & 2 \\
\hline
\end{tabular}


Z12. Livestock Total Number

a. Goat/sheep:

b. Pig:

c. Cow/Oxen

d. Buffalo/Camel:

Z13. Total monthly household income - putting together the income of all members of the household?

(Record

exact amount in Rupees. If respondent does not give any amount then record 000000. If more than 1000000 then record 999999) Mobile/Telephone number of the respondent 


\section{BIBLIOGRAPHY}

Acharya, M., \& Bennett, L. (1983). Women and the subsistence sector. World Bank Staff Working Paper, 526.

Afridi, F. (2017). Governance and public service delivery in India (Synthesis Paper S-35407-INC-1). International Growth Center.

Ahuja, A., \& Chhibber, P. (2012). Why the poor vote in India: “If I don't vote, I am dead to the state". Studies in Comparative International Development, 47(4), 389-410.

Auerbach, A., \& T. Thachil. 2018. "How clients select brokers: Competition and choice in India's slums." American Political Science Review 112 (4): 775-791.

Auerbach, A., \& T. Thachil. 2020. "Cultivating clients: Reputation, responsiveness, and ethnic indifference in India's slums". American Journal of Political Science 64 (3): 471-487.

Ban, R., \& Rao, V. (2008). Tokenism or agency? The impact of women's reservations on village democracies in south India. Economic Development and Cultural Change, 56(3), 501-530.

Banerjee, M. (2017). Why India votes? New Delhi: Routledge.

Bardhan, P., \& Mookherjee, D. (2012). Political clientelism and capture: Theory and evidence from West Bengal, India (WIDER Working Paper).

Berry, J., \& Coffman, L. (2012). Belief formation in the returns to schooling. (Working Paper F-6007-INC-1; p. 13). International Growth Center.

Bussell, J. (2019). Clients and constituents: Political responsiveness in patronage democracies. Oxford: Oxford University Press.

Chanley, V. A., Rudolph, T. J., \& Rahn, W. M. (2000). The origins and consequences of public trust in government: A time series analysis. Public Opinion Quarterly, 64(3), 239-256.

Charnysh, V., Lucas, C., \& Singh, P. (2015). The ties that bind: National identity salience and pro-social behavior toward the ethnic other. Comparative Political Studies, 48(3), 267-300. doi: 10.1177/0010414014543103.

Chattopadhyay, R., \& Duflo, E. (2001). Women as policy makers: Evidence from a India-wide randomized policy experiment (Working Paper No. 8615; Working Paper Series). National Bureau of Economic Research. doi: 10.3386/w8615.

Chhibber, P, S. Shastri, and R. Sisson. 2004. "Federal arrangements and the provision of public goods in India." Asian Survey, 44 (3): 339-352. 
Chhibber, P., \& Verma, R. (2014). The BJP's 2014 'Modi wave': An ideological consolidation of the right. Economic and Political Weekly, 49(39), 50-56.

Chhibber, P., \& Verma, R. (2018). Ideology and identity: The changing party systems of India. Oxford: Oxford University Press.

Coffey, D., Hathi, P., Khurana, N., \& Thorat, A. (2018). Explicit prejudice: Evidence from a new survey. Economic and Political Weekly, 53(1), 9.

Cook, T. E., \& Gronke, P. (2005). The skeptical American: Revisiting the meanings of trust in government and confidence in institutions. The Journal of Politics, 67(3), 784-803.

Desai, S., \& Jain, D. (1994). Maternal employment and changes in family dynamics: The social context of women's work in rural South India. Population and Development Review, 20(1), 115-136.

Deshpande, A. (2011). The grammar of caste: Economic discrimination in contemporary India. Oxford: Oxford University Press.

Dittmer, L. (Ed.) (2012). Changing patterns of democracy and political representation in India. Asian Survey, 52(2), 239-439.

National Election Study 2009 (2004). The Economic and Political Weekly, 39(51), 5345-5544.

National Election Study 2009 (2009). The Economic and Political Weekly, 44(39), 1-208.

National Election Study 2014 (2014). The Economic and Political Weekly, 49(39), $1-140$.

Hansen, T. B. (1999). The saffron wave: Democracy and Hindu nationalism in modern India. Princeton: Princeton University Press.

Hansen, T. B. (2018). Wages of violence: Naming and identity in postcolonial Bombay. Princeton: Princeton University Press.

Hawkins, K. A., Riding, S., \& Mudde, C. (2012). Measuring populist attitudes. Political Concepts. Committee on Concepts and Methods (International Political Science Association) Working Paper Series. Available at: Available at: http:// works.bepress.com/cas_mudde/72/

Jacob, S. (2015). Towards a comparative subnational perspective on India. Studies in Indian Politics, 3(1), 229-246.

Jaffrelot, C. (2015). Understanding India's 2014 elections. Studies in Indian Politics, $3(1), 1-147$.

Jaffrelot, C. (2017). India's democracy at 70: Toward a Hindu State? Journal of Democracy, 28(3), 52-63. doi:10.1353/jod.2017.0044.

Jaffrelot, C., \& Kumar, S. (2009). Rise of the plebeians: The changing face of Indian legislative assemblies. New Delhi: Routledge.

Krishna, A. (2011). One illness away: Why people become poor and how they escape poverty. Oxford: Oxford University Press.

Lind, E., \& Tyler, T. (1988). Critical issues in social justice. The social psychology of procedural justice. New York, NY: Plenum Press. doi: 10.1007/978-1-4899-2115-4.

Maneka Gandhi vs Union of India, (Supreme Court of India January 1978).

Manor, J. (2000). Small-time political fixers in India's states:" towel over armpit". Asian Survey, 40(5), 816-835.

Mansbridge, J. (1997). Social and cultural causes of dissatisfaction with US Government. Why People Don't Trust Government, 133-153. 
Miller, A. H., \& Listhaug, O. (1990). Political parties and confidence in government: A comparison of Norway, Sweden and the United States. British Journal of Political Science, 20(3), 357-386.

Mitra, S. K., \& Singh, V. B. (1999). Democracy and social change in India: A crosssectional analysis of the national electorate. New Delhi: Sage Publications.

Mudde, C. (2017). Populism: An ideational approach. In C. R. Kaltwasser, P. A. Taggart, P. O. Espejo \& P. Ostiguy (Eds.), Oxford handbook of populism (pp. 27-46). Oxford: Oxford University Press.

Mudde, C., \& Kaltwasser, C. R. (2017). Populism: A very short introduction. Oxford: Oxford University Press.

National Sample Survey Office (2014). Employment and unemployment: Situation in India (554(68/10/1); National Sample Survey. Ministry of Statistics and Programme Implementation. Retrieved from http://mospi.nic.in/sites/default/f iles/publication_reports/nss_report_554_31jan14.pdf.

Newman, K., \& Thorat, S. K. (2010). Blocked by caste: Economic discrimination in modern India. Oxford: Oxford University Press.

Newton, K., \& Norris, P. (2000). Confidence in public institutions: Faith, Culture, or Performance? In S. Pharr and R. Putnam (Eds.). Disaffected Democracies: What's Troubling the Trilateral Countries, pp. 52-73.

Office of the Registrar General \& Census Commissioner (n.d.). Census 2011. Census 2011. Retrieved April 28, 2020, from https://www.census2011.co.in/.

Omvedt, G. (1980). We will smash this prison!.: Indian women in struggle. London: Zed Press.

Palshikar, S. (2015). The BJP and Hindu nationalism: Centrist politics and majoritarian impulses. South Asia: Journal of South Asian Studies, 38(4), 719_ 735. doi:10.1080/00856401.2015.1089460.

Palshikar, S., Kumar, S., \& Lodha, S. (2017). Electoral politics in India: The resurgence of the Bharatiya Janata Party. New Delhi: Routledge.

Palshikar, S., Suri, K., \& Yadav, Y. (2014). Party competition in Indian states: Electoral politics in post-Congress polity. Oxford: Oxford University Press.

Pew Research Center (1998, March 10). How Americans View Government: Deconstructing distrust. Pew Research Center for the People and the Press. Retrieved from https://www.people-press.org/1998/03/10/how-americans-view-g overnment/.

Radhakrishnan, S. (2011). Appropriately Indian: Gender and culture in a new transnational class. Durham, NC: Duke University Press.

Ramesh, R. (2017). Does trust matter? An inquiry on citizens' trust in public institutions of Sri Lanka. Millennial Asia, 8(2), 123-145.

Roy, A., \& Hasan, M. (Eds.) (2005). Living together seperately: Cultural India in history and politics. Oxford: Oxford University Press.

Sekhri, S. (2011). Federalism versus Regional Control: Implications for GroundwaterResource in India (Working paper). International Growth Center. Retrieved from https:/www.theigc.org/wp-content/uploads/2014/10/Sekhri-201 1-2-Working-Paper.pdf.

Sharma, U. (1990). Public employment and private relations: Women and work in India. In S. Stichter \& J. L. Parpart (Eds.), Women, employment and the family in the international division of Labour (pp. 229-246). Palgrave Macmillan UK. doi:10.1007/978-1-349-20514-1_10. 
Shastri, S., Suri, K. C., \& Yadav, Y. (2009). Electoral politics in Indian states: Lok Sabha elections in 2004 and beyond. Oxford: Oxford University Press.

Singh, P. (2015). How Solidarity works for welfare: Subnationalism and social development in India. Cambridge: Cambridge University Press.

Sinha, A. (2015). Scaling up: Beyond the subnational comparative method for India. Studies in Indian Politics, 3(1), 128-133.

State of democracy in South Asia Team (2008). State of democracy in South Asia. New Delhi: Oxford University Press.

Suri, K. C. (2019). India's 2019 elections. Studies in Indian Politics, 7(2), 1-304.

Tillin, L. (2013). National and subnational comparative politics. Studies in Indian Politics, 1(1), 235-240.

Tyler, T. R. (1990). The social psychology of authority: Why do people obey an order to harm others? Law \& Society Review, 24 (4) (1990), pp. 1089-1102, JSTOR.

Tyler, T. R., \& Huo, Y. (2002). Trust in the law: Encouraging public cooperation with the police and courts. New York, NY: Russell Sage Foundation.

Tyler, T. R., \& Lind, E. A. (1992). A relational model of authority in groups. In Advances in Experimental Social Psychology (Vol. 25, pp. 115-191). Cambridge: Academic Press. doi:10.1016/S0065-2601(08)60283-X

Tyler, T. R., Rasinski, K. A., \& McGraw, K. M. (1985). The influence of perceived injustice on the endorsement of political leaders 1. Journal of Applied Social Psychology, 15(8), 700-725.

Varshney, A. (1993). Contested meanings: India's national identity, Hindu nationalism, and the politics of anxiety. Dodalus, 122(3), 227-261.

Varshney, A. (2014). India's watershed vote: Hindu nationalism in power? Journal of Democracy, 25(4), 34-45. doi:10.1353/jod.2014.0071.

Verba, S., \& Nie, N. H. (1987). Participation in America: Political democracy and social equality. Chicago, IL: University of Chicago Press.

Wahi, N., A. Bhatia, P. Shukla, D. Gandhi, S. Jain, and U. Chauhan. 2017. Land Acquisition in India: A Review of Supreme Court Cases 1950-2016. Center for Policy Research Report. New Delhi.

Weyland, K. (2001). Clarifying a contested concept: Populism in the study of Latin American politics. Comparative Politics, 1-22.

Yadav, Y. (2000). Understanding the second democratic upsurge: Trends of Bahujan participation in electoral politics in the 1990s. In F. R. Frankel, Z. Hasan, R. Bhargava \& B. Arora (Eds.), Transforming India: Social and political dynamics of democracy (Vols 120-145). Oxford: Oxford University Press.

Yadav, Y., \& Palshikar, S. (2003). From hegemony to convergence: party system and electoral politics in the Indian States, 1952-2002. Journal of Indian School of Political Economy, 15(1-2), 5-45.

Yadav, Y. and Palshikar, S. (2008), 'Ten Theses on State Politics in India', Seminar, 591 (November) 
$\Longrightarrow$ Taylor \& Francis Taylor \& Francis Group

http://taylorandfrancis.com 